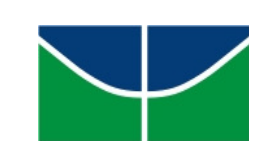

UNIVERSIDADE DE BRASÍLIA

FACULDADE DE CIÊNCIAS DA SAÚDE

DEPARTAMENTO DE ENFERMAGEM

PROGRAMA DE PÓS-GRADUAÇÃO EM ENFERMAGEM

DIANE MARIA SCHERER KUHN LAGO

QUALIDADE DE VIDA DE CUIDADORES DOMICILIARES:

RELAÇÃO ENTRE CUIDADOS PALIATIVOS, SOBRECARGA E FINITUDE HUMANA

BRASÍLIA 


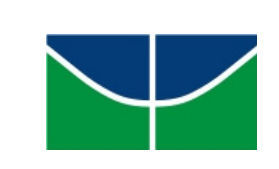

\author{
UNIVERSIDADE DE BRASÍLIA \\ FACULDADE DE CIÊNCIAS DA SAÚDE \\ DEPARTAMENTO DE ENFERMAGEM \\ PROGRAMA DE PÓS-GRADUAÇÃO EM ENFERMAGEM
}

DIANE MARIA SCHERER KUHN LAGO

\title{
QUALIDADE DE VIDA DE CUIDADORES DOMICILIARES: \\ RELAÇÃO ENTRE CUIDADOS PALIATIVOS, SOBRECARGA E \\ FINITUDE HUMANA
}

\begin{abstract}
Tese apresentada como requisito parcial para a obtenção do Título de Doutor em Enfermagem pelo Programa de Pós-Graduação em Enfermagem da Universidade de Brasília.
\end{abstract}

Área de Concentração: Políticas, Práticas e Cuidado em Saúde e Enfermagem.

Linha de Pesquisa: Processo de Cuidar em Saúde e Enfermagem.

ORIENTADORA: PROF ${ }^{\mathrm{a}} \mathrm{DR}^{\mathrm{a}}$ DIRCE GUILHEM

BRASÍLIA 


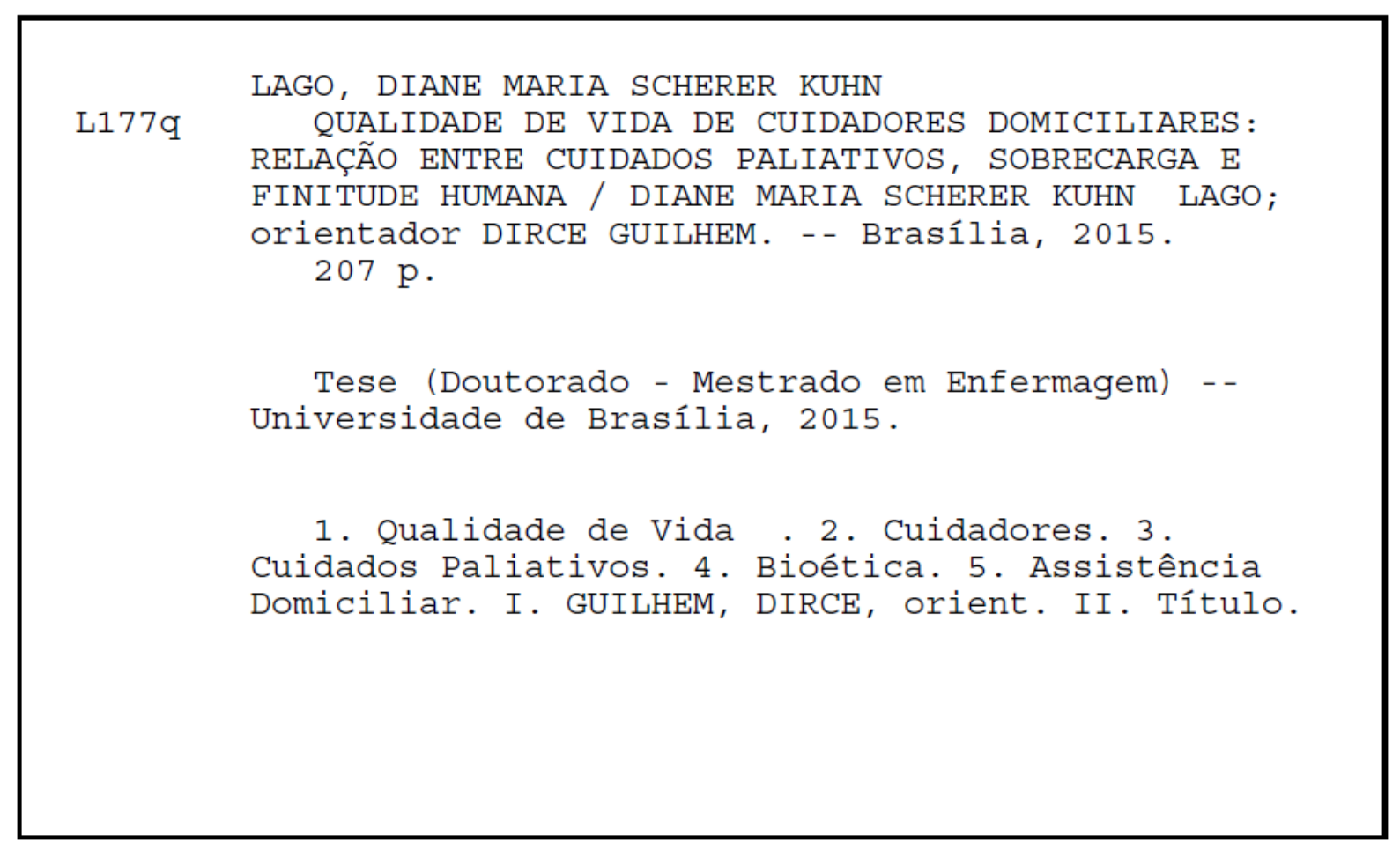




\section{QUALIDADE DE VIDA DE CUIDADORES DOMICILIARES: RELAÇÃO ENTRE CUIDADOS PALIATIVOS, SOBRECARGA E FINITUDE HUMANA}

Tese apresentada como requisito parcial para a obtenção do título de Doutor em Enfermagem pelo Programa de Pós-Graduação em Enfermagem da Universidade de Brasília.

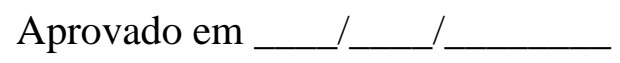

BANCA EXAMINADORA

Professora Doutora Dirce Guilhem - Presidente

Universidade de Brasília

Professora Doutora Geilsa Soraia Cavalcanti Valente - Membro efetivo e externo à UnB Universidade Federal Fluminense

Professora Doutora Tania Cristina Morais Santa Barbara Rehem - Membro efetivo e externo ao Programa

Universidade de Brasília

Professora Doutora Ana Cláudia Afonso Valladares Torres - Membro efetivo e externo ao Programa

Universidade de Brasília

Professora Doutora Keila Cristianne Trindade da Cruz - Membro efetivo e externo ao Programa

Universidade de Brasília

Professora Doutora Ana Beatriz Duarte Vieira - Membro suplente e externo ao Programa Universidade de Brasília 
Dedico este trabalho à minha família, minha mãe Maria $\mathcal{N} o e l i$, meu pai Ciro, às minhas filhas: Jéssica e Jennifer, que entenderam as minhas ausências em horas de convívio e que sempre me apoiaram de forma incondicional. Dedico também ao grande amor da minha vida, Addercio, companheiro, amigo e eterno namorado. Sem vocês nada teria sentido! 


\section{AGRADECIMENTOS}

O espaço limitado desta seção de agradecimentos, não me permite agradecer como pretendia a todas as pessoas que de alguma forma foram importantes e participaram desta construção. Por isso, deixo apenas algumas palavras, poucas, mas com profundo sentimento de reconhecido agradecimento.

À minha família, Aldercio, Jéssica e Jennifer, que sempre estiveram ao meu lado com paciência, lealdade, palavras de incentivo, de apoio e de valorização do meu esforço. Tudo que faço é para vocês!

Aos meus pais Ciro e Maria Noeli que sempre apoiaram as minhas decisões profissionais e pessoais. Grande exemplo!

Às minhas irmãs, Ângela, Claudia e Carine pelo incentivo e motivação.

À minha incansável orientadora, Professora Doutora Dirce Guilhem, em quem me espelho por considerar grande exemplo de profissional, sempre disponível, comprometida, ética e incentivadora. Que sempre esteve disposta a me ouvir e orientar o rumo certo a seguir, além de sempre compreender minhas angustias de pesquisadora.

Às minhas colegas de estudo, Graça, Janaína, Cristilene que participaram dos momentos alegres, de apoio, de união, de estudo e de concentração para novas etapas a serem seguidas.

Às minhas colegas de trabalho, em especial à Carla e à Antônia, que me incentivaram a realizar este estudo.

Às estudantes Carla Rabello, Priscila Oliveira e Kamilla Lorena que auxiliaram nas coletas de dados e participaram destes momentos muito importantes para esta conquista.

Aos profissionais do Núcleo Regional de Atenção Domiciliar (NRAD) de Ceilândia que sempre apoiaram para que o estudo fosse realizado com sucesso na coleta dos dados e no apoio aos cuidadores participantes.

Aos cuidadores que gentilmente aceitaram participar do estudo dedicando horas de conversa individual ou em grupo, com honestidade e sinceridade em busca de conhecimentos para que seja possível construir novos caminhos neste trabalho conjunto que compreende a atenção domiciliar. 
Um amigo me chamou para cuidar da dor dele. Guardei a minha no bolso.

E fui.

Clarice Lispector

Com o tempo você vai percebendo que, para ser feliz, você precisa aprender a gostar de você, a cuidar de você e, principalmente, a gostar de quem também gosta de você.

Mario Quintana 


\section{RESUMO}

LAGO, D. M. S. K. Qualidade de Vida de Cuidadores Domiciliares: Relação entre Cuidados Paliativos, Sobrecarga e Finitude Humana, 2015. 207p. Tese (Doutorado) Departamento de Enfermagem, Faculdade de Ciências da Saúde, Universidade de Brasília, Brasília, 2015.

Objetivo: Analisar os aspectos bioéticos do cuidar e a relação entre a percepção de cuidadores domiciliares sobre qualidade de vida e sobrecarga de trabalho. Método: Estudo descritivo, de corte transversal com abordagens qualitativa e quantitativa. Realizado com cuidadores principais de doentes internados em domicilio por meio de entrevistas nas residências dos mesmos entre os meses de fevereiro e junho de 2013 e da aplicação dos instrumentos para a coleta de dados: Questionário de dados sociodemográficos e clínicos, Escala de Sobrecarga do Cuidador, WHOQOL-bref e WHOQOL-old aos cuidadores idosos. O projeto foi aprovado pelo CEP da Secretaria de Estado da Saúde do Distrito Federal sob o parecer n. 187.211/2013. Resultados: Dos 33 cuidadores principais que representaram a totalidade dos cuidadores vinculados ao Núcleo Regional de Atenção Domiciliar foi possível identificar que a média de idade era de 46 anos; a maioria era do sexo feminino e familiar do doente; a função de cuidador era exercida por 75,7\% em tempo integral; 63,6\% referiram receber apoio social e 57,5\% relataram problemas de saúde em tratamento. Com relação à sobrecarga percebida, $43 \%$ apresentaram sobrecarga intensa e 30\% sobrecarga ligeira. Quanto à percepção sobre qualidade de vida, a média do IGQV foi de 51,19 pontos, sendo que $42,4 \%$ estavam insatisfeitos com a sua saúde. Entre os cuidadores idosos, o IQVI foi de 45,52 pontos. Mudanças de ordem social e espiritual na vida dos cuidadores foram percebidas no decorrer do cuidado. Aspectos bioéticos foram encontrados entre os cuidadores familiares, como autonomia nas escolhas, vulnerabilidade ao estresse e sobrecarga e a problemas de saúde físicos e psicológicos. Conclusões: A maioria dos participantes apresentou sobrecarga ligeira ou intensa. Participar do cuidado e vivenciar o sofrimento do outro pode causar inquietação e angustia ao cuidador principal. A percepção de qualidade de vida foi maior em cuidadores idosos. O medo e a incerteza do futuro afetaram diretamente os cuidadores principais que estavam no inicio do processo e o cansaço e o desânimo estiveram mais presentes em cuidadores com mais de dez anos de exercício da função de forma continua. Foi possível concluir que o cuidador principal necessita de acompanhamento e de reconhecimento por parte da equipe de saúde, da família e da sociedade. Deve receber apoio e suporte emocional para enfrentar a situação e que a discussão ampliada sobre os aspectos bioéticos e 
de sobrecarga presentes no cuidar é fundamental para a qualidade de vida dos cuidadores e para a qualidade da assistência domiciliar.

Descritores: Qualidade de Vida; Cuidadores; Cuidados Paliativos; Bioética; Assistência Domiciliar.

\begin{abstract}
LAGO, D. M. S. K. Quality Caregivers Household Life: Relationship between Palliative Care, overload and Human Finitude, 2015. 207p. Thesis (PhD) - Department of Nursing, Faculty of Health Sciences, University of Brasilia, Brasilia, 2015.
\end{abstract}

Objective: To analyze the bioethical aspects of care and the relationship between the perception of home caregivers on quality of life and work overload. Method: Descriptive Study with qualitative and quantitative approaches of cross-sectional. Conducted with primary caregivers of patients in domicile through interviews in the homes of same between February and June 2013 and the application of instruments to collect data: sociodemographic and clinical data questionnaire, the Caregiver Overload Scale, WHOQOL-bref and WHOQOL-old to elderly caregivers. The project was approved by the CEP of the Health Departament of the Federal District in the opinion n. 187211/2013. Results: Of the 33 main caregivers who represented all the home caregivers related to Regional Core Home Care was identified that the average age was 46 years; most were female sex and of the patient family; the caregiver function was exercised by $75.7 \%$ full-time; $63.6 \%$ reported receiving social support and 57.5\% reported health problems in treatment. As for the perception of quality of life, the average IGQV was 51.19 points, and $42.4 \%$ were dissatisfied with their health. Among the elderly caregivers, the IQVI was 45.52 points. Social and spiritual order changes in the lives of caregivers were perceived in the course of care. Bioethical aspects were found among family caregivers, such as autonomy in choices, vulnerability to stress and overload, and the physical and psychological health problems. Conclusions: Most of the participants had mild or severe overload. Participate in the care and experience the suffering of others can cause restlessness and anxiety to the primary caregiver. The perception of quality of life was higher in elderly caregivers. Fear and uncertainty of the future directly affected the main caregivers who were in the process of beginning and fatigue and discouragement were more present in caregivers with more than ten years of exercise of form function continues. It was concluded that the primary caregiver needs monitor and by the health care team, family and 
society and should receive support and emotional support to cope and that the expanded discussion of bioethical issues and overload present in care is critical to the quality of life of caregivers and the quality of home care.

Keywords: Quality of life; Caregivers; Palliative Care; Bioethics; Home Care.

\section{RESUMEN}

LAGO, D. M. S. K. Calidad de Vida Los cuidadores del hogar: Relación entre los cuidados paliativos, la sobrecarga y la finitud humana, 2015. 207p. Tesis (Doctorado) - Departamento de Enfermería de la Facultad de Ciencias de la Salud de la Universidad de Brasilia, Brasilia, 2015.

Objetivo: Analizar los aspectos bioéticos de la atención y la relación entre la percepción de los cuidadores caseros sobre calidad de vida y el trabajo de sobrecarga. Método: Estudio descriptivo enfoques cualitativos y cuantitativos, de corte transversal. Realizado con los cuidadores primarios de pacientes en domicilio a través de entrevistas en los hogares de los mismos, entre febrero y junio de 2013 y la aplicación de instrumentos para recopilar datos: datos de los cuestionarios sociodemográficos y clínicos, el Escala de Sobrecarga del Cuidador, WHOQOL-bref y WHOQOL-old para cuidadores de ancianos . El proyecto fue aprobado por el CEP de la Secretaría de Salud del Distrito Federal en la opinión n. 187211/2013. Resultados: De los 33 cuidadores principales que representaban a todos los cuidadores relacionados con Centro Regional de Atención Domiciliar se identificó que el promedio de edad fue de 46 años; Fueron vie más femenina de la paciente y su familia; la función de cuidador era ejercido por el 75,7\% de tiempo completo; 63,6\% informó haber recibido el apoyo social y $57.5 \%$ reportado problemas de salud en el tratamiento. En cuanto a la sobrecarga percibida, el $43 \%$ tuvo una intensa sobrecarga y el 30\% leve sobrecarga. En cuanto a la percepción de la calidad de vida, el promedio fue de 51,19 IGQV puntos y 42.4\% estaban satisfechos con su salud. Entre los cuidadores de ancianos, la IGQV fue 45,52 puntos. Cambios de orden social y espiritual en la vida de los cuidadores eran percibidas en el curso de la atención. aspectos bioéticos Fueram encontrados entre los cuidadores familiares, como la autonomía en las decisiones, la vulnerabilidad al estrés y la sobrecarga, y los problemas de salud física y psicológica. Conclusiones: La mayoría de los participantes tenían la sobrecarga leve o grave. Participar en el cuidado y experimentar el sufrimiento de los demás puede causar inquietud y ansiedad para el cuidador principal. La percepción de la calidad de vida fue mayor en los cuidadores de ancianos. El miedo y la incertidumbre del futuro afectaram 
directamente los principales cuidadores que estaban en el proceso inicial y la fatiga y el desaliento estaban más presentes en los cuidadores con más de diez años de ejercicio de la función de forma continúa. Foi possible concluir que el cuidador principal necesita supervisión y reconocimiento por parte del equipe de atención de salud, la familia y la sociedad. Recibir apoyo emocional para hacer frente y Que la discusión amplia de las cuestiones de bioética y la sobrecarga presente en el cuidado es fundamental para la calidad de vida de cuidadores y la calidad de los cuidados en el hogar.

Palabras clave: Calidad de vida; Cuidadores; Cuidados Paliativos; Bioética; Cuidados en el hogar. 


\section{LISTA DE FIGURAS}

Figura 1 - Pirâmide etária Brasil, America Latina e Caribe de 1950-2050.

Figura 2 - Distribuição percentual da população, por grandes grupos etários (anos). 31 Brasil, 1950-2050.

Figura 3 - Tempo de exercício da função de cuidador principal.

Figura 4 - Percepção sobre a sobrecarga entre cuidadores domiciliares entrevistados, 65 2014.

Figura 5 - Forma de aplicação do instrumento de avaliação da qualidade de vida da 66 Organização Mundial da Saúde (OMS) - WHOQOL-bref aos cuidadores domiciliares (n.33).

Figura 6- Média das avaliações dos cuidadores nas facetas do domínio físico do 68 WHOQOL-bref.

Figura 7 - Média das avaliações dos cuidadores nas facetas do domínio psicológico do 68 WHOQOL-bref.

Figura 8 - Média das avaliações dos cuidadores nas facetas de relações sociais do 69 WHOQOL-bref.

Figura 9- Média das avaliações dos cuidadores nas facetas meio-ambiente do 69 WHOQOL-bref.

Figura 10 - Forma de aplicação do instrumento de avaliação da qualidade de vida da 70 Organização Mundial da Saúde (OMS) - WHOQOL-old aos cuidadores domiciliares.

Figura 11 - Média das avaliações dos cuidadores nas facetas do domínio funcionamento 71 dos sentidos do WHOQOL-old

Figura 12 - Média das avaliações dos cuidadores nas facetas do domínio Autonomia - 72 AUT do WHOQOL-old

Figura 13 - Média das avaliações dos cuidadores nas facetas do domínio Atividades 72 passadas, presentes e futuras - PPF do WHOQOL-old

Figura 14 - Média das avaliações dos cuidadores nas facetas do domínio Participação 73 social - PSO do WHOQOL-old

Figura 15 - Média das avaliações dos cuidadores nas facetas do domínio Morte e morrer 73 - MEM do WHOQOL-old 
Figura 16 - Média das avaliações dos cuidadores nas facetas do domínio Intimidade - 74 INT do WHOQOL-old 


\section{LISTA DE QUADROS}

Quadro 1 - Domínios e facetas do instrumento de avaliação da qualidade de vida da OMS - WHOQOL-bref.

Quadro 2- Domínios e facetas do instrumento de avaliação da qualidade de vida em idosos da OMS - WHOQOL-old.

Quadro 3- $\quad$ Relatos das verbalizações de cuidadores entrevistados sobre 0 significado da doença do doente internado em domicilio.

Quadro 4- Relatos das verbalizações de cuidadores entrevistados sobre $\quad$ o 82 significado da morte no contexto pessoal.

Quadro 5- Relatos das verbalizações sobre sentimentos vivenciados pelos cuidadores.

Quadro 6 - $\quad$ Relatos das verbalizações sobre mudanças de ordem social ocorridas 86 após o inicio do cuidar.

Quadro 7- Relatos das verbalizações sobre mudanças no âmbito espiritual percebidas por cuidadores domiciliares.

Quadro 8- Relatos das verbalizações dos cuidadores principais familiares 90 associadas à autonomia e relacionadas ao cuidar.

Quadro 9- Relatos das verbalizações dos cuidadores principais familiares 91 associadas à vulnerabilidade ao estresse e à sobrecarga.

Quadro 10 - Relatos das verbalizações dos cuidadores principais familiares 92 associadas à vulnerabilidade ao estresse e à sobrecarga. 


\section{LISTA DE TABELAS}

Tabela 1- Dados de cuidadores de pacientes internados em domicílio 57 segundo condições econômicas. Brasília, DF, 2013, (N=33).

Tabela 2 - Dados sobre a ocupação anterior de cuidadores. Brasília, DF, 58 2013, $(\mathrm{N}=33)$.

Tabela 3 - $\quad$ Dados do apoio social referido pelos cuidadores. Brasília, DF, 59 2013. $(\mathrm{N}=33)$.

Tabela 4 - Dados clínicos de cuidadores. Brasília, DF, 2013 (N=33).

Tabela 5 - $\quad$ Dados sobre a qualidade do sono do cuidador. Brasília, DF, 2013, 61 $(\mathrm{N}=33)$.

Tabela 6- Dados descritivos da aplicação da Escala de Sobrecarga do 61 Cuidador segundo a percepção de cuidadores entrevistados. Brasília, $2013(\mathrm{n}=33)$.

Tabela 7 - Média dos escores obtidos nos Domínios e no Índice Geral de 66 Qualidade de Vida da aplicação do WHOQOL-bref em cuidadores $(\mathrm{n}=33)$.

Tabela 8 - Tabela descritiva, em número e porcentagem de cuidadores, segundo as questões sobre percepção da qualidade de vida geral e satisfação com a saúde (n=33).

Tabela 9 - Média dos escores obtidos nos Domínios e no Índice Geral de 70 Qualidade de Vida do Idoso referente à aplicação do WHOQOLold.

Tabela 10 - Estatística descritiva dos domínios do WHOQOL-bref segundo o sexo do cuidador.

Tabela 11 - Estatística descritiva dos domínios do WHOQOL-bref segundo a 75 idade do cuidador.

Tabela 12 - Estatística descritiva dos domínios do WHOQOL-bref segundo a 75 situação conjugal do cuidador.

Tabela 13 - Estatística descritiva dos domínios do WHOQOL-bref segundo o 76 grau de parentesco do cuidador para com o paciente.

Tabela 14 - Estatística descritiva dos domínios do WHOQOL-bref segundo o 76 grau de instrução do cuidador. 
Tabela 15 - Estatística descritiva dos domínios do WHOQOL-bref segundo a 76 religião do cuidador.

Tabela 16 - Estatística descritiva dos domínios do WHOQOL-bref segundo a 77 percepção do cuidador do apoio social recebido.

Tabela 17 - Estatística descritiva dos domínios do WHOQOL-bref segundo a 77 presença de doença relatada pelo cuidador.

Tabela 18 - Estatística descritiva dos domínios do WHOQOL-bref segundo a 78 presença de dor relatada pelo cuidador.

Tabela 19 - Estatística descritiva dos domínios do WHOQOL-bref segundo o 78 uso de medicamentos de forma contínua pelo cuidador.

Tabela 20 - Estatística descritiva dos domínios do WHOQOL-bref segundo a 78 qualidade do sono referida pelo cuidador.

Tabela 21 - Estatística descritiva dos domínios do WHOQOL-bref segundo a 79 atividade sexual do cuidador.

Tabela 22 - Estatística descritiva dos domínios do WHOQOL-bref segundo o 79 tempo de exercício da função de cuidador.

Tabela 23 - Estatística descritiva dos domínios do WHOQOL-bref segundo o $\quad 80$ resultado da escala de sobrecarga do cuidador.

Tabela 24 - Médias dos escores dos domínios e a correlação com a idade do 80 cuidador e com o tempo de exercício da função. 


\section{LISTA DE SIGLAS}

AD

ADS

ANVISA

AR

AUT

AVC

CAAE

CEI

CEP

CNS

DA

DALY

DCNT

$\mathrm{DM}$

EF1C

ELA

EMAD

EMAP

ESC

ESF

$\mathrm{F}$

FEPECS

GEAD
Atenção Domiciliar

Assistência Domiciliar à Saúde

Agência Nacional de Vigilância Sanitária

Artrite Reumatoide

Autonomia

Acidente Vascular Cerebral

Certificado de Apresentação para Apreciação Ética

Centro de Erradicação de Invasão

Comitê de Ética em Pesquisa

Conselho Nacional da Saúde

Doença de Alzheimer

Disabilityadjusted Life Years

Doenças Crônicas Não Transmissíveis

Diabetes Mellitus

Ensino Fundamental 1 Completo

Esclerose Lateral Amiotrófica

Equipe Multidisciplinar de Atenção Domiciliar

Equipe Multidisciplinar de Apoio

Escala de Sobrecarga do Cuidador

Estratégia de Saúde da Família

Físico

Fundação de Ensino e Pesquisa em Ciências da Saúde

Gerência de Atenção Domiciliar 
GM/MS

HAS

IBGE

ID

IGQV

IQVI

INT

MA

MEM

MMP

MS

NRAD

OBJN

OMS

$\mathrm{P}$

PACS

PC

PID

POD

PPF

PSO

QV

RA

RDC

REBEN
Gabinete do Ministro/Ministério da Saúde

Hipertensão Arterial Sistêmica

Instituto Brasileiro de Geografia e Estatística

Internação Domiciliar

Índice Geral de Qualidade de Vida

Índice de Qualidade de Vida do Idoso

Intimidade

Meio ambiente

Morte e Morrer

Miopatia Muscular Progressiva

Ministério da Saúde

Núcleo Regional de Atenção Domiciliar

Online Brazilian Journal of Nursing

Organização Mundial da Saúde

Psicológico

Programa de Agentes Comunitários de Saúde

Paralisia Cerebral

Programa de Internação Domiciliar

Programa de Oxigenoterapia Domiciliar

Atividades passadas, presentes e futuras

Participação Social

Qualidade de Vida

Região Administrativa

Resolução de Diretoria Colegiada

Revista Brasileira de Enfermagem 
Relações Sociais

RUE

Rede de Atenção às Urgências e Emergências

SAD

Serviço de Atenção Domiciliar

SAMDU

Serviço de Assistência Médica Domiciliar e de Urgência

SAMED

Serviço de Assistência Multiprofissional em Domicilio

SES/DF

Secretaria de Estado da Saúde do Distrito Federal

SI

Sobrecarga Intense

SL

Sobrecarga Ligeira

SPSS

Software Package for the Social Sciences

SS

Sem Sobrecarga

SUS

Sistema Único de Saúde

TCLE

Termo de Consentimento Livre e Esclarecido

UFPE

Universidade Federal de Pernambuco

WHOQOL-BREF World Health Organization Quality of Life Instrument

WHOQOL-OLD World Health Organization Quality of Life Instrument-Older Adults Module

ZBI

Zarit Caregiver Burden Interview 


\section{APRESENTAÇÃO}

Logo após concluir a graduação em enfermagem pela Universidade Regional do Noroeste do Estado do Rio Grande do Sul - UNIJUI em 1997, mudei-me para Brasília. Meu primeiro emprego como enfermeira foi na Estratégia de Saúde da Família, em um Programa intitulado de 'Saúde em Casa', onde atuei por mais de um ano na área rural da cidade de Sobradinho e, posteriormente na área urbana da cidade do Paranoá, ambas no Distrito Federal.

Ao findar o programa descrito acima, iniciei nova etapa profissional como professora substituta da Universidade de Brasília em 1999. Neste mesmo ano, iniciei minhas atividades no novo programa criado pelo governo do Distrito Federal da época, intitulado de 'Saúde da Família' na área urbana de Ceilândia/DF e, posteriormente, na área rural do Paranoá/DF.

Entre os anos de 1999 e 2000 fiz o curso de Especialização em Saúde da Família, coordenado pela Universidade de Brasília em parceria com o Ministério da Saúde.

Em outubro de 2000 assumi cumulativamente o cargo de enfermeira da Unidade de Terapia Intensiva do Hospital Regional de Sobradinho/DF como servidora concursada da Secretaria de Estado da Saúde do Distrito Federal. Em 2002, assumi a Gerência de Enfermagem da Regional de Saúde do Paranoá, quando da inauguração do hospital da cidade, desvinculando nessa época da Estratégia de Saúde da Família.

Entre os anos de 1999 e 2001 fiz o curso de formação em Psicanálise Clínica pela Associação Nacional de Psicanálise Clínica (ANPC).

No final do ano de 2002 assumi o cargo de técnica da Gerência de Tecnologia e Organização em Serviços de Saúde na Agência Nacional de Vigilância Sanitária (GTOSS/GGTES/ANVISA/MS). Participei de discussões sobre propostas de Resoluções de Diretoria Colegiada (RDC) sobre serviços de hemodiálise, unidades de terapia intensiva e intermediárias de saúde, bem como sobre a organização de serviços de atenção domiciliar no Brasil.

Em 2003 fiz o curso de Especialização em Bioética pela Universidade de Brasília.

No ano de 2004 assumi o cargo de Gerente de Núcleo de Serviços Próprios da Caixa de Assistência dos Funcionários do Banco do Brasil (CASSI). Nessa empresa de autogestão em saúde desenvolvi trabalhos de ordem preventiva com os usuários do serviço em uma área de abrangência com mais de 18.000 vidas vinculadas.

No ano seguinte, em 2005, fui transferida, por motivos pessoais, para o Estado do Mato Grosso do Sul para desenvolver as atividades na CASSI trabalhando em dois pontos 
estratégicos, como Gerente de Interior na cidade de Dourados/MS e de Núcleo de Serviços Próprios na cidade de Campo Grande/MS.

Nesse mesmo ano, iniciei os estudos no curso de Mestrado em Gerontologia pela Universidade Católica de Brasília, o qual conclui, em 2007, com a apresentação da Dissertação intitulada de 'O índio idoso Kaiwá: memórias e histórias de vida', sendo este tema escolhido em virtude da situação dos indígenas daquele estado, em especial da cidade de Dourados, onde residia com minha família no período.

Fui transferida novamente em 2007, por motivos pessoais. Nessa época para a cidade de Florianópolis, onde continuei como Gerente de Núcleo de Serviços Próprios e assumi interinamente o cargo de Gerente Estadual da CASSI em Santa Catarina.

Em 2009, por motivos pessoais voltei a residir em Brasília e reassumi o cargo de enfermeira da Secretaria de Secretaria de Estado da Saúde, então na Gerência de Hotelaria. Nesse mesmo ano fiz o curso de Especialização em Operacionalização dos Serviços de Saúde oferecido pela Universidade de Brasília em parceria com a Fiocruz.

Em 2010, passei no concurso para docente da Universidade de Brasília, onde desempenho minhas atividades até o momento. Entre as atividades desenvolvidas está, desde 2011, o Programa de Extensão que denominei de Saúde em Casa. Nele estudantes e professores participam de forma direta ou por meio de projetos de extensão vinculados com o propósito de conhecer, acompanhar e apoiar os pacientes e cuidadores vinculados ao Núcleo Regional de Atenção domiciliar (NRAD) de Ceilândia, bem como os profissionais do mesmo.

Em virtude deste programa surgiu o interesse em desenvolver um trabalho voltado aos cuidadores em busca do bem-estar coletivo e individual. Para tanto, foi necessário conhecer a percepção sobre a qualidade de vida deste grupo. Nesse sentido, resolvi inscrever o projeto com esse propósito na seleção para o Doutorado em Enfermagem em 2011.

Naquele ano, iniciei o curso de Doutorado na Linha de Processo de Cuidar em Saúde e Enfermagem sob a orientação da Professora Doutora Dirce Guilhem, ao qual concluo com a apresentação desta Tese. 


\section{SUMÁRIO}

1. INTRODUÇÃO 24

2. OBJETIVOS 27

2.1. OBJETIVO GERAL 28

2.2. OBJETIVOS ESPECÍFICOS 28

3. REFERENCIAL TEÓRICO 29

3.1. A ATENÇÃO À SAÚDE FRENTE À CONSTANTE MODIFICAÇÃO 30 DO PERFIL POPULACIONAL

3.2. QUALIDADE DE VIDA 42

3.3. A BIOÉTICA E A FINITUDE HUMANA 43

4. MÉTODO 47

4.1. DELINEAMENTO DO ESTUDO 48

4.2. CENÁRIO DO ESTUDO 48

4.3. PARTICIPANTES DA PESQUISA 49

4.4. CRITÉRIOS DE INCLUSÃO E EXCLUSÃO 49

4.5. COLETA DOS DADOS 49

4.6. INSTRUMENTOS DE PESQUISA E ANÁLISE DOS DADOS 49

4.6.1. Questionário de dados sociodemográficos e clínicos 49

4.6.2. Escala de Sobrecarga de Cuidador - ESC 50

4.6.3. Instrumento de avaliação da qualidade de vida abreviado - 50 WHOQOL-bref

4.6.4. Instrumento de avaliação da qualidade de vida em idosos - 51 WHOQOL-old

4.6.5. Roteiro para a realização da entrevista 53

4.7. ASPECTOS ÉTICOS 54

5. RESULTADOS 55

5.1. CARACTERIZAÇÃO DO PERFIL SOCIODEMOGRÁFICO E 56 CLIINICO DOS DOENTES E DOS CUIDADORES DOMICILIARES

5.1.1. Descrição do perfil dos doentes cuidados 56

5.1.2. Descrição do perfil dos cuidadores domiciliares 56

$\begin{array}{llllll}5.2 & \text { PERCEPÇÃO DA } & \text { SOBRECARGA } & \text { DE } & \text { CUIDADORES } & 61\end{array}$ DOMICILIARES

5.2.1 Sobrecarga física e psicológica dos cuidadores de pacientes 65 internados em domicílio

5.3 PERCEPÇÃO SOBRE QUALIDADE DE VIDA DE CUIDADORES 65 DOMICILIARES

5.3.1. Avaliação por meio da aplicação do instrumento WHOQOL - bref 65

5.3.1.1 Aplicação do instrumento WHOQOL-bref 65

5.3.1.2. Descrição do instrumento 66

5.3.1.3. Índice Geral de Qualidade de Vida (IGQV) 66

5.3.1.4. Domínios e facetas do WHOQOL-bref 67

5.3.2. Avaliação por meio da aplicação do instrumento WHOQOL - old 70

5.3.2.1. Aplicação do questionário WHOQOL-old 70

5.3.2.2. Domínios e facetas do WHOQOL-old 71 
5.3.3. Comparação das médias do escore de qualidade de vida do cuidador 74 segundo as variáveis sociodemográficas

5.3.4. Comparação das médias do escore de qualidade de vida do cuidador $\quad 80$ segundo a escala de sobrecarga do cuidador

5.3.5. Correlação entre as médias do escore de qualidade de vida do 80 cuidador e variáveis quantitativas

5.3.6. Qualidade de vida de cuidadores domiciliares na oferta de cuidados 81 paliativos

5.4 PERCEPÇÃO DO SIGNIFICADO DA DOENÇA E DA FINITUDE 81 HUMANA FRENTE À QUALIDADE DE VIDA

5.5. PERCEPÇÃO DOS SENTIMENTOS VIVENCIADOS NO CUIDADO 83 E FRENTE AO SOFRIMENTO DO DOENTE

5.6. PERCEPÇÃO DAS MUDANÇAS OCORRIDAS APÓS O INÍCIO DA 85 FUNÇÃO DE CUIDADOR E DA INFLUÊNCIA DAS MESMAS NA SUA QUALIDADE DE VIDA

5.7. ASPECTOS BIOÉTICOS DA RELAÇÃO INTRAFAMILIAR NO 89 CONTEXTO DOS CUIDADOS PALIATIVOS NA ATENÇÃO DOMICILIAR

6. DISCUSSÃO 93

6.1. PERFIL SOCIODEMOGRÁFICO E CLÍNICO DOS DOENTES 94 CUIDADOS

6.2. PERFIL SOCIODEMOGRÁFICO E CLÍNICO DOS CUIDADORES 94 DOMICILIARES FRENTE À PERCEPÇÃO DA QUALIDADE DE VIDA

6.3. PERCEPÇÃO DA SOBRECARGA DOS CUIDADORES 100 DOMICILIARES

6.4. PERCEPÇÃO DO SIGNIFICADO DA DOENÇA E DA FINITUDE 101 HUMANA FRENTE À QUALIDADE DE VIDA DOS CUIDADORES DOMICILIARES

6.5. PERCEPÇÃO DOS SENTIMENTOS VIVENCIADOS NO CUIDADO 103 E FRENTE AO SOFRIMENTO DO DOENTE

6.6. PERCEPÇÃO DAS MUDANÇAS OCORRIDAS APÓS O INÍCIO DA 104 FUNÇÃO DE CUIDADOR E DA INFLUÊNCIA DAS MESMAS NA SUA QUALIDADE DE VIDA

6.7. ASPECTOS BIOÉTICOS DA RELAÇÃO INTRAFAMILIAR NO 107 CONTEXTO DOS CUIDADOS PALIATIVOS NA ATENÇÃO DOMICILIAR

7. CONCLUSÕES

$\begin{array}{ll}\text { REFERENNCIAS } & 115\end{array}$

$\begin{array}{ll}\text { APÊNDICES } & 136\end{array}$

ANEXOS 
1. INTRODUÇÃO 


\section{INTRODUÇÃO}

Com a constante e progressiva mudança no perfil demográfico, o envelhecimento populacional é considerado uma realidade indiscutível. Estimativas revelam que no ano de 2050, um quarto da população brasileira terá mais de 60 anos de idade. ${ }^{1}$

O aumento da longevidade está associado ao surgimento de doenças crônicas e perdas funcionais importantes que atingem principalmente as pessoas com mais idade. É importante analisar de que maneira esses anos agregados serão aproveitados e qual será a qualidade desse tempo maior de vida. Estudos afirmam que o aumento da longevidade está relacionado a um maior número de anos de autonomia diminuída, resultando em necessidade de cuidados permanentes. $^{2-6}$

Condições crônicas incluem alterações causadas na vida das pessoas, das suas famílias e da comunidade na qual estão inseridas e representam alto custo financeiro do sistema de saúde, além de serem responsáveis por incapacidades e mortalidade entre adultos e idosos. ${ }^{7-8}$

Os tratamentos disponíveis às condições crônicas podem compreender longos períodos de internação. Com o propósito de oferecer cuidados integrais com o apoio da família e de amigos, a internação domiciliar e a prática dos cuidados paliativos surgem como alternativas viáveis. $^{9-10}$

A atenção domiciliar (AD) compreende o atendimento específico a uma condição eventual ou uma internação com o acompanhamento de uma equipe multidisciplinar de atenção domiciliar (EMAD) e uma equipe de apoio (EMAP). Essas equipes fazem parte de um serviço de atenção domiciliar (SAD) que pode oferecer tratamento em três modalidades distintas, AD1, AD2 e AD3 que são definidas segundo a caracterização do paciente e sua condição clínica, bem como, quanto ao tipo de atenção necessária e dos procedimentos a serem realizados. ${ }^{11}$

Desospitalização e internação domiciliar envolvem um processo que passa pela elaboração de um plano assistencial que é elaborado em conjunto entre a EMAD, o enfermo e seus familiares, pois depende da participação de todos no processo. A família se responsabiliza por disponibilizar a pessoa do cuidador, que pode ser contratada para este fim, um familiar ou um amigo que se disponha a cuidar do paciente a maior parte do tempo. ${ }^{11-12}$

O perfil do cuidador, principalmente, quando de doente em cuidados paliativos, envolve dedicação continua de tempo e conhecimento relativo ao ato de cuidar, além de carinho e atenção para com o outro. Esse processo pode causar estresse e desgaste físico e 
psicológico acarretando sobrecarga. A proximidade com a gravidade da doença e com a possibilidade iminente de morte pode potencializar o estresse. ${ }^{12-16}$

Finitude humana é uma certeza, porém o rito de passagem, como é conhecido o processo de morte e morrer exige envolvimento espiritual e psicossocial da equipe de saúde, dos familiares, do cuidador e da própria pessoa. ${ }^{17-18}$

Por envolver dedicação e poder desgastar a relação familiar dos envolvidos, a função de cuidar afeta diretamente na sua percepção sobre qualidade de vida (QV). Entendida como um construto de três aspectos distintos: subjetividade, multidimensionalidade e presença de dimensões positivas e negativas, pode-se considerar que QV é a percepção que o indivíduo tem sobre o seu estado de saúde e sobre os aspectos gerais do contexto de sua vida. ${ }^{10,19-21}$

Diversos aspectos estão associados a este conceito e ao cuidado. A bioética se faz presente no processo de adoecimento e da morte e morrer com a finalidade de estudar e acompanhar a sobrevivência humana nos contextos iniciais e finais da mesma e sempre que envolvem conflitos éticos. ${ }^{22}$

No Distrito Federal o SAD existe em sua primeira versão desde o ano de 1994. Com a ampliação, mais recentemente foi criada a Gerência de Atenção Domiciliar (GEAD) no âmbito da Secretaria de Estado da Saúde (SES/DF) que atualmente compreende 15 Núcleos Regionais de Atenção Domiciliar (NRAD) presentes nas Regionais de Saúde. ${ }^{23}$

Com a realização deste estudo espera-se contribuir para as discussões sobre a implementação da AD com ênfase na qualidade de vida dos cuidadores domiciliares.

Como está a percepção de qualidade de vida do cuidador e como ele percebe a sobrecarga envolvida no desenvolvimento da função do cuidar?

Estruturalmente, este trabalho encontra-se dividido em sete partes numeradas sequencialmente e apresentadas da seguinte forma: 1.Introdução; 2.Objetivos; 3.Referencial Teórico (com a revisão da literatura procurando contextualizar e fundamentar a pesquisa); 4.Método; 5.Resultados (obtidos na coleta dos dados); 6. Discussão (análise dos dados); 7.Conclusões. 


\section{OBJETIVOS}

\subsection{OBJETIVO GERAL}

- Analisar os aspectos bioéticos do cuidar e a relação entre a percepção de cuidadores domiciliares sobre qualidade de vida e sobrecarga de trabalho.

\subsection{OBJETIVOS ESPECÍFICOS}

- Caracterizar o perfil sociodemográfico e clínico de doentes e de cuidadores domiciliares;

- Conhecer a percepção de sobrecarga de cuidadores domiciliares;

- Conhecer a percepção sobre qualidade de vida de cuidadores domiciliares;

- Conhecer o significado atribuído à doença e à finitude humana por cuidadores domiciliares;

- Identificar os sentimentos vivenciados pelos cuidadores domiciliares durante o processo do cuidar;

- Identificar as principais mudanças relacionadas ao cuidar referidas por cuidadores domiciliares;

- Identificar os aspectos bioéticos no contexto dos cuidados paliativos na atenção domiciliar. 
3. REFERENCIAL TEÓRICO 


\section{REFERENCIAL TEÓRICO}

\subsection{A ATENÇÃO À SAÚDE FRENTE À CONSTANTE MODIFICAÇÃO DO PERFIL} POPULACIONAL

A população brasileira está modificando e o fenômeno do envelhecimento populacional é uma realidade indiscutível. O Instituto Brasileiro de Geografia e Estatística (IBGE) revela que, em 50 anos, a população do Brasil praticamente triplicou, passando de 70 milhões, em 1960, para 190,7 milhões em 2010. Traz ainda como estimativa para o ano de 2025, que $15 \%$ da população brasileira será composta por pessoas idosas e, para o ano de 2050, este percentual será de $25 \%{ }^{1}$

Nessa tendência de transição demográfica, causada pela redução da natalidade e diminuição da mortalidade, resulta em aumento da longevidade. Antigamente considerado raro, o processo de envelhecimento hoje é comum a milhões de cidadãos pelo mundo, tanto em países desenvolvidos como em países em desenvolvimento. ${ }^{24-26}$

Acompanhando a transição demográfica, outra mudança merece destaque, a epidemiológica, pois representa um grande desafio para a organização dos serviços de assistência à saúde. O processo do envelhecimento envolve prejuízos expressos pela diminuição do vigor e da força, que, quando associadas às condições crônicas, que atingem em torno de $90 \%$ das pessoas com mais de 65 anos de idade, refletem na perda funcional de órgãos ou tecidos ao longo dos anos. ${ }^{7,27}$

A estimativa de mudança populacional entre o período de 1950 a 2050 se assemelha entre os países da America Latina, Caribenhos e o Brasil, conforme observado na figura 1. ${ }^{3,7}$

Figura 1- Pirâmide etária Brasil, America Latina e Caribe de 1950-2050. ${ }^{3}$ 
1a) 1975

América Latina e Caribe

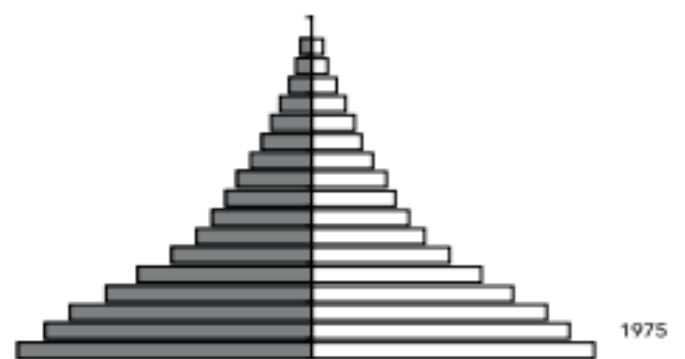

1b) 2000

América Latina e Caribe

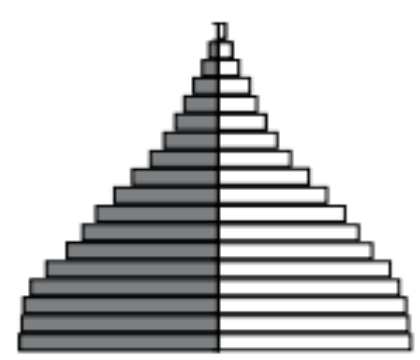

1c) 2025

América Latina e Caribe

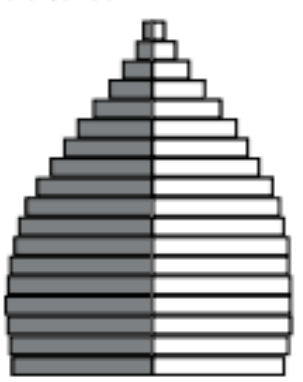

1d) 2050

América Latina e Caribe

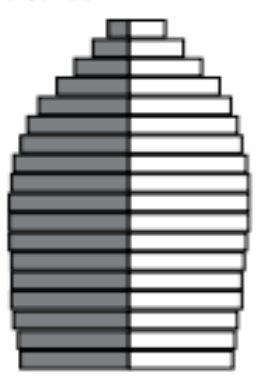

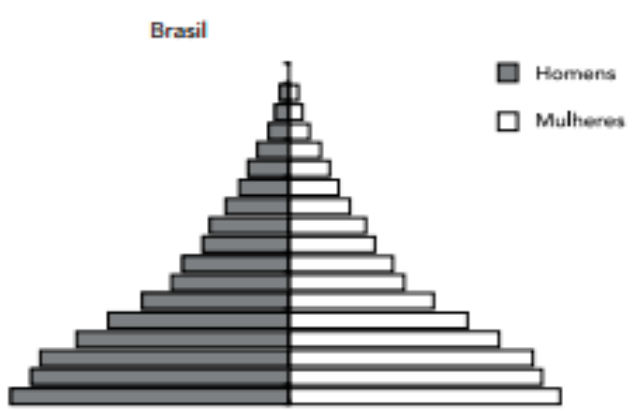

Brasil

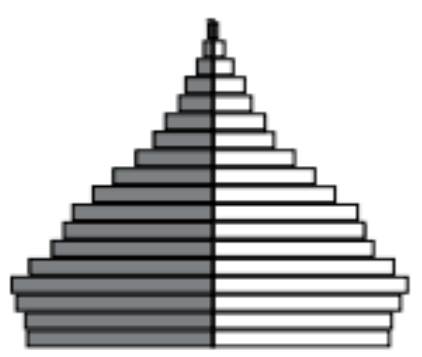

Brasil

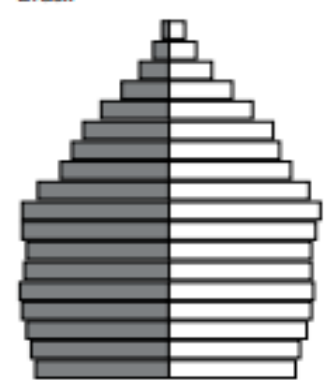

Brasil

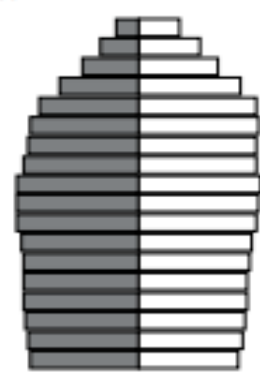

A esperança de vida, projetada pelas pesquisas publicadas pelo IBGE, para cada criança brasileira nascida em 2041 possivelmente chegará a 80 anos. ${ }^{1}$ Em 2013, a esperança foi de 71,2 anos para homens e 74,8 para mulheres. Já para 2060, há previsão de que chegue a 78 para homens e 84,4 anos para as mulheres. ${ }^{3} \mathrm{Na}$ figura 2 é possível observar os efeitos desta transição demográfica entre os anos de 1950 e 2050. 
Figura 2- Distribuição percentual da população, por grandes grupos etários (anos). Brasil, $1950-2050 .^{3}$

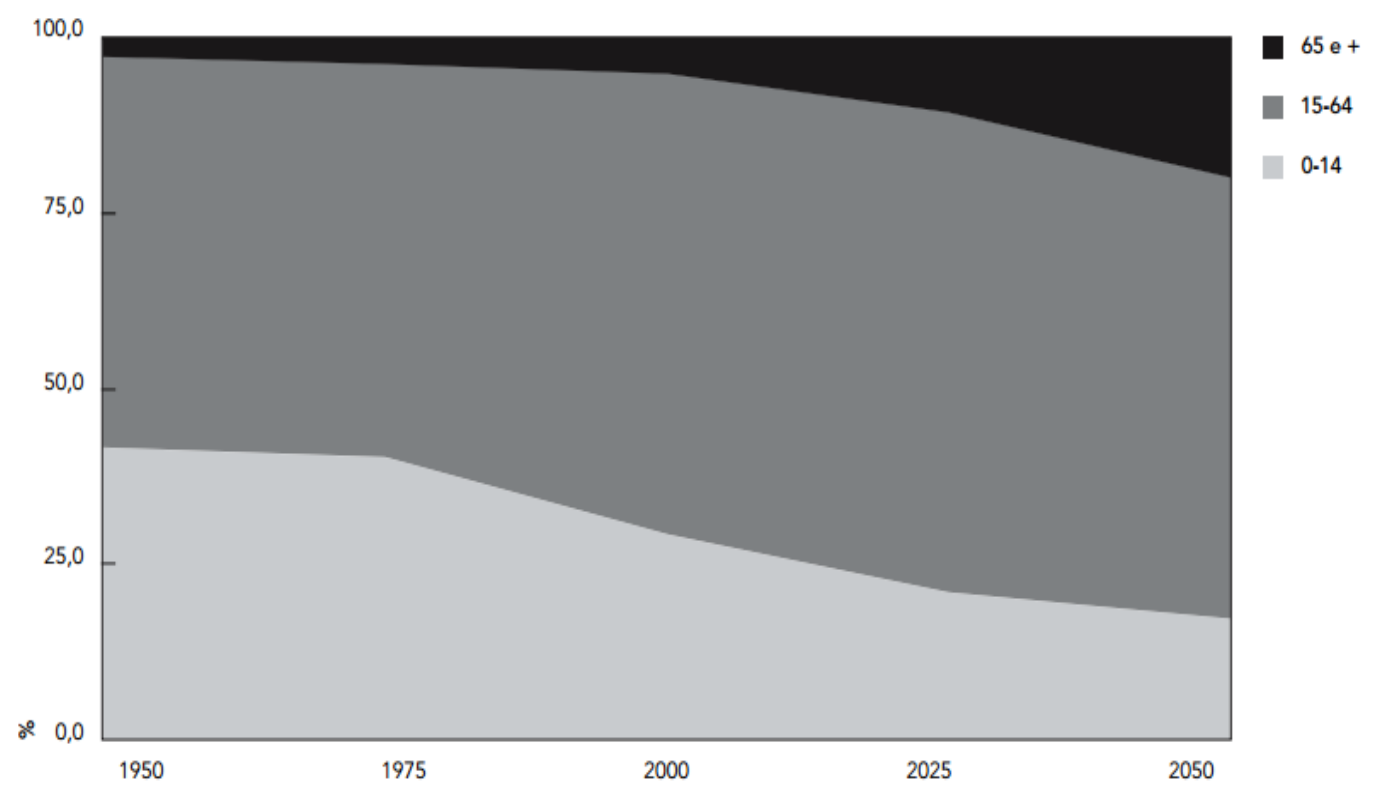

Não obstante a longevidade ser vista como uma boa noticia, uma preocupação assola pesquisadores e formuladores de políticas no mundo todo que diz respeito à qualidade deste envelhecimento, principalmente em virtude da rapidez em que ele ocorre. ${ }^{2-4}$ Pois, maior longevidade também pode estar associada a mais anos de autonomia diminuída, ou ainda de incapacidade e, portanto, maior demanda por cuidado permanente. ${ }^{4-5}$

O conhecimento da situação sanitária, incluindo as condições crônicas mais relevantes, segundo a Organização Mundial da Saúde (OMS), ${ }^{28}$ é imprescindível para a formulação de políticas baseadas em estratégias eficazes que sejam capazes de garantir qualidade, sustentabilidade e equidade.

As condições de saúde diferem quanto ao tempo de evolução, sendo que as agudas evoluem em período curto de tempo e as crônicas em períodos superiores, por mais de três meses, sendo que, na maioria dos casos, se torna definitiva ou permanente. ${ }^{3,28-29}$

Estudos são desenvolvidos no Brasil e no mundo em busca de soluções para essa problemática com o propósito de atender as necessidades e oferecer qualidade de vida à população assistida. ${ }^{5-6,29}$

As doenças eram classificadas, até pouco tempo atrás, em infecciosas e crônicodegenerativas considerando o tempo de evolução e o agravo relacionado. Porém, essa classificação não abrangia as dimensões das patologias emergentes e persistentes. ${ }^{30-32}$ 
Como essas doenças repercutem de maneira parecida na vida das pessoas, das famílias e da comunidade onde vivem, passaram a ser vistas de forma conjunta, relacionando-as entre si e não mais de forma isolada. O conjunto foi denominado de condição crônica. ${ }^{24,33}$

O termo condição crônica passou a ser utilizado por abranger todas as dimensões do agravo, incluindo as alterações causadas na vida do doente, da sua família e em toda a sociedade. ${ }^{24-25}$ Esse conceito abrange ainda condições ligadas à maternidade e ao período perinatal; aos ciclos de vida como a senilidade; aos distúrbios mentais de longo prazo; às deficiências físicas e estruturais contínuas; às doenças metabólicas; dentre outras. ${ }^{7}$

Um estudo brasileiro que utilizou estatísticas de saúde e empregou disabilityadjusted life years (DALYs - anos de vida perdidos ajustados por incapacidade) mostrou que as mesmas são responsáveis por $66 \%$ deste índice, seguidas de $24 \%$ decorrentes das doenças infecciosas maternas e perinatais e deficiências nutricionais e $10 \%$ decorrentes de causas externas. ${ }^{34}$ Nesse mesmo sentido, outro estudo revela que em 2008 as condições crônicas foram responsáveis por $63 \%$ das mortes ocorridas no mundo. ${ }^{35}$

As condições crônicas são responsáveis ainda por um alto custo financeiro do sistema de saúde, devido à necessidade de dedicação de cuidados contínuos por vários anos, incluindo as sequelas e consequências das doenças crônicas não transmissíveis (DCNTs). ${ }^{7,8}$

Com o objetivo de enfrentar esta situação, faz-se necessária a adoção de estratégias locais e mundiais focadas em políticas públicas e interação multissetorial com a articulação de diversos atores. ${ }^{36-38}$

A evolução das condições crônicas em todo o mundo, que está relacionada à mudança no perfil epidemiológico e sociodemográfico das populações apresenta-se como um grave problema de saúde pública. A OMS estima que no ano de 2020, $80 \%$ das doenças que acometerão os países em desenvolvimento advirão de problemas crônicos. Outro fator que preocupa é a baixa adesão ao tratamento. ${ }^{28,38}$

Atualmente, no Brasil e em outros países com desigualdade social significativa, as condições crônicas representam uma das mais importantes causas de mortalidade e de incapacidade entre adultos e idosos. Nesse sentido, o conceito de condição crônica pode ser atribuído ao rótulo da idade e se faz presente, principalmente, com o aumento de tempo de vida da pessoa. ${ }^{32,39}$

O Ministério da Saúde (MS), preocupado com o impacto das DCNTs na saúde pública e com o objetivo de reduzir a prevalência das mesmas, lançou em 2011 o Plano de Ações Estratégicas para o Enfrentamento das Doenças Crônicas Não Transmissíveis no Brasil, 2011- 
2022, que define e prioriza as ações e os investimentos necessários para preparar o país para enfrentar as DCNTs por este período. ${ }^{40}$

O Plano tem como principal objetivo reduzir e controlar os fatores de risco para o desenvolvimento das DCNTs, além de promover o desenvolvimento e a consequente implementação de políticas públicas efetivas, integradas, sustentáveis e baseadas em evidências. Com a definição das ações abordando os quatro principais grupos de doenças crônicas, ou seja, circulatórias, neoplasias, respiratórias crônicas e diabetes e seus principais fatores de risco comuns e modificáveis e a definição de diretrizes, o plano almeja fortalecer os serviços de saúde. ${ }^{40}$

Outra questão a ser analisada se refere ao alto número de comorbidades e sequelas existentes, principalmente entre os idosos que envolvem a perda de autonomia e de integralidade funcional e estrutural do corpo. ${ }^{5-6,38}$

Relacionado às perdas sofridas pelos doentes e seus familiares em virtude das condições crônicas, outro dado a ser analisado diz respeito ao tratamento necessário e ao cuidado a ser prestado para esta população específica, que passa por célere crescimento, pois muitas vezes não há necessidade de internação hospitalar, mas sim, de um cuidado permanente que pode ser oferecido em domicilio.

O termo Cuidados Paliativos, foi redefinido, em 2002, pela OMS como uma abordagem que aprimora a qualidade de vida dos pacientes e famílias que enfrentam problemas associados com doenças, através da prevenção e alívio do sofrimento, por meio de identificação precoce, avaliação correta e tratamento da dor, e outros problemas de ordem física, psicossocial e espiritual. ${ }^{9}$

No Brasil, algumas iniciativas do MS são importantes para a normalização dos cuidados paliativos na assistência à saúde da população. Dentre elas, a Portaria GM/MS n. 1.319 de 23 de julho de $2002{ }^{41}$ que cria, no âmbito do Sistema Único de Saúde (SUS), os Centros de Referência em Tratamento da Dor Crônica; a Portaria MS/GM n. 3.150, de 12 de dezembro de $2006^{42}$ que instituiu a Câmara Técnica em Controle da Dor e Cuidados Paliativos e a Portaria GM/MS n. 874, de 16 de maio de $2013^{43}$ que instituiu a Política Nacional para a Prevenção e Controle do Câncer na Rede de Atenção à Saúde das Pessoas com Doenças Crônicas no âmbito do SUS.

Como princípios dos cuidados paliativos podem ser descritos: a reafirmação da importância da vida, considerando a morte como um processo natural; o estabelecimento de um cuidado que não acelere a chegada da morte, nem a prolongue com medidas desproporcionais (obstinação terapêutica); a possibilidade de propiciar alívio da dor e de 
outros sintomas penosos; a integração dos aspectos psicológicos e espirituais na estratégia do cuidado e o oferecimento de um sistema de apoio à família para que ela possa enfrentar a doença do paciente e sobreviver ao período de luto. ${ }^{44}$

Esse tipo de cuidado traz, além da busca pela qualidade de vida do doente com doença avançada e dos familiares, o suporte psicossocial no período de enfrentamento da doença e, de luto, quando necessário. ${ }^{45}$

As famílias entendem como importante esse apoio recebido e percebem, segundo estudos realizados, que o mesmo acontece mais na fase inicial do processo, ou seja, na fase do diagnóstico da doença que precede, muitas vezes, a internação domiciliar. ${ }^{45-46}$

Por meio dos cuidados paliativos no domić́lio, com o apoio da equipe multidisciplinar de atenção domiciliar (EMAD), a decisão do doente pode ser respeitada e preservada. $\mathrm{O}$ fato de permanecer na sua própria residência permite ao doente conservar por mais tempo sua funcionalidade e a convivência com seus familiares e sua rede social. ${ }^{45-46}$

A internação em casa para oferecer cuidados paliativos deve seguir alguns critérios específicos para a inclusão do doente neste modelo de assistência à saúde. Entre eles, a permanência de um cuidador principal, familiar ou não e, neste caso, sob a responsabilidade financeira da família, e a orientação e acompanhamento de uma equipe do Serviço de Atenção Domiciliar (SAD) a ele vinculado. ${ }^{12}$

Amenizar o sofrimento que pode preceder a morte, acompanhado muitas vezes de angústia e medo por parte do paciente e dos familiares é um dos papeis da equipe de saúde que acompanha a família e auxilia na prestação de cuidados paliativos frente à doença e à terminalidade da vida. ${ }^{47}$

Oferecer cuidados holísticos aos familiares e ao doente é um desafio da EMAD e da equipe de cuidados paliativos. É preciso que a família entenda os benefícios e as dificuldades que enfrentará ao levar o seu ente para casa a fim de prestar assistência no domicílio. ${ }^{45-46}$

Entre os benefícios dos cuidados paliativos podem ser elencados o alívio da dor e de outros sintomas, o entendimento da morte como um processo natural do ser humano e a integração de aspectos psicológicos e espirituais na assistência ao paciente. ${ }^{11}$

A existência de diagnóstico de uma doença grave na família provoca diversas reações. Pode exigir alterações importantes na dinâmica familiar, com mudanças de papeis já definidos para que, em conjunto, sejam buscadas estratégias de enfrentamento do problema. Cuidar representa superar desafios, envolve longos períodos de tempo dispensados ao paciente, desgastes, altos custos financeiros e sociais, além de sobrecarga emocional e riscos físicos e mentais. ${ }^{12}$ 
Estudo brasileiro revela que o doente terminal passa a ser a evidência e o foco de atenção da equipe, fazendo com que o cuidador familiar principal fique mais suscetível aos fatores de risco para o cansaço e o estresse diante da morte devido à necessidade maior de apoio emocional para o cuidado domiciliar. ${ }^{47}$

O cuidado com a família passa a ser um ponto crucial no atendimento ao paciente em cuidados paliativos, pois a proposta é de oferecer atenção e conforto. Para tal, é preciso que haja conforto de todos os envolvidos no processo, pois quando um indivíduo adoece, a família toda sente as consequências do momento vivenciado. ${ }^{11,47}$

Entendendo que o processo é contínuo e complexo, o cuidador de paciente em cuidados paliativos necessita de apoio da equipe de saúde responsável em todos os aspectos: físico, emocional, psicológico e espiritual. A equipe deve estar preparada para oferecer este apoio, afinal ela também vivencia o processo do cuidar. ${ }^{11}$

A atenção domiciliar (AD) constitui em uma modalidade de atenção à saúde, agregada, de forma substitutiva ou complementar às já existentes. É oferecida no domicílio do doente e necessita de apoio da família ou de cuidadores contratados para este fim, além da equipe responsável pelo acompanhamento e orientação sobre os cuidados específicos que precisam ser dispensados ao paciente assistido. Essa forma de assistência se faz presente em vários países do mundo. ${ }^{11-12}$

Como fatores de contribuição para o aumento desse serviço estão o envelhecimento da população na transição demográfica, que vem acompanhada da transição epidemiológica e a evolução das condições crônicas, que muitas vezes, levam a uma sobrevida dependente de novas tecnologias de assistência. Além do aumento da busca pelos serviços de saúde, utilizando praticamente todos os leitos hospitalares disponíveis, a urgência da diminuição de custos relacionados ao sistema de saúde e a necessidade de humanização da assistência à saúde. ${ }^{11,48}$

Para o inicio da atenção domiciliar no Brasil há diversas versões circulantes, uma datada de 1919 que está relacionada a visitas domiciliares realizadas por enfermeiras e outra de 1949, relacionada ao surgimento do Serviço de Assistência Médica Domiciliar e de Urgência (SAMDU), como uma iniciativa do Ministério do Trabalho, além de outra afirmando que o primeiro serviço de atenção domiciliar no Brasil foi o do Hospital do Servidor Estadual Público de São Paulo, criado no ano de 1967, com a denominação de Assistência Domiciliar à Saúde (ADS). ${ }^{49-50}$

Nos últimos anos esse tipo de serviço de saúde passou por uma reativação e reestruturação e é reconhecido pelo sistema como ator importante no processo do cuidar. 
Autores afirmam que o cuidado domiciliar modificou e atende, principalmente, aos doentes com agravos de longa duração, incapacitados ou em fase terminal. ${ }^{51-52}$

Com o propósito de normalizar a internação domiciliar no Brasil foi publicada em 2002, a Lei n. 10.424. Essa Lei acrescenta o Capítulo VI e artigo 19 à Lei nº 8.080, de 1990 que define o Subsistema de Atendimento e Internação Domiciliar e estabelece, no âmbito do SUS, o atendimento e a internação domiciliar. ${ }^{53}$

Nesse mesmo caminho, a Agência Nacional de Vigilância Sanitária (ANVISA) publicou em 2006, a Resolução de Diretoria Colegiada (RDC) n. 11/2006 que estabelece os requisitos de funcionamento para os Serviços de Atenção Domiciliar públicos e privados em todo o país. ${ }^{54}$

A AD foi redefinida no ano de 2011, por meio da Portaria GM/MS 2527 e, no mesmo ano, foi lançado o Programa Melhor em Casa que integra um dos componentes das Redes de Atenção às Urgências e Emergências (RUE) e tem como objetivo organizar esse serviço tanto na rede pública como privada no território nacional, ampliando o atendimento domiciliar do SUS e, dessa forma, ajudar a reduzir as filas das emergências dos hospitais da rede pública. Em 2013, foi publicada a Portaria GM/MS 963 que revoga as anteriores e redefine a Atenção Domiciliar. $^{11,55}$

Na esfera pública, via Sistema Único de Saúde, a AD compreende dois diferentes níveis de complexidade, um contemplado pela Estratégia de Saúde da Família (ESF) e pelo Programa de Agentes Comunitários de Saúde (PACS) e o outro pelo Serviço de Atenção Domiciliar (SAD), coordenado pelo Programa Melhor em Casa. ${ }^{11,55}$

A AD pode ser organizada em três modalidades: AD1, AD2 e AD3, que são definidas em função da caracterização do paciente, do tipo de atenção necessária e dos procedimentos que deverão ser realizados para a efetivação deste cuidado. Sendo que a AD1 é de responsabilidade da Estratégia de Saúde da Familia e as AD2 e AD3 possuem financiamento específico e agregam tecnologias necessitando de equipes especializadas para o seu desenvolvimento. ${ }^{55}$

Um dos pontos fortes da AD é a interação do paciente ao seu contexto, ou seja, a sua cultura, rotina e espaço íntimo. A dinâmica familiar e os contatos ininterruptos favorecem a qualidade da atenção e proporcionam a diminuição da necessidade de internação hospitalar. Ainda como resultados secundários, a internação domiciliar (ID) potencializa uma melhor gestão dos leitos hospitalares e, dessa forma, a racionalização dos recursos. ${ }^{55}$

A AD é caracterizada como uma atividade continuada, que envolve a oferta de recursos humanos, materiais e equipamentos para pacientes com condições clínicas 
complexas, que demandam assistência semelhante à oferecida em ambiente hospitalar ou dependentes de recursos tecnológicos, com necessidades de cuidados paliativos ou para o término do tratamento de doenças que exigiram internação hospitalar. ${ }^{55}$

Pode ser decorrente de uma alta hospitalar assistida, quando o paciente é acompanhado desde a internação hospitalar pela equipe do SAD que elabora um plano de $\mathrm{AD}$, com o propósito de oferecer humanização no atendimento, além de diminuir o risco de infecção hospitalar devido à baixa imunidade causada pela doença e à exposição desnecessária aos fatores desencadeantes da mesma. ${ }^{11,55}$

O plano de atenção é desenvolvido em todos os casos de alta hospitalar assistida e define o tipo de atendimento necessário para cada doente. Com ele o SAD pretende assegurar aos pacientes em tratamento domiciliar melhor qualidade de vida e a manutenção do vínculo familiar. ${ }^{55}$

Por todos esses aspectos, entende-se que o propósito da AD é também o seu maior desafio: oferecer uma assistência de qualidade, de forma contínua, contextualizada no ambiente cultural e familiar do paciente adaptando-se a ambientes diferentes do hospitalar e tendo o apoio da família quanto à disponibilização do cuidador, da infraestrutura e do apoio psicossocial necessário para a qualidade de vida, tanto do próprio doente, quanto da sua família. $^{55}$

A população estimada no Distrito Federal pelo IBGE para o ano de 2014 foi de 2.852.372 habitantes, dividida em 31 Regiões Administrativas (RA). A Região Administrativa RA IX - Ceilândia, oficialmente criada pela Lei n. 49/89 e o Decreto n. 11.921/89, surgiu em março de 1971, em decorrência da Campanha de Erradicação de Invasões (CEI), que foi o primeiro projeto de erradicação de favelas realizado no Distrito Federal pelo governo local, representa $16 \%$ desse total. ${ }^{56}$

No Distrito Federal, no ano de 1994, profissionais da SES/DF criaram o primeiro Serviço de Assistência Multiprofissional em Domicílio (SAMED) na RA V - Sobradinho. Esse serviço foi ampliado e, atualmente, existe a Gerência de Atenção Domiciliar (GEAD), que presta assistência domiciliar por meio de 16 equipes multiprofissionais dos seus 15 Núcleos Regionais de Atenção Domiciliar (NRAD), vinculados às Coordenações Gerais de Saúde da SES-DF em 15 Regiões Administrativas (RAs). ${ }^{57}$

Os núcleos atendem aos doentes em dois programas distintos, sendo o Programa de Oxigenoterapia Domiciliar (POD) direcionado a pessoas com doenças pulmonares e insuficiência respiratória crônica causada por lesões pulmonares irreversíveis e o Programa de Internação Domiciliar (PID) destinado a assistir pessoas portadoras de doenças crônicas ou 
sequelas, com quadro clínico estável, que estejam acamadas e que necessitam de um cuidador e/ou de cuidados paliativos neurológicos ou oncológicos, dentre outras características. Porém, nenhum dos dois programas atende doentes de alta complexidade. ${ }^{57-58}$

As EMADs são formadas prioritariamente por médicos, enfermeiros, técnicos em enfermagem, fisioterapeuta e/ou assistente social, além de outros profissionais como fonoaudiólogo, nutricionista, terapeuta ocupacional, odontólogo, psicólogo e farmacêutico, fisioterapeuta e assistente social que podem compor as EMAPs. ${ }^{59}$

Segundo dados da GEAD, somente no ano de 2012, os 15 NRADs realizaram 113.460 visitas domiciliares, 238.086 atendimentos ambulatoriais, 443.196 procedimentos domiciliares e tinham 904 pacientes ativos, sendo que desde a abertura do Programa no DF, 5.406 pacientes já haviam sido cadastrados. ${ }^{57}$

O cuidador, quando é uma pessoa da família ou muito próxima ao doente ou ainda um vizinho é chamado de 'cuidador informal' e quando é uma pessoa contratada para o fim de cuidar, é denominado de 'cuidador formal'. Outra designação diz respeito ao tempo e à dedicação ao doente, ele pode ser 'cuidador principal', se assumir a maior parte das responsabilidades pelos cuidados ou 'cuidador secundário', se auxiliar na prestação de cuidados por um período menor e se responsabilizar apenas pelo apoio ao cuidador principal e ainda de 'cuidador terciário', quando auxilia esporadicamente no cuidado ao doente. ${ }^{55,60-63}$

O cuidado direcionado aos doentes internados em domicílio e em cuidados paliativos demandam importante tempo de dedicação do cuidador e isso pode fazer com que ele se distancie de parte de suas atividades cotidianas, sendo necessária adaptação a uma nova rotina que inclui as exigências terapêuticas e de apoio ao doente. ${ }^{63-64}$

Diante da necessidade do cuidado domiciliar, ajustes podem ser indispensáveis na rotina doméstica como a mudança de horários na realização de tarefas de casa. Dentro dessa ótica, o cuidado pode acarretar em sobrecarga do cuidador, restringindo suas atividades, trazendo preocupações e muitas vezes, o isolamento social associado à insegurança. ${ }^{11,65}$

As dificuldades enfrentadas são ainda mais acentuadas quando a situação de saúde do doente é grave e coloca o cuidador diante da morte ou da falta de apoio emocional e prático. Fatores estes que podem potencializar o cansaço e o estresse. ${ }^{11,66-69}$

Estudos revelam que efeitos negativos nas relações familiares e sociais, nas relações de trabalho e inclusive nas atividades de lazer, incluindo reações emocionais desproporcionais são relatados por cuidadores domiciliares de enfermos. O cuidado de doentes em fase terminal, com foco paliativo, é considerado exigente e pode acarretar em desgaste emocional 
e físico, de forma significativa, afetando a saúde mental do familiar cuidador, podendo inclusive limitar a sua capacidade de continuar a ser um cuidador. ${ }^{11,65-67}$

Neste sentido, o familiar, no papel de cuidador, pode ser considerado, por vezes, protetor e por outras, doente. A doença em fase terminal e a convivência com o doente em cuidados paliativos tem um caráter contagiante, pois aflige os seus contatos próximos. Tal situação reflete a importância e a necessidade de oferecer aos cuidadores familiares, suporte emocional e psicológico com o propósito de prepará-los para ao enfrentamento do processo. 11,69

O papel da EMAD é crucial na orientação à família do paciente internado em domicílio, pois além de propiciar a escuta, também pode propor e organizar, junto à família, sempre que for possível, o rodízio de cuidadores. Pretende-se diminuir, com essa estratégia, o desgaste físico e emocional do cuidador principal, além de estabelecer uma escala de folga ao reforçar a importância do autocuidado como fator preventivo do estresse. ${ }^{11,70-71}$

Dado o exposto, a organização, por parte da EMAD, de grupos de discussão entre os cuidadores para troca de experiências pode proporcionar o compartilhamento de conhecimentos auxiliando no desempenho e contribuindo para melhora do estado emocional do cuidador, aliviando o desgaste e atenuando a insegurança. ${ }^{61,67}$

A EMAD também sofre as consequências do cuidado aos doentes em domicílio e em cuidados paliativos, pois se envolve diretamente, não só com o doente, mas com o cuidador e com a família e precisa estar preparado para esse cuidado, principalmente o apoio ao cuidador principal. Estudos desenvolvidos com profissionais de saúde, integrantes de equipes de assistência revelaram que estes profissionais apresentam dificuldades importantes em controlar sua própria ansiedade e estresse. ${ }^{11,72}$

A proposta da ID pode ser vista com entusiasmo pelo doente e seus familiares, por propiciar uma continuidade de relação, em ambiente familiar e cercado por seus amigos e pelas suas relações sociais. Porém, também pode ser vista como um declínio do processo de cura, para continuar o tratamento apenas com propósito paliativo, causando insegurança e estresse aos cuidadores que não estão preparados para este cuidado intenso e prolongado. ${ }^{72}$

A transferência para o cuidado paliativo provoca intensas emoções entre doentes e familiares e estudo demonstra que também provoca sentimentos de fracasso entre profissionais de saúde responsáveis pelo processo terapêutico do paciente durante a ID. Esse sentimento pode ser considerado de impotência e as instituições de ensino responsáveis pela formação destes profissionais exercem papel importante no preparo para este cuidado, considerando a ID como parte da dinâmica terapêutica de doentes em cuidados paliativos e 
não vista como um fracasso profissional, mas sim, como recurso adicional ao tratamento por internação hospitalar. ${ }^{68}$

O apoio psicossocial aos cuidadores deve envolver também a equipe assistencial. Como medida de suporte essencial pode-se destacar o acompanhamento da rede de apoio, composta por familiares, cuidadores e EMAD. A família deve participar do tratamento e receber suporte para aprender os cuidados que deverão ser dispensados ao doente e também para enfrentar, compreender e compartilhar a situação de doença e a sua própria situação, conflitos, medo e angústia frente ao papel de responsabilidade complexa que irá desenvolver a partir deste momento. ${ }^{68-70}$

A presença dos diagnósticos de ansiedade e depressão foi detectada em estudos realizados com cuidadores principais familiares, revelando que as mudanças impostas aos cuidadores, em função do surgimento de doenças que necessitem de cuidados paliativos no domicílio, provocam alterações importantes na rotina dos mesmos e desequilíbrio com sobrecarga física, social e econômica. ${ }^{69-71}$

Estudo revela que as relações familiares são abaladas com o surgimento da doença. A família, quando bem estruturada pode desenvolver este processo com união e trazer à tona sentimentos fortes de respeito e amor, com carinho, atenção e cuidado. Em alguns casos, estes sentimentos são reforçados durante o processo da doença. Porém, em outras famílias pode ocorrer o distanciamento dos membros de forma involuntária e inconsciente em busca de proteção e blindagem ao sofrimento. ${ }^{69}$

O que parece estar associado a esta reação diferenciada entre as famílias é a forma como o cuidador assume o papel a ele destinado. Se por vontade ou instinto ou por conjuntura. $\mathrm{O}$ que assume por vontade se sente motivado a manter um relacionamento com o outro e satisfaz seus sentimentos por meio dessa relação. Já o que assume por instinto, o faz de maneira impulsiva e tende a se sentir obrigado a fazê-lo por uma conjuntura social, por ser o único familiar disponível ou mais próximo ou ainda, o que tem uma melhor de aproximação social e emotiva com o doente. Nesses casos, o nível de sobrecarga geralmente se apresenta intenso e acarreta em danos psicossociais ao cuidador de forma mais acentuada e imediata. ${ }^{69-}$ 71 


\subsection{QUALIDADE DE VIDA}

O termo 'Qualidade de Vida' (QV) é utilizado de formas diferentes e com abordagens distintas. É importante entender esse universo quanto à multiplicidade de questões que o envolvem, desde parâmetros econômicos, sociais e de saúde. ${ }^{74-75}$

Pode ser interpretado como a percepção que as pessoas têm sobre a sua vida o sentimento e a compreensão do seu cotidiano, envolvendo, desta forma, questões de saúde, trabalho, educação, moradia, transporte e participação nas decisões que lhes dizem respeito. ${ }^{66}$ QV é entendida ainda como um conceito amplo e complexo que abarca o construto e interrelaciona o ambiente e os aspectos físicos e psicológicos, o nível de independência, as relações sociais e as crenças pessoais. ${ }^{75-76}$

Ainda pode ser analisada quanto à objetividade das condições materiais como as relações estabelecidas na sociedade ou quanto à subjetividade quando o que interessa é como o indivíduo se percebe em relação ao conhecimento sobre as suas condições físicas, emocionais e sociais relacionadas aos aspectos sociais, temporais e culturais. ${ }^{75}$

A análise da QV permite, portanto, ao envolver os aspectos objetivos e subjetivos, traçar o perfil do indivíduo ou do grupo ao qual pertence em relação ao seu acesso a bens e serviços e ao seu bem-estar. Podendo, inclusive, avaliar questões imensuráveis como felicidade, prazer, angústia e/ou tristeza. ${ }^{75}$

Sempre que forem aplicadas escalas de avaliação da QV é importante entender que a caracterização prévia do ambiente histórico, social e cultural em que vive o indivíduo ou o grupo é fator fundamental para uma análise efetiva. Pois não é possível que haja uma análise sobre QV sem que haja uma contextualização na qualidade de vida coletiva. ${ }^{75-76}$

Os métodos de avaliação da QV são numerosos e divergentes tanto quanto as definições existentes para o termo. As crescentes buscas por uma definição universal da compreensão de como as pessoas vivem e da possibilidade de sugerir formas para que elas possam viver melhor bem como da possibilidade de orientar políticas públicas e tratamentos de saúde que tratem o ser humano de forma mais ampliada faz com que novas ideias sobre essa avaliação surjam no decorrer dos anos. ${ }^{75,77-78}$

Três aspectos circundam o conceito sobre QV, em diferentes construtos, que são: a subjetividade, a multidimensionalidade e a presença de dimensões positivas e negativas. Dessa forma, considera-se QV, a percepção que o indivíduo tem sobre o seu estado de saúde e sobre os aspectos gerais do contexto de sua vida. Portanto, significa avaliar a situação pessoal 
de cada pessoa em cada uma das dimensões relacionadas a sua própria qualidade de vida. ${ }^{76,78,}$ $80-81$

Estudos realizados no Brasil analisaram a QV em individuos com condições crônicas de saúde-doença ou utilizaram os instrumentos de avaliação existentes como auxiliares para a análise de resultados de intervenções terapêuticas. ${ }^{81-83}$

Devido às diversas formas de utilização do conceito de QV que pode ser considerado sinônimo de saúde ${ }^{80-84}$, de felicidade ${ }^{85}$, ou ainda, de estilo de vida ${ }^{86}$, é necessário definir delimitações mais claras e específicas para que o mesmo possa ser empregado em operacionalizações e em análises científicas. ${ }^{86}$

Para os profissionais da área de saúde esse conceito ainda tem muitas discrepâncias devido a sua enorme complexidade. Pode variar conforme a disciplina em qual está sendo avaliado. Entre os conceitos mais acolhidos e empregados está o que define QV como o resultado da avaliação do grau de excelência na vida em relação a alguns padrões implícitos ou explícitos de uma sociedade em particular. ${ }^{86-87}$

A OMS define como qualidade de via a percepção do indivíduo de sua posição na vida, no contexto da cultura e sistema de valores nos quais vive e em relação aos seus objetivos, expectativas, padrões e preocupações. Este conceito será utilizado coo referência neste estudo.

\subsection{A BIOÉTICA E A FINITUDE HUMANA}

A Bioética, entendida como a ética da vida, despontou na década de 1970 como uma proposta inovadora com o objetivo de subsidiar a análise das questões éticas relacionadas a problemas morais e normativos na área biomédica. ${ }^{88-89}$

Utilizando-se de bases filosóficas, a bioética é considerada a ciência que estuda a sobrevivência humana e atua na defesa da melhoria das condições de vida. Neste contexto, o inicio e o fím da vida são temas de estudo contínuos por envolver conflitos éticos atuais. ${ }^{82}$ Especificamente, o fim da vida passa por modificações decorrentes do avanço tecnológico e dos estudos científicos realizados, resultando em maior longevidade e sobrevida das pessoas doentes em acompanhamento. ${ }^{22,90-93}$

O portador de enfermidade progressiva e incurável, quando em fase terminal da mesma, ou seja, apresentando quadro de deterioração clínica com consequente perda de peso, fraqueza generalizada, comprometimento da mobilidade e dificuldades em manter a higiene pessoal, sofre em companhia dos familiares pela não possibilidade de cura. ${ }^{94}$ 
O apoio vindo da família, do cuidador ou do sistema de saúde tem como propósito acompanhar e auxiliar os doentes terminais no processo de morte e morrer. A falha nesse apoio pode levar a um sofrimento maior durante a trajetória de sobrevivência. ${ }^{95}$

O neologismo 'finitude' surgiu em meados do século XVII, na língua inglesa, com o propósito de definir o que é finito, ou seja, o que se limita no tempo e espaço. Desta forma, utilizada para a condição humana como o fim da vida. Sempre se reporta ao seu antagônico, o infinito. ${ }^{96}$

A finitude pode ser entendida como característica universal da condição existencial humana ou como vulnerabilidade, já que representa a possibilidade do ser humano de ser ferido, de adoecer e de morrer. ${ }^{96}$

A Bioética, disciplina que aborda os pontos de vista de cientistas e pensadores sobre os temas polêmicos que envolvem a ética da vida e seus valores, entende como finitude humana a possibilidade de adoecimento singular ou por epidemias que podem reduzir a qualidade de vida e o número da população envolvida. ${ }^{17}$

O pensamento e a discussão sobre a finitude não faz parte do ser humano em todas as fases da vida. Costuma-se pensar neste fim somente em condições extremas de perigo ou ameaça. Associa-se este pensamento quando da presença de condições crônicas. O envelhecer traz como consequência a aproximação do fim da vida de forma natural e compreensível, porém, não melhor aceita por parte do idoso, do que em sua fase juvenil. No entanto, é aceita de forma menos traumática pela sociedade, quando vista como a finitude do 'outro'. ${ }^{94,98}$

A dificuldade em pensar sobre a própria morte pode ser percebida como uma forma de proteção própria contra o sofrimento. As pessoas, não obstante o reconhecimento da vulnerabilidade humana frente à morte, a pensam como situação alheia à sua individualidade, presente somente no 'outro'. A aceitação da morte é mais fácil quando associada à terminalidade do processo de doença a qual o 'outro' sofre. ${ }^{94,99}$

O medo da morte está presente nos seres humanos a ponto de causar uma busca incessante pela imortalidade. Vários rituais, presentes no Ocidente e no Oriente buscam explicar de diversas maneiras o que é e o que há entre o nascimento e a morte. O luto invocado após a morte de alguém próximo representa a perda e o rompimento de um vínculo existente entre as pessoas. Os profissionais de saúde que lidam com a morte no seu cotidiano devem estar preparados para enfrentar a situação e auxiliar a família e os amigos a entender esse processo que é considerado doloroso por todos que dele participam. ${ }^{94,99}$

O progresso científico e tecnológico na área da biomedicina associado ao crescente consumo de medicamentos e à dificuldade em aceitar frustrações, além da extensa 
necessidade de acompanhar as urgências das soluções diárias no trabalho e na sociedade atual com a esperança de saúde perfeita e longevidade aumentada, faz com que a complexa discussão sobre a finitude humana seja adiada infinitamente. ${ }^{94,99}$

A morte, nem sempre vem acompanhada de sofrimento ou de dor, mas representa o desconhecido e remete ao medo e a presença de pensamentos obscuros por parte da pessoa que vivencia o processo e por parte da sua família, que, muitas vezes, prefere se afastar do seu ente acreditando que não poderá auxiliá-lo neste processo e, também pela sua própria dificuldade em enfrentar a situação. ${ }^{100-101}$

O apoio à família deve partir dos profissionais de saúde envolvidos no cuidado ao doente nesta fase terminal da vida. Esses profissionais devem buscar preparo específico e se atualizar nesta área que exige envolvimento de diversos conhecimentos sobre a existência humana e a saúde mental, além dos técnicos e científicos, baseados na doença e no tratamento. ${ }^{11,17,75,101-103}$

O fim da vida exige apoio psicológico ao doente, à família, ao cuidador domiciliar e, quando for o caso, ao profissional de saúde que se dedica ao cuidado técnico. O envolvimento psicossocial, cultural e espiritual da equipe de saúde é fundamental para que o rito de passagem, como pode ser chamado o processo da morte e do morrer, transcorra da forma natural e prevista. ${ }^{17-18}$

Não obstante a morte ter sua ocorrência prevista desde o nascimento, ainda é considerada, em muitas vezes, como um acontecimento inesperado que rompe vínculos previamente estabelecidos entre todos os envolvidos no processo. O mistério que envolve este rito, explica o medo presente e a dificuldade em aceitá-lo. ${ }^{100-101}$

Os profissionais de saúde devem estar preparados e ter desenvolvida a competência, a eficácia e a sensibilidade para enfrentar esta situação. As Instituições de Ensino Superior tem um papel importante na formação holística deste profissional para que ele tenha condições de acompanhar os doentes terminais e seus familiares, não só com foco no conhecimento teóricoprático visível, mas também o subjetivo vivido. ${ }^{101,103}$

Como princípios do cuidado paliativo estão: o conhecimento sobre a proximidade da morte; o controle sobre a situação vivenciada; a preservação da dignidade e da privacidade; o alívio da dor e de outros sintomas; a escolha do local da morte; o recebimento do suporte emocional e espiritual; o controle de quem participará deste momento; a possibilidade de ter tempo para dizer adeus e partir quando for o momento. Esses princípios representam um dos principais pontos fundamentais da bioética que é o respeito à pessoa. ${ }^{17,95}$ 
Dentre os mistérios do mundo, a morte é um dos mais impactantes e aterrorizantes. Afinal, o que há depois da morte? Para onde vamos? Estas perguntas fazem com que várias reflexões surjam. Quando a doença aparece e é preciso oferecer cuidados de saúde sem o propósito finito de cura, mas para oferecer dias de conforto e tempo para a preparação do fim, este medo se fortalece. Não é raro, perceber que a família toda adoece quando um dos membros está ferido e recebendo cuidados especiais. ${ }^{17-18,97,99}$

O tema da morte é temido e negado por muitos até o momento fatídico, quando não há mais possibilidade de fuga ou de se esconder. E a equipe de saúde? Está preparada para atender as pessoas em situação de vivência do processo de morrer? Este preparo deve ser contínuo e permanente. Voltado para as questões humanitárias e de espiritualidade. No intuito de proteger as famílias, desde os primórdios, os moribundos eram afastados do convívio para que descansassem em paz nos últimos dias que lhes restavam em hospitais, onde, acreditavase que as dores seriam amenizadas e o sofrimento diminuído. ${ }^{96-99}$ Mas e o apoio espiritual e sentimental para o enfrentamento deste processo. De quem viria?

O avanço tecnológico não traz, por si só, dignidade no fim da vida, traz a proposta de longevidade, de ampliação do prazo. O processo de morrer envolve atenção, apoio e carinho, cuidados esses que podem ser dispensados pela equipe de saúde e pelos familiares do doente. 100-102-103

A finitude da vida humana é uma certeza. Como o processo vai ocorrer para cada pessoa é uma surpresa do destino. Quem terá o apoio de um cuidador para oferecer os cuidados paliativos se forem necessários? O papel dos serviços de saúde é estar ao lado do doente em todos os momentos preparando a família e o cuidador para que esse processo ocorra de forma natural e menos dolorosa. 
4. MÉTODO 


\section{MÉTODO}

\subsection{DELINEAMENTO DO ESTUDO}

Para alcançar os objetivos propostos, optou-se por um delineamento de pesquisa observacional, descritiva, de corte transversal com a utilização de métodos mistos procurando abranger a complexidade do tema, com abordagens qualitativa e quantitativa.

Foi utilizada a abordagem quantitativa com a finalidade de identificar as características sociodemográficas e clínicas dos cuidadores participantes, bem como conhecer a percepção da qualidade de vida e da sobrecarga dos mesmos. Autores descrevem a pesquisa quantitativa como o estudo centrado na objetividade recorrendo à linguagem matemática para descrever as causas de um fenômeno, as relações entre variáveis. ${ }^{104-105}$

A abordagem qualitativa foi utilizada no intuito de conhecer a historia de cuidado, envolvendo os sentimentos e as vivências individuais dos cuidadores, pois no método qualitativo, é valorizado o acolhimento de angústias e ansiedades da pessoa em estudo. Ele permite trabalhar com o universo de significados, motivos, aspirações, crenças, valores e atitudes, o que corresponde a um espaço mais profundo das relações, dos processos e dos fenômenos que não podem ser reduzidos à operacionalização de variáveis. Nesse contexto trabalhar qualitativamente implica entender e interpretar sentidos e significações que uma pessoa dá aos fenômenos em foco, via observação ampla e entrevistas em profundidade. ${ }^{104-106}$

A utilização conjunta da pesquisa qualitativa e quantitativa permite recolher mais informações do que se poderia conseguir isoladamente, pois um método completa o outro enriquecendo a análise do trabalho em questão. ${ }^{105-106}$

\subsection{CENÁRIO DO ESTUDO}

Este estudo foi realizado tendo como cenário, as residências dos doentes do PID, classificados como AD2, vinculados ao Núcleo Regional de Atenção Domiciliar da Regional de Saúde de Ceilândia/DF.

O NRAD de Ceilândia foi o sétimo núcleo a ser implantado na Secretaria de Estado de Saúde do Distrito Federal, no ano de 2009. Compreende uma Equipe Multidisciplinar de Atenção Domiciliar e uma Equipe Multidisciplinar de Apoio (EMAP) e situa-se no prédio adjacente ao Hospital Regional de Ceilândia (HRC).

\subsection{PARTICIPANTES DA PESQUISA}


Para a realização deste estudo, foram entrevistados os cuidadores principais de 33 doentes do PID, caracterizando o total dos doentes vinculados ao NRAD de Ceilândia no período da coleta de dados.

\subsection{CRITÉRIOS DE INCLUSÃO E EXCLUSÃO}

Participaram do estudo, cuidadores principais de doentes internados em domicílio, de ambos os sexos, tendo como critério de inclusão: ter maior de 18 anos de idade, ser cuidador principal e aceitar participar da pesquisa, assinando o Termo de Consentimento Livre e Esclarecido (TCLE) - apêndice 1.

Foi definido como critério de exclusão: não ter condições cognitivas para responder a todos os instrumentos relacionados.

\subsection{COLETA DOS DADOS}

A coleta de dados foi realizada entre os meses de fevereiro e junho do ano de 2013, por meio da aplicação dos instrumentos descritos a seguir e da entrevista com o cuidador principal na residência do doente internado em domicilio, sendo que todas as visitas foram previamente agendadas e confirmadas por telefone e foi assegurado privacidade para o participante.

Foi respeitado o tempo de cada um para responder aos instrumentos, considerando a necessidade de interrupção devido à prestação dos cuidados para com o doente. Em alguns casos, a coleta foi realizada em até três períodos distintos, sendo que todos os cuidadores participantes foram entrevistados pela pesquisadora principal. O tempo destinado para cada cuidador participar deste estudo variou entre três e 12 horas (divididas em mais de um encontro).

Para a coleta de dados obteve-se a participação de três estudantes do curso de enfermagem que faziam parte do Programa de Extensão Universitária Saúde em Casa, desenvolvido no NRAD de Ceilândia e coordenado pela pesquisadora principal deste estudo.

\subsection{INSTRUMENTOS DE PESQUISA E ANÁLISE DOS DADOS}

Foram aplicados aos participantes, cinco instrumentos de pesquisa validados ou testados previamente: 


\subsubsection{Questionário de dados sociodemográficos e clínicos (apêndice 2)}

Para conhecer o perfil dos cuidadores participantes, nos aspectos sociodemográfico e clínico, foi criado um questionário específico para este estudo contemplando variáveis sociais, demográficas e clínicas, como sexo, idade, grau de instrução, presença de doença e de dor, uso de medicamentos, percepção de apoio e outros.

Esse instrumento foi validado com a aplicação para três cuidadores domiciliares de doentes vinculados ao NRAD, mas que foram excluídos da população deste estudo, por terem sido desligados posteriormente à coleta, devido ao óbito dos doentes.

\subsubsection{Escala de Sobrecarga de Cuidador - ESC (anexo 1)}

Esse instrumento, na versão resumida, é composto por 22 questões que permitem avaliar a sobrecarga objetiva e subjetiva do cuidador incluindo informações sobre saúde, vida social, vida pessoal, situação financeira, situação emocional e tipo de relacionamento. Esse instrumento foi validado para a população brasileira em $2004 .{ }^{107}$

A escala das respostas varia de 0 a 4 , de acordo com a presença ou a intensidade de uma resposta afirmativa $(0=$ nunca, $1=$ raramente, $2=$ algumas vezes, $3=$ frequentemente e 4 = sempre). A exceção é o último item da escala, no qual o cuidador responde se está se sentindo sobrecarregado no papel de cuidador e as possíveis respostas são: $0=$ nem um pouco, 1 = um pouco, 2 = moderadamente, 3 = muito e 4 = exageradamente. Todos os itens são pontuados. O escore total da escala é tido acionando todos os itens e deve variar de 0 a 88 . Quanto maior o escore, maior a sobrecarga. ${ }^{107}$

\subsubsection{Instrumento de avaliação da qualidade de vida abreviado - WHOQOL-bref (anexo 2)}

Esse instrumento, desenvolvido pela OMS para se conhecer a percepção subjetiva sobre qualidade de vida das pessoas, contém 26 perguntas, das quais 24 são distribuídas em quatro domínios: físico, psicológico, relações sociais e meio ambiente. Os domínios são representados por várias facetas e suas questões foram formuladas para uma escala psicométrica com nível de concordância e de intensidade, capacidade, frequência e avaliação, de respostas do tipo Likert com cinco pontos ( 1 a 5), invertidos unicamente nas questões 3, 4 e 26, nas quais $1=5,2=4,3=3,4=2$ e $5=1$. O instrumento apresenta, além dos quatro domínios, duas questões gerais. Uma faz referência à percepção da qualidade de vida e outra à 
satisfação com a saúde. ${ }^{75} \mathrm{O}$ quadro 01 apresenta composição do instrumento quanto aos domínios e facetas da Qualidade de Vida.

Quadro 1- Domínios e facetas do instrumento de avaliação da qualidade de vida da OMS WHOQOL-bref.

\begin{tabular}{|c|c|c|}
\hline Domínios & Facetas & Questões \\
\hline \multirow{7}{*}{ Físico $(\mathrm{F})$} & Dor e desconforto & Q3 \\
\hline & Dependência de medicação ou de tratamentos & Q4 \\
\hline & Energia e fadiga & Q10 \\
\hline & Mobilidade & Q15 \\
\hline & Sono e repouso & Q16 \\
\hline & Atividades da vida cotidiana & Q17 \\
\hline & Capacidade de trabalho & Q18 \\
\hline \multirow{6}{*}{ Psicológico (P) } & Sentimentos positivos & Q5 \\
\hline & Espiritualidade, religião, crenças pessoais & Q6 \\
\hline & Pensar, aprender, memória e concentração & Q7 \\
\hline & Autoimagem e aparência & Q11 \\
\hline & Autoestima & Q19 \\
\hline & Sentimentos negativos & Q26 \\
\hline \multirow{3}{*}{ Relações sociais (RS) } & Relações pessoais & Q20 \\
\hline & Atividade sexual & Q21 \\
\hline & Suporte (apoio) social & Q22 \\
\hline \multirow{8}{*}{ Meio ambiente (MA) } & Segurança física e proteção & Q8 \\
\hline & Ambiente físico (poluição, barulho, trânsito, clima) & Q9 \\
\hline & Recursos financeiros & Q12 \\
\hline & $\begin{array}{llllll}\text { Oportunidades para } & \text { adquirir } & \text { novas } & \text { informações } & \text { e } \\
\text { habilidades } & & & & & \\
\end{array}$ & Q13 \\
\hline & Participação em e oportunidades de recreação/lazer & Q14 \\
\hline & Ambiente no lar & Q23 \\
\hline & Cuidados de saúde e sociais: disponibilidade e qualidade & Q24 \\
\hline & Transporte & Q25 \\
\hline
\end{tabular}

E para melhor compreensão da percepção de qualidade de vida dos cuidadores com 60 anos ou mais de idade, que neste estudo reforam representados por 11 cuidadores, foi aplicado WHOQOL-old complementando as informações colhidas no WHOQOL-bref. 


\subsubsection{Instrumento de avaliação da qualidade de vida em idosos - WHOQOL-old (anexo} 3).

O instrumento desenvolvido pela OMS para avaliação da qualidade de vida em idosos é composto por 24 itens com resposta do tipo Likert de 1 a 5, atribuídos a 6 domínios: funcionamento dos sentidos, autonomia, morte e morrer, atividades passadas, presentes e futuras, participação social e intimidade e suas respectivas facetas. Os escores dos seis domínios combinados geram também um escore total. ${ }^{108} \mathrm{O}$ quadro 02 apresenta os domínios e as facetas de avaliação da qualidade de vida em idosos.

Quadro 2- Domínios e facetas do instrumento de avaliação da qualidade de vida em idosos da OMS - WHOQOL-old.

\begin{tabular}{|c|c|c|}
\hline Domínios & Facetas & Questões \\
\hline $\begin{array}{l}\text { Funcionamento dos } \\
\text { sentidos }\end{array}$ & $\begin{array}{l}\text { Perda nos sentidos afetam a vida diária } \\
\text { Avaliação do funcionamento dos sentidos } \\
\text { Problemas com o funcionamento dos sentidos interferindo na } \\
\text { habilidade de interagir } \\
\text { Perda de funcionamento dos sentidos afeta a participação em } \\
\text { atividades }\end{array}$ & $\begin{array}{l}\text { Q1 } \\
\text { Q2 } \\
\text { Q10 }\end{array}$ \\
\hline Autonomia & $\begin{array}{l}\text { Liberdade para tomar suas próprias decisões } \\
\text { Sente que controla seu futuro } \\
\text { Pessoas ao seu redor respeitam a sua liberdade } \\
\text { Consegue fazer as coisas que gostaria de fazer }\end{array}$ & $\begin{array}{l}\text { Q3 } \\
\text { Q4 } \\
\text { Q5 } \\
\text { Q11 }\end{array}$ \\
\hline $\begin{array}{c}\text { Atividades passadas, } \\
\text { presentes e futuras }\end{array}$ & $\begin{array}{l}\text { Satisfeito com as suas oportunidades para continuar alcançando } \\
\text { outras realizações } \\
\text { Recebeu o reconhecimento que merece na sua vida } \\
\text { Satisfeito com aquilo que alcançou na sua vida } \\
\text { Feliz com as coisas que pode esperar daqui pra frente }\end{array}$ & $\begin{array}{l}\text { Q12 } \\
\text { Q13 } \\
\text { Q15 } \\
\text { Q19 }\end{array}$ \\
\hline Participação social & $\begin{array}{l}\text { Tem o suficiente para fazer em cada dia } \\
\text { Satisfeito com a maneira com a qual você usa seu tempo } \\
\text { Satisfeito com o seu nível de atividade } \\
\text { Satisfeito com as oportunidades para participar de atividades na } \\
\text { comunidade }\end{array}$ & $\begin{array}{l}\text { Q14 } \\
\text { Q16 } \\
\text { Q17 } \\
\text { Q18 }\end{array}$ \\
\hline Morte e morrer & $\begin{array}{l}\text { Preocupado com a maneira pela qual irá morrer } \\
\text { Medo de poder controlar a sua morte } \\
\text { Medo de morrer } \\
\text { Teme sofrer dor antes de morrer }\end{array}$ & $\begin{array}{l}\text { Q6 } \\
\text { Q7 } \\
\text { Q8 } \\
\text { Q9 }\end{array}$ \\
\hline Intimidade & Tem um sentimento de companheirismo em sua vida & Q21 \\
\hline
\end{tabular}




\begin{tabular}{|l|l|l|}
\hline & Sente amor em sua vida & Q22 \\
& Oportunidade para amar & Q23 \\
& Oportunidade para ser amado & Q24 \\
\hline
\end{tabular}

Neste estudo, optou-se por apresentar os dados em uma escala de 0 a 100 por ser mais facilmente interpretada e estar associada a percentuais, sendo que os escores mais altos significam melhor qualidade de vida.

Os participantes foram orientados a responder o instrumento utilizando como base as últimas duas semanas, de acordo com as normas de aplicação da OMS.

Foram avaliadas as respostas médias de cada uma das facetas com o propósito de conhecer as facetas com avaliação satisfatória e insatisfatória. Ao verificar os valores obtidos em cada uma das facetas ( 24 questões) e para a qualidade de vida geral e à saúde (02 questões) foram obtidos os escores para as dimensões. ${ }^{108}$

Os dados foram analisados com a utilização do programa estatístico SPSS 18. Dos valores obtidos para cada uma das vinte e quatro facetas que compõem os quatro domínios dos instrumentos WHOQOL - bref e os seis domínios do WHOQOL - old, foram definidas as médias das respostas, o que possibilitou verificar quais facetas foram avaliadas como positivas quais foram avaliadas de forma negativa.

\subsubsection{Roteiro para a realização da entrevista (apêndice 3)}

Para identificação dos sentimentos vivenciados e das mudanças sociais decorrentes da função do cuidar, foi realizada uma entrevista semiestruturada com roteiro norteador contendo os seguintes eixos: a) Do diagnóstico inicial até a internação domiciliar; b) O significado da doença; c) O significado da morte; d) Sentimentos frente ao sofrimento; e) Mudanças no cotidiano do cuidador.

As entrevistas foram realizadas com uma média de 40 minutos cada e foram gravadas em áudio e posteriormente transcritas para fins de análise.

Para avaliação dos resultados foi utilizado o método de análise de conteúdo do proposto por Bardin que consiste em um conjunto de técnicas de análise das comunicações visando obter, por procedimentos sistemáticos e objetivos de descrição do conteúdo das mensagens, indicadores que permitam a inferência de conhecimentos relativos às condições de produção das mensagens. Também é definida como a avaliação que permite a identificação da existência de temas ou núcleos de sentido em uma mensagem, cuja presença ou frequência 
apresentam a significância no conteúdo das análises, e que se apresenta como adequada às pesquisas qualitativas em saúde. ${ }^{110-111}$

Os instrumentos serão correlacionados entre si e apresentados em forma descritiva em análise qualitativa.

\subsection{ASPECTOS ÉTICOS}

Em cumprimento a Resolução CNS n. 466/12, que versa sobre Pesquisa Envolvendo Seres Humanos, este projeto foi aprovado pelo Comitê de Ética da Secretaria de Estado de Saúde do Distrito Federal - CEP/FEPECS/SES/DF, sob o parecer n. 187.211 de 21 de janeiro de 2013 (anexo 4).

Para participar da pesquisa os cuidadores foram orientados quanto aos objetivos, justificativa e metodologia adotada. E, de forma livre e orientada, optaram pela participação, por meio da assinatura do TCLE, em duas vias, sendo uma do participante e outra do pesquisador para compor o conjunto de documentos da pesquisa.

Foi assegurado aos participantes o sigilo, a confiabilidade, a privacidade, a proteção da sua imagem e a não estigmatização, garantindo que as informações obtidas com o estudo fossem usadas no âmbito acadêmico, para o desenvolvimento da ciência e para a melhoria da qualidade de vida dos próprios participantes.

Foram respeitados valores culturais, sociais, morais, religiosos, éticos, bem como hábitos e costumes, que devem refletir na pesquisa e no significado de qualidade de vida para a população pesquisada. 


\section{RESULTADOS}

Por se tratar de fenômeno complexo a ser avaliado, foram utilizados instrumentos distintos com abordagens diferentes para que o mesmo fosse analisado como construtos multidimensionais, de natureza objetiva e subjetiva, determinados socialmente pelas condições de vida e relativizado pelo contexto familiar, histórico e cultural no qual os cuidadores estão inseridos. Os referidos instrumentos buscaram captar dados subjetivos, objetivos e específicos do cuidado e das dimensões da vida dos cuidadores.

Foi publicada a nota prévia publicada no periódico Online Brazilian Journal of Nursing (OBJN) - apêndice 4.

Os resultados obtidos, após o tratamento estatístico, foram apresentados em tópicos sequenciais com o propósito de responder aos objetivos do estudo, sendo que alguns representam artigos submetidos ou publicados em periódicos relacionados ao tema do estudo.

\subsection{CARACTERIZAÇÃO DO PERFIL SOCIODEMOGRÁFICO E CLÍNICO DOS DOENTES E DOS CUIDADORES DOMICILIARES}

\subsection{1 - Descrição do perfil dos doentes cuidados}

Os doentes cuidados pelos participantes deste estudo estavam internados em domicílio em AD2 e acompanhados por um Núcleo de Atenção Domiciliar, vinculado à Gerência de Atenção Domiciliar da Secretaria de Estado da Saúde do Distrito Federal. A maioria $(54,5 \%)$ é do sexo feminino. Possuem entre 2 e 95 anos, sendo que $31 \%$ possuem mais de 80 e a média é de 60,9 anos de idade.

As patologias mais recorrentes foram: acidente vascular cerebral (AVC), (39,4\%); neoplasias (18,2\%); doença de Alzheimer (DA) (15,2\%) e paralisia cerebral (PC) (9\%). Das demais doenças, 9\% estavam relacionadas ao Sistema Nervoso Central como distrofia muscular (DM), miopatia muscular progressiva (MMP) e esclerose lateral amiotrófica (ELA). Outros $9,2 \%$ correspondiam a doenças distintas.

\subsection{2 - Descrição do perfil dos cuidadores domiciliares}

Dos cuidadores, apenas 18,2\% não são parentes do paciente. Tratam-se de vizinhos, amigos e cuidadores contratados para este fim. Os demais fazem parte da família em até segundo grau de parentesco. 
Os 33 participantes do estudo compreenderam o total de cuidadores principais dos doentes internados em domicílio e acompanhados no Programa de Internação Domiciliar (PID) pelo Núcleo de Atenção Domiciliar da Regional de Saúde de Ceilândia durante o período da coleta dos dados.

Caracterizada principalmente pelo sexo feminino, a amostra revelou que $51,5 \%$ dos cuidadores apresentaram idade superior a 40 anos, sendo que $69,7 \%$ são mães, esposas ou filhas dos doentes.

Quanto à religião, 54,5\% se declararam católicos. Os dados revelaram que 36,4\% dos cuidadores declararam ter o ensino fundamental completo, o que compreende ao menos 8 anos de estudo formal, sendo que 9,1\% concluíram um curso de graduação. A tabela 1 apresenta os dados econômicos da amostra estudada.

Tabela 1 - Dados de cuidadores de pacientes internados em domicílio segundo condições econômicas. Brasília, DF, 2013, (N=33).

\begin{tabular}{lcc}
\hline CONDIÇÕES ECONÔMICAS & (N= 33) & \% \\
\hline RENDA FAMILIAR & & \\
Até 1 salário mínimo & 05 & 15,1 \\
Entre 1 e 3 salários mínimos & 15 & 45,5 \\
Entre 3 e 4 salários mínimos & 08 & 24,2 \\
Mais de 5 salários mínimos & 02 & 6,1 \\
Não informou/não sabe & 03 & 9,1
\end{tabular}

\section{TIPO DE RESIDÊNCIA}

Própria

$22 \quad 66,7$

Alugada

$08 \quad 24,3$

Cedida/emprestada

$03 \quad 9,0$

\section{NÚMERO DE PESSOAS QUE VIVEM NA RESIDÊNCIA}

$<$ de 3

$09 \quad 27,4$

3 a 5

19

57,5

$>$ de 5

05

15,1

Total

33

100

Entre os cuidadores, 39,4\% possuem renda familiar superior a três salários mínimos. A residência da maioria é de alvenaria e com mais de 5 cômodos, sendo que 72,6\% residem com mais de três pessoas na mesma casa. 
A função de cuidador é exercida pela maioria $(75,7 \%)$ em tempo integral, ou seja, não há horário definido para inicio e fim da tarefa diária. A tabela 2 apresenta os aspectos relacionados à ocupação atual e anterior.

Tabela 2 - Dados sobre a ocupação anterior de cuidadores. Brasília, DF, 2013, (N=33)

\begin{tabular}{lcc}
\hline ASPECTOS RELACIONADOS AO TRABALHO & $\mathbf{( N = 3 3 )}$ & \% \\
\hline SITUAÇÃO ATUAL & 25 & 75,8 \\
Cuidador em tempo integral & 05 & 15,1 \\
Cuidador por 8 horas/dia & 03 & 9,1 \\
Cuidador por menos de 8 horas/dia & & \\
OCUPAÇÃO ANTERIOR & 23 & 69,7 \\
Emprego formal (com registro em carteira de trabalho) & 10 & 30,3 \\
Autônomo/atividade informal/dona de casa & $\mathbf{3 3}$ & $\mathbf{1 0 0}$ \\
\hline Total & & \\
\hline
\end{tabular}

O tempo decorrido desde o inicio do exercício da função de cuidador difere entre os cuidadores entrevistados. Há casos em que o cuidador exercia a função há apenas 03 meses e outro que exercia há 40 anos. O resultado é demonstrado na figura 03.

Figura 3 - Tempo de exercício da função de cuidador principal.

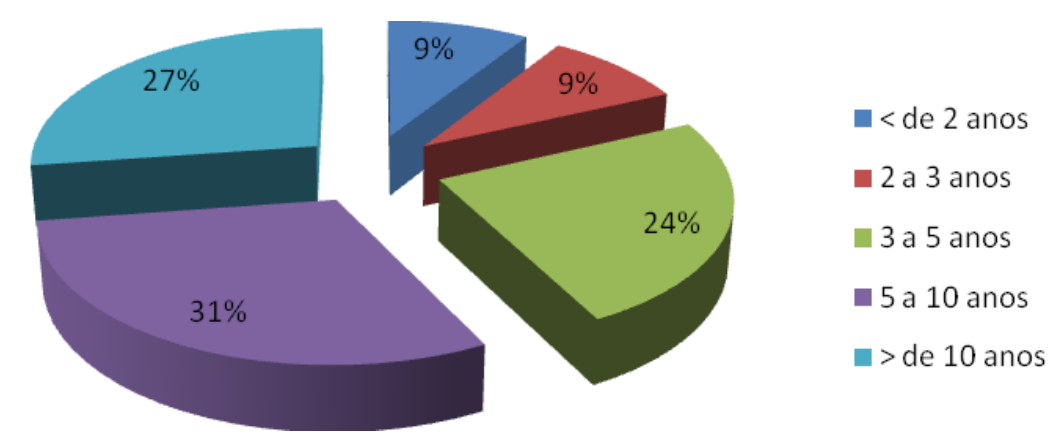

A percepção sobre o apoio social recebido para o exercício da função de cuidador foi referido por $63,6 \%$ da amostra estudada, sendo que, destes, 54,5\% referiram receber apoio de familiares. A tabela 3 apresenta os aspectos relacionados à rede de apoio social informal. 
Tabela 3 - Dados do apoio social referido pelos cuidadores. Brasília, DF, 2013. (N=33).

\begin{tabular}{lcc}
\hline PERCEPÇÃO DA REDE DE APOIO SOCIAL & $(\mathbf{N}=\mathbf{3 3})$ & $\mathbf{\%}$ \\
\hline PERCEPÇÃO DE CONTAR COM APOIO & 21 & 63,6 \\
Sim & 12 & 36,4 \\
Não & & \\
COMPOSIÇÃO DA REDE DE APOIO & 02 & 6,1 \\
Amigos & 18 & 54,5 \\
Familiares & 01 & 3,0 \\
Vizinho & 05 & 15,2 \\
Profissional de saúde & & $\mathbf{1 0 0}$ \\
\hline Total & &
\end{tabular}

*Alguns cuidadores citaram mais de uma fonte de apoio

Sobre a situação clínica, os cuidadores referiram problemas de saúde $(57,5 \%)$, bem como, presença de dores no corpo e $75,8 \%$ relataram o uso de medicamentos contínuos ou intermitentes, alguns, de forma indiscriminada, sem prescrição médica. As doenças crônicas não transmissíveis representam $78,7 \%$ dos problemas de saúde relatados. Os dados estão apresentados na tabela 4 .

Tabela 4 - Dados clínicos de cuidadores. Brasília, DF, 2013 (N=33).

(continua)

\begin{tabular}{lcc}
\hline ASPECTOS DE SAÚDE & $(\mathbf{N}=\mathbf{3 3})$ & $\%$ \\
\hline PROBLEMA DE SAÚDE * & 19 & 57,6 \\
Sim & 14 & 42,4 \\
Não & & \\
TIPOS DE PROBLEMA DE SAÚDE & 05 & 15,2 \\
Problema endócrino & 013 (N=33). (conclusão) & \\
Tabela 4 - Dados clínicos de cuidadores. Brasília, DF, 2013 & 09 & 27,3 \\
Problema cardiovascular & 03 & 9,1 \\
Problema osteomuscular & 06 & 18,2 \\
Problema reumatológico/doença autoimune & 03 & 9,1 \\
Problema psiquiátrico & 05 & 15,2 \\
Outros & 03 \\
\hline
\end{tabular}




\begin{tabular}{llc}
\hline Não relataram & 14 & 42,4 \\
PRESENÇA DE DOR & & 75,7 \\
Sim & 25 & 24,3 \\
Não & & \\
INTESIDADE DA DOR & 08 & 15,2 \\
Fraca & 11 & 33,3 \\
Moderada & 09 & 27,3 \\
Intensa & & \\
LOCAL DA PRESENÇA DE DOR & 15 & 45,4 \\
Dor na coluna/costas & 13 & 39,4 \\
Membros e articulações & 04 & 12,1 \\
Outro tipo de dor & & \\
TRATAMENTO MEDICAMENTOSO CONTÍNUO & 19 & 57,6 \\
Sim & 14 & 42,4 \\
Não & & \\
PRINCIPAIS MEDICAMENTOS UTILIZADOS & 06 & 31,6 \\
Antidepressivos & 08 & 42,1 \\
Ansiolíticos & 10 & 19,0 \\
Analgésicos & 08 & 42,1 \\
Outros (anti-hipertensivos e antiglicêmicos) & &
\end{tabular}

\section{Total}

*Alguns cuidadores relataram mais de um problema de saúde e o uso de mais de um tipo de medicação.

O uso de medicamentos de forma contínua foi citado por 57,5\% e, dentre os medicamentos mais utilizados estão analgésicos (30\%), ansiolíticos (24\%) e antidepressivos (18\%). Outro problema constatado foi a automedicação referida pela maioria dos entrevistados.

$\mathrm{O}$ uso de medicamentos analgésicos de forma indiscriminada está relacionado aos relatos de dores no corpo. Dos cuidadores que relataram sentir dor, $45 \%$ informaram que possuem dor nas costas a ponto de afetar o seu desempenho nas atividades de vida diárias corriqueiramente, e, por esse motivo, utilizam medicação analgésica quase que diariamente.

Com relação à qualidade do sono, $78 \%$ dos entrevistados relataram o sono como ruim. Sendo que $60 \%$ relataram ter o sono interrompido regularmente devido à situação que se encontravam de preocupação e de cuidado continuado ao paciente. A tabela 5 apresenta os dados de forma detalhada. 
Tabela 5 - Dados sobre a qualidade do sono do cuidador. Brasília, DF, 2013, (N=33)

\begin{tabular}{lcc}
\hline QUALIDADE DO SONO & $(\mathbf{N}=\mathbf{3 3})$ & $\mathbf{\%}$ \\
\hline QUALIDADE DO SONO & 07 & 21,2 \\
Boa & 26 & 78,8 \\
Ruim & & \\
CONTINUIDADE DO SONO & 13 & 39,4 \\
Contínuo & 20 & 60,6 \\
Interrompido & & \\
HORAS DE SONO/DIA & 03 & 9,1 \\
< de 4 horas & 17 & 51,5 \\
4 a 6 horas & 05 & 15,2 \\
\hline \multicolumn{1}{c}{ a 8 horas } & $\mathbf{0 8}$ & $\mathbf{2 4 , 2}$ \\
\hline > de 8 horas & & \\
\hline
\end{tabular}

\subsection{PERCEPÇÃO DA SOBRECARGA DE CUIDADORES DOMICILIARES}

A Escala de Sobrecarga do Cuidador (ESC) ou Inventário de Sobrecarga do Cuidador - Zarit Caregiver Burden Interview (ZBI) avalia a sobrecarga do cuidador por meio de questões relativas à frequência de sentimentos, em aspectos distintos, manifestados pelo cuidador para com o paciente a quem dispensa os cuidados. Os resultados descritivos, de cada item, em número e porcentagem, encontram-se na tabela 06.

Tabela 6 - Dados descritivos da aplicação da Escala de Sobrecarga do Cuidador segundo a percepção de cuidadores entrevistados. Brasília, 2013 (n=33).

(continua)

\begin{tabular}{|c|c|c|c|c|c|c|}
\hline Questão & $\begin{array}{l}\text { Nunca } \\
\text { n (\%) }\end{array}$ & $\begin{array}{c}\text { Raramente } \\
\text { n }(\%)\end{array}$ & $\begin{array}{l}\text { Algumas } \\
\text { vezes } \\
\text { n }(\%)\end{array}$ & $\begin{array}{c}\text { Frequente } \\
\text { mente } \\
\text { n }(\%)\end{array}$ & $\begin{array}{c}\text { Sempre } \\
\text { n }(\%)\end{array}$ & $\begin{array}{l}\text { Total } \\
\text { n }(\%)\end{array}$ \\
\hline $\begin{array}{l}\text { 1. O Sr/Sra sente que } \mathrm{S}^{*} \text { pede } \\
\text { mais ajuda do que ele (ela) } \\
\text { necessita? }\end{array}$ & $24(72)$ & $02(06)$ & 03 (09) & $01(03)$ & 03 (09) & $33(100)$ \\
\hline $\begin{array}{l}\text { 2. } \mathrm{O} \text { (a) } \mathrm{Sr} / \mathrm{Sra} \text { sente que por causa } \\
\text { do tempo que o(a) } \mathrm{Sr} / \mathrm{Sra} \text { gasta } \\
\text { com o(a) } \mathrm{S}^{*} \text {, o(a) (a) } \mathrm{Sr} / \mathrm{Sra} \text { não } \\
\text { tem tempo suficiente para si } \\
\text { mesmo? }\end{array}$ & $01(03)$ & 06 (18) & 04 (12) & 04 (12) & $18(54)$ & $33(100)$ \\
\hline
\end{tabular}


Tabela 6 - Dados descritivos da aplicação da Escala de Sobrecarga do Cuidador segundo a percepção de cuidadores entrevistados. Brasília, 2013 (n=33).

(continua)

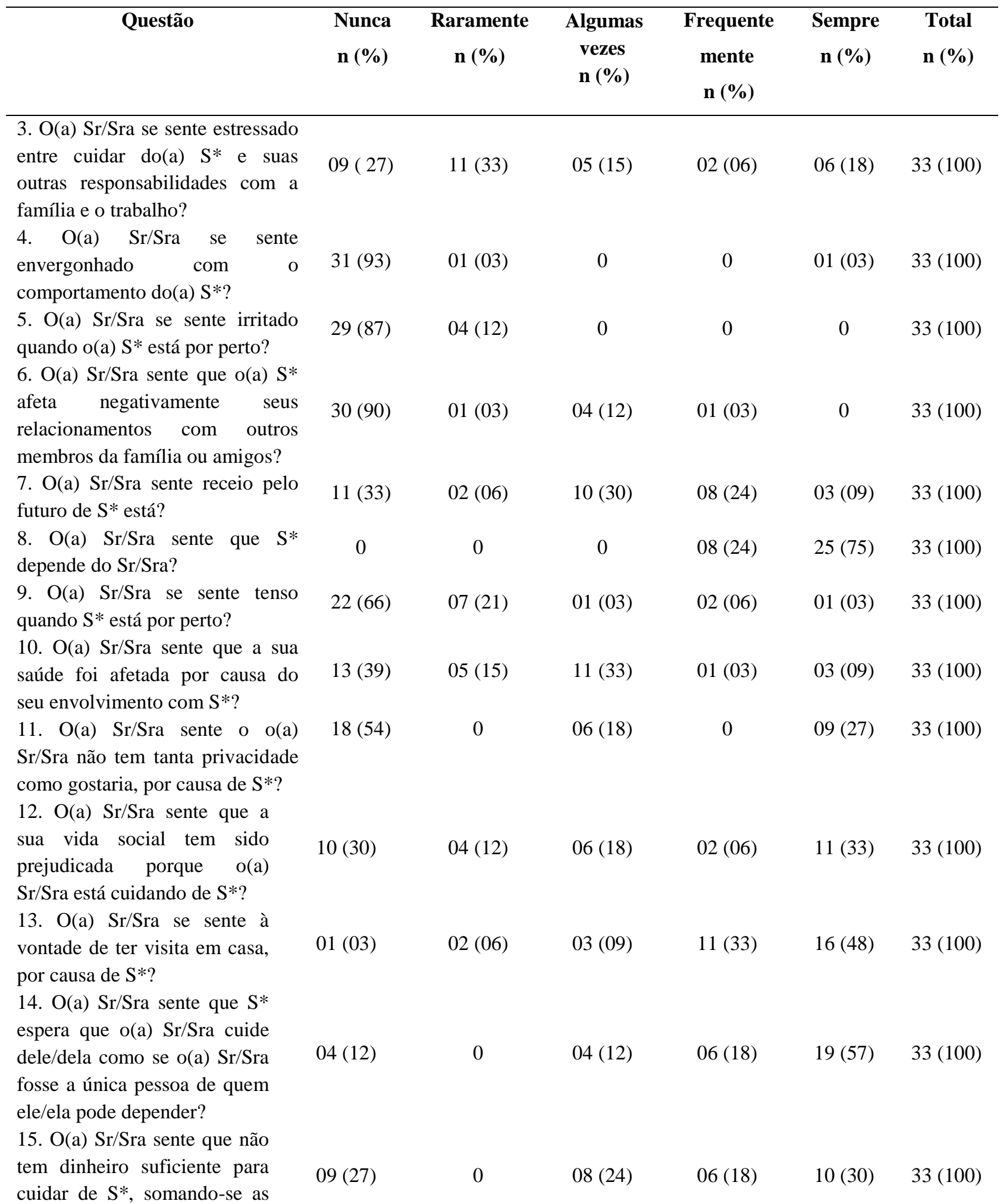


Tabela 6 - Dados descritivos da aplicação da Escala de Sobrecarga do Cuidador segundo a percepção de cuidadores entrevistados. Brasília, 2013 (n=33).

(conclusão)

\begin{tabular}{|c|c|c|c|c|c|c|}
\hline Questão & $\begin{array}{l}\text { Nunca } \\
\text { n }(\%)\end{array}$ & $\begin{array}{c}\text { Raramente } \\
\text { n }(\%)\end{array}$ & $\begin{array}{l}\text { Algumas } \\
\text { vezes } \\
\text { n }(\%)\end{array}$ & $\begin{array}{c}\text { Frequente } \\
\text { mente } \\
\text { n }(\%)\end{array}$ & $\begin{array}{c}\text { Sempre } \\
\text { n }(\%)\end{array}$ & $\begin{array}{l}\text { Total } \\
\text { n }(\%)\end{array}$ \\
\hline $\begin{array}{l}\text { 16. O(a) } \mathrm{Sr} / \mathrm{Sra} \text { sente que será } \\
\text { incapaz de cuidar de } \mathrm{S}^{*} \text { por } \\
\text { muito mais tempo? }\end{array}$ & $20(60)$ & 0 & $07(21)$ & $02(06)$ & 04 (12) & $33(100)$ \\
\hline $\begin{array}{l}\text { 17. } \mathrm{O} \text { (a) } \mathrm{Sr} / \mathrm{Sra} \text { sente que } \\
\text { perdeu o controle da sua vida } \\
\text { desde a doença de } \mathrm{S}^{*} \text { ? }\end{array}$ & $13(39)$ & 03 (09) & 04 (12) & 09 ( 27) & 04 (12) & $33(100)$ \\
\hline $\begin{array}{l}\text { 18. } \mathrm{O} \text { (a) } \mathrm{Sr} / \mathrm{Sra} \text { gostaria de } \\
\text { simplesmente deixar que } \\
\text { outra pessoa cuidasse de } \mathrm{S}^{*} \text { ? }\end{array}$ & $17(51)$ & 0 & $11(33)$ & $03(09)$ & $02(06)$ & $33(100)$ \\
\hline $\begin{array}{l}\text { 19. O(a) } \mathrm{Sr} / \mathrm{Sra} \text { se sente em } \\
\text { dúvida sobre o que fazer por } \\
\mathrm{S}^{*} \text { ? }\end{array}$ & $20(60)$ & $01(03)$ & $05(15)$ & 04 (12) & $03(09)$ & $33(100)$ \\
\hline $\begin{array}{l}\text { 20. O(a) } \mathrm{Sr} / \mathrm{Sra} \text { sente que } \\
\text { deveria estar fazendo mais por } \\
\mathrm{S}^{*} \text { ? }\end{array}$ & 05 (15) & $05(15)$ & $12(36)$ & $10(30)$ & $01(03)$ & $33(100)$ \\
\hline $\begin{array}{l}\text { 21. } \mathrm{O} \text { (a) } \mathrm{Sr} / \mathrm{Sra} \text { sente que } \\
\text { poderia cuidar melhor de } \mathrm{S}^{*} \text { ? }\end{array}$ & $13(39)$ & $05(15)$ & $08(24)$ & $06(18)$ & $01(03)$ & $33(100)$ \\
\hline $\begin{array}{l}\text { 22. De uma maneira geral, } \\
\text { quando o(a) } \mathrm{Sr} / \mathrm{Sra} \text { se sente } \\
\text { sobrecarregado(a) por cuidar } \\
\text { de } \mathrm{S}^{*} \text { ? }\end{array}$ & $02(06)$ & $05(15)$ & $14(42)$ & $07(21)$ & $05(15)$ & $33(100)$ \\
\hline
\end{tabular}

A maioria dos entrevistados (72\%) relatou não pensar que o paciente, objeto do seu cuidado, pedia mais ajuda do que necessitavam. Quando questionados se sentiam que deixavam de ter tempo suficiente para si mesmo devido à dedicação para com o paciente, $54 \%$ relataram que tem esse sentimento sempre. As opiniões se dividiram quando questionados se eles se sentiam prejudicados em sua vida social por estarem cuidando do doente, sendo que $39 \%$ responderam que frequentemente ou sempre e $42 \%$ responderam que nunca ou raramente tinham esse sentimento.

Quanto à questão sobre o grau de dependência direta do paciente sobre a sua pessoa, como se fosse a única pessoa de quem o paciente pudesse depender, a maioria dos entrevistados $(75 \%)$ respondeu que possuíam esse sentimento frequentemente ou sempre.

A maior parte dos entrevistados (93\%) não se sentia envergonhada com o comportamento do paciente a quem dedicava o cuidado e nem irritada com a sua presença 
(87\%). Da mesma forma, $90 \%$ dos entrevistados relataram não sentir que cuidar do paciente afetava negativamente seus relacionamentos com outros membros da família ou amigos.

A amostra ficou dividida quando questionada sobre se sente que perdeu o controle sobre a sua vida desde que começou a cuidar do paciente, sendo que $39 \%$ responderam que tinham esse sentimento frequentemente ou sempre e $39 \%$ responderam que nunca ou raramente sentiam isso.

A sensação de não ter dinheiro suficiente para cuidar do doente, somando-se as despesas da casa foi relatado por $48 \%$ dos cuidadores entrevistados, todos familiares do mesmo. Em contrapartida, $51 \%$ relataram nunca sentir que poderiam deixar outra pessoa cuidando do paciente. Ao terem sido questionados se poderiam cuidar melhor do paciente, apenas $21 \%$ relataram que tinham esse sentimento frequentemente ou sempre. E $60 \%$ dos entrevistados alegaram nunca sentir dúvida sobre o que fazer pelo doente.

Para $93 \%$ dos cuidadores, o sentimento de estar sobrecarregado por cuidar do paciente esteve presente ao menos uma vez, sendo que, destes, $36 \%$ conviviam com esse sentimento frequentemente ou sempre.

O escore do instrumento pode variar entre 0 e 88 , diferenciando entre sem sobrecarga (SS), sobrecarga ligeira (SL) e sobrecarga intensa (SI) sendo que quanto maior o escore, maior a sobrecarga. Nesta amostra, a escala variou de 39 a 80, com média de 57,4 e mediana de 55. Porém, $43 \%$ dos cuidadores estudados referiram SI. Essa situação pode ser observada na figura 4.

Figura 4- Percepção da sobrecarga entre cuidadores domiciliares entrevistados, 2014.

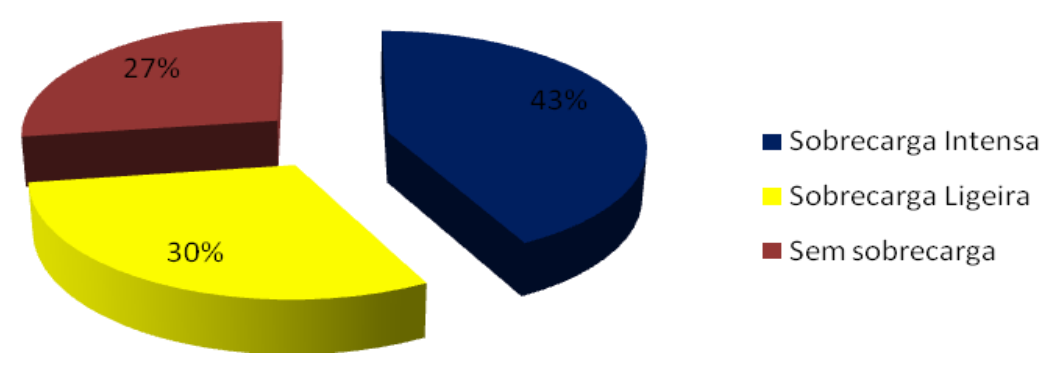




\subsection{1 - Sobrecarga física e psicológica dos cuidadores de pacientes internados em domicílio}

Ao correlacionar dados do perfil com a percepção de sobrecarga de cuidadores foi elaborado e publicado o artigo intitulado de 'Sobrecarga física e psicológica dos cuidadores de pacientes internados em domicílio' no periódico: Revista de Enfermagem UFPE on line, Recife, 9 (supl. 1): 319-26, jan., 2015 - (apêndice 4).

\section{3 - PERCEPÇÃO SOBRE QUALIDADE DE VIDA DE CUIDADORES DOMICILIARES}

\subsection{1 - Avaliação por meio da aplicação do instrumento WHOQOL - bref}

\subsubsection{1 - Aplicação do instrumento WHOQOL-bref}

O instrumento foi aplicado a 33 cuidadores em domicílio, sendo que destes, 25 reponderam o instrumento sozinhos, de forma autoadministrada, 5 foram assistidos pelo entrevistador ao responder e outros 3 tiveram o apoio direto do entrevistador, cabendo a este a administração do questionário. Esta situação pode ser visualizada na figura 5.

Figura 5- Forma de aplicação do instrumento de avaliação da qualidade de vida da Organização Mundial da Saúde (OMS) - WHOQOL-bref aos cuidadores domiciliares (n.33)

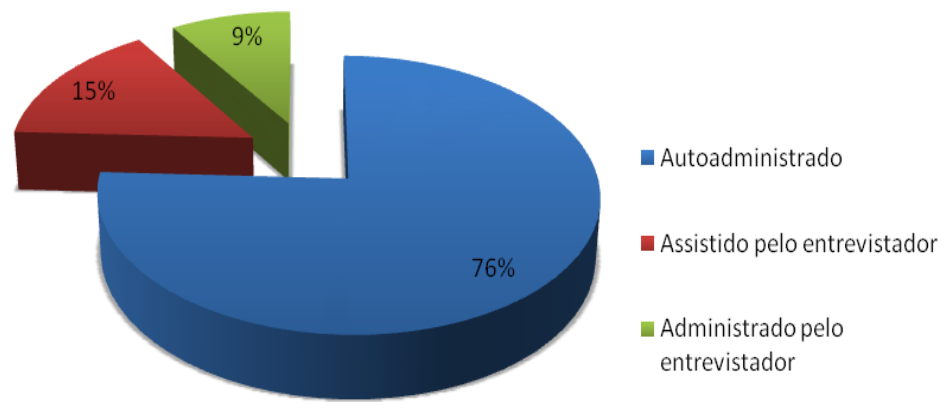

\subsubsection{2 - Descrição do instrumento}

O instrumento WHOQOL-bref divide-se em facetas e domínios para a avaliação das dimensões da qualidade de vida. A tabela 7 apresenta os valores da média dos escores dos domínios, calculada em uma escala de 0 a 100, de acordo com as orientações do WHOQOL- 
group. O domínio 'Relações Sociais' apresentou o maior escore $(55,30)$ e o domínio 'Meio Ambiente' apresentou o menor $(46,12)$.

Tabela 7 - Média dos escores obtidos nos Domínios e no Índice Geral de Qualidade de Vida da aplicação do WHOQOL-bref em cuidadores $(n=33)$.

\begin{tabular}{lccc}
\hline \multicolumn{1}{c}{ DOMÍNIOS } & MÉDIA (dp) & Min-Max & Mediana \\
\hline IGQV & $51,19(11,51)$ & $31,74-68,27$ & 50,96 \\
D1 - Físico & $53,79(11,84)$ & $25,00-78,57$ & 53,57 \\
D2 - Psicológico & $52,27(13,46)$ & $29,17-75,00$ & 50,00 \\
D3 - Relações Sociais & $55,30(18,84)$ & $25,00-100,00$ & 50,00 \\
D4 - Meio Ambiente & $46,12(16,67)$ & $15,63-84,38$ & 43,75 \\
\hline
\end{tabular}

\subsubsection{3 - Índice Geral de Qualidade de Vida (IGQV)}

Os cuidadores, quando questionados sobre o que achavam da sua qualidade de vida e da sua saúde, apresentaram-se entre os que consideram sua qualidade de vida como 'nem ruim, nem boa' $(45,5 \%)$ e sua saúde como 'insatisfeitos' (42,4\%). A tabela 8 apresenta os dados sobre a percepção da qualidade de vida e da saúde de forma descritiva.

Tabela 8 - Tabela descritiva, em número e porcentagem de cuidadores, segundo as questões sobre percepção da qualidade de vida geral e satisfação com a saúde (n=33).

\begin{tabular}{|c|c|c|c|c|c|c|}
\hline Questões & $\begin{array}{c}\text { Muito ruim } \\
\text { n } \\
\%\end{array}$ & $\begin{array}{c}\text { Ruim } \\
\text { n } \\
\%\end{array}$ & $\begin{array}{c}\text { Nem ruim } \\
\text { nem boa } \\
\text { n } \\
\%\end{array}$ & $\begin{array}{c}\text { Boa } \\
\mathbf{n} \\
\%\end{array}$ & $\begin{array}{c}\text { Muito } \\
\text { boa } \\
\text { n } \\
\%\end{array}$ & $\begin{array}{c}\text { Total } \\
\text { n } \\
\%\end{array}$ \\
\hline \multirow{3}{*}{$\begin{array}{c}\text { Q1 “Como você } \\
\text { avaliaria sua } \\
\text { qualidade de vida?" }\end{array}$} & 0 & 5 & 15 & 12 & 1 & 33 \\
\hline & 0,0 & 15,1 & 45,5 & 36,4 & 3,0 & 100 \\
\hline & $\begin{array}{c}\text { Muito } \\
\text { insatisfeito } \\
\text { n } \\
\%\end{array}$ & $\begin{array}{c}\text { Insatisfeito } \\
\text { n } \\
\%\end{array}$ & $\begin{array}{c}\text { Nem } \\
\text { satisfeito nem } \\
\text { insatisfeito } \\
\text { n } \\
\%\end{array}$ & $\begin{array}{c}\text { Satisfeito } \\
\text { n } \\
\%\end{array}$ & $\begin{array}{c}\text { Muito } \\
\text { satisfeito } \\
\text { n } \\
\%\end{array}$ & $\begin{array}{c}\text { Total } \\
\mathbf{N} \\
\%\end{array}$ \\
\hline \multirow{2}{*}{$\begin{array}{c}\text { Q2“Quão } \\
\text { satisfeito(a) você está } \\
\text { com a sua saúde?” }\end{array}$} & 0 & 14 & 8 & 9 & 2 & 33 \\
\hline & 0,0 & 42,4 & 24,2 & 27,3 & 6,1 & 100 \\
\hline
\end{tabular}




\subsubsection{4 - Domínios e facetas do WHOQOL-bref}

Nas figuras de n. 6 a 9 podem-se observar as médias obtidas nas avaliações das facetas de cada domínio do WHOQOL-bref. O instrumento indica como melhor resposta o número 5 e como pior, o número 1. As facetas relacionadas à 'dor e desconforto' e à 'dependência de tratamentos ou medicamentos' referentes ao domínio físico e a 'sentimentos negativos' referente ao domínio psicológico tiveram os valores invertidos de acordo com as orientações da OMS para fins de comparação.

Quanto ao domínio físico (figura 6), os entrevistados relataram satisfação com a sua capacidade para o trabalho $(39,4 \%)$ e consideraram ser capazes de se locomoverem $(66,7 \%)$. Porém, apresentaram insatisfação quanto ao sono $(42,4 \%)$ e relataram que a dor física impede bastante ou extremamente de fazer o que precisam $(45,5 \%)$.

Figura 6 - Média das avaliações dos cuidadores nas facetas do domínio físico do WHOQOLbref

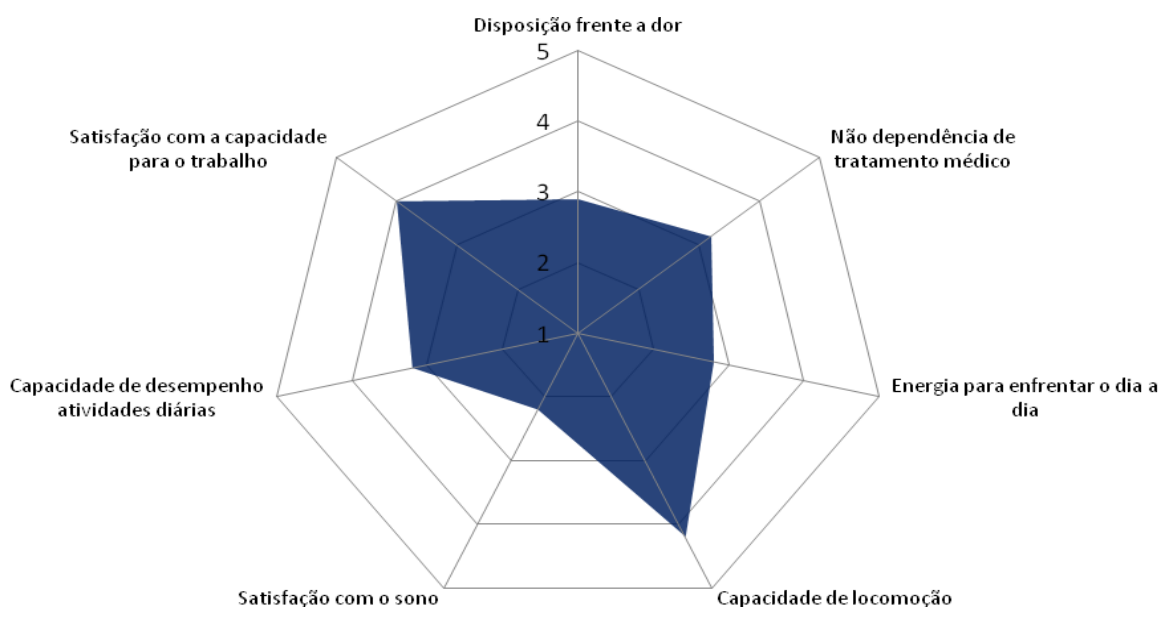

Com relação ao domínio psicológico (figura 7), as facetas referentes à satisfação consigo mesmo, relacionada à autoestima $(39,4 \%)$, a aceitação da aparência física $(45,4 \%)$ e às crenças pessoais $(45,4 \%)$ foram as que obtiveram maior avaliação positiva pelos entrevistados. Em contrapartida, a faceta de avaliação sobre o aproveitamento da vida teve o menor rendimento $(18,2 \%)$. 
Figura 7- Média das avaliações dos cuidadores nas facetas do domínio psicológico do WHOQOL-bref

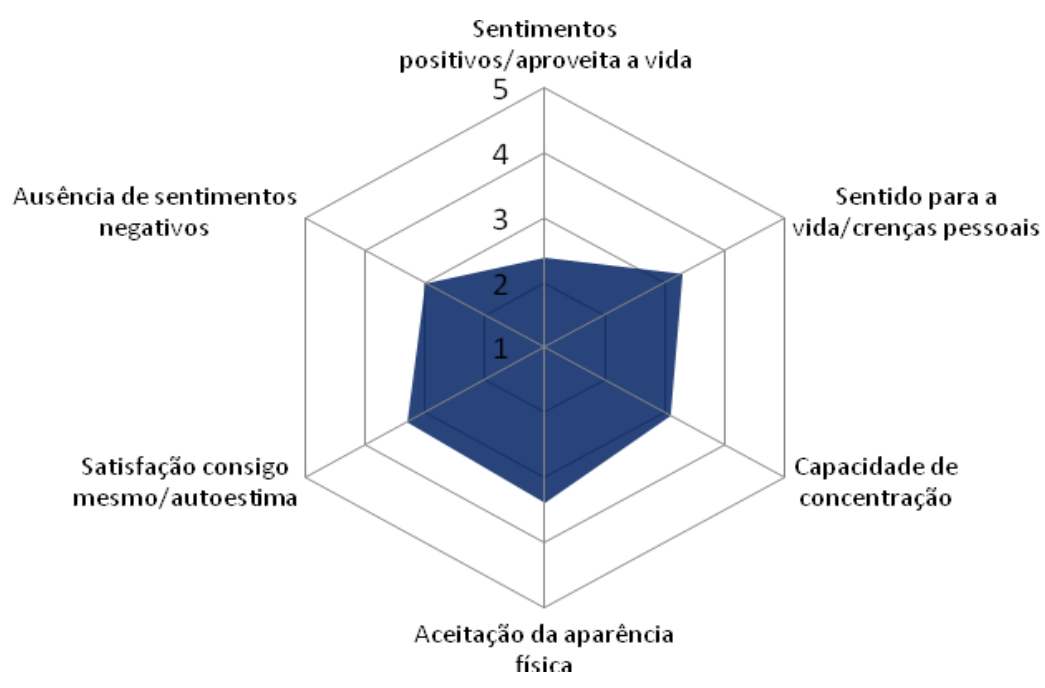

No domínio de relações sociais (figura 8), a faceta que mais apresentou satisfação entre os entrevistados foi a de relações pessoais $(54,5 \%)$ o que reflete a convivência com amigos e parentes. Em contrapartida, apenas 30,3\% dos cuidadores relataram estar satisfeitos com a sua vida sexual.

Figura 8- Média das avaliações dos cuidadores nas facetas de relações sociais do WHOQOLbref.

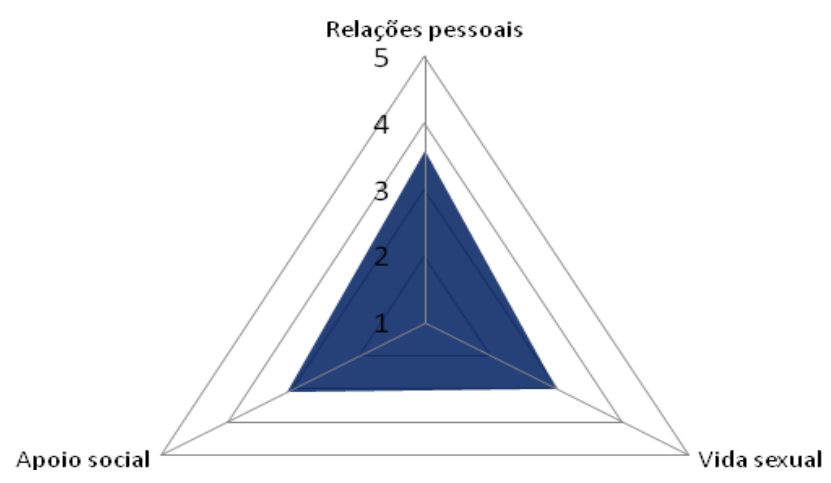

O domínio referente ao meio ambiente (figura 9) foi o que obteve menor avaliação entre os entrevistados, sendo que a faceta 'oportunidade de lazer' foi a que representou menor satisfação $(21,2 \%)$, seguida de condições financeiras $(27,3 \%)$. Por outro lado, 48,5\% dos cuidadores avaliaram se sentir seguros em sua vida diária e 51,5\% se relataram satisfeitos com as condições de moradia. 
Figura 9- Média das avaliações dos cuidadores nas facetas meio-ambiente do WHOQOLbref.

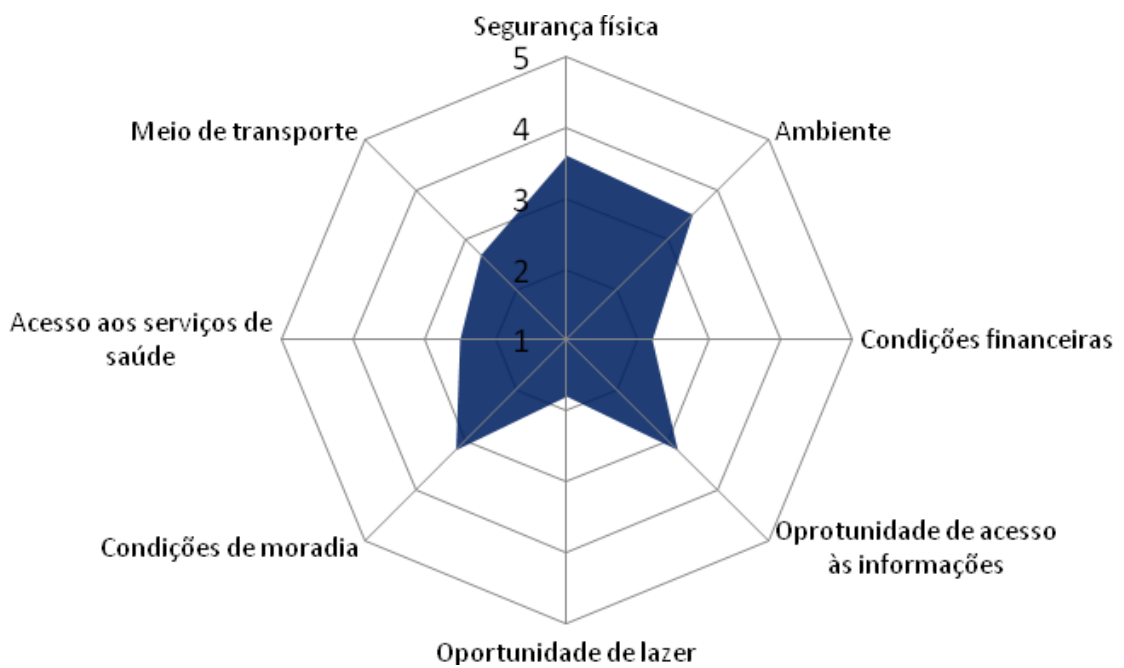

\subsection{2 - Avaliação por meio da aplicação do instrumento WHOQOL - old}

\subsubsection{1 - Aplicação do questionário WHOQOL-old}

O instrumento foi aplicado a 10 cuidadores em domicílio, sendo que 4 dos entrevistados respondeu o questionário de forma autoadministrada, 4 foram assistidos pelo entrevistador ao responder e outros 2 tiveram o apoio direto do entrevistador, cabendo a este a administração do questionário. Esta situação pode ser visualizada na figura 10.

Figura 10- Forma de aplicação do instrumento de avaliação da qualidade de vida da Organização Mundial da Saúde (OMS) - WHOQOL-old aos cuidadores domiciliares.

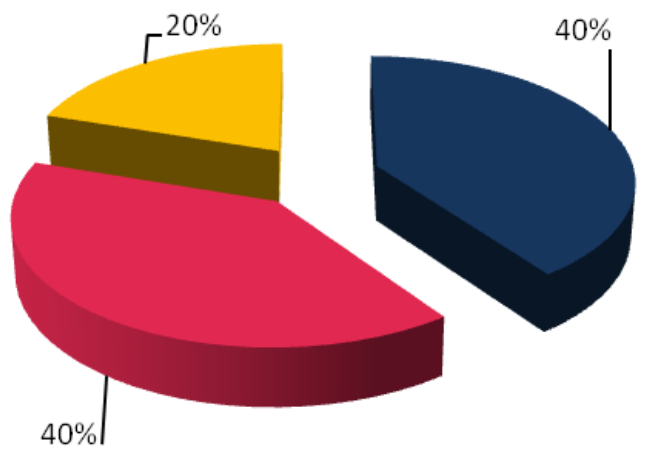

- Autoadministrado

Assistidos pelo entrevistador

Administrado pelo entrevistador 
O instrumento WHOQOL-old divide-se em 24 facetas e 6 domínios para a avaliação das dimensões da qualidade de vida do idoso. A tabela 9 apresenta os valores da média dos escores dos domínios, calculada em uma escala de 0 a 100, de acordo com as orientações do WHOQOL-group. O domínio 'Intimidade' apresentou o maior escore $(52,50)$ e o dominio 'Morte e morrer' apresentou o menor escore $(38,13)$ entre os cuidadores idosos deste estudo.

Tabela 9 - Média dos escores obtidos nos Domínios e no Índice Geral de Qualidade de Vida do Idoso referente à aplicação do WHOQOL-old.

\begin{tabular}{lccc}
\hline \multicolumn{1}{c}{ DOMíNIOS } & MÉDIA (dp) & Min-Max & Mediana \\
\hline Qualidade de Vida do idoso - IGQVI & $45,52(5,38)$ & $37,50-53,13$ & 44,30 \\
D1/old - Funcionamento do sensório (FS) & $46,88(14,80)$ & $31,25-75,00$ & 37,50 \\
& & & 40,60 \\
D2/old - Autonomia (AUT) & $45,63(15,04)$ & $31,25-75,00$ & 43,30 \\
D3/old - Atividades passadas, presentes e & $44,38(10,40)$ & $31,25-62,50$ & \\
futuras (PPF) & & & 43,80 \\
D4/old - Participação social (PSO) & $45,63(10,23)$ & $31,25-62,50$ & 37,50 \\
D5/old - Morte e morrer (MEM) & $38,13(12,31)$ & $25,00-62,50$ & 50,00 \\
D6/old - Intimidade (INT) & $52,50(15,37)$ & $37,50-93,75$ & \\
\hline
\end{tabular}

\subsubsection{2 - Dominios e facetas do WHOQOL-old}

Nas figuras de n. 11 a 16 podem-se observar as médias obtidas nas avaliações das facetas de cada domínio do WHOQOL-old. O instrumento indica como melhor resposta o número 5 e como pior, o número 1 . As facetas relacionadas à 'perda nos sentidos que afetam a vida diária', 'avaliação do funcionamento dos sentidos', referentes ao domínio do 'funcionamento dos sentidos' e 'preocupado com a maneira pela qual irá morrer', 'medo de poder controlar a sua morte', 'medo de morrer', 'teme sofrer dor antes de morrer', referentes ao domínio 'morte e morrer' e ainda a faceta 'problemas com o funcionamento dos sentidos interferindo na habilidade de interagir', referente ao domínio 'intimidade' tiveram os valores invertidos de acordo com as orientações da OMS para fins de comparação.

Quanto ao funcionamento dos sentidos, a faceta que apresentou maior insatisfação (30\%) foi a que diz que a perda nos sentidos afeta a sua vida diária.

Figura 11 - Média das avaliações dos cuidadores nas facetas do domínio funcionamento dos sentidos do WHOQOL-old 


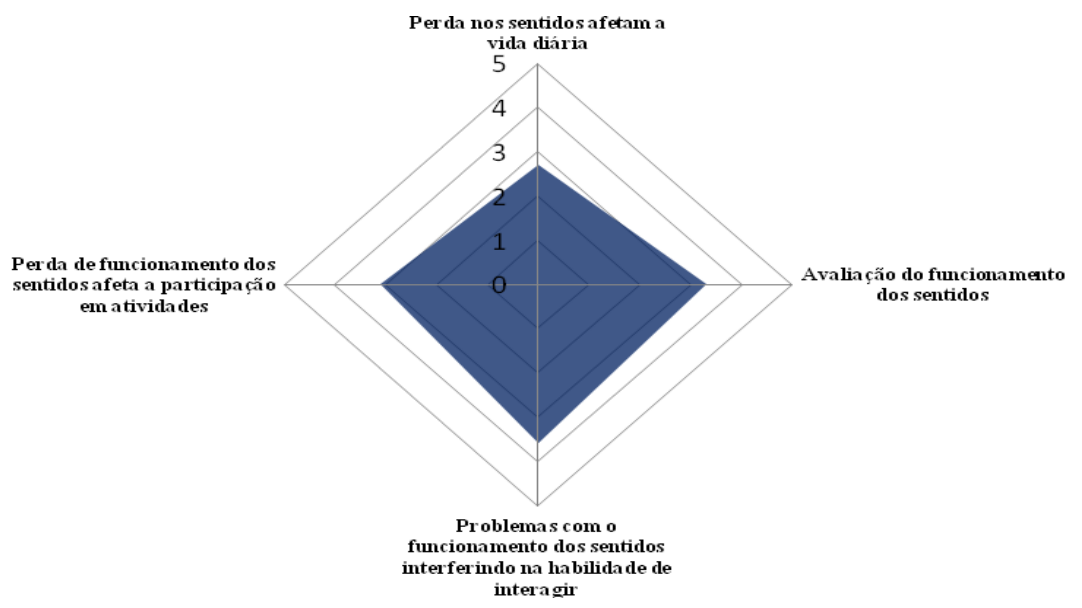

Com relação ao domínio Autonomia, a faceta que apresentou maior insatisfação é a em que o cuidador refere como sente que controla o seu futuro. Nesse caso, 4 participantes relataram que percebem não controlar nada do seu futuro.

Figura 12 - Média das avaliações dos cuidadores nas facetas do domínio Autonomia - AUT do WHOQOL-old

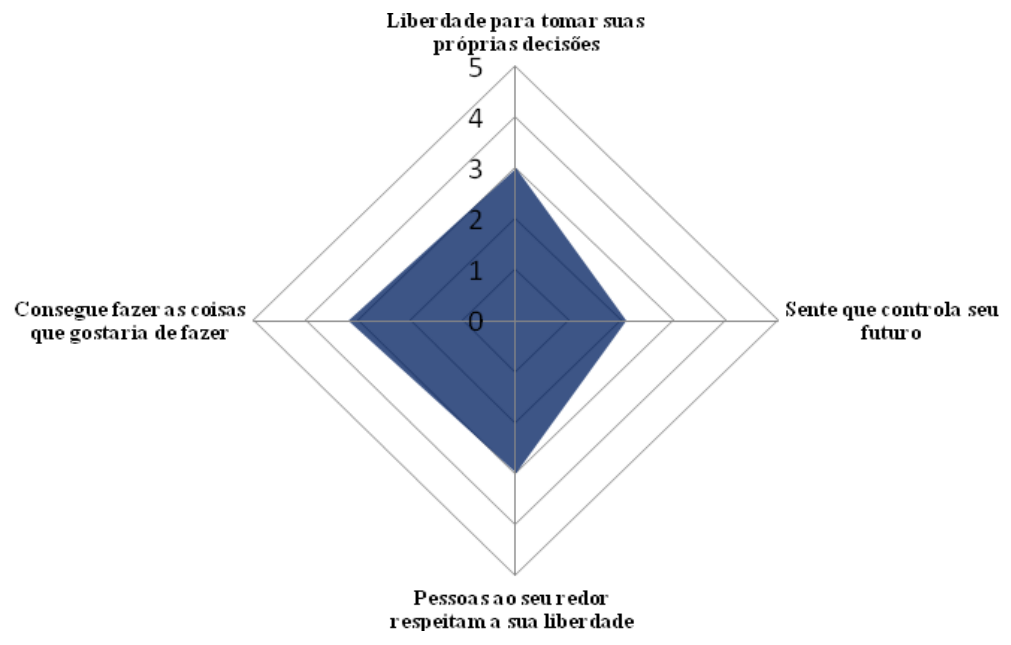

No domínio relacionado às atividades passada, presentes e futuras, 5 cuidadores relataram estar satisfeito ou muito satisfeito com o que alcançou na vida. 
Figura 13 - Média das avaliações dos cuidadores nas facetas do domínio Atividades passadas, presentes e futuras - PPF do WHOQOL-old

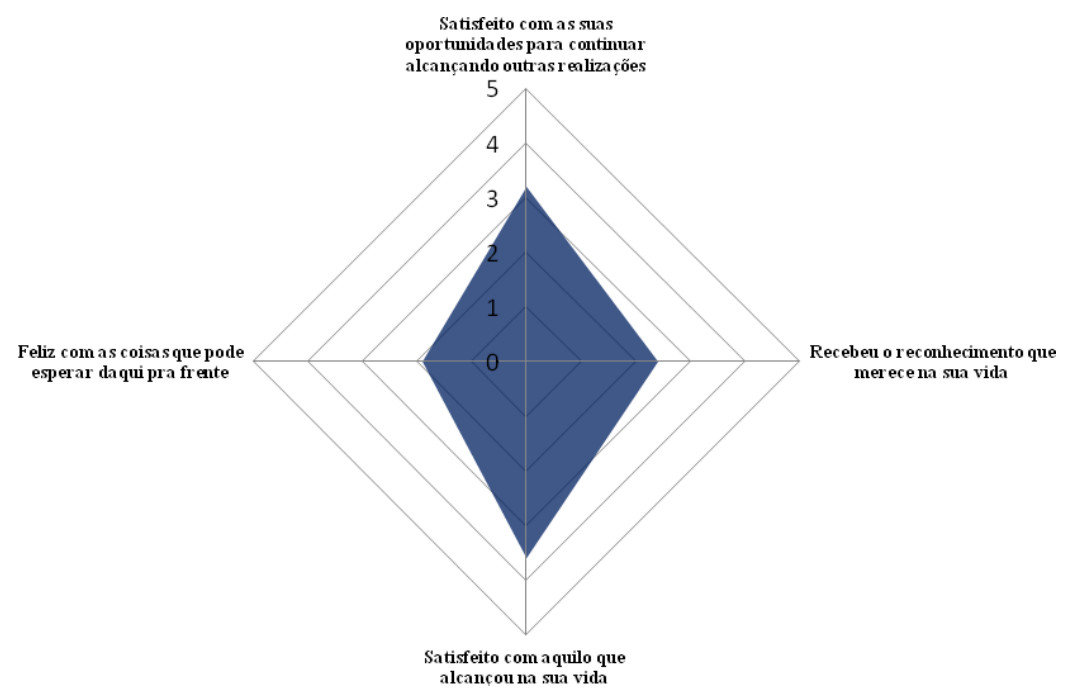

Com relação à participação social, 5 participantes relataram estar insatisfeitos com a maneira com a qual usam seu tempo.

Figura 14 - Média das avaliações dos cuidadores nas facetas do domínio Participação social PSO do WHOQOL-old

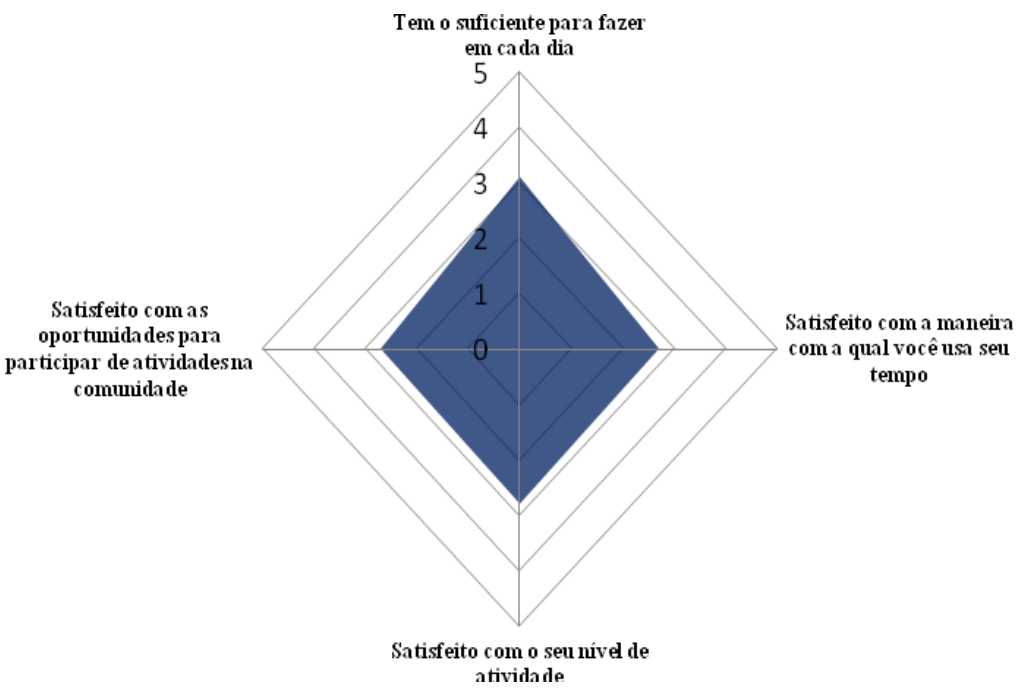

Já no domínio sobre a morte e o morrer, 9 indicaram que tem bastante ou extremo medo de não poder controlar a sua própria morte. 
Figura 15 - Média das avaliações dos cuidadores nas facetas do domínio Morte e Morrer MEM do WHOQOL-old

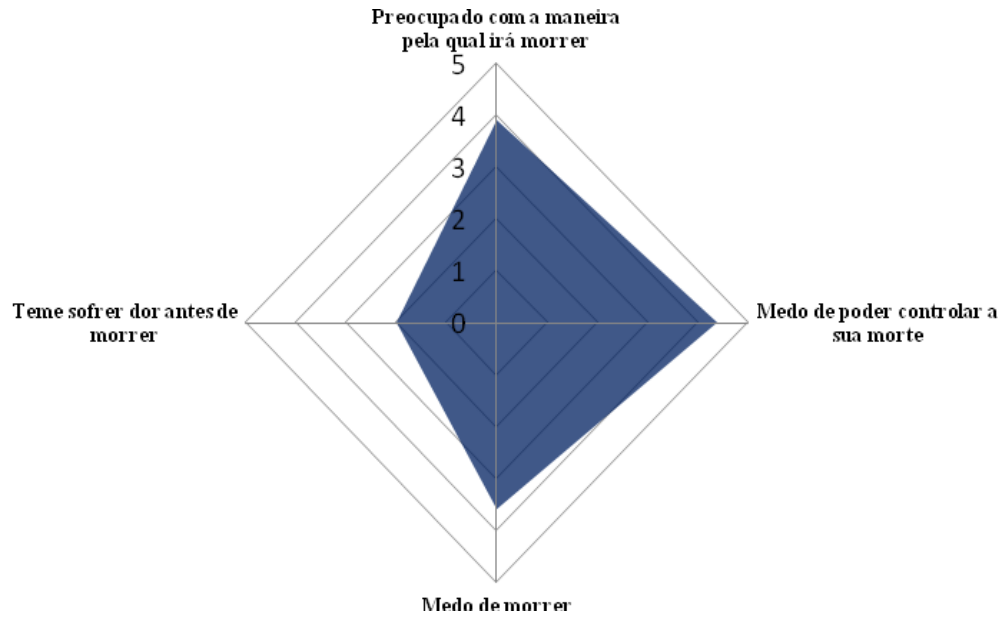

E, por fim, com relação ao domínio Intimidade, 7 indicaram que sentem amor em suas vidas, mas, por outro lado, 6 relataram não sentir que tenham oportunidade para ser amado.

Figura 16 - Média das avaliações dos cuidadores nas facetas do domínio Intimidade - INT do WHOQOL-old

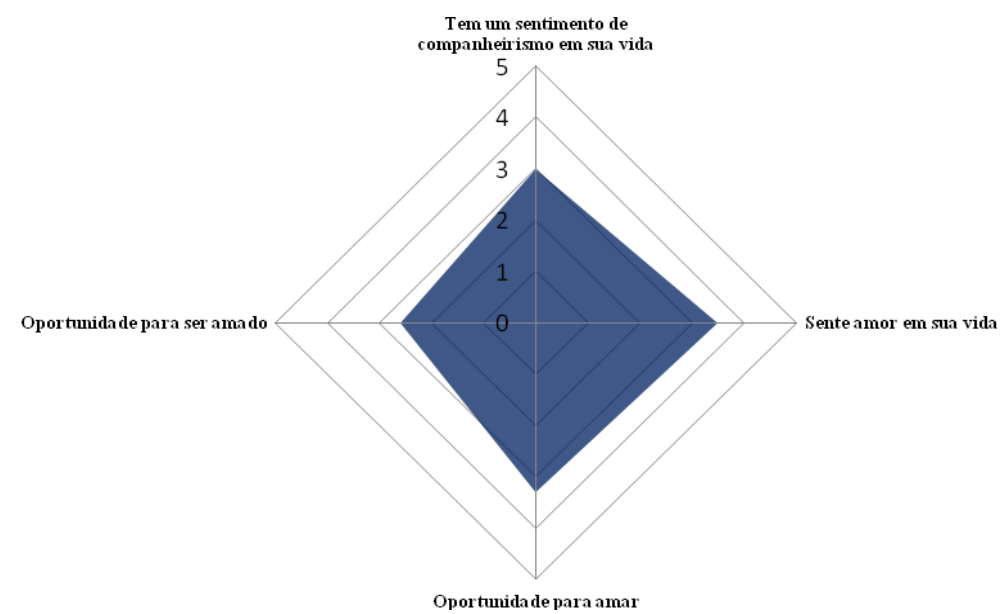

5.3.3 - Comparação das médias do escore de qualidade de vida do cuidador segundo as variáveis sociodemográficas

Os escores médios obtidos no IGQV e nos diferentes domínios foram comparados de acordo com as variáveis qualitativas do cuidador: sexo, idade, situação conjugal, grau de 
parentesco, grau de instrução, religião, apoio percebido, presença de dor, presença de doença, uso de medicamentos, qualidade do sono e atividade sexual.

Os dados obtidos pela comparação das médias dos escores para cada uma das variáveis são apresentados nas tabelas 10 a 22, a seguir.

Tabela 10 - Estatística descritiva dos domínios do WHOQOL-bref segundo o sexo do cuidador.

\begin{tabular}{lccccc}
\hline \multirow{2}{*}{ Domínios do WHOQOL-bref } & \multicolumn{4}{c}{ Sexo do cuidador } & \multirow{2}{*}{ P\# } \\
\cline { 2 - 5 } & \multicolumn{2}{c}{ Feminino } & \multicolumn{2}{c}{ Masculino } & \\
\cline { 2 - 5 } & Média & $\mathrm{dp}$ & Média & $\mathrm{dp}$ & \\
\hline IGQV & 50,96 & 11,15 & 48,32 & 11,49 & 0,080 \\
Físico & 52,71 & 12,60 & 52,68 & 14,69 & 0,468 \\
Psicológico & 51,58 & 12,60 & 48,96 & 8,59 & 0,369 \\
Relações Sociais & 55,17 & 19,09 & 47,92 & 26,68 & 0,457 \\
Meio Ambiente & 46,88 & 14,35 & 42,19 & 12,10 & 0,369 \\
\hline
\end{tabular}

P\# - Teste T

*Diferença estatisticamente significativa $(\mathrm{p}<0,05)$

Tabela 11 - Estatística descritiva dos domínios do WHOQOL-bref segundo a idade do cuidador.

\begin{tabular}{|c|c|c|c|c|c|c|c|c|}
\hline \multirow{3}{*}{$\begin{array}{c}\text { Domínios do } \\
\text { WHOQOL-bref }\end{array}$} & \multicolumn{8}{|c|}{ Idade do cuidador } \\
\hline & \multicolumn{2}{|c|}{20 a 29 anos } & \multicolumn{2}{|c|}{30 a 39 anos } & \multicolumn{2}{|c|}{40 a 59 anos } & \multicolumn{2}{|c|}{60 anos ou mais } \\
\hline & Média & $\mathrm{dp}$ & Média & $\mathrm{dp}$ & Média & $\mathrm{dp}$ & Média & $\mathrm{dp}$ \\
\hline IGQV & 47,39 & 10,38 & 54,93 & 10,65 & 45,55 & 9,15 & 55,38 & 10,64 \\
\hline Físico & 52,04 & 11,27 & 55,80 & 13,63 & 52,68 & 11,48 & 54,29 & 12,69 \\
\hline Psicológico & 51,79 & 13,36 & 49,48 & 13,44 & 46,88 & 4,81 & 59,17 & 15,06 \\
\hline Relações Sociais & 53,57 & 26,73 & 61,46 & 17,22 & 43,75 & 4,81 & 60,83 & 17,59 \\
\hline Meio Ambiente & 36,61 & 10,47 & 54,69 & 21,13 & 39,84 & 12,50 & 50,94 & 14,13 \\
\hline
\end{tabular}


Tabela 12 - Estatística descritiva dos domínios do WHOQOL-bref segundo a situação conjugal do cuidador.

\begin{tabular}{|c|c|c|c|c|c|}
\hline \multirow[t]{3}{*}{ Domínios do WHOQOL-bref } & \multicolumn{4}{|c|}{ Situação conjugal } & \multirow[t]{3}{*}{$\mathbf{P} \#$} \\
\hline & \multicolumn{2}{|c|}{ Com companheiro } & \multicolumn{2}{|c|}{ Sem companheiro } & \\
\hline & Média & $\mathrm{dp}$ & Média & $\mathrm{dp}$ & \\
\hline IGQV & 51,10 & 11,15 & 50,68 & 9,58 & 0,154 \\
\hline Físico & 53,74 & 12,10 & 54,62 & 12,15 & 0,252 \\
\hline Psicológico & 52,58 & 10,89 & 51,47 & 9,87 & 0,320 \\
\hline Relações Sociais & 54,76 & 12,05 & 53,43 & 11,89 & 0,254 \\
\hline Meio Ambiente & 45,39 & 9,87 & 44,85 & 10,85 & 0,207 \\
\hline
\end{tabular}

P\# - Teste T

*Diferença estatisticamente significativa $(\mathrm{p}<0,05)$.

Tabela 13 - Estatística descritiva dos domínios do WHOQOL-bref segundo o grau de parentesco do cuidador para com o paciente.

\begin{tabular}{|c|c|c|c|c|c|}
\hline \multirow[t]{4}{*}{ Domínios do WHOQOL-bref } & \multicolumn{4}{|c|}{ Grau de parentesco } & \multirow[t]{4}{*}{ P\# } \\
\hline & \multirow{2}{*}{\multicolumn{2}{|c|}{ Sem parentesco }} & \multicolumn{2}{|c|}{ Familiar: } & \\
\hline & & & \multicolumn{2}{|c|}{$\begin{array}{l}\text { Esposo(a)/filho(a)/mãe- } \\
\text { pai/neto(a)/irmão(ã) }\end{array}$} & \\
\hline & Média & $\mathrm{dp}$ & Média & $\mathrm{dp}$ & \\
\hline IGQV & 55,13 & 11,40 & 50,32 & 9,27 & 0,442 \\
\hline Físico & 53,57 & 12,75 & 53,84 & 7,14 & 0,871 \\
\hline Psicológico & 59,03 & 13,86 & 50,77 & 9,65 & 0,249 \\
\hline Relações Sociais & 66,67 & 16,66 & 52,78 & 25,27 & 0,516 \\
\hline Meio Ambiente & 50,00 & 17,32 & 45,25 & 13,97 & 0,440 \\
\hline
\end{tabular}

P\# - Teste T

*Diferença estatisticamente significativa $(\mathrm{p}<0,05)$. 
Tabela 14 - Estatística descritiva dos domínios do WHOQOL-bref segundo o grau de instrução do cuidador.

\begin{tabular}{|c|c|c|c|c|c|c|c|c|c|c|}
\hline \multirow{3}{*}{$\begin{array}{c}\text { Domínios do } \\
\text { WHOQOL-bref }\end{array}$} & \multicolumn{10}{|c|}{ Grau de Instrução do cuidador } \\
\hline & \multicolumn{2}{|c|}{$\begin{array}{c}\text { Sem instrução } \\
\text { formal }\end{array}$} & \multicolumn{2}{|c|}{$\begin{array}{l}\text { Fundamental } \\
\text { incompleto }\end{array}$} & \multicolumn{2}{|c|}{$\begin{array}{l}\text { Fundamental } \\
\text { completo }\end{array}$} & \multicolumn{2}{|c|}{$\begin{array}{l}\text { Ensino médio } \\
\text { incompleto }\end{array}$} & \multicolumn{2}{|c|}{$\begin{array}{c}\text { Ensino médio } \\
\text { completo ou } \\
\text { mais }\end{array}$} \\
\hline & Média & $\mathrm{dp}$ & Média & $\mathrm{dp}$ & Média & $\mathrm{dp}$ & Média & $\mathrm{dp}$ & Média & $\mathrm{dp}$ \\
\hline IGQV & 50,00 & 8,52 & 51,32 & 9,23 & 56,25 & 7,89 & 48,56 & 9,85 & 51,40 & 12,16 \\
\hline Físico & 44,64 & 7,89 & 52,23 & 10,12 & 62,50 & 12,25 & 50,00 & 7,89 & 56,17 & 11,89 \\
\hline Psicológico & 60,42 & 12,10 & 54,17 & 12,10 & 46,88 & 13,20 & 48,96 & 8,58 & 53,79 & 10,12 \\
\hline Relações Sociais & 54,17 & 7,56 & 53,13 & 11,89 & 62,50 & 11,56 & 52,08 & 12,10 & 56,82 & 9,86 \\
\hline Meio Ambiente & 39,06 & 17,85 & 48,05 & 12,15 & 57,81 & 11,89 & 44,14 & 11,56 & 43,18 & 12,56 \\
\hline
\end{tabular}

Tabela 15 - Estatística descritiva dos domínios do WHOQOL-bref segundo a religião do cuidador.

(continua)

\begin{tabular}{|c|c|c|c|c|c|}
\hline \multirow{3}{*}{$\begin{array}{c}\text { Domínios do } \\
\text { WHOQOL-bref }\end{array}$} & \multicolumn{4}{|c|}{ Religião } & \multirow[t]{3}{*}{ P\# } \\
\hline & \multicolumn{2}{|c|}{ Católica } & \multicolumn{2}{|c|}{ Evangélica/Espírita } & \\
\hline & Média & $\mathrm{dp}$ & Média & $\mathrm{dp}$ & \\
\hline IGQV & 47,77 & 11,25 & 55,71 & 10,65 & 0,179 \\
\hline Físico & 50,19 & 10,53 & 59,05 & 12,10 & 0,442 \\
\hline Psicológico & 47,37 & 9,85 & 57,22 & 12,30 & 0,192 \\
\hline Relações Sociais & 50,00 & 8,52 & 62,22 & 13,20 & 0,137 \\
\hline Meio Ambiente & 43,42 & 7,56 & 50,42 & 11,89 & $0,000^{*}$ \\
\hline
\end{tabular}

P\# - Teste T

*Diferença estatisticamente significativa $(\mathrm{p}<0,05)$. 
Tabela 16 - Estatística descritiva dos domínios do WHOQOL-bref segundo a percepção do cuidador do apoio social recebido.

\begin{tabular}{|c|c|c|c|c|c|}
\hline \multirow{3}{*}{$\begin{array}{c}\text { Domínios do } \\
\text { WHOQOL-bref }\end{array}$} & \multicolumn{4}{|c|}{ Apoio recebido } & \multirow[t]{3}{*}{ P\# } \\
\hline & \multicolumn{2}{|c|}{$\begin{array}{l}\text { Relata ter recebido de alguém (familiar, } \\
\text { amigos, igreja, profissional de saúde) }\end{array}$} & \multicolumn{2}{|c|}{ Relata não ter recebido } & \\
\hline & Média & $\mathrm{dp}$ & Média & $\mathrm{dp}$ & \\
\hline IGQV & 52,69 & 17,85 & 48,40 & 9,85 & 0,442 \\
\hline Físico & 55,18 & 13,95 & 51,49 & 12,32 & 0,197 \\
\hline Psicológico & 53,54 & 12,89 & 50,00 & 14,52 & 0,062 \\
\hline Relações Sociais & 54,58 & 9,84 & 55,56 & 13,56 & $0,045^{*}$ \\
\hline Meio Ambiente & 48,91 & 20,20 & 40,89 & 12,89 & $0,037 *$ \\
\hline
\end{tabular}

P\# - Teste T

*Diferença estatisticamente significativa $(\mathrm{p}<0,05)$.

Tabela 17 - Estatística descritiva dos domínios do WHOQOL-bref segundo a presença de doença relatada pelo cuidador.

\begin{tabular}{lccccc}
\hline Domínios do WHOQOL-bref & \multicolumn{3}{c}{ Presença de doença diagnosticada } & P\# \\
\cline { 2 - 5 } & \multicolumn{2}{c}{ Sim } & Não & \\
\cline { 2 - 5 } & Média & $\mathrm{dp}$ & 47,25 & 9,82 & 0,233 \\
\hline IGQV & 54,10 & 11,75 & 50,00 & 8,63 & 0,307 \\
Físico & 56,58 & 13,27 & 50,30 & 13,02 & 0,360 \\
Psicológico & 53,73 & 13,95 & 51,79 & 20,20 & 0,353 \\
Relações Sociais & 57,89 & 17,89 & 39,96 & 14,04 & 0,184 \\
Meio Ambiente & 50,66 & 17,32 & & &
\end{tabular}

P\# - Teste T

*Diferença estatisticamente significativa $(\mathrm{p}<0,05)$. 
Tabela 18 - Estatística descritiva dos domínios do WHOQOL-bref segundo a presença de dor relatada pelo cuidador.

\begin{tabular}{|c|c|c|c|c|c|}
\hline \multirow[t]{3}{*}{ Domínios do WHOQOL-bref } & \multicolumn{4}{|c|}{ Presença de dor } & \multirow[t]{3}{*}{$\mathbf{P \#}$} \\
\hline & \multicolumn{2}{|c|}{ Sim } & \multicolumn{2}{|c|}{ Não } & \\
\hline & Média & $\mathrm{dp}$ & Média & $\mathrm{dp}$ & \\
\hline IGQV & 50,79 & 11,95 & 52,12 & 10,66 & $0,014^{*}$ \\
\hline Físico & 53,88 & 12,74 & 53,57 & 11,71 & 0,263 \\
\hline Psicológico & 54,35 & 14,62 & 47,50 & 13,25 & 0,294 \\
\hline Relações Sociais & 53,62 & 19,11 & 59,17 & 19,63 & 0,349 \\
\hline Meio Ambiente & 44,43 & 16,32 & 50,00 & 16,51 & 0,328 \\
\hline
\end{tabular}

P\# - Teste T

*Diferença estatisticamente significativa $(\mathrm{p}<0,05)$.

Tabela 19 - Estatística descritiva dos domínios do WHOQOL-bref segundo o uso de medicamentos de forma contínua pelo cuidador.

\begin{tabular}{|c|c|c|c|c|c|}
\hline \multirow[t]{3}{*}{ Domínios do WHOQOL-bref } & \multicolumn{4}{|c|}{ Uso de medicamentos psicoterápicos } & \multirow[t]{3}{*}{ P\# } \\
\hline & \multicolumn{2}{|c|}{ Sim } & \multicolumn{2}{|c|}{ Não } & \\
\hline & Média & $\mathrm{dp}$ & Média & $\mathrm{dp}$ & \\
\hline IGQV & 45,19 & 11,76 & 52,53 & 10,9 & 0,048 \\
\hline Físico & 47,62 & 13,11 & 55,16 & 11,35 & 0,050 \\
\hline Psicológico & 50,69 & 10,35 & 52,62 & 14,21 & 0,473 \\
\hline Relações Sociais & 45,83 & 21,57 & 57,41 & 17,95 & 0,265 \\
\hline Meio Ambiente & 39,06 & 17,76 & 47,69 & 16,34 & 0,334 \\
\hline
\end{tabular}

P\# - Teste T

*Diferença estatisticamente significativa $(\mathrm{p}<0,05)$. 
Tabela 20 - Estatística descritiva dos domínios do WHOQOL-bref segundo a qualidade do sono referida pelo cuidador.

(continua)

\begin{tabular}{lccccc}
\hline Domínios do WHOQOL-bref & \multicolumn{4}{c}{ Qualidade do sono } & P\# \\
\cline { 2 - 5 } & \multicolumn{2}{c}{ Boa/sono contínuo } & \multicolumn{2}{c}{ Ruim/sono interrompido } \\
\cline { 2 - 5 } & Média & $\mathrm{dp}$ & Média & $\mathrm{dp}$ & 0,266 \\
\hline IGQV & 52,60 & 12,48 & 47,44 & 11,03 & 0,476 \\
Físico & 53,72 & 14,68 & 53,97 & 11,22 & 0,335 \\
Psicológico & 55,03 & 14,37 & 44,91 & 13,14 & 0,420 \\
Relações Sociais & 59,72 & 19,50 & 43,52 & 19,03 & 0,482 \\
Meio Ambiente & 47,14 & 25,54 & 43,40 & 14,08 & \\
\hline
\end{tabular}

P\# - Teste T

*Diferença estatisticamente significativa $(\mathrm{p}<0,05)$.

Tabela 21 - Estatística descritiva dos domínios do WHOQOL-bref segundo a atividade sexual do cuidador.

\begin{tabular}{|c|c|c|c|c|c|}
\hline \multirow[t]{3}{*}{ Domínios do WHOQOL-bref } & \multicolumn{4}{|c|}{ Atividade sexual } & \multirow[t]{3}{*}{ P\# } \\
\hline & \multicolumn{2}{|c|}{ Sim } & \multicolumn{2}{|c|}{ Não } & \\
\hline & Média & $\mathrm{dp}$ & Média & $\mathrm{dp}$ & \\
\hline IGQV & 51,44 & 9,01 & 50,78 & 11,83 & 0,171 \\
\hline Físico & 50,71 & 10,75 & 54,76 & 12,69 & 0,331 \\
\hline Psicológico & 52,50 & 9,46 & 51,39 & 15,21 & 0,455 \\
\hline Relações Sociais & 60,83 & 23,91 & 52,78 & 14,27 & 0,338 \\
\hline Meio Ambiente & 47,19 & 15,48 & 45,39 & 17,13 & 0,396 \\
\hline
\end{tabular}

P\# - Teste T

*Diferença estatisticamente significativa $(\mathrm{p}<0,05)$. 
Tabela 22 - Estatística descritiva dos domínios do WHOQOL-bref segundo o tempo de exercício da função de cuidador.

\begin{tabular}{lccccc}
\hline \multicolumn{1}{c}{$\begin{array}{c}\text { Domínios do } \\
\text { WHOQOL-bref }\end{array}$} & \multicolumn{5}{c}{ Tempo como cuidador } \\
\cline { 2 - 6 } & $<$ de 2 anos & 2 a 2,5 anos & 3 a 4,5 anos & 5 a 10 anos & $\begin{array}{c}>\text { de 10 } \\
\text { anos }\end{array}$ \\
\cline { 2 - 6 } & Média & Média & Média & Média & Média \\
\hline IGQV & 42,63 & 58,97 & 52,19 & 55,63 & 46,79 \\
Físico & 42,86 & 51,19 & 58,44 & 57,14 & 50,00 \\
Psicológico & 48,61 & 55,56 & 48,11 & 60,71 & 51,39 \\
Relações Sociais & 38,89 & 80,56 & 58,33 & 55,95 & 48,15 \\
Meio Ambiente & 35,42 & 60,42 & 47,44 & 51,34 & 38,19 \\
\hline
\end{tabular}

P\# - Teste T

*Diferença estatisticamente significativa $(\mathrm{p}<0,05)$.

\subsection{4 - Comparação das médias do escore de qualidade de vida do cuidador segundo a} escala de sobrecarga do cuidador

Tabela 23 - Estatística descritiva dos domínios do WHOQOL-bref segundo o resultado da escala de sobrecarga do cuidador.

\begin{tabular}{lcccccc}
\hline \multirow{2}{*}{ Domínios do WHOQOL-bref } & \multicolumn{5}{c}{ Escala de Sobrecarga do Cuidador } \\
\cline { 2 - 7 } & \multicolumn{2}{c}{ Sem sobrecarga } & \multicolumn{2}{c}{ Sobrecarga ligeira } & \multicolumn{2}{c}{ Sobrecarga intensa } \\
\cline { 2 - 7 } & Média & dp & Média & dp & Média & dp \\
\hline IGQV & 52,06 & 10,59 & 51,44 & 11,85 & 49,57 & 11,70 \\
Físico & 58,16 & 11,72 & 51,98 & 13,46 & 49,29 & 9,75 \\
Psicológico & 50,89 & 13,01 & 53,75 & 11,86 & 52,78 & 15,69 \\
Relações Sociais & 57,41 & 20,18 & 56,67 & 18,63 & 52,98, & 17,17 \\
Meio Ambiente & 47,99 & 14,67 & 47,19 & 16,22 & 42,01 & 15,96 \\
\hline
\end{tabular}

5.3.5 - Correlação entre as médias do escore de qualidade de vida do cuidador e variáveis quantitativas

A percepção da qualidade de vida e da sobrecarga dos cuidadores está relacionada a vários fatores quantitativos e qualitativos. A tabela 24 apresenta as correlações entre as 
médias do escore dos domínios e facetas do WHOQOL-bref, a idade e o tempo de exercício como cuidador.

Tabela 24 - Médias dos escores dos domínios e a correlação com a idade do cuidador e com o tempo de exercício da função.

\begin{tabular}{lccc}
\hline \multicolumn{1}{c}{ Domínios WHOQOL-bref } & Idade cuidador & $\begin{array}{c}\text { Tempo como } \\
\text { cuidador }\end{array}$ & $\begin{array}{c}\text { Escala de Sobrecarga do } \\
\text { Cuidador - ESC }\end{array}$ \\
\hline IGQV & 0,15 & 0,08 & $0,01^{*}$ \\
Domínio físico & 0,06 & 0,25 & 0,15 \\
Domínio psicológico & 0,18 & $0,01^{*}$ & $-0,09$ \\
Domínio Relações sociais & $0,04^{*}$ & $-0,01$ & $-0,13$ \\
Domínio Meio ambiente & 0,15 & $-0,01$ & 0,06 \\
\hline
\end{tabular}

* correlação significativa

\subsection{6 - Qualidade de vida de cuidadores domiciliares na oferta de cuidados paliativos}

Ao correlacionar dados do perfil com a percepção de qualidade de vida de cuidadores foi elaborado e submetido o artigo intitulado de 'Qualidade de vida de cuidadores domiciliares na oferta de cuidados paliativos' ao periódico: Revista Brasileira de Enfermagem (REBEN) - apêndice 5.

\subsection{PERCEPÇÃO DO SIGNIFICADO DA DOENÇA E DA FINITUDE HUMANA FRENTE À QUALIDADE DE VIDA}

A situação do doente e a proximidade com o fim da vida suscitam sentimentos diversos que podem refletir diretamente no significado da vida para os cuidadores entrevistados. A influência na qualidade de vida do cuidador depende do significado particular que ele tem sobre a doença. O quadro 3 apresenta verbalizações que exemplificam estes relatos.

Quadro 3 - Relatos das verbalizações de cuidadores entrevistados sobre o significado da doença do doente internado em domicilio.

(continua) 


\begin{tabular}{|c|c|c|}
\hline & $\begin{array}{c}\text { Vista de forma } \\
\text { positiva/necessária/ } \\
\text { salutar }\end{array}$ & $\begin{array}{l}\text { doença para a vida da gente... Adoeceu parou tudo. Por isso tem que } \\
\text { cuidar primeiro da saúde. A gente não sabe quando se a gente vai } \\
\text { morrer ou não. Então está doente, procura um médico." (E16) } \\
\text { "Ah, depende... Às vezes a doença é um mal necessário. Só não é para o } \\
\text { bem quando a pessoa fica com sequelas grandes, fica dependente. } \\
\text { Porque a gente sabe que a pessoa sofre, né." (E17) } \\
\text { “A doença é tipo um resgate. Um resgate assim, suponhamos que você } \\
\text { não usa bem o seu organismo, exagera em alguma coisa, aí chega um } \\
\text { tempo que né, o organismo tem que resgatar aquele tipo de coisa." } \\
\text { (E18) } \\
\text { "Doença é um sinal de que você precisa mudar alguma coisa em você... } \\
\text { Às vezes é pra mostrar que não estamos nos cuidando direito." (E15) } \\
\text { "Nem todo mundo fica doente antes de morrer. Eu acho que é bom, } \\
\text { sabe? Quem fica doente tem tempo pra pedir perdão, pra se preparar } \\
\text { pra ir pro Céu. Eu quero ficar doente, mas não precisa ser por muito } \\
\text { tempo, (risos).”(E13) }\end{array}$ \\
\hline $\begin{array}{l}\text { Significado } \\
\text { da doença }\end{array}$ & $\begin{array}{l}\text { Vista de forma } \\
\text { negativa/castigo/ } \\
\text { sofrimento }\end{array}$ & 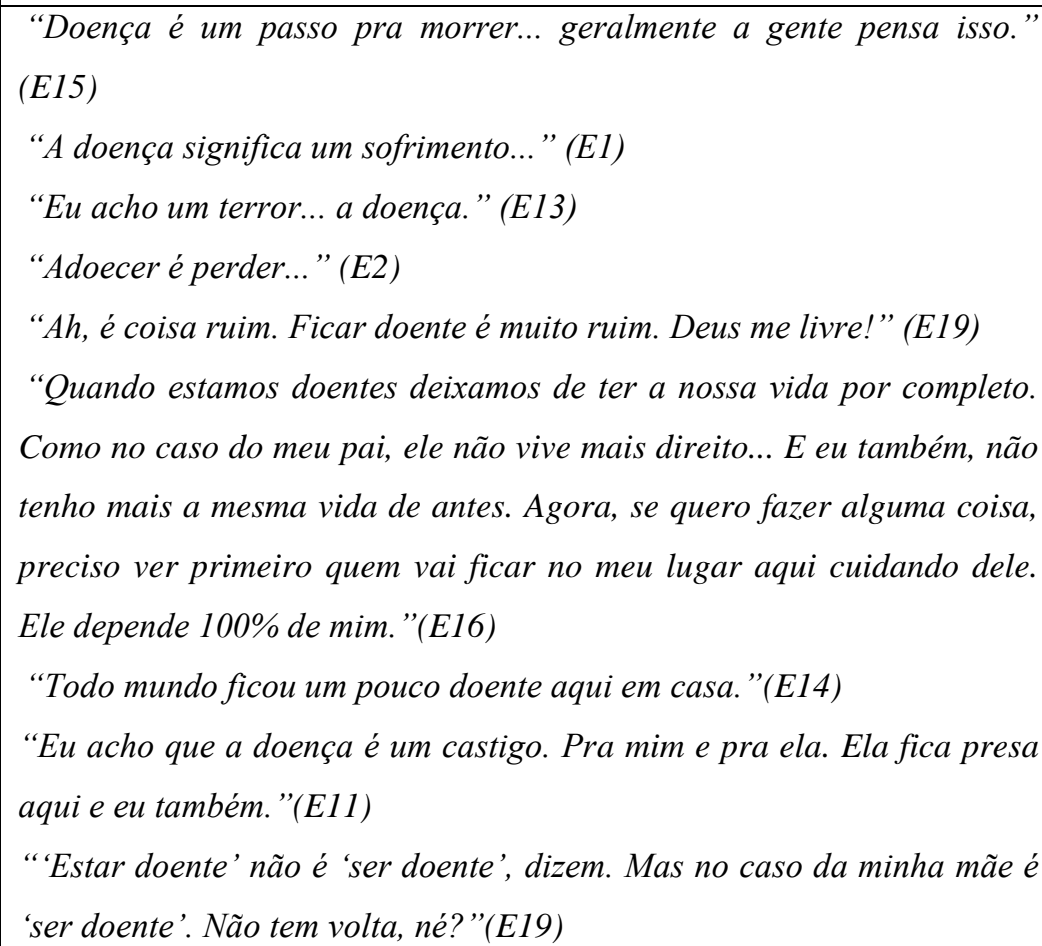 \\
\hline
\end{tabular}

Nesse mesmo sentido, o significado que o cuidador dá para a morte reflete na sua qualidade de vida. O quadro 4 apresenta verbalizações que exemplifiquem essas significações que podem se positivas ou negativas. 
Quadro 4 - Relatos das verbalizações de cuidadores entrevistados sobre o significado da morte no contexto pessoal.

(continua)

\begin{tabular}{|c|c|c|}
\hline $\begin{array}{c}\text { Significado da } \\
\text { morte }\end{array}$ & $\begin{array}{c}\text { Vista de forma } \\
\text { positiva/alívio/d } \\
\text { escanso/process } \\
\text { o natural }\end{array}$ & $\begin{array}{l}\text { “A morte pra ele, no caso, eu acho que seria um alívio. Pra mim também } \\
\text { (a morte dele). Um alívio em relação de saber que ele não estaria sofrendo } \\
\text { mais." (E7) } \\
\text { "Morte pra mim seria que a gente não espera, mas que vai acontecer. Ou } \\
\text { seja, o fim." (E15) } \\
\text { "É a passagem dessa vida pra outra. A gente morre pra essa vida e } \\
\text { ressuscita pra Deus." (E16) } \\
\text { “A morte é o final da vida. No caso da minha avó seria o final do } \\
\text { sofrimento, porque ela é totalmente lúcida. Então ela sofre muito por não } \\
\text { poder responder, não poder interagir. Então em alguns casos a morte é } \\
\text { deixar o sofrimento." (E17) }\end{array}$ \\
\hline & & $\begin{array}{l}\text { “A morte talvez seja o fim do sofrimento aqui e começo de um novo } \\
\text { aprendizado do outro lado. Se é que existe o outro lado... eu tenho um } \\
\text { pouquinho de duvida, mas...” (E18) } \\
\text { "A morte em um certo ponto dependendo da pessoa se Deus levar mesmo } \\
\text { é a paz. Quando ela estava mesmo a gente pedia era pra Deus ter piedade } \\
\text { dela e levar. Agora tá melhorando...” (E19) } \\
\text { “'Morrer' pode ser 'descansar', né?”,(E6) } \\
\text { "Morrer não é ruim. É uma forma de começar de novo. Em outro mundo, } \\
\text { né? Tem gente que diz que o morto volta. Prefiro não pensar assim, acho } \\
\text { que quem morre, morre... vai embora."(E4) } \\
\text { "Eu não tenho medo da morte, nem acho que vou ficar muito triste } \\
\text { quando ele morrer, porque ele vai para de sofrer."(E3) }\end{array}$ \\
\hline & $\begin{array}{c}\text { Vista de forma } \\
\text { negativa/fim/se } \\
\text { m volta }\end{array}$ & $\begin{array}{l}\text { “O ruim, que eu acho da morte é que ninguém sabe como é } \\
\text { morrer.”(E21) } \\
\text { “A morte existe e temos que passar por ela e pronto. Acho que a morte } \\
\text { não é nada de bom, não." (E13) } \\
\text { "Morte é o fim... só o fim." (E27) } \\
\text { “Pra mim, a morte é ruim. Eu não tô preparada pra morrer ainda. Acho } \\
\text { que nunca vou estar. E ela também não tá. Tinha que viver muito } \\
\text { mais...”(E6) } \\
\text { "Morrer, todo mundo vai, mas não é bom, né?(E28) } \\
\text { "Acho que Deus tem um propósito pra levar todo mundo embora daqui, } \\
\text { mas eu não acho graça nenhuma. A gente viver sempre pensando que } \\
\text { pode morrer. Pra que viver então? (E25) }\end{array}$ \\
\hline
\end{tabular}




\subsection{PERCEPÇÃO DOS SENTIMENTOS VIVENCIADOS NO CUIDADO E FRENTE AO SOFRIMENTO DO DOENTE}

O sofrimento vivenciado pelos doentes reflete diretamente na qualidade de vida dos cuidadores, pois suscita sentimentos de ansiedade podem desencadear o estresse. Os cuidadores entrevistados responderam ao questionamento de forma livre e vários sentimentos foram relatados. O quadro 5 apresenta a categorização das respostas nas formas positivas e negativas dos entrevistados à pergunta: 'Quais são os seus sentimentos frente ao sofrimento do paciente?'.

Quadro 5 - Relatos das verbalizações sobre sentimentos vivenciados pelos cuidadores.

(continua)

\begin{tabular}{|c|c|c|}
\hline \multirow{2}{*}{$\begin{array}{c}\text { Sentimentos } \\
\text { positivos }\end{array}$} & Esperança & $\begin{array}{l}\text { “Olha... no inicio eu sofria muito, mas agora com o passar do tempo e o que } \\
\text { eu entendi em oração.” (E16) } \\
\text { “Olho pra ela e vejo que ainda não está no fim. Tenho esperança de ela ter } \\
\text { uma vida melhor... Ela conversa, é mais tranquila agora do que era antes. } \\
\text { Acho que ela é uma pessoa melhor agora." (E9) } \\
\text { “Eu tenho esperança que ela vai melhorar e eu digo pra ela: tu vai andar, vai } \\
\text { sair dessa cama, acredita em mim. Ela sorri com o olhar quando digo isso”, } \\
\text { (E32) } \\
\text { "Deus nunca abandona os seus. Ela é muito nova ainda e ELE não vai levar... } \\
\text { agora não. Por isso, faço de tudo pra cuidar bem dela."(E7) }\end{array}$ \\
\hline & $\begin{array}{c}\text { Orgulho/admir } \\
\text { ação }\end{array}$ & $\begin{array}{l}\text { "Eu tenho maior orgulho dela. Ela é famosa, importante. Ficou conhecida na } \\
\text { televisão." (E33) } \\
\text { "Admiro muito ela por ser tão forte, determinada. Ela faz muita coisa e diz } \\
\text { que vai ficar boa." (E21) } \\
\text { "Me sinto muito orgulhosa de ter uma mãe assim, guerreira. Ela nunca } \\
\text { desiste!” (E14) } \\
\text { "Eu entendo que ela é um exemplo. O sentimento que eu sinto é de respeito } \\
\text { pela perseverança que ela tem."(E19) }\end{array}$ \\
\hline $\begin{array}{c}\text { Sentimentos } \\
\text { negativos }\end{array}$ & Angústia & $\begin{array}{l}\text { “A minha angústia é tentar interpretar o que ele está sentindo naquele } \\
\text { momento.” (E12) } \\
\text { “Olha, eu sinto muita angustia né? Eu quero aliviar a dor, fazer o que eu } \\
\text { puder pra aliviar a dor, ou pra aliviar o problema ou pra tirar. Entendeu?” } \\
\text { (E3) } \\
\text { "Então eu não aguento vê o sofrimento da pessoa." (E18) } \\
\text { "Eu me sinto mal demais, muito mal.” (E19) } \\
\text { "Será que eu estou cuidando bem dele? Será que ele tem tudo o que }\end{array}$ \\
\hline
\end{tabular}




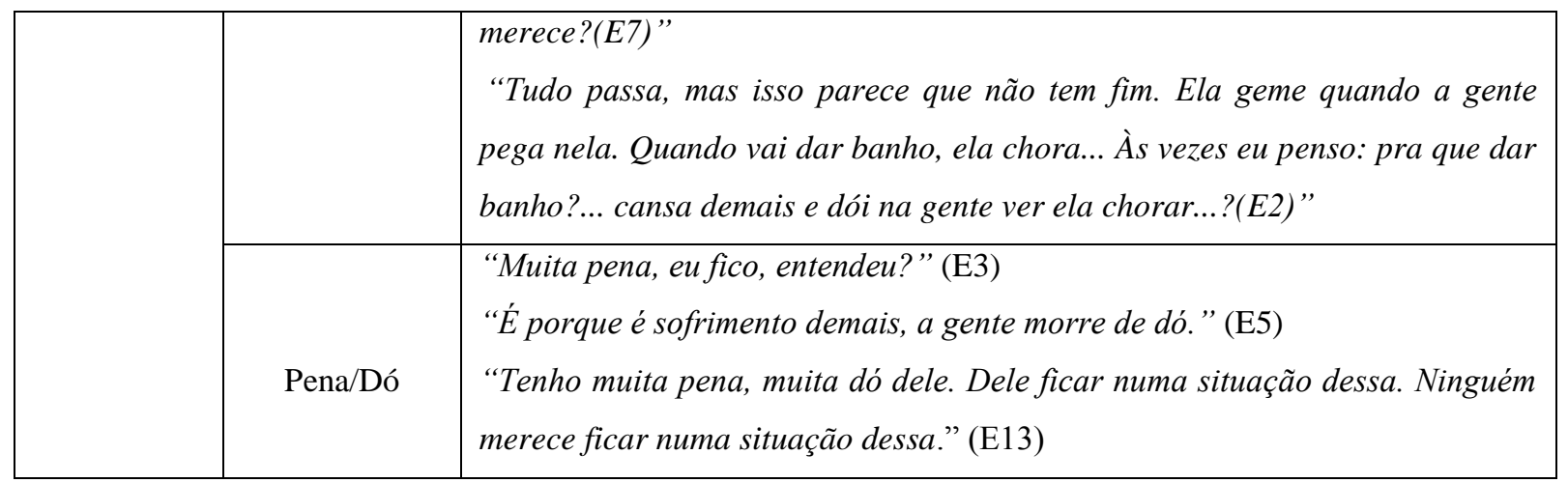

Quadro 5 - Relatos das verbalizações sobre sentimentos vivenciados pelos cuidadores.

(conclusão)

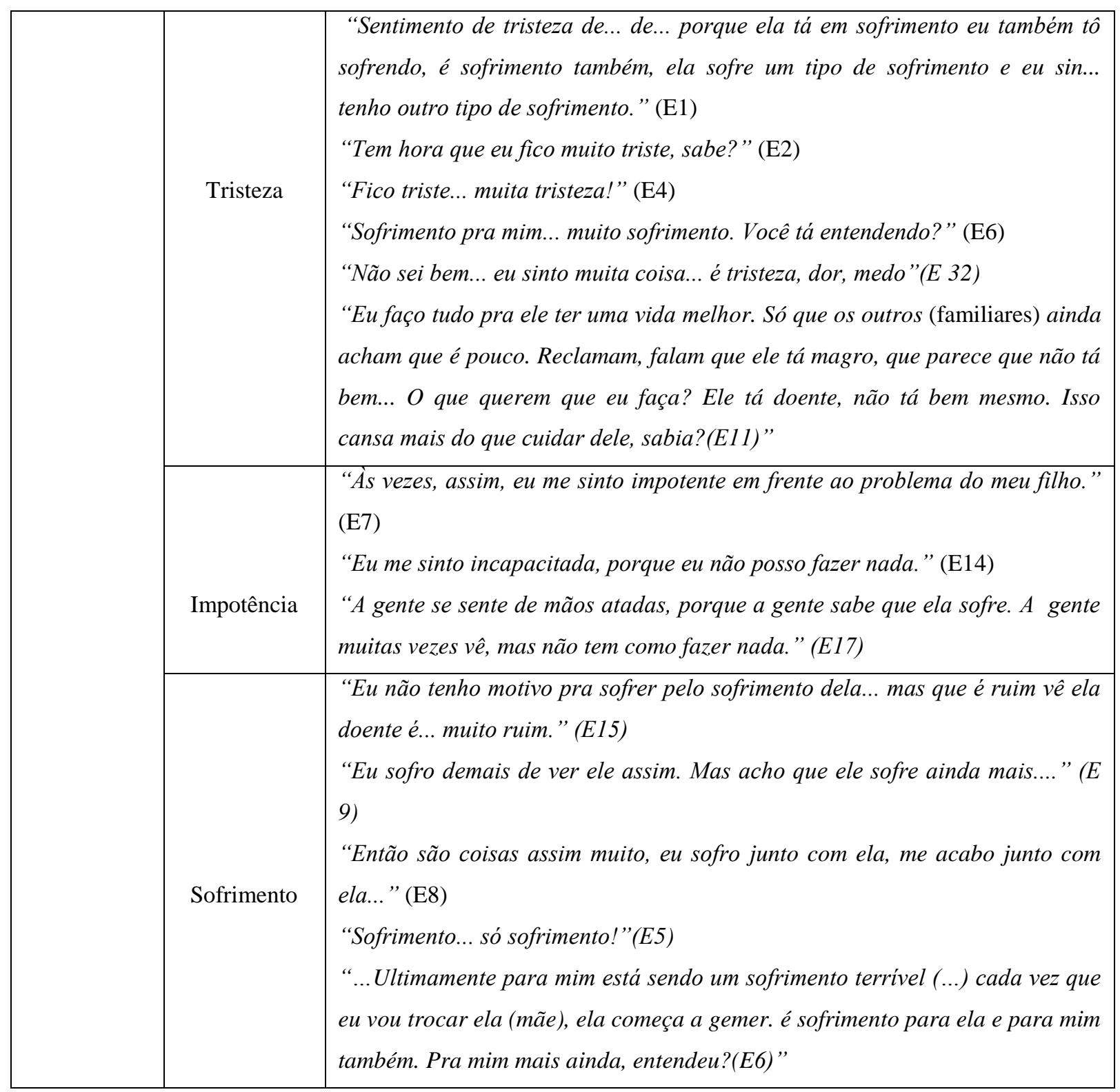




\subsection{PERCEPÇÃO DAS MUDANÇAS OCORRIDAS APÓS O INÍCIO DA FUNÇÃO DE CUIDADOR E DA INFLUÊNCIA DAS MESMAS NA SUA QUALIDADE DE VIDA}

Muitas mudanças foram relatadas pelos cuidadores entrevistados com relação às suas vidas. Estas mudanças estão relacionadas diretamente à situação enfrentada na condição de cuidador de paciente internado em domicílio. Para melhor visualização, o quadro 6 apresenta a categorização das mudanças de ordem social descritas nas respostas dos entrevistados.

Quadro 6 - Relatos das verbalizações sobre mudanças de ordem social ocorridas após o inicio do cuidar.

(continua)

\begin{tabular}{|c|c|c|}
\hline & Dedicação/tempo & $\begin{array}{l}\text { “Eu mudei totalmente minha vida, vivo em função dela. Nunca mais tive } \\
\text { que trabalhar nem nada." (E15) } \\
\text { "É assim que a gente vive aqui em casa: de manhã é ela, à tarde ela, à } \\
\text { noite ela.” (E15) } \\
\text { “Passo } 24 \text { horas com ela. A minha vida é ela. Tenho muito carinho por } \\
\text { ela... Acho que é retribuição!”(E21) } \\
\text { “Eu parei de trabalhar, mas até achei bom. Tenho mais tempo pra cuidar } \\
\text { não só dela, mas de todos aqui em casa.”(E31) } \\
\text { "Hoje a minha vida é ela.”(E33) } \\
\text { “Eu abri mão da faculdade, né? Eu me privei de muita coisa para cuidar } \\
\text { do meu filho. Só eu cuido dele, não tem outra pessoa.(E2)”. } \\
\text { “Tô muito feliz por poder cuidar dela o tempo todo.” (E9) }\end{array}$ \\
\hline Social & $\begin{array}{c}\text { Afastamento } \\
\text { social }\end{array}$ & $\begin{array}{l}\text { "Minha vida mudou mais a parte social, porque como eu fico aqui o tempo } \\
\text { inteiro então eu não tenho assim... Vida social eu tenho, saio, tenho amigos, } \\
\text { mas drasticamente foi a questão social. Eu fico muito presa, porque como } \\
\text { eu cuido dela o dia inteiro, de segunda a sexta então eu não posso ir ao } \\
\text { banco, não posso ir ao mercado porque ela é totalmente dependente. Eu } \\
\text { não posso deixar ela sozinha. O que mais mudou foi a falta dela”.. (E17) } \\
\text { "No inicio tinha muitas visitas, a casa ficava cheia, até de pessoas que ele } \\
\text { não via de muito tempo... parentes vinham ver como ele tava. Depois de uns } \\
\text { seis meses, mais ou menos, quase não vem ninguém, nem ligam pra saber } \\
\text { como ele tá. Acho que foi como uma despedida. Só no começo, depois } \\
\text { esqueceram. Muito triste... E ele pede...”(E18) } \\
\text { "Pôxa vida! Tenho } 30 \text { anos e a minha vida tá parada... minha vida é tão } \\
\text { programada que eu tenho que pensar antes de sair... Parei de estudar, de } \\
\text { trabalhar... acho que até parei de viver... namorar... quando?(E5)”" }\end{array}$ \\
\hline
\end{tabular}




\begin{tabular}{|l|l|}
\hline \multirow{1}{*}{} & $\begin{array}{l}\text { Ixi, mudou... se existir 1000\% mudou 1000\%, porque eu não tenho mais } \\
\text { projeto de vida. Mudou tudo. Eu não posso mais sair pra trabalhar, eu não } \\
\text { posso mais ganhar meu dinheiro, não posso mais planejar de ir numa festa, } \\
\text { suponhamos uma promoção... porque a partir do momento que você não } \\
\text { trabalha você não pode planejar seu futuro, porque não tem dinheiro pra } \\
\text { planejar o futuro.(E18) } \\
\text { "Ficou muito dificil de ir passear, ver amigos, ir nas festas da família. As } \\
\text { pessoas nem convidam mais de tantas vezes que disse não." (E32) } \\
\text { "Acho que as pessoas tem preconceito com gente doente. Aí mistura tudo, } \\
\text { ninguém nem liga mais pra saber como a gente tá. Uma vez, uma mulher lá } \\
\text { da igreja me disse: - Quando ele morrer, você volta para igreja... você faz }\end{array}$ \\
\hline
\end{tabular}

Quadro 6 - Relatos das verbalizações sobre mudanças de ordem social ocorridas após o inicio do cuidar.

(conclusão)

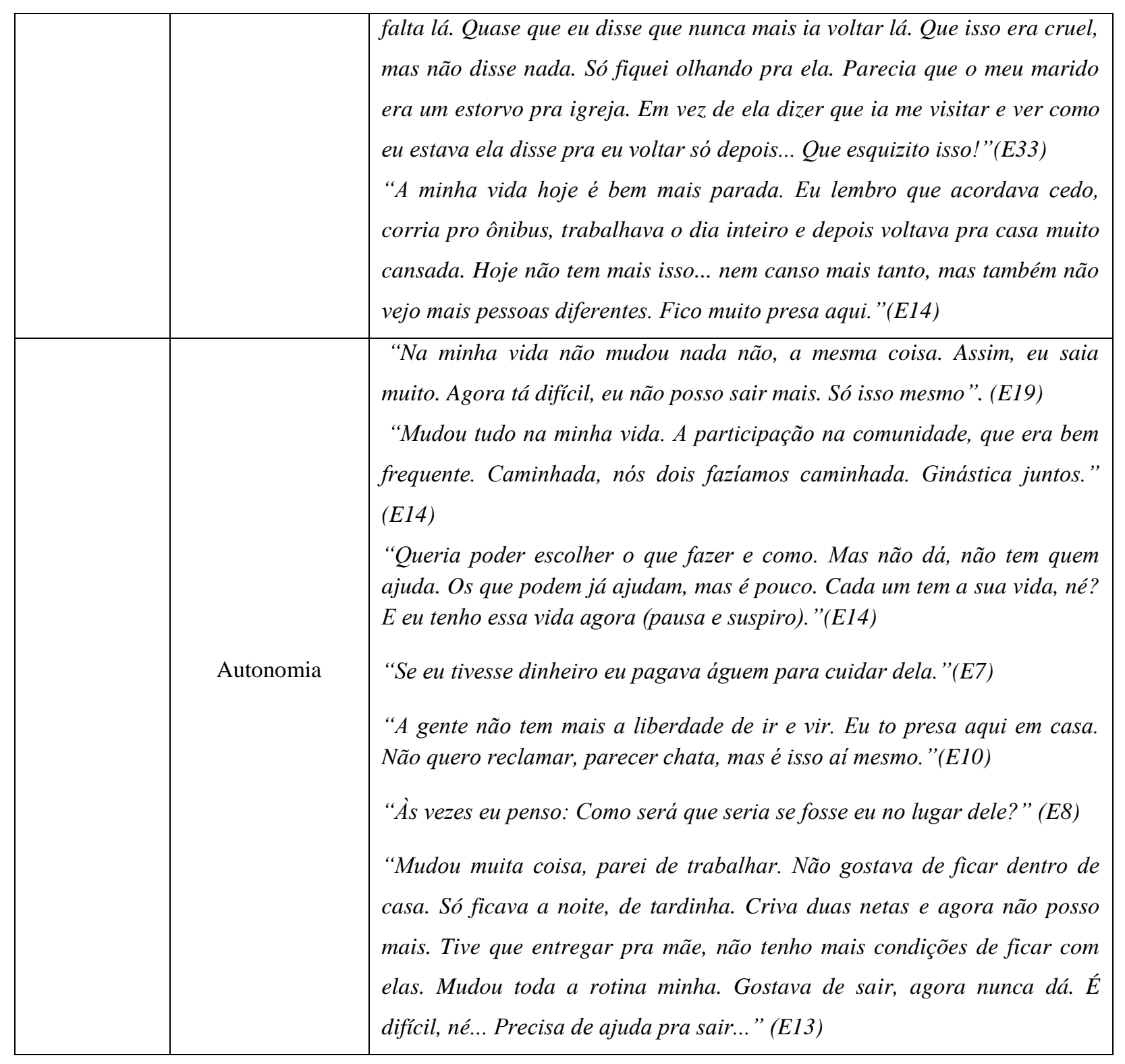




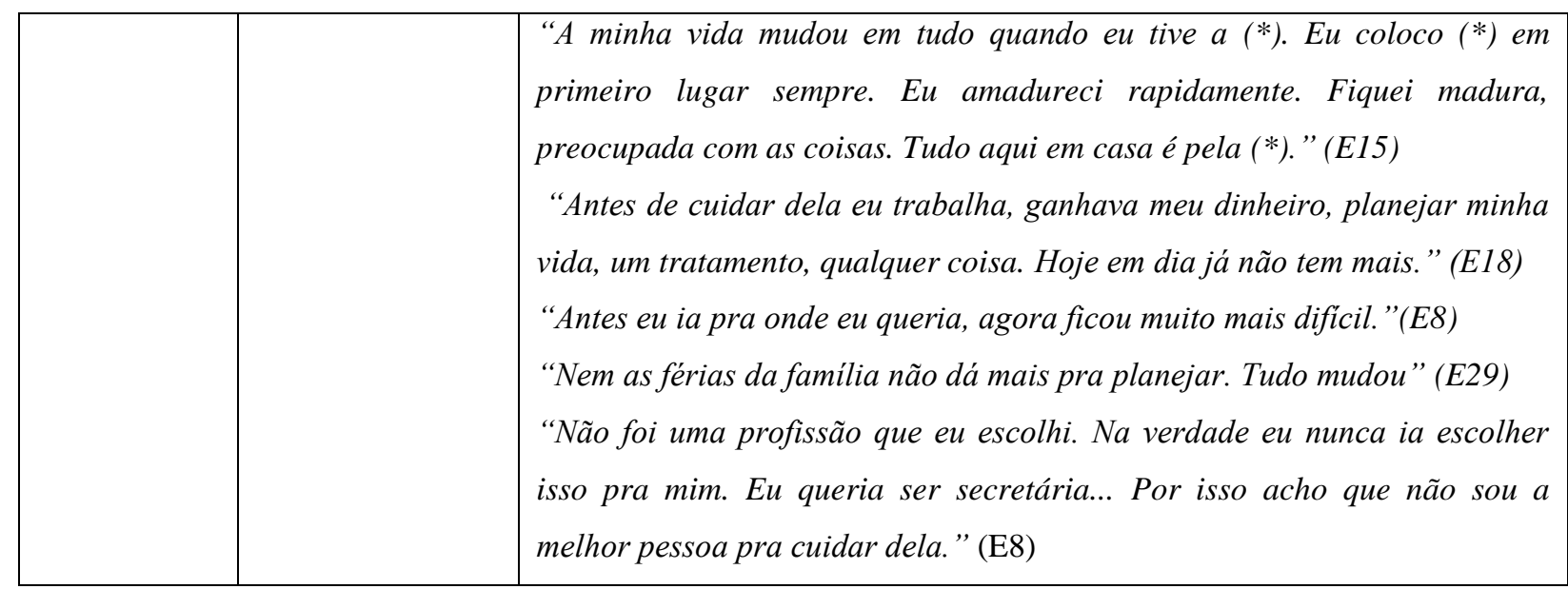

Mudanças presentes nos relatos dos cuidadores domiciliares no âmbito espiritual podem ser visualizadas no quadro 7.

Quadro 7 - Relatos das verbalizações sobre mudanças no âmbito espiritual percebidas pelos cuidadores domiciliares.

(continua)

\begin{tabular}{|c|c|c|}
\hline \multirow[t]{2}{*}{ Espiritual } & Superação & $\begin{array}{l}\text { “Com a doença dele eu vi que eu posso superar muitas e muitas coisas... } \\
\text { que não tem obstáculo pra gente não vencer não. Dá pra superar. E antes } \\
\text { eu não tinha essa segurança.” (E14) } \\
\text { "Tive uma doença muito grave, na época que ela tinha } 10 \text { anos. Um } \\
\text { câncer de ovário, mas Deus me curou par eu cuidar dela. E estou aqui } \\
\text { contando a história.” (E15) } \\
\text { "Vi que a vida tem um sentido muito estranho e que todos nós temos a } \\
\text { nossa missão. A minha é essa agora.” (E12) } \\
\text { "Eu acho que é uma chance que eu tenho pro meu crescimento. Pra ser } \\
\text { sempre melhor... uma pessoa melhor.” (E18) } \\
\text { "Então muitos obstáculos eu consegui enfrentar. E eu pensava que eu não } \\
\text { era capaz. E agora eu vejo que eu tenho essa capacidade.” (E14) } \\
\text { "Eu achava que era fraco, mas agora sei que sou muito forte!”(E9) }\end{array}$ \\
\hline & Relacionamentos & $\begin{array}{l}\text { "Meu sentimento em relação ao amor ao próximo mudou muito. Eu não } \\
\text { sentia vontade de ficar no hospital, cuidar de alguém. E hoje se disser que } \\
\text { eu vou ficar um dia todo no hospital, eu fico." (E14) } \\
\text { "Eu consigo ver agora que todos nós somos iguais mesmo. E que cada um } \\
\text { pode estar no lugar do meu pai e precisar de alguém pra cuidar dele. Por } \\
\text { isso, eu estou mais amiga, escuto mais os outros e penso. E se for } \\
\text { comigo... quem vai me cuidar?” (E5) } \\
\text { "Muita gente que vinha aqui no inicio não vem mais ajudar, mas liga pra } \\
\text { dizer o que eu devo fazer. Eu fico quieta, mas às vezes eu acho que a } \\
\text { minha paciência se acabou...” (E9) }\end{array}$ \\
\hline
\end{tabular}




\begin{tabular}{|l|l|}
\hline & $\begin{array}{c}\text { "Muitas coisas que eu era mais agressiva, alguma parte que eu nunca } \\
\text { tinha parado assim pra refletir hoje eu já fico mais... assim, de ajudar o } \\
\text { próximo. Toda vida nós fomos de ajudar." (E14) } \\
\text { “Eu não tenho muita paciência com essas pessoas que dizem que só } \\
\text { querem ajudar. Eles criticam o tempo todo...” (E16) } \\
\text { "Muitas vezes me pego pensando... Quem é meu amigo? Ainda tenho } \\
\text { amigos? Parece que a vida dá um nó. (E3)" } \\
\text { "Hoje eu tenho mais amigos do que antes... não em quantidade, mas } \\
\text { amigos de verdade. Eu sei quem eu quero do meu lado. Consigo ser mais } \\
\text { verdadeira também com eles. Eu digo quando quero ficar sozinha. Antes } \\
\text { eu não conseguia ser muito sincera com os outros. Eu sempre achava que }\end{array}$ \\
\hline
\end{tabular}

Quadro 7 - Relatos das verbalizações sobre mudanças no âmbito espiritual percebidas pelos cuidadores domiciliares.

(conclusão)

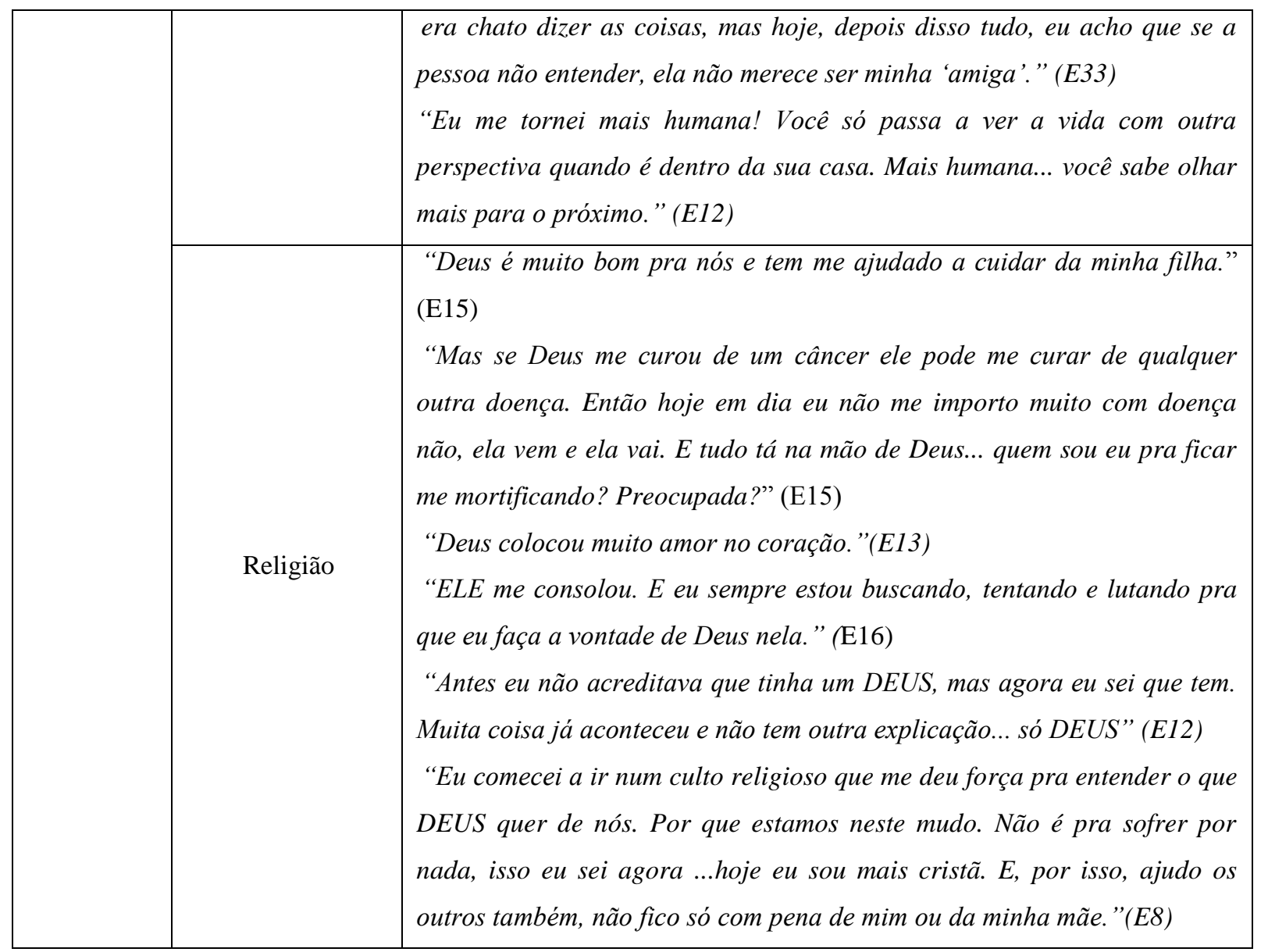

\subsection{ASPECTOS BIOÉTICOS DA RELAÇÃO INTRAFAMILIAR NO CONTEXTO DOS CUIDADOS PALIATIVOS NA ATENÇÃO DOMICILIAR}


Artigo elaborado para submissão ao periódico - Acta Bioethica (apêndice 7)

Dos 33 cuidadores entrevistados, 6 não tem parentesco algum com o paciente que cuidam. Para fins de avaliação dos aspectos bioéticos envolvidos na relação intrafamiliar, estes foram excluídos nesta análise.

Com base nos relatos dos cuidadores sobre o processo do cuidar, foi possível elencar alguns aspectos bioéticos relacionados, que foram categorizados da seguinte forma: 'Autonomia nas escolhas da sua vida'; 'Vulnerabilidade ao estresse e sobrecarga' e Vulnerabilidade a problemas de saúde físicos e psicológicos, conforme quadro abaixo.

Transformar-se em cuidador principal envolve questões de ordem pessoal, social e psicológica. O fato de ter de assumir a função sem preparo prévio e, muitas vezes sem esperar, influencia diretamente na autonomia de suas vidas. O quadro 8 apresenta relatos associados à autonomia do cuidador.

Quadro 8 - Relatos das verbalizações dos cuidadores principais familiares associadas à autonomia e relacionadas ao cuidar.

\begin{tabular}{|c|c|c|}
\hline \multirow{5}{*}{$\begin{array}{l}\text { Autonomia nas } \\
\text { escolhas da } \\
\text { vida }\end{array}$} & $\begin{array}{l}\text { Perdendo o controle do } \\
\text { tempo }\end{array}$ & $\begin{array}{l}\text { "Pôxa vida! Tenho } 30 \text { anos e a minha vida tá parada... minha } \\
\text { vida é tão programada que eu tenho que pensar antes de sair... eu } \\
\text { não posso... Parei de estudar, de trabalhar... acho que até parei } \\
\text { de viver...namorar...quando?"(E5) }\end{array}$ \\
\hline & $\begin{array}{l}\text { As incertezas do } \\
\text { amanhã e o } \\
\text { desencontro com os } \\
\text { projetos pessoais }\end{array}$ & $\begin{array}{l}\text { “Eu abri mão da faculdade, né? Eu me privei de muita coisa para } \\
\text { cuidar do meu filho. Só eu cuido dele, não tem outra pessoa." } \\
\text { (E2) }\end{array}$ \\
\hline & Empatia/alteridade & $\begin{array}{l}\text { "Ás vezes eu penso: Como será que seria se fosse eu no lugar } \\
\text { dele?" (E8) }\end{array}$ \\
\hline & $\begin{array}{l}\text { Cobrança } \\
\text { interna/expectativa de } \\
\text { si como cuidadores }\end{array}$ & $\begin{array}{l}\text { “Será que eu estou cuidando bem dele? Será que ele tem tudo o } \\
\text { que merece?” (E7) } \\
\text { “Não foi uma profissão que eu escolhi. Na verdade eu nunca ia } \\
\text { escolher isso pra mim. Eu queria ser secretária...Por isso acho } \\
\text { que não sou a melhor pessoa pra cuidar dela."(E6) }\end{array}$ \\
\hline & $\begin{array}{l}\text { Desencontro com o } \\
\text { reconhecimento } \\
\text { esperado e o recebido }\end{array}$ & $\begin{array}{l}\text { “Eu faço tudo pra ele ter uma vida melhor. Só que os outros } \\
\text { (familiares) ainda acham que é pouco. Reclamam, falam que ele } \\
\text { tá magro, que parece que não tá bem... O que querem que eu } \\
\text { faça? Ele tá doente, não tá bem mesmo. Isso cansa mais do que }\end{array}$ \\
\hline
\end{tabular}




\begin{tabular}{|l|l|l|}
\hline Liberdade de escolha & $\begin{array}{l}\text { cuidar dele, sabia?" (E11) } \\
\text { "A gente não tem mais a liberdade de ir e vir. Eu to presa aqui } \\
\text { em casa. Não quero reclamar, parecer chata, mas é isso aí } \\
\text { mesmo." (E9) } \\
\text { "Queria poder escolher o que fazer e como. Mas não dá, não tem } \\
\text { quem ajuda. Os que podem já ajudam, mas é pouco. Cada um tem } \\
\text { a sua vida, né? E eu tenho essa vida agora (pausa e suspiro).” } \\
\text { (E14) } \\
\text { "Se eu tivesse dinheiro eu pagava águem para cuidar dela." (E7) }\end{array}$ \\
\hline
\end{tabular}

A convivência com o sofrimento alheio de outra pessoa pode resultar em sobrecarga, sendo, em muitas vezes, necessário disfarçar os próprios sentimentos para preservar o outro. O cuidado pode resultar em pressão e estresse e, consequentemente em uma sobrecarga física e emocional do cuidador. O quadro 9 apresenta relatos que exemplificam a situação de vulnerabilidade do cuidador.

Quadro 9 - Relatos das verbalizações dos cuidadores principais familiares associadas à vulnerabilidade ao estresse e à sobrecarga.

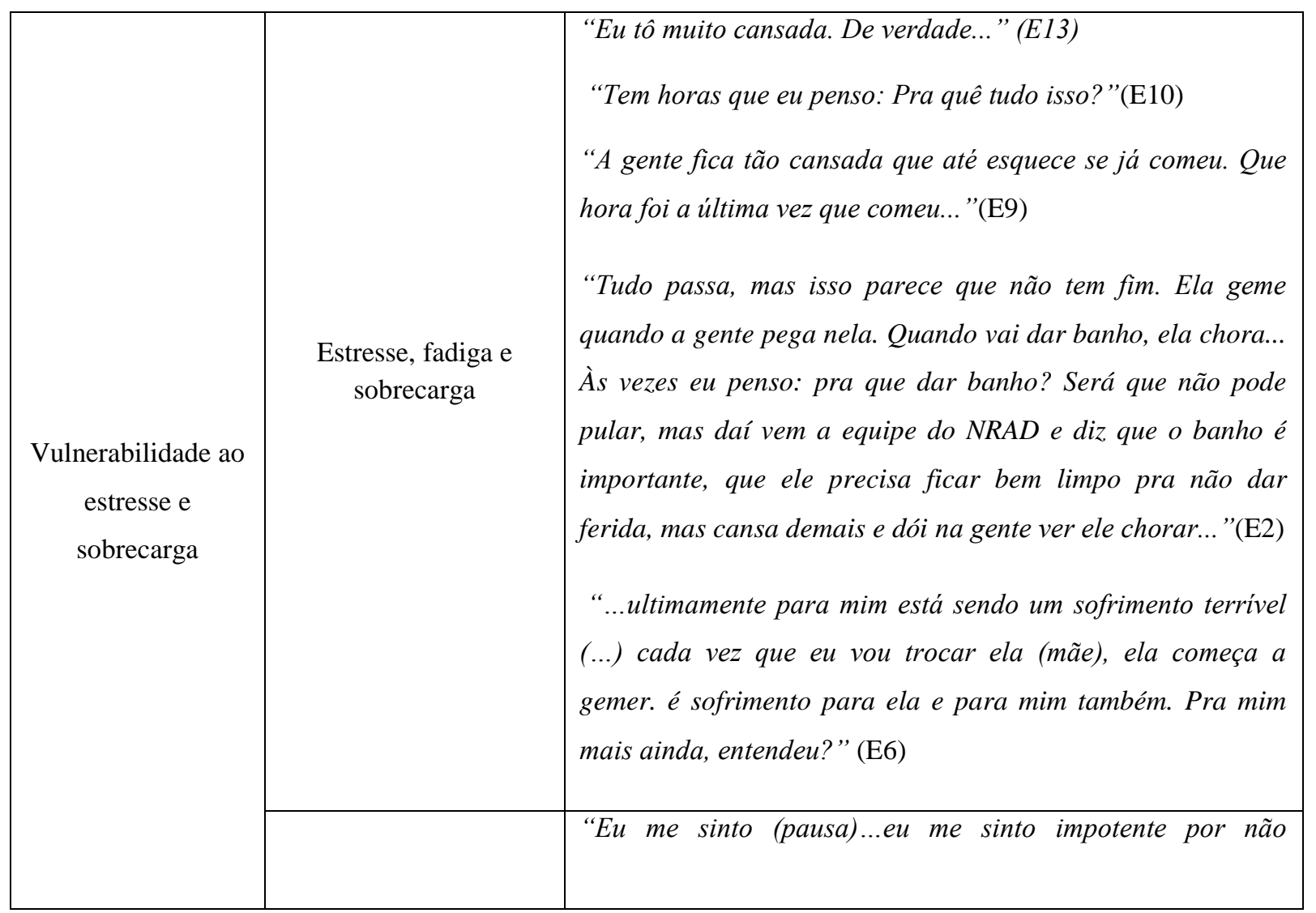




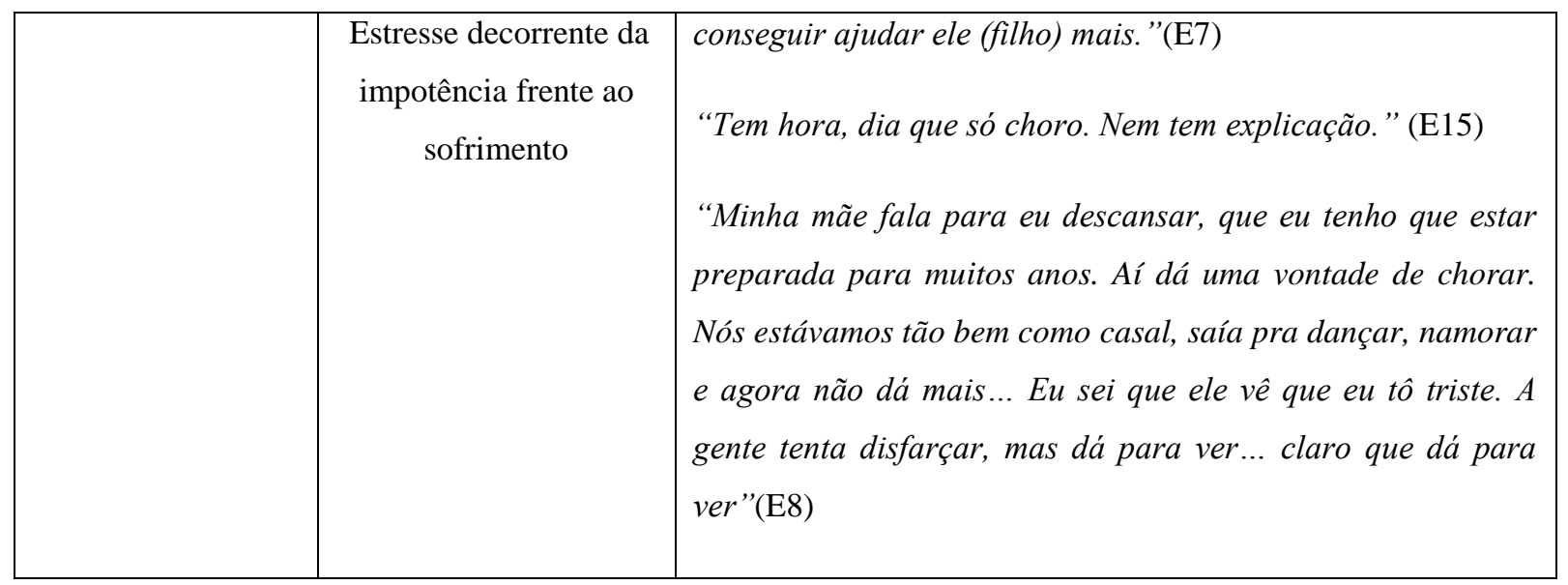

O trabalho contínuo, sem intervalos de descanso regulares, carregar o paciente para a cadeira de rodas ou para mudar de decúbito no leito são situações que causam dores e lesões, podendo acarretar em desgaste físico e emocional. O quadro 10 apresenta relatos que evidenciam a vulnerabilidade do cuidador frente ao estresse e à sobrecarga.

Quadro 10 - Relatos das verbalizações dos cuidadores principais familiares associadas à vulnerabilidade ao estresse e à sobrecarga.

\begin{tabular}{|c|c|c|}
\hline & Desgaste físico & $\begin{array}{l}\text { "Eu acho que perdi o meu equilibrio, mental e físico... } \\
\text { Tem dias que fico bem tontinha!”(E10) } \\
\text { "Ele (pai) é pesado e a gente precisa mudar de lado toda } \\
\text { hora pra não dar ferida. Muitas vezes eu fazia sozinha... } \\
\text { Agora não consigo fazer mais. Machuquei as costas.”(E3) }\end{array}$ \\
\hline $\begin{array}{l}\text { Vulnerabilidade } \\
\text { frente aos problemas } \\
\text { de saúde físicos e } \\
\text { psicológicos }\end{array}$ & $\begin{array}{l}\text { Desgaste } \\
\text { emocional/psicológico }\end{array}$ & $\begin{array}{l}\text { “Ele me xinga toda hora. Fala pra eu sair, fazer festa. } \\
\text { Que era tudo o que eu queria, que ele ficasse numa cama } \\
\text { pra eu poder ficar solteira novamente." (E10) } \\
\text { “Isso dói. Diz que ele tá assim porque a culpa é minha... } \\
\text { E ninguém mais quer cuidar dele. Então só tem eu, ele é } \\
\text { meu marido e eu tenho que aceitar...”(E31) } \\
\text { “Ele (pai) é muito teimoso mesmo... Toda hora ele } \\
\text { arranca o curativo, a gente coloca e ele tira. É } \\
\text { difícil...”(E7) }\end{array}$ \\
\hline
\end{tabular}


6. DISCUSSÃO 


\section{DISCUSSÃ̃}

Neste capítulo são discutidos os resultados do estudo com base na literatura utilizando a percepção sobre a qualidade de vida e a sobrecarga do cuidador como variáveis dependentes e as demais como variáveis independentes.

Os resultados encontrados viabilizaram a correlação entre dados sociodemográficos dos cuidadores com a percepção da qualidade de vida em todos os domínios e da sobrecarga, além da influência da doença, da proximidade da morte e do cuidar frente aos sentimentos vivenciados, à qualidade de vida e às mudanças percebidas em suas vidas. Além disso, foi possível associar os aspectos bioéticos envolvidos no processo do cuidar em domicílio.

\subsection{PERFIL SOCIODEMOGRÁFICO E CLÍNICO DOS DOENTES CUIDADOS}

Ao analisar o perfil dos doentes foi possível comparar os resultados encontrados com outros estudos realizados com cuidadores e com pacientes atendidos em domicílio de forma geral, sendo que a predominância é de enfermos do sexo feminino e idosos, apesar do programa atender a pacientes de todas as idades, sem distinção, pois a idade não interfere no processo de adesão ao programa, por esse não ser um critério de seleção. ${ }^{12,113-115}$

Este dado reflete a aproximação do envelhecimento com as doenças crônicodegenerativas mais comumente associadas ao perfil do acompanhamento domiciliar. As patologias recorrentes neste estudo são: acidente vascular cerebral (AVC), neoplasias e doença de Alzheimer (DA), o que corrobora com diversos estudos sobre internação domiciliar no Brasil e no mundo. ${ }^{113-118}$

\subsection{PERFIL SOCIODEMOGRÁFICO E CLÍNICO DOS CUIDADORES DOMICILIARES FRENTE À PERCEPÇÃO DA QUALIDADE DE VIDA}

A qualidade de vida, entendida neste estudo como o construto baseado na percepção do cuidador sobre aspectos subjetivos e objetivos, incluindo questões imensuráveis como felicidade, prazer e angústia, é tema discutido por vários pesquisadores. ${ }^{119-123}$

Os dados revelam que há variância nos resultados entre os cuidadores, sendo que a autopercepção da qualidade de vida sofre influência de diversas variáveis como idade, sexo, relação de parentesco com o paciente, apoio social recebido e outros. 
Quatro condições são avaliadas comumente pelas famílias dos pacientes para a escolha do cuidador principal: o grau de parentesco, o gênero, a proximidade física e a proximidade afetiva. $^{124-125}$

Neste estudo, os cuidadores têm, em média, 46 anos variando entre 20 e 73 anos. O IGQV teve um escore maior em 7,99 pontos em cuidadores com mais de 60 anos de idade quando comparado com cuidadores com menos de 30 anos. No domínio psicológico há correlação positiva entre a idade do cuidador e a percepção de qualidade de vida, que pode ser explicado devido à atividade de cuidador gerar estresse e sobrecarga emocional, além da privação do convívio social e atividades diversas e, inversamente, quanto mais idade tiver o cuidador, mais experiência de vida e capacidade de resiliência e de aceitação dos fatos ele terá, além do idoso apresentar, em sua maioria, uma agenda social diminuída. ${ }^{113,115-116,124-125}$

Foi encontrada uma fraca correlação positiva entre a idade do cuidador e a percepção da sua sobrecarga.

Como aguardado, houve predomínio de mulheres, sendo a maioria dos cuidadores composta por familiares, principalmente filhas ou esposas. Essas características são frequentemente encontradas em estudos, seja no âmbito nacional ou internacional. ${ }^{123-128}$

Está culturalmente implícito na sociedade que cabe aos filhos e aos cônjuges cuidar dos adoentados que necessitam de cuidados especiais e contínuos. Esses achados reforçam o papel social da mulher, historicamente determinado, de cuidadora principal e da mesma forma que o cuidado a pessoas dependentes fique na responsabilidade de parente próximo, pertencente ao núcleo familiar, como encontrado em outros estudos. ${ }^{62,124-128}$

Em algumas famílias, o cuidado é desenvolvido e aceito em forma de retribuição, principalmente quando se trata de filhas(os) cuidando de genitores. Estudo aponta que as filhas, em geral, sentem necessidade de demonstrar a gratidão pelo cuidado recebido e, desta forma, desenvolvem maior aceitação pelo papel que lhes cabe. ${ }^{125}$

É importante destacar que o modelo familiar baseado na divisão sexual do trabalho, onde o homem é o responsável pelo sustento, ou seja, é o provedor e a mulher é a responsável pelas tarefas diárias e assistenciais da casa ainda prevalece não só na sociedade brasileira, mas em todo o mundo, visto a similaridade nas características sociodemográficas de diversos estudos internacionais. Este perfil tende a mudar, pois a mulher está cada vez mais presente no mercado de trabalho e representa mudanças na estrutura e na organização familiar. ${ }^{128-130}$

Nesse caso, cabe avaliar quais competências são exigidas para a função de cuidador. Segundo Le Boterf ${ }^{129}$, competência se refere à disposição para uma ação pertinente frente a 
uma situação específica. Outros autores definem competência humana como um conjunto que envolve conhecimento, habilidade e atitude. ${ }^{130-131}$

O cuidador social que pode ser o familiar ou pessoa próxima que aceita cuidar, necessita de preparo específico para desenvolver a função. Este preparo envolve além das competências, o acompanhamento do cuidador por profissional de saúde para o suporte emocional, pois cuidar de alguém de forma contínua requer, por parte de quem oferece o cuidado, condições físicas e emocionais, além de motivação e disponibilidade. ${ }^{132-133}$

O modelo de cuidado informal aos pacientes providenciado pelo núcleo familiar afeta diretamente as mulheres de maneira perversa, pois compromete negativamente o seu bem estar e o desenvolvimento profissional, resultando em sobrecarga. ${ }^{116}$ Essa sobrecarga, mesmo que percebida pelo cuidador, raramente é discutida, aceita e entendida pela família que entende o cuidado como uma questão naturalmente imposta e não sujeita à escolha. ${ }^{134-137}$

Não há diferenças significativas na percepção da qualidade de vida entre cuidadores que referiram situação conjugal estável e os que referiram não possuir companheiro(a) no momento da entrevista. Porém, no tocante ao grau de parentesco com o paciente os dados diferem significativamente, sendo que os cuidadores que relataram não ter grau de parentesco apresentaram escores mais positivos, como 13,89 pontos a mais no domínio relações sociais e 8,26 pontos a mais no domínio psicológico.

Todos os cuidadores entrevistados referiram ter alguma religião, mesmo alguns terem relatado não serem praticantes assíduos devido à falta de tempo e de oportunidade para frequentar os espaços destinados às orações coletivas. $\mathrm{O}$ fato de assumirem ter religião e seguir os preceitos fundamentais revela a existência da espiritualidade e da crença em algo transcendente. ${ }^{137}$ Este dado corrobora com outro estudo que observou correlação negativa entre a percepção individual de bem estar e a sobrecarga do cuidador, sendo que cuidadores que utilizavam a religião e a crença espiritual como estratégias de enfrentamento possuíam melhor relação com a pessoa cuidada e menor grau de depressão. Em outro estudo, realizado com cuidadoras familiares de pacientes com demência o resultado foi de maior sobrecarga entre as que relataram ter religião. ${ }^{138}$

Neste estudo, foi possível identificar diferença no IGQV entre evangélicos ou espíritas e católicos na avaliação da qualidade de vida, sendo que o índice foi percebido no primeiro grupo com 7,94 pontos a mais do que no segundo e esta diferença se acentua no domínio 'relações sociais', com 12,22 pontos de diferença.

O grau de instrução formal referido pelos entrevistados com predominância do ensino fundamental completo corresponde à média encontrada em outros estudos semelhantes, 
porém, cabe ressaltar que $18 \%$ dos cuidadores iniciaram ou concluíram algum curso superior, sendo esta amostra composta por filhas dos doentes. ${ }^{119,128,135,139}$

Os dados revelam que os cuidadores que possuem o ensino fundamental completo apresentaram IGQV mais elevado e, no domínio psicológico, os cuidadores sem instrução formal tiveram o escore maior. Este resultado reforça a questão da oportunidade de trabalho que a escolaridade proporciona, pois sem instrução, as chances de desenvolver outra função diminuem, reduzindo desta forma, a frustração que a situação poderia propiciar. No mesmo sentido, estudos apontam que o grau de instrução influencia na escolha do cuidador familiar por estar relacionado ao fato da inserção no mercado de trabalho formal ser mais difícil quanto menor o grau e, por isso, a pessoa tem mais facilidade para abrir mão de outra função desempenhada até o momento. ${ }^{140-142}$

As condições econômicas dos cuidadores estão diretamente relacionadas ao escore de qualidade de vida nos domínios relações sociais e do meio ambiente, pois quanto maior a renda, maiores as médias obtidas. Neste estudo, os cuidadores que apresentaram renda familiar superior a 3 salários mínimos obtiveram média de escore de 62,50 e 55,47 nos dois domínios, respectivamente.

Importante ressaltar que muitas vezes, ocorre a necessidade do cuidador parar de trabalhar ou se ausentar do emprego formal, o que gera a diminuição da renda familiar. Neste estudo, 57,6\% dos entrevistados se afastaram do trabalho formal e, consequentemente, não estão resguardados os seus direitos trabalhistas como a aposentadoria por tempo de serviço. $143-144$

Outro dado importante a ser analisado diz respeito à percepção do apoio social recebido pelo cuidador, pois $36,4 \%$ referiram não receber nenhum tipo de ajuda. Dos que referiram de forma positiva, $85,7 \%$ informaram que o receberam de familiares próximos. $\mathrm{O}$ apoio pode ser recebido de forma indireta de amigos como em momentos de distração ou de lazer e não só dividindo tarefas diretamente ligadas ao cuidado para com o paciente. ${ }^{\text {143-147 }}$

Estudo indica que pessoas que possuem um alto nível de apoio social apresentam adequada autoestima, autoconfiança e apresentam maior capacidade para enfrentar situações adversas. Da mesma forma, estudos confirmam a correlação positiva entre a percepção positiva da sua saúde e bem estar e a presença de apoio social das pessoas. ${ }^{146,148-149}$

Cuidar de outra pessoa, principalmente quando em tempo integral, como é o caso de $75,7 \%$ dos entrevistados, expõe o cuidador principal de forma prolongada aos diversos estressores presentes na situação, pois exige dedicação, disponibilidade de tempo e, em muitos casos, desprendimento de força física, devido à necessidade de movimentar o paciente 
acamado. Esse cuidador, quando não recebe o apoio da família ou de amigos, pode, em consequência do desgaste, adoecer física ou mentalmente. ${ }^{137,140-141,145-148}$

Neste contexto, 63,6\% dos entrevistados relataram apresentar um ou mais problemas de saúde e o uso de medicamentos de forma contínua. As patologias mais referidas estão relacionadas ao sistema cardiovascular e endócrino e às doenças autoimunes ou psiquiátricas. Estudos distintos trazem resultados similares sobre o adoecimento do cuidador. Vários fatores estão associados a este resultado: a idade média do cuidador, o tempo de dedicação diário, a percepção do apoio recebido, a necessidade de alteração da rotina, dentre outros. ${ }^{150,151-154}$

Os dados possibilitaram observar a correlação fraca negativa entre a presença de morbidades e a percepção da QV, sendo que os cuidadores que referiram não possuir morbidades e se declararam saudáveis apresentaram 6,85 pontos a mais na média do índice de qualidade de vida geral do que os demais. Essa diferença se acentuou no domínio meio ambiente, chegando a 10,7 pontos a mais. ${ }^{155}$

A presença de dor foi autorreferida por $75,7 \%$ dos cuidadores entrevistados e a correlação entre a percepção da QV e de dor como moderada ou grave se apresenta de forma negativa, sendo que, quanto mais acentuada a dor referida, menor é o escore de qualidade de vida nos domínios físico e psicológico. As dores nas costas/coluna e na cabeça foram as mais citadas e estão diretamente relacionadas ao desgaste físico e mental devido ao desenvolvimento das tarefas do cuidado ao paciente e à preocupação com a doença e o bem estar do familiar. Esses dados corroboram com outros estudos realizados. ${ }^{156-157}$

É importante que o cuidador seja visto pela equipe de atenção domiciliar como um aliado para a expansão do cuidado na residência do paciente e que seja ofertado apoio ao mesmo para o desenvolvimento das atividades, além de suporte emocional, quando necessário. ${ }^{158-159}$ Pois o cuidado de forma integral somente se desenvolve quando a outra pessoa é considerada como alguém importante para o cuidador, para que esse se disponha a participar do seu destino, do sofrimento, dos sucessos e, por que não dizer, da sua vida. Essa dedicação e envolvimento pessoal com o paciente podem gerar inquietações, preocupações e responsabilidades por parte do cuidador. ${ }^{157}$

O cuidado pode ser visto como uma forma de expressão que envolve postura ética e compromisso de contribuição ao bem estar e preservação da dignidade humana. Para tal, os cuidadores devem estar intencionados espiritualmente ao ato de cuidar, para que possam contribuir com a história e com a vida. ${ }^{156}$

O autocuidado negligenciado, identificado nas falas dos cuidadores entrevistados está de acordo com outros estudos que mostram que, muitas vezes, o familiar encarregado de 
cuidar de outro dedica boa parte do tempo diário aos cuidados que acaba abrindo mão da sua própria vida social, inclusive de momentos de lazer. Porém, McCoughlan ${ }^{157}$ ressalta que para que o cuidador possa usufruir das questões positivas do ato de cuidar, deve cuidar de si mesmo, tanto de forma física quanto emocional.

Não obstante pesquisadores terem aumentado os estudos sobre o sono nos últimas décadas, ainda não há uma definição clara sobre a função deste fenômeno. Porém, pode-se definir o sono como um estado neurológico complexo e restaurador, necessário ao funcionamento do organismo. ${ }^{158}$ Neste estudo, 54,5\% dos cuidadores relataram ter seis ou mais horas de sono por dia. A variável do sono interfere diretamente na qualidade de vida do cuidador, sendo que os dados deste estudo indicam que quanto maior o número de horas de sono, maior o escore de qualidade de vida no domínio psicológico. O sono é necessário para o descanso e o preparo da nova jornada de trabalho diário e está relacionado também à presença de morbidades e ao uso de analgésicos e de medicamentos ansiolíticos. ${ }^{119,158-162}$

O uso de medicamentos de forma contínua, principalmente de analgésicos e psicoterápicos apresenta uma correlação positiva no escore de qualidade de vida, ou seja, o uso destas substâncias traz resultado satisfatório para o controle da dor e da ansiedade, acarretando em melhor percepção da qualidade de vida, principalmente nos domínios físico e psicológico. Dado contrário foi encontrado em estudo realizado com cuidadores de idosos, em 2008, em que, quanto maior o número de medicamentos utilizados, menor a percepção de qualidade de vida no domínio físico. ${ }^{161}$

Os cuidadores que relataram prática da atividade sexual ativa $(45,4 \%)$ apresentam escore mais elevado no domínio 'relações sociais'. Destes, 46,6\% são filhas(os), 26,6\% são mães, 6,06\% são irmãs(aos) e 20\% são cuidadores contratados formalmente pela família do doente. Este dado revela que os(as) cuidadores(as) que são esposas(os) dos pacientes relataram não ter vida sexual ativa. Isso reforça o dado encontrado na literatura de que o impacto negativo do convívio com doença crônica se expressa mais na esposa. ${ }^{137}$

Cabe ressaltar que o cuidador familiar, em geral, apresenta um envolvimento próximo com o paciente, que faz com que sejam aflorados sentimentos frente ao sofrimento pela doença e/ou pela aproximação da finitude humana. Neste estudo, os cuidadores familiares apresentaram média de escore de IGQV com 4,81 pontos a mais do que os cuidadores que não possuem grau de parentesco com o paciente. No dominio relações sociais a diferença foi ainda maior, de 13,89 pontos.

Neste estudo, tempo de exercício da função de cuidador foi bastante diferenciado entre os cuidadores, sendo desde 3 meses a 40 anos, com média de 7,2 anos. Houve, no entanto, 
fraca correlação positiva entre o tempo de exercício da função de cuidador e a sua percepção de qualidade de vida geral. A correlação é fortalecida na percepção sobre o domínio físico da qualidade de vida. ${ }^{118,162}$

O tempo, em anos, em que uma pessoa se dedica a cuidar de outra influencia a sua percepção sobre QV geral, sendo que os cuidadores que estão desempenhando a função há menos de 2 ou há mais de 10 anos apresentam índice inferior aos que cuidam entre 2 e 10 anos. Ou seja, logo no início do processo de cuidar há um desgaste acentuado, principalmente no domínio relações sociais, em virtude do afastamento social e das perdas sofridas. Ao longo dos anos nesta função, o desgaste se acentua no dominio físico, devido à necessidade de apoio à mobilidade do paciente acamado. ${ }^{162}$

\subsection{PERCEPÇÃO DA SOBRECARGA DOS CUIDADORES DOMICILIARES}

Os dados gerais indicam que 52\% dos cuidadores deste estudo apresentaram sobrecarga intensa e $33 \%$ sobrecarga ligeira, sendo que apenas $15 \%$ não apresentaram sobrecarga. Ao analisar o perfil dos cuidadores com sobrecarga intensa, percebe-se que se tratam de cuidadores familiares que residem na mesma casa, junto ao doente $(85,7 \%)$, tem menos de 8 horas de sono por dia $(78,6 \%)$ e 57,1\% referem não receber apoio social.

Outro dado, relacionado diretamente à sobrecarga do cuidador, diz respeito ao grau de dependência do doente, sendo que $75 \%$ dos entrevistados relataram sentir sempre ou frequentemente ser a única pessoa com o qual o paciente pode contar e todos eles apresentaram sobrecarga ligeira ou intensa. Este sentimento sobrecarrega o cuidador devido à sensação de obrigação de atender todas as necessidades do doente e em não se afastar do mesmo por períodos prolongados, afetando, portanto, seus momentos de lazer e de descanso. Estudos realizados para avaliar a relação entre a dependência dos pacientes e a sobrecarga dos

cuidadores também concluíram que estes dados estão diretamente relacionados. ${ }^{165-166}$

Não obstante $93 \%$ dos cuidadores entrevistados terem sinalizado não se sentir envergonhados diante do comportamento do doente e $87 \%$ terem informado não ficar irritados com a presença do mesmo, 39\% responderam que sentem frequentemente ou sempre que perderam o controle sobre a sua vida desde que começaram a cuidar do paciente. Este dado representa que a dependência do paciente sobrecarrega o cuidador e corrobora com estudos que indicam que os cuidadores, em muitos casos, são podados de sua privacidade e da possibilidade de viver a própria vida. ${ }^{140,165}$ 
Essa privação tem destaque no inicio do processo, no período de adaptação entre o doente, o cuidador e a família. Porém, nesse período a maioria dos cuidadores relatou receber visitas de familiares e de amigos, sendo que o isolamento social é mais percebido após os dois primeiros anos. Neste estudo, a sobrecarga intensa foi percebida por $42,4 \%$ cuidadores, sendo que, destes, 71,4\% exercem a função entre 2 e 10 anos. Estudo identificou correlação positiva entre o tempo de exercício da função e a sobrecarga do cuidador, ou seja, quanto maior o tempo, maior a sobrecarga. ${ }^{164}$ No entanto, esta correlação é muito controversa, pois envolve diversas questões subjetivas e objetivas.

\subsection{PERCEPÇÃO DO SIGNIFICADO DA DOENÇA E DA FINITUDE HUMANA FRENTE À QUALIDADE DE VIDA DOS CUIDADORES DOMICILIARES}

A convivência diária com a doença e com o sofrimento do outro, além do sentimento de responsabilidade pelo cuidado prestado e pelo bem estar do doente, pode resultar em um processo reflexivo sobre o sentido da vida.

Compreender a doença e aceitar as limitações que ela impõe, incluindo o fim da vida, muitas vezes, é o caminho para poder oferecer o cuidado com abrandamento do pesar e sofrimento por parte do cuidador. E, desta forma, (re) construir um sentido ao interpretar a situação vivenciada, que pode ser entendida como uma oportunidade (ressignificação) ou como um infortúnio (não ressignificação). Reconhecer sua própria limitação fortalece o cuidador para o desenvolvimento da sua função com menor sofrimento. ${ }^{15,167}$

Ao definir doença como um caminho que não precisa ser necessariamente avaliado como positivo ou negativo, mas, simplesmente, percorrido, estudo suscita a discussão sobre a transformação do paciente e da família nesse processo que, em muitos casos, pode ser longo. 168

A consciência da mortalidade ou da finitude humana é intensificada entre os doentes ou familiares que enfrentam a possibilidade da morte iminente frente à doença instalada resultando numa consequente ressignificação para a vida. ${ }^{94}$

A doença, quando vista pelos cuidadores de forma positiva, como um processo naturalmente aceito como parte do envelhecimento ou como consequência da própria vida, traz conforto e resiliência quanto ao tratamento e às mudanças impostas em suas vidas.

O "enfrentamento", também definido como "coping”, "adaptação", "lidar com" é entendido como um termo complexo que se refere a uma série de ideias abstratas, compreendendo um conjunto de estratégias empregadas pelas pessoas para lidar com 
situações adversas em forma de adaptação. Pesquisadores afirmam que a influência da religião e da espiritualidade na vida das pessoas é considerada como importante fonte de fortalecimento para o enfrentamento de doenças e no cuidado a saúde. ${ }^{139,165}$

Estudos demonstram o caráter disruptivo da doença crônica na dinâmica familiar, principalmente no caso de crianças. Neste estudo, também foi possível perceber que a percepção sobre os efeitos da doença na dinâmica familiar foram mais evidenciados nos cuidadores familiares de crianças doentes ou que desenvolveram as doenças ainda na infância. $50,66,90$

No contexto deste estudo, alguns cuidadores se referiram à doença como um processo necessário de reflexão, como um "tempo para pedir perdão" (E13), para "um resgate” (E18), ou ainda, "para gente purificar nossa alma" (E16). Com base nestes relatos é possível perceber a utilização do enfrentamento com espiritualidade e/ou religiosidade. Os modos de enfrentamento refletem comportamentos utilizados para lidar com um estressor e classificam de acordo com a estratégia utilizada, como confronto, autocontrole, afastamento, aceitação das responsabilidades, fuga ou com a função, que pode ser focado no problema ou focado na emoção. ${ }^{169}$

Para alguns cuidadores, porém, a doença é vista como "um castigo" (E11), "um sofrimento" (E1), "um terror" (E13). Nestes casos, o cuidador entende a doença como algo ruim, que não tem um propósito, dificultando a aceitação da doença e do processo, pelo qual passam juntos: o doente, o cuidador e a familia. O cuidado propiciado em domicilio com fins paliativos proporciona, além do alivio da dor, apoio psicológico e espiritual para o doente e para a família frente ao sofrimento decorrente da doença. ${ }^{103}$

A morte ou a iminência da morte em virtude do processo do adoecer, traz sentimentos distintos entre os cuidadores entrevistados. Alguns veem a morte simplesmente como algo inevitável, porém negativo: "só o fim" (E27), "não é bom" (E28), "é ruim" (E6). Principalmente por desconhecer o que há após a mesma. Como no relato da cuidadora: “ $O$ ruim que eu acho da morte é que ninguém sabe como é morrer" (E21).

Outros veem a morte como uma possibilidade de descanso do paciente que sofre com a doença: “... É a paz” (E19), “... A morte é deixar o sofrimento” (E17), “Morrer pode ser descansar, né?” (E6) “... Nem vou ficar muito triste quando ele morrer, porque ele vai deixar de sofrer" (E3). E ainda é vista como uma oportunidade de recomeçar: "A morte talvez seja o fim do sofrimento aqui e começo de um novo aprendizado do outro lado" (E18).

Morrer em casa, ainda que muitas pessoas assim o desejem, é tarefa difícil de ser cumprida, pois muitos familiares ainda escolhem levar o paciente até o hospital quando o fim 
da vida se aproxima. Atitude essa entendida como de proteção, por medo de enfrentar o momento sozinho, ou ainda pelo sentimento de impotência frente à situação, considerada estressante por gerar ansiedade. ${ }^{103}$

\subsection{PERCEPÇÃO DOS SENTIMENTOS VIVENCIADOS NO CUIDADO E FRENTE AO SOFRIMENTO DO DOENTE}

Entre os sentimentos referidos pelos cuidadores como os vivenciados durante o processo de cuidar, alguns se destacam por estarem diretamente associados às estratégias de enfrentamento utilizadas como a 'esperança' de que o paciente tenha um revigoramento, principalmente no sentido espiritual: "Tenho esperança de ela ter uma vida melhor... Ela conversa, é mais tranquila agora do que era antes. Acho que ela é uma pessoa melhor agora” (E9). É preocupante, porém, em alguns casos, quando o cuidador não aceita a condição de terminalidade do paciente e usa a esperança de cura como o único desfecho possível. $^{103}$

Neste estudo, fica claro esta condição no relato de um cuidador: "Eu tenho esperança que ela vai melhorar e eu digo pra ela: tu vai andar, vai sair dessa cama, acredita em mim. Ela sorri com o olhar quando digo isso"(E32). Essa paciente tem um diagnóstico de doença degenerativa e em fase terminal. Pelos relatos do cuidador ele está ciente desta condição, porém, não a aceita e diz que tem fé na cura. Outro relato deixa clara a esperança de cura: "Deus nunca abandona os seus. Ela é muito nova ainda e ELE não vai levar... agora não. Por isso, faço de tudo pra cuidar bem dela" (E7). Como no estudo de Euzébio e Rabinovich $^{126}$, alguns cuidadores acreditavam na condição de cura e atribuíam-na a Deus e ao esforço do paciente.

Da mesma forma, sentimentos aflorados, principalmente quando se trata de cuidador familiar, são de admiração e orgulho com relação ao paciente, que remetem ao autocontrole e a aceitação: "Admiro muito ela por ser tão forte, determinada" (E21) e "Me sinto muito orgulhosa de ter uma mãe assim, guerreira. Ela nunca desiste!’(E14).

Outros sentimentos vivenciados pelos cuidadores remetem à angústia pelo sofrimento do paciente sob sua responsabilidade sem conseguir entender o que ele está sentindo: “ $A$ minha angústia é tentar interpretar o que ele está sentindo naquele momento” (E12) ou por dificuldades em sanar necessidades como alívio da dor: "Olha, eu sinto muita angustia né? Eu quero aliviar a dor, fazer o que eu puder pra aliviar a dor, ou pra aliviar o problema ou pra tirar. Entendeu?" (E3). 
Diante da situação, a impotência foi um dos sentimentos relatados por alguns dos cuidadores, em função da dificuldade em resolver problemas. Se sentem "de mãos atadas" (E17). Além da tristeza por presenciar e vivenciar o sofrimento do paciente: "Então são coisas assim muito, eu sofro junto com ela, me acabo junto com ela” (E5). Essa tristeza, em alguns casos, é coletiva e vivenciada por toda a família que acompanha o doente no domicilio, geralmente associada ao passado e às características do doente como uma pessoa ativa e alegre, mas que agora sofre com a doença e alterando significativamente a dinâmica familiar. Este sofrimento pode ser acentuado quando o paciente se trata de criança. ${ }^{164,170}$

Os sentimentos experienciados pelos cuidadores neste estudo são ambíguos, pois revelam a satisfação por propiciar o cuidado e o bem estar do paciente como um dever cumprido até o desgaste físico e mental pela quantidade de ações exclusivas que dependem de tempo e dedicação. ${ }^{171}$ A compreensão dos inúmeros sentimentos contraditórios que podem aparecer juntos e que permeiam o cuidar é fundamental para o processo de ressignificação da vida do cuidador ${ }^{95}$

Não obstante vários cuidadores neste estudo terem relatado desgaste devido às mudanças na vida em torno do cuidado, os sentimentos positivos associados permitem aos mesmos o controle da situação ou a ausência da sobrecarga intensa.

\subsection{PERCEPÇÃO DAS MUDANÇAS OCORRIDAS APÓS O INÍCIO DA FUNÇÃO DE CUIDADOR E DA INFLUÊNCIA DAS MESMAS NA SUA QUALIDADE DE VIDA}

Os cuidadores relataram mudanças ocorridas em suas vidas, que foram categorizadas neste estudo como de ordem social e espiritual.

De ordem social, as mudanças mais encontradas estão relacionadas à dedicação ao doente, que, muitas vezes, exige tempo integral, sem espaço para a vida privada do cuidador. Um dos relatos explicita bem essa questão: "É assim que a gente vive aqui em casa: de manhã é ela, à tarde ela, à noite ela” (E15). Neste caso, não só o cuidador alterou a sua vida, mas o restante da familia também. Outro relato exemplifica a mesma questão: "Passo 24 horas com ela. A minha vida é ela" (E21). Estudo desenvolvido por Pontes-Fernandes e Petean ${ }^{171}$ com mães de crianças com erros inatos do metabolismo revelou que um dos principais motivos que levam à sobrecarga da mãe é a falta de tempo para si.

Outra mudança de ordem social vivenciada está relacionada ao afastamento social. Um dos cuidadores desabafou: "Ixi, mudou... se existir 1000\% mudou 1000\%, porque eи não tenho mais projeto de vida. Mudou tudo. Eu não posso mais sair pra trabalhar, eu não posso 
mais ganhar meu dinheiro, não posso mais planejar de ir numa festa...” (E18). Neste caso, fica evidente o desgaste devido ao isolamento e às mudanças sofridas.

O cuidador principal permanece a maior parte do tempo só com o doente, que, em muitos casos, não deambula e não se comunica verbalmente. Uma das cuidadoras contou um episódio ocorrido há poucos dias com uma pessoa conhecida na igreja que ela frequentava: "Acho que as pessoas têm preconceito com gente doente. Aí mistura tudo, ninguém nem liga mais pra saber como a gente tá. Uma vez, uma mulher lá da igreja me disse: ( - Quando ele morrer, você volta para igreja... você faz falta lá). Quase que eu disse que nunca mais ia voltar lá. Que isso era cruel, mas não disse nada. Só fiquei olhando pra ela. Parecia que o meu marido era um estorvo pra igreja. Em vez de ela dizer que ia me visitar e ver como eu estava ela disse pra eu voltar só depois... Que esquisito isso!"(E33). Este relato exemplifica o quanto pode ser sofrível para a pessoa perder os contatos externos e vai de encontro com um dos principais propósitos da internação domiciliar que é o de propiciar o convívio social com amigos e familiares no processo de internação e a plena interação entre profissionais de saúde, paciente, sua família e o cuidador. ${ }^{11,171-172}$

O processo que é considerado contínuo apresenta alterações importantes com relação ao tempo, sendo que, no inicio, há um número maior de visitas, tanto da equipe de saúde como de familiares, vizinhos e amigos. Com o passar do tempo, as dificuldades vivenciadas no período de adaptação diminuem e as visitas ficam mais escassas. É nesta fase que o cuidador se percebe mais sozinho, como no caso desta cuidadora: "No inicio tinha muitas visitas, a casa ficava cheia, até de pessoas que ele não via de muito tempo... parentes vinham ver como ele tava. Depois de uns seis meses, mais ou menos, quase não vem ninguém, nem ligam pra saber como ele tá. Acho que foi como uma despedida. Só no começo, depois esqueceram. Muito triste... E ele pede...” (E18). A pressão e o estresse ficam mais evidentes. As mudanças relacionadas ao lazer ficam evidentes em outros estudos realizados com cuidadores. $66,116,124,139$

Ainda na ordem social, a alteração na sua autonomia implica diretamente na tomada de decisões refrentes à sua vida pessoal e profissional. No lado pessoal, vale ressaltar que a maior parte dos cuidadores familiares são filhas, mães ou esposas. No caso de mãe de criança doente o processo se inicia em idade precoce e envolve os sonhos e as ambições futuras, como desta cuidadora: "A minha vida mudou em tudo quando eu tive a (*). Eu coloco (*) em primeiro lugar sempre. Eu amadureci rapidamente. Fiquei madura, preocupada com as coisas. Tudo aqui em casa é pela (*)”(E15). Este relato demonstra sentimentos ambíguos com relação ao cuidar. Em contrapartida, estudos apontam que quando a cuidadora é mãe do 
paciente, a sobrecarga tende a ser diminuída, pois pode envolver sentimentos de gratificação no cuidar, suplantando os prejuízos advindos desta função. ${ }^{139,174}$

Cuidar de uma pessoa dependente interfere no estilo de vida do cuidador, que geralmente é alterado devido às necessidades do outro. Essas modificações podem causar a sensação de perda da autonomia para conduzir sua própria vida e de ter de viver em função do outro, pois muitas vezes, atividades em convívio social ou de lazer são dificultadas ou nulas. Atividades essas que são essenciais para que o cuidador possa refazer suas forças e assegurar o autocontrole. ${ }^{66,90,116,172}$

No caso de esposa cuidadora, o desempenho da função também trouxe alterações importantes, principalmente devido à necessidade de parar de trabalhar como descrito nos relatos a seguir: "Mudou muita coisa, parei de trabalhar. Não gostava de ficar dentro de casa. Só ficava a noite, de tardinha. Criava duas netas e agora não posso mais. Tive que entregar pra mãe, não tenho mais condições de ficar com elas. Mudou toda a rotina minha. Gostava de sair, agora nunca dá. É difícil, né? ... Precisa de ajuda pra sair” (E13). E Antes de cuidar dela eu trabalha, ganhava meu dinheiro, planejava minha vida, um tratamento, qualquer coisa. Hoje em dia já não tem mais" (E18). Nestes casos, houve diminuição da renda que impactou diretamente no bem-estar das famílias. A autonomia de assumir um emprego fora de casa ou de sair mais para encontros sociais também está relacionada aos objetivos da internação domiciliar como o de propiciar maior autonomia do paciente e da família para as decisões do dia a dia no cuidar. ${ }^{125,133}$

Quanto às mudanças que envolvem questões espirituais, foi possível perceber neste estudo que as mesmas envolvem a aceitação da religião, as modificações no relacionamento social e na capacidade de superação dos cuidadores.

A religião foi citada por alguns cuidadores como fonte de apoio ao enfrentamento das necessidades do dia a dia, como no relato: "Eu comecei a ir num culto religioso que me deu força pra entender o que DEUS quer de nós. Por que estamos neste mudo. Não é pra sofrer por nada, isso eu sei agora e hoje eu sou mais cristã. E, por isso, ajudo os outros também, não fico só com pena de mim ou da minha mãe" (E8). A crença em Deus também foi citada por outra cuidadora, como segue: "Mas se Deus me curou de um câncer ele pode me curar de qualquer outra doença. Então hoje em dia eu não me importo muito com doença não, ela vem e ela vai. E tudo tá na mão de Deus... quem sou eu pra ficar me mortificando? Preocupada?" (E15). No mesmo sentido, a crença em Deus e a espiritualidade frente à situação fortalecem o cuidador e a familia para enfrentar a situação no contexto da doença terminal e, como discutido anteriormente, aceitar a morte como uma saída para finalizar o sofrimento. ${ }^{13,175}$ 
Os relacionamentos pessoais do cuidador foram modificados durante o processo de cuidar. Os relatos neste sentido dizem respeito às alterações de comportamento, associadas às mudanças pessoais percebidas como a agressividade nas discussões com outras pessoas, a paciência desenvolvida ou ainda, a alteridade ao olhar a situação do paciente. Os relacionamentos são afetados de forma direta, muitas vezes, por interferência dos outros no seu modo de cuidar: "Eu não tenho muita paciência com essas pessoas que dizem que só querem ajudar. Eles criticam o tempo todo...” (E16) ou por sentir que há pouca ajuda e muita cobrança: "Muita gente que vinha aqui no inicio não vem mais ajudar, mas liga pra dizer o que eu devo fazer. Eu fico quieta, mas às vezes eu acho que a minha paciência se acabou..." (E9). Paciência é um dos atributos entendidos como essenciais para o cuidador domiciliar. ${ }^{61,}$ 174

\subsection{ASPECTOS BIOÉTICOS DA RELAÇÃO INTRAFAMILIAR NO CONTEXTO DOS CUIDADOS PALIATIVOS NA ATENÇÃO DOMICILIAR}

Atender aos anseios do doente em fase terminal pode ser um período bastante desgastante para os familiares, pois causa impacto emocional em todos os envolvidos. A busca pela qualidade neste período delicado do que ainda resta da vida é tarefa árdua. Cabe à equipe de saúde oferecer alento aos familiares e ao doente nesse processo que pode ser longo e desgastante. $^{176}$

Paliativo é todo cuidado realizado aos portadores de doenças que não responderam ao tratamento convencional curativo e que necessitam de alivio da dor e de outros sintomas, que podem ter origem psicológica, social ou espiritual, com enfoque na qualidade de vida. ${ }^{177-178}$

Na década de 60, o termo 'cuidados paliativos' foi enfatizado pelo fortalecimento da filosofia 'hospice' originada na idade média com o propósito de oferecer um lugar para acolher o enfermo, cuidá-lo e dar-lhe dignidade, como uma casa de hóspedes. Neste ambiente deve ser ofertado o cuidado, com compaixão e empatia, ao doente que está em fase terminal e à sua família. ${ }^{178}$

Cuidados paliativos podem ser entendidos como sendo um conjunto de ações que objetivam controlar os sintomas integrais do doente, envolvendo o corpo, a mente, o espírito e o social que afligem o homem em sua finitude. Ainda pode ser entendido como um processo de acompanhamento dos doentes e da família, desde o inicio dos sintomas até o fim do processo de forma interdisciplinar, respeitando a integralidade das ações. ${ }^{13,180}$ 
A prática dos cuidados paliativos segue alguns princípios fundamentais para a garantia dos direitos do cidadão doente como o de manter controle sobre as ocorrências, garantir sua dignidade e privacidade, ter dominio sobre com quem pretende partilhar este momento, ter tempo para se despedir e ainda, partir quando for o momento sem utilizar de práticas que causem ou prolonguem sofrimento. ${ }^{34,92,191}$

As doenças crônicas não transmissíveis (DCNT) são amplamente discutidas no ambiente da gestão de saúde no Brasil e no mundo e são consideradas as principais demandas para os cuidados paliativos. Decorrentes, muitas vezes, de falha na promoção da saúde e na prevenção de agravos. A cronicidade das doenças não transmissíveis afeta o bem estar e a qualidade de vida de pessoas pertencentes a uma maior faixa etária. ${ }^{10,13,19}$

A concepção do que seja a doença crônica passa por reformulações nos últimos anos, compreendendo algumas características como: previsão de necessidade de por um longo tempo de supervisão e cuidados, alteração patológica não reversível no sistema corporal, dentre outra. ${ }^{33,182}$

Porém, o termo condição crônica surgiu com o propósito de descrever a situação vivida pelo doente e sua família, pois esse termo abarca tanto as doenças crônicas transmissíveis, como AIDS e não transmissíveis, como as doenças cardiovasculares, quanto às incapacidades estruturais como amputações e cegueira. O principal ponto em comum é o fato de serem persistentes e de necessitarem de cuidado permanente. ${ }^{181-183}$

Neste estudo, $31 \%$ da amostra de doentes, alvo de cuidados oferecidos pelos entrevistados, possuem 80 anos ou mais de idade e todos possuem doença crônica não transmissível, tendo como destaques a doença de Alzheimer e a sequela de acidente vascular cerebral (AVC).

Cuidar do doente na própria casa é tarefa que pode parece simples, mas que tem caráter complexo, pois envolve questões de decisão como a escolha do cuidador principal, a definição de por quantas horas diárias esse cuidado será dispensado e qual o espaço que será destinado para oferecer conforto ao doente. A decisão, em geral, cabe à família do doente com o apoio da EMAD e é fundamentada em dados importantes e em variáveis como a patologia envolvida e o estágio da mesma, o perfil do doente, o grau de autonomia e independência do mesmo, dentre outros.

O apoio da equipe de saúde que acompanha o processo de internação no domicilio é fundamental, pois compreende a orientação e a capacitação para o desenvolvimento dos cuidados. O preparo do cuidador escolhido, que, muitas vezes, é alguém da família nuclear, 
precisa ser abrangente e envolve o conhecimento de técnicas e procedimentos necessários, além de humanização para o cuidado ofertado. ${ }^{178}$

O cuidado domiciliar entrelaça o doente, a família, o cuidador e a equipe de profissionais de saúde com suas características individuais e específicas. Neste complexo, a família assume a responsabilidade do cuidar e percebe a necessidade própria de receber atenção, principalmente para manter a sensatez e o equilíbrio frente ao estresse. A equipe multidisciplinar de atenção domiciliar (EMAD) deve oferecer apoio a fim de amenizar o sofrimento e as dificuldades encontradas pelos envolvidos no processo: doente, cuidador e família. $14,46,64,80,117$

Aspectos bioéticos foram encontrados no desenvolver deste estudo, como a alteridade do cuidador de familiar doente, o cuidar paliativo frente à terminalidade da vida, a dignidade humana e o respeito pelas pessoas, a autonomia do cuidador e do doente, a vulnerabilidade ao estresse e à sobrecarga e a vulnerabilidade aos problemas de saúde de ordem física e psicológica. A família é importante em todas as fases da vida humana, mas tem destaque no inicio e no fim, pois nesses dois estágios, a fragilidade e a vulnerabilidade são intensificadas. 176

São identificadas várias fases decorrentes do cuidar no domicilio entre as verbalizações dos cuidadores. Fases do processo que compreendem desde a 'inicial' com o surgimento da doença que pode ser abrupto ou incipiente, com a escolha do cuidador, com a modificação do ambiente doméstico e com a definição das ações a serem desempenhadas, a intermediária com a adaptação de todos os envolvidos na nova situação e a final com o término da internação domiciliar que pode ser pela melhora do doente ou pela sua ausência.

$\mathrm{Na}$ fase inicial, alguns sentimentos comuns são referidos pelos cuidadores como o medo, a apreensão sobre a responsabilidade e a incerteza da sua própria capacidade de enfrentar a situação imposta. Este sentimento inquietante pode ser comparado como uma sensação de perigo iminente, como a necessidade de aprender a nadar para não se afogar. A alteridade e o respeito à pessoa são identificados nas verbalizações de cuidadores familiares que estão neste período inicial com menos de dois anos de exercício da função. ${ }^{155,163,176,184}$

Com o decorrer do cuidado, outros sentimentos são identificados, como o cansaço e o desânimo relacionados ao futuro, tanto do doente como dele próprio. Surge, após a adaptação, a sensação de solidão, pois as visitas diminuem e o tempo de dedicação ao doente influencia na sua liberdade de escolha e na sua autonomia. ${ }^{155,176}$

Durante esse período, a vulnerabilidade do cuidador se acentua, pois a continuidade do cuidar, o deixar pra trás ambições e desejos devido às circunstâncias faz com que ele se 
perceba estagnado perante a sua própria vida. Este sentimento fica mais acentuado entre os jovens e com escolaridade maior, pois são os que abrem mão de oportunidades de trabalho e sociais. Muitas vezes, os sentimentos ambíguos, decorrentes desse processo, são velados, pois o cuidador familiar teme não ser compreendido. ${ }^{178,183}$

Entendendo que o processo é contínuo e complexo, o cuidador de doente que recebe os cuidados paliativos necessita do apoio da equipe de saúde responsável em todos os aspectos: físico, emocional, psicológico e espiritual. A equipe deve estar preparada para oferecer este apoio, afinal ela também vivencia o processo do cuidar.

Portanto, os cuidados paliativos estão inteiramente implantados no âmbito da reflexão bioética, sobretudo no que se diz respeito aos seus princípios, que devem ser considerados no paciente na finitude da vida. ${ }^{92}$ 
7. CONCLUSÕES 


\section{CONCLUSÕES}

Com relação aos objetivos propostos, o presente estudo realizado com 33 cuidadores domiciliares, permitiu chegar às conclusões apresentadas a seguir:

Quanto às características dos doentes:

- $54,5 \%$ do sexo feminino;

- Média de 60,9 anos de idade;

- Morbidades mais frequentes: AVC, neoplasias, DA e paralisia cerebral.

Quanto às características dos cuidadores:

- $87,6 \%$ eram do sexo feminino;

- $81,8 \%$ eram familiares dos doentes;

- Média de 46 anos de idade;

- $61 \%$ possuíam entre 3 e 5 anos de estudo formal;

- Morbidades mais frequentes: HAS, DM, AR e artrose;

- $45 \%$ relataram sentir dores na coluna;

- $60 \%$ relataram dormir até 6 horas por dia;

- $78 \%$ relataram ter a qualidade do sono ruim;

- Média de 10 anos de exercício da função de cuidador.

Quanto à sobrecarga referida:

- $41 \%$ apresentaram sobrecarga intensa;

- $31 \%$ apresentaram sobrecarga ligeira;

- $28 \%$ não apresentaram sobrecarga;

- $75 \%$ relataram possuir frequentemente ou sempre o sentimento de que o paciente o via como a única pessoa com quem podia contar;

- $51 \%$ relataram nunca sentir que poderiam deixar outra pessoa cuidando do paciente;

- $36 \%$ relataram sentir frequentemente ou sempre estar sobrecarregado por cuidar do paciente.

Quanto à percepção da qualidade de vida:

- Com avaliação do WHOQOL-bref aos 33 cuidadores:

- Média de IGQV de 51,19;

- Domínio com maior escore: relações sociais com 55,30;

- Domínio com menor escore: meio ambiente com 46,12; 
- $45,5 \%$ referiram percepção sobre a qualidade de vida geral como nem boa nem ruim;

- $42,4 \%$ referiram estar insatisfeitos com a própria saúde.

- Com avaliação do WHOQOL-old aos 10 cuidadores com mais de 60 anos de idade:

- Média de IQVI de 45,52;

- Domínio com maior escore: intimidade com 52,50;

- Domínio com menor escore: morte e morrer com 38,13.

$\mathrm{O}$ estudo indicou que os cuidadores domiciliares de pacientes acompanhados por equipes de um Núcleo Regional de Atenção Domiciliar do Distrito Federal cuidavam de pessoas predominantemente idosas que apresentavam doenças crônico-degenerativas.

A maioria dos cuidadores principais apresentou sobrecarga ligeira ou intensa. A presença de doença e de dor física, associada à sobrecarga influencia na percepção de qualidade de vida e torna o cuidador mais vulnerável a ele próprio necessitar de cuidados domiciliares no futuro.

A percepção de qualidade de vida foi melhor em cuidadores idosos, que pode estar relacionado à maior capacidade de resiliência e de aceitação dos fatos pela maior experiência de vida, e com menor tempo de estudo, que pode estar relacionado ao menor número de oportunidades de trabalho formal e a justificativa pela escolha da função.

Participar do cuidado e vivenciar o sofrimento do outro pode causar inquietação e angustia ao cuidador principal. O apoio social recebido da família, de amigos ou da equipe de saúde é fundamental para amenizar o desgaste físico ou psicológico do cuidador nessa situação.

Outro fator considerado importante para a qualidade de vida é o reconhecimento por parte do cuidador da sua própria limitação frente ao cuidado e ao sofrimento alheio. Entender e aceitar a doença como oportunidade de aprendizado espiritual e a morte como a terminalidade de vida de forma natural compreende melhor aceitação e menor desgaste associado ao ato de cuidar.

A relação próxima do cuidador principal e do paciente, principalmente quando se trata de parentesco direto, demonstrou maior envolvimento com o objetivo de amenizar o sofrimento e de preparar o momento da despedida. 
A ressignificação da vida foi relatada por vários cuidadores no sentido de reelaboração do seu papel no contexto social desencadeada pela situação vivenciada, que, para a maioria, ocorreu de forma inesperada e não programada.

Dentre as mudanças mais percebidas pelos cuidadores domiciliares principais, participantes deste estudo, estão as relacionadas aos aspectos sociais, como o afastamento social e espirituais, como a superação.

Foi possível identificar aspectos bioéticos relacionados ao cuidado domiciliar como a vulnerabilidade ao estresse e à sobrecarga, bem como aos problemas físicos e psicológicos, além da diminuição da autonomia nas escolhas da sua vida. O medo e a incerteza do futuro afetaram diretamente os cuidadores principais que estavam no inicio do processo e o cansaço e o desânimo estiveram mais presentes em cuidadores com mais de dez anos de exercício da função de forma continua.

Como limitação deste estudo, pode-se citar o número reduzido de participantes, apesar de representar $100 \%$ dos cuidadores de pacientes internados em domicílio no NRAD avaliado. Além da questão emocional que perpassa todo o estudo, por envolver questões pessoais, familiares e sociais que também influenciam na vida do pesquisador.

Pode-se concluir neste estudo que o cuidador principal precisa ser acompanhado e reconhecido como aliado para a expansão do cuidado no domicilio por parte da equipe de saúde, da família e da sociedade, recebendo apoio e suporte emocional para o enfrentamento da situação.

Entende-se também que a discussão ampliada sobre os aspectos bioéticos e de sobrecarga presentes no cuidar é fundamental para a qualidade de vida dos cuidadores e para a qualidade da assistência domiciliar. 


\section{REFERÊNCIAS}

1. IBGE - Instituto Brasileiro de Geografia e Estatística. Perfil dos municípios brasileiros 2013. Disponível em: $\langle$ http://biblioteca.ibge.gov.br/visualizacao/livros/liv86302.pdf $>$. Citado em 15 de janeiro de 2015.

2. KLUGE, F.; ZAGHENI, E.; LOICHINGER, C.; et al. The Advantages of Demographic Change after the Wave: Fewer and Older, but Healthier, Greener, and More Productive? Ed. Jennifer Beam Dowd. PLoS ONE 9.9, 2014. Disponível em: $\langle$ http://journals.plos.org/plosone/article?id=10.1371/journal.pone.0108501 >. Citado em 05 junho de 2015.

3. WONG, L. L. R.; CARVALHO, J. A. O rápido processo de envelhecimento populacional brasileiro: sérios desafios para as políticas públicas. Revista Brasileira Estatística Populacional. São Paulo. 23(1):5-26, 2006. Disponível em: $<$ http://www.scielo.br/scielo.php?pid=S0102-30982006000100002\&script=sci_arttext $>$. Acesso em 22 de março de 2015.

4. TURRA, C. M. Os limites do corpo: a longevidade em uma perspectiva demográfica. Rev. UFMG, Belo Horizonte, 19(1 e 2):156-81, 2012.. Disponível em: <https://www.ufmg.br/revistaufmg/pdf/REVISTA_19_web_156-181.pdf >. Acesso em 25 de novembro de 2014.

5. CAMPOLINA, A. G.; ADAMI, F.; SANTOS, J. L. F.; LEBRÃO, M. L. A transição de saúde e as mudanças na expectativa de vida saudável da população idosa: possíveis impactos da prevenção de doenças crônicas. Cad. Saúde Pública, Rio de Janeiro, 29(6):1217-29, 2013. Disponível em: $\langle$ http://www.scielosp.org/scielo.php?script=sci_arttext\&pid=S0102311X2013001000018>.

Acesso em 22 de março de 2015.

6. CAMARGOS, M. C. S; MACHADO, C. J.; RODRIGUES, R. N. Expectativa de Vida livre de incapacidade funcional para idosos: um estudo comparativo para o Brasil, grandes regiões e unidades da federação, 1998 e 2003. Trabalho apresentado no XVI Encontro Nacional de Estudos Populacionais, realizado em Caxambu- MG - Brasil, de 29 de setembro a 03 de outubro de 2008. Departamento de Demografia - CEDEPLAR/UFMG, $2008 . \quad$ Disponível em: $<$ http://www.abep.nepo.unicamp.br/encontro2008/docsPDF/ABEP2008_1381.pdf>. Acesso em 22 de novembro de 2014.

7. MENDES, E. V. O cuidado das condições crônicas na atenção primária a saúde: o imperativo da consolidação da estratégia saúde da família. Organização Panamericana de Saúde, 2012, 512p.

8. CAMARANO, A. A (Organizadora). Cuidados de longa duração para a população idosa: um novo risco social a ser assumido? Rio de Janeiro, Ipea, 2010. 350p.

9. RODRIGUES, I. G. Cuidados Paliativos: Análise de conceito [dissertação]. Ribeirão Preto: Universidade de São Paulo; 2004. Disponível em: 
<http://www.teses.usp.br/teses/disponiveis/22/22132/tde-17082004-101459/pt-br.php>.

Acesso em 23 de março de 2015.

10. AMADOR, D. D.; REICHERT, A. P. S.; LIMA, R. A. G.; ET AL. Conceptions of care and feelings of the caregiver of children with cancer. Acta paul. enferm. [online]. 2013, vol.26, n.6, pp. 542-546. ISSN 1982-0194. Disponível em: <http://www.scielo.br/pdf/ape/v26n6/en_06.pdf >. Citado em 05 de junho de 2015.

11. BRASIL. Ministério da Saúde. Manual Instrutivo Melhor em Casa. 19p. Brasília, 2013. Disponível em: 〈http://189.28.128.100/dab/docs/geral/cartilha_melhor_em_casa.pdf>. Acesso em 22 de março de 2015.

12. SILVA, C. A. M.; ACKER, J. I. B. V. O cuidado paliativo domiciliar sob a ótica de familiares responsáveis pela pessoa portadora de neoplasia. Rev Bras Enferm 60(2):150-4, $2007 . \quad$ Disponível em: $<$ http://www.scielo.br/scielo.php?script=sci_arttext\&pid=S003471672007000200005\&lng=en $\underline{\text { \&nrm}=i s o \& t \operatorname{lng}=\mathrm{pt}>}$. Acesso em 25 de novembro de 2014.

13. PROOT, I. M.; ABU-SAAD, H. H.; CREBOLDER, H. F. J. M.; GOLDSTEEN, M.; LUKER, K. A.; WIDDERSHOVEN, G. A. M. Vulnerability of family caregivers in terminal palliative care at home; balancing between burden and capacity. Scand. J. Caring Sci. 2003. Disponível em: <http://www.ncbi.nlm.nih.gov/pubmed/12753511>. Acesso em 30 de junho de 2013.

14. CHERLIN, E.; FRIED, T.; PRIGERSON, H. G.; SCHULMAN-GREEN, D.; JOHNSON-HURZELER, R.; BRADLEY, E. H. Communication between Physicians and Family Caregivers about Care at the End of Life: When Do Discussions Occur and What Is Said? J. Palliat. Med. 2005. Disponível em: <http://www.ncbi.nlm.nih.gov/pmc/articles/PMC1459281/>. Acesso em 30 de junho de 2013.

15. MUNCK, B.; FRIDLUND, B.; MARTENSSON, J. Next-of-kin caregivers in palliative home care: from control to loss of control. J. Adv. Nurs. 2008. Disponível em: <http://www.ncbi.nlm.nih.gov/pubmed/19120572>. Acesso em 27 de junho de 2013.

16. SEAMARK, D. A.; LAWRENCE, C.; GILBERT, J. Characteristics of referrals to an inpatient hospice and a survey of general practitioner perceptions of palliative care. J R Soc Med. Feb; 89(2):79-84 [Internet], 1996. Disponível em: <http://www.ncbi.nlm.nih.gov/pmc/articles/PMC1295662/>. Acesso em 08 de julho de 2013.

17. ESPOSITO, C. Finito. In: MARASSI, M. Enciclopedia filosofica. Milano: Bompiani; 2006. Vol. 5, p. 4294-305. Apud Schramm FR. Finitude e Bioética do Fim da Vida. Rev Bras Canc, 58(1): 73-78, 2012. Disponível em: $<$ http://www.inca.gov.br/rbc/n_58/v01/pdf/11_artigo_opinicao_finitude_bioetica_fim_vida.pd f>. Acesso em 15 de junho de 2013.

18. ACADEMIA NACIONAL DE CUIDADOS PALIATIVOS (ANCP). Manual de cuidados paliativos. Rio de Janeiro: Diagraphic, 2009. Disponível em: $\langle$ http://www.paliativo.org.br/biblioteca_resultadobusca.php?spublicacao=Livros $>$. Acesso em 12 de maio de 2012. 
19. FERRISS, A. L. A. Theory of Social Structure and the Quality of Life. Applied Research in Quality of Life, Columbia, v.1, n. 1, p.117-123, 2006. Disponível em: $<$ http://link.springer.com/article/10.1007\%2Fs11482-006-9003-1 >. Acesso em 13 de novembro de 2013.

20. FARQUHAR, M. Definitions of quality of life: a taxonomy. Journal of Advanced Nursing, Oxford, v. 22, n.3, p.502-508, 1995. Disponível em: <http://onlinelibrary.wiley.com/doi/10.1046/j.1365>. Acesso em 12 de junho de 2013.

21. FRANÇA, I. S. X.; COURA, A. S.; FRANÇA, E. G.; BASÍlIO, N. N. V.; SOUTO, R. Q. Qualidade de vida de adultos com lesão medular: um estudo com WHOQOL-bref. Rev Esc Enferm USP 2011; 45(6):1364-71. Disponível em: <http://www.ee.usp.br/site/Index.php/paginas/mostrar/1419/2094/147>. Acesso em $30 \mathrm{de}$ maio de 2013.

22. MENEZES, R. A. Entre normas e práticas: tomada de decisões no processo saúde/doença. Physis (Rio de Janeiro). 2011; 21(4):1429-49. Disponível em: 〈http://www.scielo.br/scielo.php?pid=S0103-73312011000400014\&script=sci_arttext $>$.

Acesso em 22 de maio de 2013.

23. DISTRITO FEDERAL. Secretaria de Estado de Planejamento e Orçamento do Distrito Federal - SEPLAN. Companhia de Planejamento do Distrito Federal - CODEPLAN. Pesquisa distrital por amostra de domicílios - PDAD - 2013, Brasília, 2013. Disponível em: <http://www.codeplan.df.gov.br/images/CODEPLAN/PDF/Pesquisas\%20Socioecon\%C3 \%B4micas/PDAD/2013/Ceil\%C3\%A2ndia-PDAD\%202013.pdf>. Acesso em 21 de março de 2015.

24. ALVES, J. E. D. A transição demográfica e a janela de oportunidade. São Paulo: Instituto Fernand Braudel de Economia Mundial, 2008.13p. Disponível em: $<$ http://en.braudel.org.br/research/archive/downloads/a-transicao-demografico-e-a-janela-deoportunidade.pdf>. Acesso em 25 de fevereiro de 2015.

25. VASCONCELOS, A. M. N.; GOMES, M. M. F. Transição demográfica: a experiência brasileira. Epidemiologia e Serviços de Saúde. 2012; 21(4):10. Disponível em: $\langle$ http://scielo.iec.pa.gov.br/scielo.php?pid=S167949742012000400003\&script=sci_arttext $>$. Acesso 13 de junho de 2013.

26. VERAS, R. P.; CALDAS, C. P.; DANTAS, S. B.; SANCHO, L. G.; SCSÚ, B.; MOTTA, L. B.; CARDINALE, C. Avaliação dos gastos com o cuidado do idoso com demência. Rev Psiq Clín, 35(1): 5-12, 2007. Disponível em: 〈http://www.scielo.br/scielo.php?pid=S0101-60832007000100001\&script=sci_arttext $>$.

Acesso em 21 de maio de 2015.

27. FARIA, A. P. S.; BELLATO, R. A vida cotidiana de quem vivencia a condição crônica do diabetes mellitus. Rev Esc Enferm USP. 2009. 43(4): 752-9. Disponível em: <http://www.scielo.br/pdf/reeusp/v43n4/a03v43n4.pdf $>$. Acesso em 23 de maio de 2013.

28. WHO (World Health Organization). Health topics: Chronic diseases. Geneva: World Health Organization; 2013. Disponível em: 
<http://www.who.int/topics/noncommunicable_diseases/en/>. Acesso em 06 de agosto de 2014.

29. SINGH, D. How can chronic disease management programmes operate across care settings and providers? Copenhagen: Regional Office for Europe of the World Health Organization, European Observatory on Health Systems and Policies; 2008. Disponível em: $<$ http://www.euro.who.int/_data/assets/pdf_file/0009/75474/E93416.pdf $>$. Acesso em 25 de maio de 2014.

30. BARCELÓ, A.; LUCIANI, S.; AGURTO, I.; ORDUÑES, P.; TASCA, R.; SUED, M. Melhoria dos cuidados crônicos por meio das redes de atenção a saúde. Washington, D.C., OPAS, 2012. Disponível em: <http://apsredes.org/site2012/wpcontent/uploads/2012/05/Melhoria-dos-Cuidados Cr\%C3\%B4nicos_port2.pdf $>$. Acesso em 23 de maio de 2015.

31. VERAS, R. P. Envelhecimento populacional contemporâneo: demandas, desafios e inovações. Rev Saúde Pública, 43(3):548-54, 2009; Disponível em: 〈http://www.scielo.br/scielo.php?pid=S0034-89102009005000025\&script=sci_arttext $>$.

Acesso em 12 de julho de 2014.

32. FREITAS, M. C.; MENDES, M. M. R. Condição crônica: análise do conceito no contexto da saúde do adulto. Rev Lat Am Enfermagem. 2007; 15 (4): 590-7. Disponível em: $<$ http://www.scielo.br/scielo.php?script=sci_arttext\&pid=S010411692007000400011\&lng=pt $\underline{\text { \&nrm}=i s o \& t \operatorname{lng}=\mathrm{pt} \& u s e r I D=-2}>$. Acesso em 12 de julho de 2014.

33. FARIA, A. P. S.; BELLATO, R. A compreensão do fenômeno condição crônica por diabetes mellitus a partir da experiência de adoecimento. Rev. Eletr. Enf. [Internet]. 2010; 12 (3):520-7. Disponível em: <https://www.fen.ufg.br/fen_revista/v12/n3/v12n3a15.htm>. Acesso em 12 de julho de 2014.

34. SCHRAMM, J. M.; OLIVEIRA, A. F.; LEITE, I. C. Transição epidemiológica e o estudo de carga de doenças no Brasil. Cien Saúde Coletiva 2004; 9: 897-908. Disponível em: 〈http://www.scielo.br/scielo.php?script=sci_arttext\&pid=S1413-81232004000400011 >. Acesso em 12 de julho de 2014.

35. ALWAN, A.; MACLEAN, D. R.; RILEY, L. M., et al. Monitoring and surveillance of chronic non-communicable diseases: progress and capacity in high-burden countries. Lancet. 2010; 376(9755):1861-8. Disponível em: <http://www.thelancet.com/journals/lancet/article/PIIS01406736\%2810\%29618533/abstract> Acesso em 23 de maio de 2015.

36. ANTUNES, F. P.; COSTA, M. C. N.; PAIM, J. S., et al. Desigualdades sociais na distribuição espacial das hospitalizações por doenças respiratórias. Cad. Saúde Pública, 29(7):1346-56, 2013. Disponível em: <http://www.scielo.br/pdf/csp/v29n7/09.pdf >. Acesso em 13 de julho de 2014.

37. PEIXOTO, S. V.; GIATTI, L.; ALFRADIQUE, M. E.; LIMA-COSTA, M. F. Custos das internações hospitalares entre idosos brasileiros no Sistema Único de Saúde. Epidemiologia e Serviços de Saúde, 13(4):239-46, 2004 Disponível em: 
$\langle$ http://scielo.iec.pa.gov.br/scielo.php?pid=S1679-49742004000400006\&script=sci_arttext $>$. Acesso em 25 de junho de 2014.

38. MONTEIRO, M. F. G. A carga de doença associada com algumas causas de internação hospitalar realizada pelo SUS. Epidemiologia e Serviços de Saúde 200413(1): 7$14 . \quad$ Disponível em: 〈http://scielo.iec.pa.gov.br/scielo.php?pid=S167949742004000100002\&script=sci_arttext $>$. Acesso em 23 de maio de 2015.

39. TRENTINI, M.; BELTRAME, V. Relações humanizadas na assistência às pessoas com diabetes mellitus. Acta. Sci. Health. Sci. 2004. 26(2):261-9. Disponível em: <http://www.researchgate.net/publication/244948255_Relaes_humanizadas_na_assistncia_s_ pessoas_com_diabetes_mellitus >. Acesso em 25 de julho de 2014.

40. BRASIL. Ministério da Saúde. Secretaria de Vigilância em Saúde. Departamento de Análise da Situação de Saúde. Plano de ações estratégicas para o enfrentamento das doenças crônicas não transmissíveis (DCNT) no Brasil 2011-2022. Brasília, 2011. Disponível em: 〈http://www.sbn.org.br/noticias/acoes_estrategicas.pdf>. Acesso em $13 \mathrm{de}$ junho de 2014.

41. BRASIL. Ministério da Saúde. Portaria GM/MS n. 1319 de 23 de julho de 2002. Disponível em: 〈http://dtr2001.saude.gov.br/sas/PORTARIAS/Port2002/Gm/GM-1319.htm>. Acesso em 13 de junho de 2014.

42. BRASIL. Ministério da Saúde. Portaria MS/GM n. 3.150, de 12 de dezembro de 2006. Institui a Câmara Técnica em Controle da Dor e Cuidados Paliativos. Disponível em: <http://www.cremesp.org.br/?siteAcao=LegislacaoBusca\&nota=362>. Acesso em 13 de junho de 2014.

43. BRASIL. Ministério da Saúde. Portaria GM/MS n. 874, de 16 de maio de 2013. Institui a Política Nacional para a Prevenção e Controle do Câncer na Rede de Atenção à Saúde das Pessoas com Doenças Crônicas no âmbito do Sistema Único de Saúde (SUS). Disponível em: $\langle$ http://bvsms.saude.gov.br/bvs/saudelegis/gm/2013/prt0874_16_05_2013.html $>$. Acesso em 13 de junho de 2014.

44. RODRIGUES, M. A.; SEIDL, E. M. F. A importância do apoio social em pacientes coronarianos. Paidéia, Ribeirão Preto, v.18, n.40, p. 279-288, 2008. Disponível em: <www.scielo.br/pdf/paideia/v18n40/06.pdf $>$. Acesso em 25 de março de 2015.

45. FLORIANI, C. A. Cuidador familiar: sobrecarga e proteção. Rev Bra Can 50(4): 341345, 2004. Disponível em: $\langle$ http://www2.ufpel.edu.br/medicina/bioetica/CuidadorFamiliar.pdf $>$. Acesso em 23 de agosto de 2014.

46. TODD, K.; ROBERTS, S.; BLACK, C. The Living with Cancer Education Programme. II. Evaluation of an Australian education and support programme for cancer patients and their family and friends. Euro Journ Cancer Care, 11(4):280-9, 2002 Disponível em: $<$ htt://www.ncbi.nlm.nih.gov/pubmed/12492464>. Acesso em 20 de agosto de 2013. 
47. FERREIRA, N. M. L. A.; SOUZA, C. L. B.; STUCHI, Z. Cuidados paliativos e família. Rev Cienc Med (Campinas); 17(1), jan.-fev, 2008. Disponível em: $<$ http://bases.bireme.br/cgibin/wxislind.exe/iah/online/?IsisScript=iah/iah.xis\&src=google\&ba $\underline{\text { se}=L I L A C S \& l a n g}=p \&$ nextAction=lnk\&exprSearch=509370\&indexSearch=ID $>$. Acesso em 20 de agosto de 2013.

48. BRASIL. Ministério da Saúde. Portaria n. 1.208, de 18 de junho de 2013. Dispõe sobre a integração do Programa Melhor em Casa (Atenção Domiciliar no âmbito do SUS) com o Programa SOS Emergências, ambos inseridos na Rede de Atenção às Urgências. Disponível em: $<$ http://bvsms.saude.gov.br/bvs/saudelegis/gm/2013/prt1208_18_06_2013.html >. Acesso em 30 de junho de 2013.

49. BARROS, M. B. A.; FRANCISCO, P. M. S. B.; ZANCHETTA, L. M.; CÉSAR, C. L. G. Tendências das desigualdades sociais e demográficas na prevalência de doenças crônicas no Brasil, PNAD: 2003- 2008. Ciência \& Saúde Coletiva, 16(9):3755-68, 2011. Disponível em: 〈http://www.scielo.br/pdf/csc/v16n9/a12v16n9.pdf >. Acesso em 23 de junho de 2014.

50. AMARAL, N. N.; CUNHA, M. C. B.; LABRONICI, R. H. D. D.; OLIVEIRA, A. S. B.; GABBAI, A. A. Assistência domiciliar à saúde (Home Health Care): sua história e relevância para o atual Sistema de Saúde. Rev Neurociência 9(3):111-17, 2001. Disponível em: $<$ http://revistaneurociencias.com.br/edicoes/2001/RN\%2009\%2003/Pages\%20from\%20R N\%2009\%2003-5.pdf $>$. Acesso em 23 de junho de 2014.

51. PASKULIN, L. M. G.; DIAS, V. R. F. G. Como é ser cuidado em casa: as percepções dos clientes. Rev Bras Enferm, Brasília (DF), 55(2): 119-25, 2002. Disponível em: <http://www.lume.ufrgs.br/bitstream/handle/10183/101520/000342285.pdf?sequence=1 >. Acesso 15 de junho de 2013. Jun 15.

52. DUARTE, Y. A. O.; DIOGO, M. .J. E. Atendimento domiciliário: um enfoque gerontológico. In: DUARTE, Y. A. O.; DIOGO, M. J. E. (organizadores). Atendimento domiciliar: um enfoque Gerontológico. São Paulo: Atheneu; 2000, 630 p.

53. BRASIL, Ministério da Saúde. Lei n. 10.424 de 2002. Estabelece no âmbito do Sistema Único de Saúde o atendimento e a internação domiciliar, Brasília, 2002. Disponível em: 〈http://presrepublica.jusbrasil.com.br/legislacao/99524/lei-10424-02>. Acesso em 30 de junho de 2014.

54. BRASIL, Ministério da Saúde. Agência Nacional de Vigilância Sanitária - ANVISA. RDC n. 11 de 2006. Dispõe sobre o regulamento técnico de funcionamento de serviços que prestam atenção domiciliar. Brasília, 2006. Disponível em: <http://portal.anvisa.gov.br/wps/wcm/connect/1978e4804745973e9f9ddf3fbc4c6735/RDC+N \%C2\%BA11-2006.pdf?MOD=AJPERES $>$. Acesso em 30 de junho de 2014.

55. BRASIL, Ministério da Saúde. Portaria GM/MS 2527 de outubro de 2011. Redefine a Atenção Domiciliar no âmbito do Sistema Único de Saúde (SUS). Disponível em: <http://bvsms.saude.gov.br/bvs/saudelegis/gm/2011/prt2527_27_10_2011.html>. Acesso em 30 de junho de 2014. 
56. DISTRITO FEDERAL. Secretaria de Estado de Planejamento e Orçamento do Distrito Federal - SEPLAN. Companhia de Planejamento do Distrito Federal - CODEPLAN. Pesquisa distrital por amostra de domicílios - PDAD - 2013, Brasília, 2013. Disponível em: $<$ http://www.codeplan.df.gov.br/images/CODEPLAN/PDF/Pesquisas\%20Socioecon\%C3 $\%$ B4micas/PDAD/2013/Ceil\%C3\%A2ndia-PDAD\%202013.pdf>. Acesso em 30 de junho de 2014.

57. VILlaS BÔAS., M. L. C. A experiência do Serviço de Atenção Domiciliar do Distrito Federal. Apresentação realizada no XVI Fórum De Atenção Domiciliar "O SAD que temos e o SAD que queremos" em Ribeirão Preto - SP, 2013. Disponível em: <http://www.ribeiraopreto.sp.gov.br/saude/programas/sad/forum/2013/experiencia_servico.pd f $>$. Acesso em 30 de junho de 2014.

58. DISTRITO FEDERAL. Secretaria de Estado de Saúde do Distrito Federal - SESDF. Programas - $\quad$ Internação Domiciliar. Disponível em: 〈http://www.saude.df.gov.br/programas/287-programa-de-internacao-domiciliar.html >.

Acesso em 30 de junho de 2014.

59. SERAFIM, A. P.; RIBEIRO, R. A. B. Internação domiciliar no SUS: breve histórico e desafios sobre sua implementação no Distrito Federal. Com. Ciências Saúde. 2011. 22(2): 163-168. Disponível

em: $<$ http://www.escs.edu.br/pesquisa/revista/2011Vol\%2022_2_8_Internacao.pdf $>$. Acesso em 30 de junho de 2014.

60. CALDAS, C. P. O idoso em processo de demência: o impacto na família. In: MINAYO, M..C..S. \& COIMBRA JÚNIOR, C..E. A. (Orgs.), Antropologia, saúde e envelhecimento, Fiocruz, PP. 51-71. Rio de Janeiro, 2002. Disponível em: $<$ http://bases.bireme.br/cgibin/wxislind.exe/iah/online/?IsisScript=iah/iah.xis\&src=google\&ba $\underline{\text { se}=L I L A C S \& l a n g=p \& n e x t A c t i o n}=1 n k \&$ exprSearch=318633\&indexSearch=ID $>$. Acesso em 23 de junho de 2015.

61. GLOBERMAN, J. Balancing tensions in families with Alzheimer's disease: the self and the family. Journal of Aging Studies, 8, 211-232, 1994. Disponível em: $<$ http://www.researchgate.net/publication/222742508_Balancing_tensions_in_families_with_ Alzheimer\%27s_disease_The_self_and the family>. Acesso em 23 de junho de 2015.

62. SILVERSTEIN, M.; LITWAK, E. A. Task-specific typology of intergenerational family structure in later life. The Gerontologist, 33(2), 258-264, 1993. Disponível em: <http://www.ncbi.nlm.nih.gov/pubmed/8468019>. Acesso em 23 de junho de 2015.

63. SANTOS, S. M. A. Idosos, família e cultura: um estudo sobre a construção do papel do cuidador. Campinas, SP: Alínea. 2010, 3ª Edição, 230p.

64. FALCÃO, D. V. S.; BUCHER-MALUSCHKE, J. S.N. F. Cuidar de familiares idosos com a doença de Alzheimer: uma reflexão sobre aspectos psicossociais. Psicol. estud. vol.14 no.4 Maringá Oct./Dec. $2009 . \quad$ Disponível em: <http://www.scielo.br/scielo.php?script=sci_arttext\&pid=S141373722009000400018\&lng=pt $\underline{\text { \&nrm}=\mathrm{iso} \& \mathrm{tlng}=\mathrm{pt}>}>$. Acesso em 23 de junho de 2015. 
65. INOCENTI, A.; RODRIGUES, I. G.; MIASSO, A. I. Vivências e sentimentos do cuidador familiar do paciente oncológico em cuidados paliativos. Rev. Eletr. Enf., 2009 Disponível em: <http://www.fen.ufg.br/revista/v11/n4/sumario.htm>. Acesso em 2013, jun 30.

66. PROOT, I. M.; ABU-SAAD, H. H.; CREBOLDER, H. F. J. M.; GOLDSTEEN, M.; LUKER, K. A.; WIDDERSHOVEN, G. A. M. Vulnerability of family caregivers in terminal palliative care at home; balancing between burden and capacity. Scand. J. Caring Sci. 2003. Disponível em: 〈http://www.ncbi.nlm.nih.gov/pubmed/12753511>. Citado em 15 de setembro de 2013.

67. CHERLIN, E.; FRIED, T.; PRIGERSON, H. G.; SCHULMAN-GREEN, D.; JOHNSON-HURZELER, R.; BRADLEY, E. H. Communication between Physicians and Family Caregivers about Care at the End of Life: When Do Discussions Occur and What Is Said? J. Palliat. Med. 2005. Disponível em: <http://www.ncbi.nlm.nih.gov/pmc/articles/PMC1459281/>. Acesso em 30 de junho de 2013.

68. MUNCK, B.; FRIDLUND, B.; MARTENSSON, J. Next-of-kin caregivers in palliative home care: from control to loss of control. J. Adv. Nurs. 2008. Disponível em: <http://www.nlm.nih.gov/pubmed/19120572>. Acesso em 30 de junho de 2013.

69. SEAMARK, D. A.; LAWRENCE, C.; GILBERT, J. Characteristics of referrals to an inpatient hospice and a survey of general practitioner perceptions of palliative care. J R Soc Med. Feb;89(2):79-84, $1996 . \quad$ Disponível em: <http://www.ncbi.nlm.nih.gov/pmc/articles/PMC1295662/>. Acesso em 08 de julho de 2013.

70. BACK, A. L.; ANDERSON, W. G.; BUNCH, L.; MARR, L. A.; WALLACE, J. A, YANG, H. B.; ARNOLD, A. M. Communication About Cancer Near the End of Life. Communication about cancer near the end of life. Cancer. 113(7 Suppl):1897-1910, 2008. Disponível em: 〈http://onlinelibrary.wiley.com/doi/10.1002/cncr.23653/pdf >. Acesso em 30 de junho de 2013.

71. FLORIANI, C. A.; SCHRAMM, F. R. Cuidador do idoso com câncer avançado: um ator vulnerado. Cadernos de Saúde Pública, Rio de Janeiro, v. 22, n. 3, p. 527-534, mar. 2006. Disponível em: 〈http://www.scielo.br/pdf/csp/v22n3/07.pdf > . Acesso em 23 de junho de 2013.

72. REZENDE, V. L.; DERCHAIN, S. M.; BOTEGA, N. J.; LANDULFO, D. V. Revisão crítica dos instrumentos utilizados para avaliar aspectos emocionais, físicos e sociais do cuidador de pacientes com câncer na fase terminal da doença. Rev Bras Canc, 51(1): 79-87, 2005. Disponível em: 〈http://www.inca.gov.br/rbc/n_51/v01/pdf/revisao5.pdf $>$ Acesso em 23 de junho de 2013.

73. HAYASHI, V. D.; CHICO, E.; FERREIRA, N. M. L. A. Enfermagem de família: um enfoque em oncologia. Revista Enfermagem UERJ, Rio de Janeiro, v. 14, n. 1, p. 13-20, jan./mar. $2006 . \quad$ Disponível em: $<$ http://www.webartigos.com/artigos/ocuidadordepacientescomcancer/4927/\#ixzz2bDTBn $\underline{E} 4 \mathrm{a}>$. Acesso em 23 de junho de 2013. 
74. THE WHOQOL GROUP. The World Health Organization quality of life assessment: position paper from the world health organization, 1995. Soc Sci Med. 1995;41:1403-9. 2. Disponível em: 〈http://www.sciencedirect.com/science/article/pii/027795369500112K >. Acesso em 23 de junho de 2013.

75. FLECK, M. P. A., et al. Application of the portuguese version of the abbreviated instrument of quality life WHOQOL-bref. Rev Saude Publica. 2000. 34(2):178-83. Disponível em: $\quad<$ http://www.scielo.br/scielo.php?script=sci_arttext\&pid=S0034$\underline{89102000000200012>}$. Acesso em 23 de junho de 2013.

76. LOBO, A. J. S.; SANTOS, L.; GOMES, S. Nível de dependência e qualidade de vida da população idosa. Rev Bras Enferm [online]. 2014 nov-dez; 67(6): 913-9. Disponível em: $<$ http://www.scielo.br/scielo.php?script=sci_arttext\&pid=S003471672014000600913\&lng=pt \&nrm=iso > . Citado em 05 de junho de 2015.

77. GONÇALVES, A.; VILARTA, R (Org.). Qualidade de Vida e Atividade Física: Explorando Teoria e Prática. Barueri. Manole, 2004.

78. FERRISS, A. L. A. Theory of Social Structure and the Quality of Life. Applied Research in Quality of Life, Columbia, v.1, n. 1, p.117-123, 2006. Disponível em: $<$ http://link.springer.com/article/10.1007\%2Fs11482-006-9003-1>. Acesso em 13 de novembro de 2013.

79. BECK, A. R. M.; LOPES, M. H. B. M. Cuidadores de crianças com câncer: aspectos da vida afetados pela atividade do cuidador. Rev Bras Enferm 2007; 60(6): 670-5. Disponível em: $\quad$ http://www.scielo.br/scielo.php?script=sci_arttext\&pid=S0034$\underline{71672007000600010}$ > . Acesso em 13 de novembro de 2013.

80. FARQUHAR, M. Definitions of quality of life: a taxonomy. Joumal of Advanced Nursing, Oxford, v. 22, n.3, p.502-508, 1995. Disponível em: <http://onlinelibrary.wiley.com/doi/10.1046/j.1365 >. Acesso em 12 de junho de 2013.

81. FRANÇA, I. S. X.; COURA, A. S.; FRANÇA, E. G.; BASÍLIO, N. N. V.; SOUTO, R. Q. Qualidade de vida de adultos com lesão medular: um estudo com WHOQOL-bref. Rev Esc Enferm USP 2011; 45(6):1364-71. Disponível em: <http://www.ee.usp.br/site/Index.php/paginas/mostrar/1419/2094/147>. Acesso em 30 de maio de 2013.

82. BAMPI, L. N. S.; GUILHEM, D.; LIMA, D. D. Qualidade de vida em pessoas com lesão medular traumática: um estudo com o WHOQOL-bref. Rev Bras Epidemiol 2008. 11(1): 67-77. Disponível em: <http://www.scielo.br/pdf/rbepid/v11n1/06.pdf >. Acesso $12 \mathrm{de}$ setembro de 2013.

83. MICHALOS, A. C.; ZUMBO, B. D.; HUBLEY, A. M. Health and the quality of life. Social Indicators Research: An International and Interdisciplinary Journal for Qualityof-Life Measurement. 51, 245-286, 2000. Disponível em: 〈http://www.cdc.gov/hrqol/>. Acesso 12 de setembro de 2013.

84. SCHMIDT, C. E.; BESTMANN, B.; KUCHLER, T.; LONGO, W. E.; KREMER, B. Impact of age on quality of life in patients with rectal cancer. World J Surg. 29, 190-7. 2005. 
Disponível em: <http://link.springer.com/article/10.1007/s00268-004-7556-4\#page-2>. Acesso 10 de setembro de 2012.

85. HUBLEY, A. M.; RUSSELL, L. Prediction of subjective age, desired age, and age satisfaction in older adults: Do some health dimensions contribute more than others? International Journal of Behavioral Development (Special issue on Subjective Age), 33, 12-21, 2009. Disponível em:< http://www.hubleylab.ca/>. Acesso 10 de setembro de 2012.

86. RAPHAEL, D.; STEINMETZI, B.; RENWICK, R.; ROOTMAN, I.; BROWN, I.; SEHDEV, H.; PHILLIPS, S.; SMITH, T. The Community Quality of Life Project: a health promotion approach to understanding communities. Oxford University Press. vol. 14, n. 3, 1999. Disponível em: <http://heapro.oxfordjournals.org/content/14/3/197.full.pdf+html >. Acesso 10 de setembro de 2012.

87. BARBOSA, R. M. S. P. Resenha do livro "Atividade Física, Saúde e Qualidade de Vida: conceitos e sugestões para um estilo de vida ativo", de Markus Vinicius Nahas. Rev Bras Ciênc Esporte vol.34 n.2 Porto Alegre apr./june, 2012. Disponível em: 〈http://www.scielo.br/scielo.php?pid=S0101-2892012000200018\&script=sci_arttext $>$. Acesso 10 de setembro de 2012.

88. SEIDL, E. M. F.; ZANNON, C. M. L. C. Qualidade de vida e saúde: aspectos conceituais e metodológicos. Cad Sau Pub, Rio de Janeiro, 20(2):580-588, mar-abr, 2004. Disponível em: 〈http://www.scielo.br/pdf/csp/v20n2/27.pdf>. Acesso 10 de setembro de 2012.

89. PRUDENTE, C. O. M.; BARBOSA, M. A.; PORTO, C. C. Qualidade de vida de cuidadores primários de crianças com paralisia cerebral: revisão da literatura. Rev Eletr Enf [Internet]. 2010; 12(2):367-72. Disponível em: <https://www.fen.ufg.br/revista/v12/n2/v12n2a22.htm>. Acesso 25 de agosto de 2013.

90. NOGUEIRA, M. F.; COSTA, S. F. G.; HENRIQUES, M. E. R. M. Produção científica em bioética no campo da enfermagem: revisão integrativa da literatura. J Nurs UFPE on line. Disponível <http://www.researchgate.net/publication/29438847_Produo_cientfica_em_biotica_no_camp o_da_enfermagem_reviso_integrativa_da_literatura>. Acesso 30 de setembro de 2012.

91. ANDRADE, C. G. DE.; COSTA, S. F. G DA.; VASCONCELOS, M. F.; ZACCARA, A. A. L.; DUARTE, M. C. S.; EVANGELISTA, C. B. Bioética, cuidados paliativos e terminalidade: revisão integrativa da literatura. Rev enferm UFPE on line, Recife, 7(esp):888-97, $2013 \quad$ Mar Disponível em: $<$ http://www.revista.ufpe.br/revistaenfermagem/index.php/revista/article/view/3775/pdf_2 240>. Citado em 25 de Setembro de 2013.

92. NUNES, L. Ética em cuidados paliativos: limites ao investimento curativo. Revista $\begin{array}{lllllll}\text { Bioética } & 2008 & 16 & \text { (1): } 41 & - & 50 . & \text { Disponível em: }\end{array}$ <http://www.scielo.br/scielo.php?script=sci_arttext\&pid=S0034-71672007000600010 >. Acesso em 21 de março de 2015.

93. VILAÇA, C. M.; BARREIROS, D. S.; GALLI, F. A., et. al. O autocuidado de cuidadores informais em domicílio. Percepção de acadêmicos de enfermagem. Rev Elet de 
Enfermagem, [online] v.7, n.2, p. 221-226, 2005. Disponível em: <http://www.fen.ufg.br/revista/revista7_2/relato_02.htm>. Citado em 25 de setembro de 2013.

94. REGO, S.; PAlÁCiOS, M. A finitude humana e a saúde pública. Cad. Saúde Pública, Rio de Janeiro, 22(8):1755-1760, 2006 Ago. Disponível em: $\langle$ http://www.scielo.br/scielo.php?script=sci_arttext\&pid=S0102-311X2006000800025>.

Citado em 25 de julho de 2013.

95. ACADEMIA NACIONAL DE CUIDADOS PALIATIVOS (ANCP). Manual de cuidados paliativos. Rio de Janeiro: Diagraphic, 2009. Disponível em: $\langle$ http://www.paliativo.org.br/biblioteca_resultadobusca.php?spublicacao=Livros $>$. Acesso em 12 de maio de 2012.

96. O'NEILL, B.; FALLON, M. ABC of palliative care: principles of palliative care and pain control. Br Med J. 1997;315:801-4. Disponível em: <http://www.bmj.com/content/315/7111/801>. Acesso em 12 de maio de 2012.

97. WITTMANN-VIEIRA, R.; GOLDIM, J. R. Bioética e Processo de Enfermagem. In ALMEIDA, M. A, et al. Processo de enfermagem na prática clínica: estudos clínicos realizados no Hospital de Clínicas de Porto Alegre. Porto Alegre: Artmed; 2011. p. 67-75.

98. OLIVEIRA, A. C.; SILVA, M. J. Autonomy in palliative care: concepts and perceptions of health teamwork. Acta Paul Enferm. 2010; 23(2):212-7. Disponível em: $<$ http://www.scielo.br/scielo.php?pid=S010321002010000200010\&script=sci_arttext\&tlng=e n $>$. Acesso em 15 de maio de 2015.

99. NEGREIROS, T. C. G. M. Espiritualidade: desejo de eternidade ou sinal de maturidade? Revista Mal estar e Subjetividade. v. 3, n. 2, p. 275-91, 2003. Disponível em: $\langle$ http://pepsic.bvsalud.org/scielo.php?pid=S1518-61482003000200003\&script=sci_arttext $>$.

Acesso em 15 de maio de 2015.

100. KOVÁCS, M. J (org). Morte e Desenvolvimento Humano. São Paulo: Editora Casa do Psicólogo: São Paulo, 2002. 253 p

101. SCHRAMM, F. R. Finitude e Bioética do Fim da Vida. Rev Bras Canc, 58(1): 73-78, 2012. Disponível em: <http://www.inca.gov.br/rbc/n_58/v01/pdf/11_artigo_opinicao_finitude bioetica_fim_vida.pd f $>$. Acesso em 15 de junho de 2013.

102. PEREIRA, M.; FILGUEIRAS, M. A. Dependência no processo de envelhecimento: uma revisão sobre cuidadores informais de idosos. Rev Aten Prim à Saúde, 12(1),72-82, 2009. Disponível em: <http://bases.bireme.br/cgibin/wxislind.exe/iah/online/?IsisScript=iah/iah.xis\&src=google\&base=LILACS\&lang=p\&nex

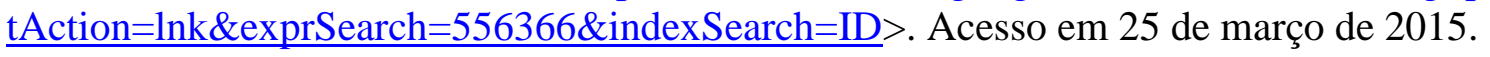

103. ALENCAR, S. C. S.; LACERDA, M. R.; CENTA, M. L. Finitude humana e enfermagem: reflexões sobre o (des)cuidado integral e humanizado ao paciente e seus familiares durante o processo de morrer. Fam Saúde Desenv Curitiba, v.7, n.2, p.171-180, maio/ago.

2005.

Disponível

em: 
$<$ http://ojs.c3sl.ufpr.br/ojs2/index.php/refased/article/view/8045/5668>. Citado em 13 de outubro de 2013.

104. MINAYO, M. C. S.; MINAYO-GOMÉZ, C. Difíceis e possíveis relações entre métodos quantitativos e qualitativos nos estudos de problemas de saúde. In: GOLDENBERG, P.; MARSIGLIA, R. M. G.; GOMES, M. H. A (Orgs.). O clássico e o novo: tendências, objetos e abordagens em ciências sociais e saúde. Rio de Janeiro: Fiocruz, 2003 p.117-42 Disponível em: <http://books.scielo.org/id/d5t55/09>. Acesso em 25 de março de 2015.

105. RAUSCH, P. K.; VITALI, M. P. Pesquisa Quantitativa e Qualitativa: A integração do conhecimento científico. Sau. \& Transf. Soc., Florianópolis, 2013 v. 4, n. 1, p. 16-18, Disponível em: 〈http://www.redalyc.org/pdf/2653/265325753005.pdf >. Acesso em 25 de março de 2015.

106. TURATO, E. R. Tratado de Metodologia da Pesquisa Clínico-Qualitativa: construção téorico-epistemológica, discussão comparada e aplicada nas áreas da saúde e humanas. 3rd ed. Petrópolis: Vozes; 2008.685p.

107. TAUB, A.; ANDREOLI, S. B.; BERTOLlUCCI, P. H. Sobrecarga de cuidador de pacientes com demência: confiabilidade da versão brasileira do inventário de sobrecarga de Zarit. Cad Saúde Pública. 2004 20(2):372-6. Disponível em: $<$ http://www.scielo.br/scielo.php?pid=S0102311X2004000200004\&script=sci_abstract\&tlng $=\mathrm{pt}>$. Acesso em 13 de maio de 2014.

108. FLECK, M. P.; CHACHAMOVICH, E.; TRENTINI, C. Development and validation of the Portuguese version of the WHOQOL-Old module. Rev Saúde Pública. 2006 40(5):785-91. Disponível em: <http://www.ufrgs.br/psiquiatria/psiq/WHOQOLOLD\%20Manual\%20POrtugues.pdf>. Acesso em 04 de maio de 2015.

109. MINAYO, M. C. S (Org.). Pesquisa social: teoria, método e criatividade. Petrópolis: Vozes, 2001.

110. BARDIN, L. Análise de Conteúdo. Lisboa: Edições 70, 2014. Reimp. 288p.

111. MINAYO, M. C. O desafio do conhecimento: pesquisa qualitativa em saúde. 12 edição. Rio de Janeiro: Hucitec, 2010, 408p.

112. MINAYO, M. C. S. O desafio do conhecimento: pesquisa qualitativa em saúde. Rio de Janeiro: Abrasco, 2007. Disponível em: <http://www.scielo.br/scielo.php?pid=S1413-

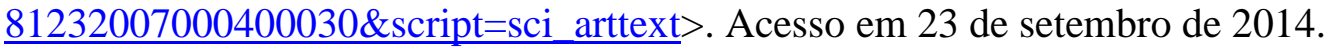

113. AMENDOLA, F.; OLIVEIRA, M. A. C.; ALVARENGA, M. R. M. Qualidade de vida dos cuidadores de pacientes dependentes no programa de saúde da família. Texto Contexto Enferm. 2008. 17(2):266-72. Disponível em: 〈http://www.scielo.br/pdf/tce/v17n2/07.pdf $\rangle$. Acesso em 21 de setembro de 2014.

114. PÉREZ, L. L.; DÍAZ, M. D.; CEBRERA, E. H.; HERNÁNDEZ, O. S. Síndrome Del "cuidador" em uma población atentida por equipo multidisciplinario de atención geriátrica.

Rev Cubana Enfermer 2001; 17(2): 107-11. Disponível em: 
<http://scielo.sld.cu/scielo.php?script=sci_arttext\&pid=S0864-03192001000200007>. Acesso em 21 de setembro de 2014.

115. RODRIGUES, S. L. A.; WATANABE, H. A. W.; DERNTL, A. M. A saúde de idosos que cuidam de idosos. Rev Esc Enferm USP 2006; 40(4):493-500. Disponível em: 〈http://www.scielo.br/pdf/reeusp/v40n4/v40n4a06.pdf>. Acesso em 21 de setembro de 2014.

116. GARCIA, M. A. A.; FRIGERIO, R. M.; MIYAMOTO, D. A. Qualidade de vida dos cuidadores de pacientes dependentes no programa de Saúde da Família. Texto Contexto Enferm, Florianópolis, 2008 Abr-Jun; 17(2): 266-72. SS. Idosos e cuidadores fragilizados? Mundo Saúde. 2005 Out/Dez; 29 (4): 645-52. Disponível em: <http://www.scielo.br/scielo.php?pid=S0104-07072008000200007\&script=sci_arttext $>$.

Acesso em 23 de maio de 2015.

117. LAMPERT, M. A., et.al. Perfil de doentes crônicos de um serviço de internação domiciliar da Região Sul do Brasil. J Nurs Health. 2013.3(2):14756. Disponível em: $<$ http://periodicos.ufpel.edu.br/ojs2/index.php/enfermagem/article/view/3554>. Acesso em 22 de março de 2015.

118. PASKULIN, L. M. G.; DIAS, V. R. F. G. Como é ser cuidado em casa: as percepções dos clientes. Rev Bras Enferm, Brasília (DF), 55(2): 119-25, 2002. Disponível em: $<$ http://www.scielo.br/scielo.php?pid=S0034-71672002000200005\&script=sci_arttext $>$.

Acesso em 30 de setembro de 2014.

119. BAMPI, L. N. S.; BARALDI, S.; GUILHEM, D., et al. Nurse undergraduate students' perception of quality of life. Rev. Gaúcha Enferm. [online]. 2013, vol.34, n.2, pp. 125-132. ISSN 1983-1447. Disponível em: 〈http://www.scielo.br/pdf/rgenf/v34n2/en_v34n2a16.pdf >. Citado em 05 junho de 2015.

120. GIACOMONI, C. H. Bem-estar subjetivo: em busca da qualidade de vida. Temas em Psicologia da SBP-2004. Vol. 12, no 1, 43- 50. Disponível em: <http://pepsic.bvsalud.org/pdf/tp/v12n1/v12n1a05.pdf> . Acesso em 25 de fevereiro de 2015.

121. PEREIRA, D. F.; TEIXEIRA, C. S.; SANTOS, A. Qualidade de vida: abordagens, conceitos e avaliação. Rev. bras. Educ. Fís. Esporte, São Paulo, v.26, n.2, p.241-50, abr./jun. 2012. Disponível em: 〈http://www.scielo.br/pdf/rbefe/v26n2/07.pdf $>$. Acesso em 30 de setembro de 2014.

122. OllVEIRA, M. F.; SILVA, L. M.; OLIVEIRA, F. T.; GOMES, T. T. A qualidade de vida de cuidadores de pacientes com Paralisia Cerebral. J Health Sci Inst. 2013; 31(4):421-4. Disponível em <http://www.unip.br/comunicacao/publicacoes/ics/edicoes/2013/04_outdez/V31_n4_2013_p4 21-424.pdf $>$. Acesso em 30 de setembro de 2014.

123. FERREIRA, C. G.; ALEXANDRE, T. S.; LEMOS, N. D. Fatores Associados à Qualidade de Vida de Cuidadores de Idosos em Assistência Domiciliária. Saúde Soc. São Paulo, v.20, n.2, p.398-409, 2011. Disponível em: 〈http://www.scielo.br/pdf/sausoc/v20n2/12.pdf>. Acesso em 30 de setembro de 2014. 
124. KARSCH, U. M. Idosos dependentes: famílias e cuidadores. Cad Saúde Pública, 200319 (3): 861-66. Disponível em: 〈http://www.scielo.br/pdf/csp/v19n3/15890.pdf>. Acesso em 30 de setembro de 2014.

125. RODRIGUEZ, P. R. El apoyo informal a lãs personas mayores em España y La protección social a La dependência. Del facilismo a lós derechos de ciudadanía. Rev Esp Geriatr Gerontol. 2005; 40 (supl 3): 5-15. Disponível em: $<$ http://www.caritas.es/imagesrepository/CapitulosPublicaciones/525/08\%20EL\%20APOYO \%20INFORMAL\%20COMO\%20DESTINATARIO.pdf>. Acesso em 25 de março de 2015.

126. ZOHAR, N.; GREENBERGER, C.; BACHNER, Y. G. Profile, burden, and quality of life of Israeli stroke survivor caregivers: a longitudinal study. Journal of Neurosciense Nursing, Glenview, v. 41, n. 2, p.92-104, 2009. Disponível em: <http://www.ncbi.nlm.nih.gov/pubmed/19361125>. Acesso em 30 de setembro de 2014.

127. NERI, A. L. Velhice e qualidade de vida da mulher. In: Neri, A. L. (organizador). Desenvolvimento e envelhecimento: perspectivas biológicas, psicológicas e sociológicas. São Paulo: Papirus; 2007. P.161-71.

128. CALDAS, C. P. O idoso em processo de demência: o impacto na família. In: Minayo, M. C. S. \& COIMBRA JÚNIOR, C. E. A. (Orgs.), Antropologia, saúde e envelhecimento, Fiocruz, PP. 51-71. Rio de Janeiro, 2002. Disponível em: <http://bases.bireme.br/cgibin/wxislind.exe/iah/online/?IsisScript=iah/iah.xis\&src=google\&base=LILACS\&lang=p\&nex

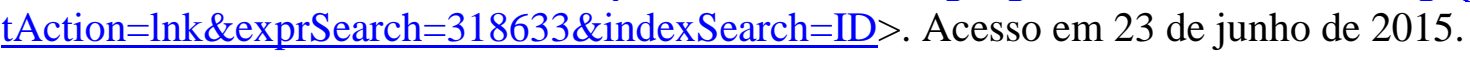

129. LE BOTERF, G. Desenvolvendo a Competência dos Profissionais. $3^{\text {a }}$. Edição. Porto Alegre: Bookman-Artmed Editora, 2003, 278p.

130. SILVA, F. M. As relações entre estratégia e gestão por competências. Gestão Contemporânea, Porto Alegre, ano 9, n. 11, p. 35-59, jan./jun. 2012. Disponível em: $<$ http://seer4.fapa.com.br/index.php/arquivo/article/view/118/77>. Acesso em 18 de fevereiro de 2015.

131. DUTRA, J. S. Competências: conceitos e instrumentos para gestão de pessoas na empresa moderna. São Paulo: Editora Atlas, 2004, 208p.

132. NOGUEIRA, M. A. A.; AZEREDO, Z. A.; SANTOS, A. S. Competências do cuidador informal atribuídas pelos enfermeiros comunitários: um estudo Delphi. Rev. Eletr. Enf. [Internet]. 2012. oct/dec;14(4):749-59. Disponível em: <http://www.revistas.ufg.br/index.php/fen/article/view/13205/13338>. Acesso em 13 de fevereiro de 2015.

133. BARBOSA, A. P. Quem é o cuidador social e qual é o seu papel? Ed. E-papers. $1^{\mathrm{a}}$ edição, 2013. 136 p.

134. PRINCE, M., et.al. Strain and its correlates among carers of people with dementia in low-income and middle-income countries. A 10/66 Dementia Research Group populationbased survey. Int J Geriatr Psychiatry. 2012. Jul;27(7):670-82. Disponível em: 〈http://www.ncbi.nlm.nih.gov/pubmed/22460403 >. Acesso em 13 de fevereiro de 2015. 
135. FERREIRA, H. P.; MARTINS, L. C.; BRAGA, A. L. F.; GARCIA, M. L. B. O impacto da doença crônica no cuidador. Rev Bras Clin Med. São Paulo, 2012 julago;10(4):278-84. Disponível em: $\quad$ http://files.bvs.br/upload/S/16791010/2012/v10n4/a3045.pdf>. Acesso em 13 de fevereiro de 2015.

136. ALMEIDA, A. M.; NUNES, F. A.; REZEK, G. S. S., et al. Qualidade de vida, autoestima, depressão e espiritualidade em pais cuidadores de menores diabéticos. Rev. Med. Res., Curitiba, v.4, n.2, p. 94-100, abr./jun. 2012. Disponível em: <http://www.crmpr.org.br/publicacoes/cientificas/index.php/revista-do-medico residente/article/view/248/238>. Acesso em 13 de fevereiro de 2015

137. SILVA, C. F.; PASSOS, V. M. A.; BARRETO, S. M. Frequência e repercussão da sobrecarga de cuidadoras familiares de idosos com demência. Rev. Bras. Geriatr. Gerontol., Rio de Janeiro, 2012; 15(4):707-731 Disponível em: <http://www.scielo.br/pdf/rbgg/v15n4/11.pdf $>$. Acesso em 13 de fevereiro de 2015

138. COCO, G. L., et al. Individual and health-relatde quality of life assessment in amyotrophic lateral sclerosis pateients and their caregivers. J. Neurological Sciences 2005; 238: 11-17.

139. UESUGUI, H. M.; FAGUNDES, D. S.; PINHO, D. L. M. Perfil e grau de dependência de idosos e sobrecarga de seus cuidadores. Acta paul. enferm., São Paulo 2011. 24(5) 685698. Disponível em: 〈http://www.scielo.br/pdf/ape/v24n5/15v24n5.pdf >. Acesso em 23 de março de 2015.

140. IGNACIO, M. G., et. al. Aspectos da sobrecarga em cuidadores de pacientes terminais por câncer: revisão de literatura. Psicologia Hospitalar, 20119 (1), 24-46. Disponível em: $\langle$ http://pepsic.bvsalud.org/scielo.php?pid=S167774092011000100003\&script=sci_arttext $>$.

Acesso em 13 de fevereiro de 2015.

141. DUMONT, S.; TURGEON, J.; ALLARD, P.; GAGNON, P.; CHARBONNEAU, C.; VÉZINA, L. Caring for a loved one with advanced cancer: determinants of psychological distress in family caregivers. Journal of Palliative Medicine, 2006. 9(4), 912-21. Disponível em: 〈http://www.ncbi.nlm.nih.gov/pubmed/16910806>. Acesso em 13 de fevereiro de 2015

142. PESCE, R. P., et al. Risco e proteção: em busca de equilíbrio promotor de resiliência. Psicol. teor. pesqui., Brasília , v.20, p.135-143, 2004. Disponível em: http://www.scielo.br/pdf/ptp/v20n2/a06v20n2.pdf>. Acesso em 13 de fevereiro de 2015.

143. FRANCIONI, F. F.; SILVA, D. M. G. V. Compreendendo o processo de viver com diabetes mellitus em uma comunidade de Florianópolis, Santa Catarina: das práticas de autoatenção ao apoio social. 186p. Tese (Doutorado em Enfermagem). Programa de PósGraduação em Enfermagem, Universidade Federal de Santa Catarina, Florianópolis, 2010. Disponível em: https://repositorio.ufsc.br/handle/123456789/94465>. Acesso em 14 de fevereiro de 2015

144. SANTOS, S. S. C.; PELZER, M. T.; RODRIGUES, M. C. T. Condições de enfrentamento dos familiares cuidadores de idosos portadores de doença de Alzheimer. Rev. Bras. de Ciên. do Envelh. Hum. Passo Fundo, v. 4, n. 2, p. 114- 126, Jul/Dez, 2007. 
Disponível em: 〈http://www.upf.br/seer/index.php/rbceh/article/view/133>. Acesso em 23 de março de 2014.

145. ANJOS, K. F.; BOERY, R. N. S. O.; PEREIRA, R. Quality of life of relative caregivers of elderly dependents at home. Texto contexto - enferm. [online]. 2014 [, vol.23, n.3, pp. 600-608. ISSN 0104-0707. Disponível em: $\langle$ http://www.scielo.br/pdf/tce/v23n3/0104-0707-tce-23-03-00600.pdf > . Citado em 05 junho de 2015.

146. LEVER, J. P.; MARTINEZ, Y. I. C. Pobreza y apoio social: un estudio comparativo en tres niveles socioeconômicos. Interam. j. psychol., Porto Alegre, v. 41, n. 2, p. 177- 188, $2007 . \quad$ Disponível em: $<$ http://bases.bireme.br/cgibin/wxislind.exe/iah/online/?IsisScript=iah/iah.xis\&src=google\&ba $\underline{\text { se}=L I L A C S \& l a n g}=p \& n e x t A c t i o n=l n k \&$ exprSearch=494475\&indexSearch=ID $>$. Acesso em 13 de fevereiro de 2015.

147. ANDRADE, S. F. O.; MELO, M. O.; RODRIGUES, M. J., et al. Qualidade de Vida e Sobrecarga de Cuidadores de Crianças com Câncer. Psicol. cienc. prof. [online]. 2014 vol.34, n.4 pp. 1014-1031. Disponível em: http://www.scielo.br/scielo.php?script=sci_arttext\&pid=S141498932014000401014\&lng=pt

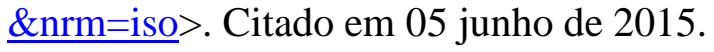

148. CUNHA, M. A., et al. Suporte Social: Apoio A Pessoas Com Doenças Crônicas. In: Jornada Augm, 14., 2006, Campinas. Anais eletrônicos. Campinas: AUGM, UNICAMP, 2006. Disponível em: <http://www.cori.unicamp.br/jornadas/completos/UFSC/>. Acesso em 13 de fevereiro de 2015

149. SILVA, I., et al. Efeitos do apoio social na qualidade de vida, controle metabólico e desenvolvimento de complicações crônicas em indivíduos com diabetes. Psicol. saúde doenças, Lisboa, v. 4, n. 1, p. 21-32, 2003. Disponível em: $<$ http://www.scielo.oces.mctes.pt/scielo.php?pid=S164500862003000100002\&script=sci_pdf $\underline{\mathrm{t} \ln \mathrm{g}=\mathrm{pt}>}>$. Acesso em 13 de fevereiro de 2015.

150. FONSECA, N. R.; PENNA, A. F. G.; SOARES, M. P. G. Ser cuidador familiar: um estudo sobre as conseqüências de assumir este papel. Physis Revista de Saúde Coletiva, Rio de Janeiro, 18 [4]: 727-743, 2008. Disponível em: $<$ http://www.scielo.br/scielo.php?script=sci_arttext\&pid=S0103-73312008000400007>. Acesso em 13 de fevereiro de 2015.

151. MARCO, E., et al. Deterioro de La calidad de vida en cuidadores familiares de pacientes con discapacidad por ictus: una entidad a considerar. Revista de Calidad Asistencial, Barcelona, (in press). Vol. 25. Num 06. Nov-Dec 2010. Disponível em: $<$ http://www.elsevier.es/es-revista-revista-calidad-asistencial-256-articulo-deterioro-calidadvida-cuidadores-familiares-13187631>. Acesso em 13 de fevereiro de 2015

152. ZOHAR, N.; GREENBERGER, C.; BACHNER, Y. G. Profile, burden, and quality of life of Israeli stroke survivor caregivers: a longitudinal study. Journal of Neurosciense Nursing, Glenview, 2009 v. 41, n. 2, p.92-104. Disponível em: <http://www.ncbi.nlm.nih.gov/pubmed/19361125>. Acesso em 24 de março de 2015. 
153. SANTOS, R. L.; SOUSA, M. F. B.; BRASIL, D.; DOURADO, M. Intervenções de grupo para sobrecarga de cuidadores de pacientes com demência: uma revisão sistemática. Rev Psiq Clin. 2011;38(4):161-7. Disponível em: <http://www.scielo.br/readcube/epdf.php?doi=10.1590/S010160832011000400009\&pid=S01 01-60832011000400009\&pdf_path=rpc/v38n4/a09v38n4.pdf>. Acesso em 13 de fevereiro de 2015.

154. MARTÍN-CARRASCO, M., et al. Effectiveness of a psychoeducational intervention program in the reduction of caregiver burden in alzheimer's disease patients' caregivers. Int J Geriatr Psychiatry. 2009. 24:489-99. Disponível em: <http://www.ncbi.nlm.nih.gov/pubmed/18949763>. Acesso em 13 de fevereiro de 2015.

155. VOLPATO, F. S. Pacientes oncológicos: um olhar sobre as dificuldades vivenciadas pelos familiares cuidadores. Imaginario. 2007 13(14): 511-544. Disponível em: $<$ http://pepsic.bvsalud.org/pdf/ima/v13n14/v13n14a24.pdf> $>$. Acesso em 13 de fevereiro de 2015.

156. WALDOW, V. R. Cuidado humano: o resgate necessário. Porto Alegre (RS): Sagra Luzzatto; 1998. In: COELHO, E. A. C.; FONSECA, R. M. G. S. Pensando o cuidado na relação dialética entre sujeitos sociais. Rev Bras Enferm 2005 mar-abr; 58(2):214-7. Disponível em: 〈http://www.scielo.br/pdf/reben/v58n2/a17.pdf>. Acesso em 23 de março de 2015.

157. MCCOUGHLAN, M. A necessidade de cuidados paliativos. In: PESSINI, L.; BERTACHINI, L. Humanização e cuidados paliativos. 2. ed. São Paulo: Loyola, 2004. Cap. 11, p. 167-180.

158. CHRISTOFOLETTI, G.; OLIANI, M. M.; BUCKEN-GOBBI, L. T., et al. Physical activity attenuates Atividade física, sono e qualidade de vida na doença de Alzheimer 205 Rev Bras Ativ Fis e Saúde, Pelotas/RS, 7(3):200-205, Jun/2012 neuropsychiatric disturbances and caregiver burden in patients with dementia. Clinics 2011; 66: 613-618.

159. COELHO, F. G. M.; SANTOS-GALDURÓZ, R. F.; GOBBI, S.; STELLA, F. Atividade Física sistematizada e desempenho cognitivo em idosos com demência de Alzheimer: uma revisão sistemática. Rev Bras Psiquiatr, 2009; 31:163-170.

160. PAULO, M. G., et. al. Avaliação da Qualidade de Vida de Cuidadores de Idosos Portadores de Deficiência Auditiva: Influência do Uso de Próteses Auditivas. Arq. Int. Otorrinolaringol. / Intl. Arch. Otorhinolaryngol., São Paulo, v.12, n.1, p. 28-36, 2008. Disponível em: $\langle$ http://www.arquivosdeorl.org.br/conteudo/pdfForl/479.pdf $>$. Acesso em 30 de setembro de 2014.

161. ORNSTEIN, K.; GAUGLER, J. E. The problem with "problem behaviors": a systematic review of the association between individual patient behavioral and psychological symptoms and caregiver depression and burden within the dementia patient-caregiver dyad. Int Psychogeriatr. 2012;22:1-17.

162. ANDRÉN, S.; ELMSTAHL, S. The relationship between caregiver burden, caregivers' perceived health and their sense of coherence in caring for elders with dementia. J Clin Nurs. 2008;17(6):790-9. 
163. ANDRADE, L. M., et al. A problemática do cuidador familiar do portador de acidente vascular cerebral. Revista da Escola de Enfermagem da USP, São Paulo, v. 43, n. 1, p. 37 43, 2009[Acesso em 23 de maio de 2015). Disponível em:

164. GARRIDO, R.; MENEZES, P. R. Impacto em cuidadores de idosos com demência em um serviço psicogeriátrico. Rev. Saúde Pública, 2004; 38(6): 835-41.

165. LACERDA, A. Apoio social e a concepção do sujeito na sua integração entre corpo-mente: uma articulação de conceitos no campo da saúde pública. $94 \mathrm{f}$. Dissertação (Mestrado em Ciências na Área de Saúde Pública) - Escola Nacional de Saúde Pública, Fundação Oswaldo Cruz, Rio de Janeiro, 2002.

166. FERNANDES, M. G. M.; GARCIA, T. R. Atributos da tensão do cuidador familiar de idosos dependentes. Rev. Esc Enferm USP, 2009; 43(4):818-24. Disponível em: <www.ee.usp.br/reeusp/>. Acesso em 23 de maio de 2015.

167. BARROS, M. B. A.; FRANCISCO, P. M. S. B.; ZANCHETTA, L. M.; CÉSAR, C. L. G. Tendências das desigualdades sociais e demográficas na prevalência de doenças crônicas no Brasil, PNAD: 2003- 2008. Ciência \& Saúde Coletiva, 16(9):3755-68, 2011. Disponível em: 〈http://www.scielo.br/pdf/csc/v16n9/a12v16n9.pdf>. Acesso em 23 de maio de 2015.

168. SELLI, L.; JUNGES, J. R.; MENEGUEL, S.; VIAL, E. A. O cuidado na ressignificação da vida diante da doença. O Mundo da Saúde São Paulo: 2008: jan/mar 32(1):85-90. Disponível em: 〈http://www.saocamilo-sp.br/pdf/mundo_saude/58/85a90.pdf $>$. Acesso em 23 de março de 2015.

169. BERTOLIN, D. C.; PACE, A. E.; KUSUMOTA, L.; HAAS, V. Associação entre os modos de enfrentamento e as variáveis sociodemográficas de pessoas em hemodiálise crônica. Rev Esc Enferm USP 2011.; 45(5): 1070-6 Disponível em: <http://www.scielo.br/pdf/reeusp/v45n5/v45n5a06.pdf>. Acesso em 23 de março de 2015.

170. ORGANIZAÇÃO MUNDIAL DA SAÚDE. Cuidados inovadores para condições crônicas: componentes estruturais de ação: relatório mundial / Organização Mundial da Saúde - $\quad$ Brasília, 2003. Disponível $<$ http://www.who.int/chp/knowledge/publications/icccportuguese.pdf $>$. Acesso em 23 de maio de 2015.

171. PONTES-FERNANDES, A. C.; PETEAN, E. B. L. Sobrecarga Emocional e Qualidade de Vida em Mães de Crianças com Erros Inatos do Metabolismo. Psicologia: Teoria e Pesquisa. Out-Dez 2011, Vol. 27 n. 4, pp. 459-465.

172. WESTPHAL, A. C.; ALONSO, N. B.; SILVA, T. I., et al. Comparação da Qualidade de Vida e Sobrecarga dos Cuidadores de Pacientes com Epilepsia por Esclerose Mesial Temporal e Epilepsia Mioclônica Juvenil. J Epilepsy Clin Neurophysiol 2005; 11(2):71-76. Disponível em: <http://www.scielo.br/readcube/epdf.php?doi=10.1590/S167626492005000200001\&pid=S16 76 26492005000200001\&pdf_path=jecn/v11n2/a01v11n2.pdf $>$ Acesso em 23 de maio de 2015. 
173. MARONESI, L. C.; SILVA, N. R.; CANTU, S. O.; SANTOS, A. R. Indicadores de estresse e sobrecarga em cuidadores formais e informais de pacientes oncológicos. Estudos e Pesquisa em Psicologia. v. 14, n. 3. 2014. Disponível em: <http://www.epublicacoes.uerj.br/index.php/revispsi/issue/view/906>. Acesso em 21 de janeiro de 2015.

174. SOUSA, A. T. O.; FRANÇA, J. R. F. S.; NÓBREGA, M. M. L., et al. Palliative care: a conceptual analysis. Online braz j nurs. 2010. 9(2):1-5. Disponível em: <http://www.objnursing.uff.br/index.php/nursing/article/view/j.16764285.2010.2947/667>.

Acesso em 23 de janeiro de 2015.

175. NIGHTINGALE, M. Religion, spirituality and ethnicity: what it means for caregivers of persons with Alzheimer's disease and related disorders. Dementia, 2003: 2(3):379-91 MURRAY-SWANK, A., et al. Relisiosity, psychosocial adjustment, and subjective burden of persons who care for those with mental illness. Psychiatric Services, 2006: 57: 361-65

176. YAMADA, K. N.; DELlAROZA, S. M. G.; SIQUEIRA, J. E. Aspectos éticos envolvidos na assistência a idosos dependentes e seus cuidadores. O Mundo da Saúde. São Paulo: 2006. out/dez 30 (4): 667-672. Disponível em: <http://www.saocamilosp.br/pdf/mundo_saude/41/19_aspectos_eticos.pdf >. Citado em 15 de Setembro de 2013.

177. WATERKEMPER, R.; REIBNITZ, K. S. Cuidados paliativos: a avaliação da dor na percepção de enfermeiras. Rev Gaúcha Enferm., Porto Alegre (RS) 2010 mar;31(1):84-91. Disponível em: $\quad$ http://www.scielo.br/scielo.php?pid=S1983-

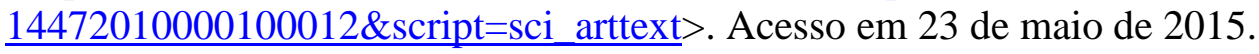

178. FLORIANI, C. A. Moderno movimento hospice: kalotanásia e o revivalismo estético da boa morte. Rev. bioét. (Impr.). 2013; 21 (3): 397-404. Disponível em: <http://www.scielo.br/pdf/bioet/v21n3/a03v21n3.pdf>. Acesso em 23 de maio de 2015.

179. SILVA, R. C. F.; HORTALE, V. A. Cuidados paliativos oncológicos: elementos para o debate de diretrizes nesta área. Cad. Saúde Pública 2006; 22(10): 2055-2066.

180. SIMONI, M.; SANTOS, M. L. Considerações sobre cuidado paliativo e trabalho hospitalar: uma abordagem plural sobre o processo de trabalho de enfermagem. Psicol USP 2003; 14(2): 169-94.

181. FARIA, A. P. S.; BELLATO, R. A compreensão do fenômeno condição crônica por diabetes mellitus a partir da experiência de adoecimento. Rev. Eletr. Enf. [Internet]. 2010 12(3):520-7. Disponível em: 〈http://dx.doi.org/10.5216/ree.v12i3.6953>. Acesso em 23 de maio de 2015.

182. SOUZA, S. P. S.; LIMA, R. A. G. Condição crônica e normalidade: rumo ao movimento que amplia a potência de ser feliz. Rev Lat Am Enfermagem. 2007;15(1):156-64

183. SANTOS, D. M. A.; LATTARO, R. C. C.; ALMEIDA, D. A. Cuidados paliativos de enfermagem ao paciente oncológico terminal: revisão da literatura. Rev Ini Cient Lib. V.1, n.1, 2011. Disponível em: $\langle$ http://www.libertas.edu.br/revistalibertas/revistalibertas1/artigo05.pdf $>$. Citado em 15 de setembro de 2013. 
184. O'CONNEL, B.; BAKER, L. Managing as carers of stroke survivors: strategies from the field. International Journal of Nursing Practice, 2006 10, 121-126. Disponível em: $<$ http://www.researchgate.net/publication/8557643_Managing_as_carers_of_stroke_survivors _strategies_from_the field $>$. Acesso em 23 de maio de 2015. 
APÊNDICE 1

Termo de consentimento livre e esclarecido - TCLE 


\section{Termo de consentimento livre e esclarecido - TCLE}

$\mathrm{O}$ (a) $\operatorname{Sr}($ a) está sendo convidado a participar do projeto de pesquisa: PERCEPÇÃO SOBRE QUALIDADE DE VIDA DE CUIDADORES DE PACIENTES EM UM PROGRAMA DE ATENÇÃO DOMICILIAR - RELAÇÃO ENTRE QUALIDADE DE VIDA, FINITUDE HUMANA E SOBRECARGA DO CUIDADOR.

O objetivo desta pesquisa é analisar a relação entre a percepção da qualidade de vida e da sobrecarga de trabalho com a percepção da finitude humana e as implicações psicossociais do cuidar de pacientes internados em domicílio.

$\mathrm{O}$ (a) senhor(a) receberá todos os esclarecimentos necessários antes e no decorrer da pesquisa e lhe asseguramos que seu nome não aparecerá, sendo mantido o mais rigoroso sigilo através da omissão total de quaisquer informações que permitam identificá-lo(a).

A sua participação será através de uma entrevista que o(a) senhor(a) deverá responder no domicílio do paciente que o(a) senhor(a) cuida na data combinada. Não existe obrigatoriamente um tempo pré-determinado para responder a entrevista. Será respeitado o tempo de cada um para responder. Informamos que o senhor(a) pode se recusar a responder qualquer questão que lhe traga constrangimento, podendo desistir de participar da pesquisa em qualquer momento sem nenhum prejuízo para o(a) senhor(a).

Informamos ainda que a entrevista será gravada em áudio e depois transcrita para que as informações sejam aproveitadas na íntegra para análise. Os resultados da pesquisa serão divulgados em reunião com os participantes que será previamente agendada, podendo os mesmos ser publicados posteriormente. Os dados e materiais utilizados na pesquisa ficarão sob a guarda da pesquisadora principal.

Os riscos decorrentes da sua participação na pesquisa se referem aos psicossociais, pois serão discutidos temas que envolvem os sentimentos individuais e podem gerar ansiedade e sofrimento psicológico. Como benefícios o(a) senhor(a) será convidado a participar de um grupo de discussão que ocorrerá quinzenalmente com equipe psicossocial nas dependências do NRAD e terá atendimento individual, se necessário. Nesses momentos o(a) senhor(a) terá a oportunidade de discutir suas angústias e ansiedades e refletir sobre as questões envolvidas na pesquisa como qualidade de vida e finitude humana, além de trocar informações com demais cuidadores participantes da pesquisa. Os grupos e o atendimento individual serão disponibilizados até seis meses após a sua participação na pesquisa.

Se o(a) senhor(a) tiver qualquer dúvida em relação a esta pesquisa, por favor entre em contato com a pesquisadora responsável, Prof ${ }^{a}$ Diane Maria Scherer Kuhn Lago, pelos 
telefones: 61-8138 0348 ou 61- 31078419 e e-mail: diane@unb.br ou ainda, com o comitê de Ética em Pesquisa - CEP da Secretaria de Estado de Saúde do Distrito Federal - SES-DF no endereço SMHN - Q.03 - Conjunto A Bloco 1 - Edifício FEPECS - Brasília-DF Telefone: (061) 3325-4955 e email: cepsesdf@ saude.df.gov.br.

Este documento foi elaborado em duas vias, sendo que uma ficará com o pesquisador responsável e outra com o(a) senhor(a).

Nome completo do participante:

Documento CPF ou RG:

Telefone de contato:

Assinatura:

Nome completo da pesquisadora principal: Diane Maria Scherer Kuhn Lago

CPF: 575.859.200-59

Telefone: (61) 81380348 e (61) 92624848

Assinatura: 
APÊNDICE 2

Questionário de dados sociodemográficos e clínicos 


\section{Questionário de dados sociodemográficos e clínicos}

1. Dados sociodemográficos:

1.1. Identificação:

1.2. Iniciais do nome:

1.3. Idade:

1.4. DN:

1.5. Sexo ( ) F ( ) M

2. Escolaridade

( ) Analfabeto

( ) Sabe ler e escrever

( ) Ensino fundamental 1 ( $4^{\circ}$ série ou $5^{\circ}$ ano) completo

( ) Ensino fundamental 1 ( $4^{\circ}$ série ou $5^{\circ}$ ano) incompleto

( ) Ensino fundamental $2\left(8^{\circ}\right.$ série ou $9^{\circ}$ ano) completo

( ) Ensino fundamental 1 ( $8^{\circ}$ série ou $9^{\circ}$ ano) incompleto

( ) Ensino médio completo

( ) Ensino médio incompleto

( ) Ensino superior completo

( ) Ensino superior incompleto

( ) Outro. Especificar

3. Estado civil

( ) Solteiro (a)

( ) Casado (a)

( ) Separado/divorciado (a)

( ) Viúvo

( ) Outro. Especificar

4. Religião:

Praticante ( ) sim ( ) não 
5. Endereço:

6. Qual o grau de parentesco com o paciente?

( ) filho(a)

( ) $\operatorname{esposo}(a)$

( ) irmão(a)

( ) tio(a)

( ) neto(a)

( ) sobrinho(a)

( ) outro. Especificar

( ) nenhum

6. Ocupação:

6.4.Principal ocupação atual:

6.5.Em que ocupação você trabalhou a maior parte da vida?

6.6.Exerce trabalho remunerado atualmente?

( ) sim, exercendo atividade - Qual?

( ) sim, mas afastado - Quanto tempo?

( ) não, desempregado

( ) não, dona de casa

( ) não, estudante

( ) não, outro

7. Renda aproximada em salário mínimo no último mês:

( ) até 1

( ) 2 a 3

( ) 4 a 5

( ) 5 a 10

( ) mais de 10

8. Condições de moradia: 
8.4. Quantas pessoas no total moram neste domicílio?

8.5. Você mora neste mesmo domicílio?

8.6. Se não, onde mora?

8.7. Quantas pessoas moram na sua casa?

8.8. A residência em que você vive é

( ) alugada

( ) própria quitada

( ) própria financiada

( ) cedida

( ) outro

8.6 Energia elétrica

( ) $\operatorname{sim}$

( ) não

8.7 Abastecimento de água

( ) pública

( ) poço ou nascente

( ) outros

8.8 Tratamento de água no domicílio

( ) filtração

( ) fervura

( ) cloração

( ) sem tratamento

$\underline{\text { 8.9 Tipo de residência }}$

( ) apartamento

( ) casa

( ) tijolo

( ) madeira 
( ) material aproveitado

( ) outro

Destino do lixo

( ) coleta pública

( ) enterrado/queimado

( ) céu aberto

Destino do esgoto

( ) rede de esgoto

( ) fossa

( ) céu aberto

23. Há quanto tempo é cuidador?

23.1. Você sente dor? Se sim, onde?

24. Qual a intensidade da dor?
( ) fraca
( ) moderada
( ) intensa
( ) insuportável
( ) não se aplica

25. Você faz algum tratamento de saúde?
( ) $\operatorname{sim}$
( ) não

26. É portador de alguma doença? Qual(is)?

27. Quando foi percebida e diagnosticada a doença?

28. Faz tratamento na rede pública de saúde? Há quanto tempo?

29. Esteve internado em hospital?
( ) não
( ) sim. Por quanto tempo? 
185. Você toma algum remédio para depressão ou calmante?

Se sim, qual (is)?

32. Quantas horas, em média, você dorme por dia?

33. O seu sono é:

( ) contínuo

( ) interrompido - Com que frequência?

34. Você tem atividade sexual
( ) $\operatorname{sim}$
( ) não

35. De quem você recebe ajuda?
( ) amigos
( ) parentes
( ) vizinho
( ) profissional de saúde
( ) outros
( ) ninguém

Alguma observação que queira acrescentar:

Observação do entrevistador: 
APÊNDICE 3

Roteiro norteador para entrevista 


\section{Roteiro norteador para entrevista}

Parte A - Faça um relato livre da sua história de cuidado com o paciente desde o diagnóstico até a internação domiciliar.

Parte B - O que a doença significa para o(a) $\mathrm{Sr}(\mathrm{a})$ ?

Parte C - O que a morte significa para o(a) $\mathrm{Sr}(\mathrm{a})$ ?

Parte D - Quais são os seus sentimentos frente ao sofrimento do paciente?

Parte E - O que mudou na sua vida após o(a) Sr(a) ter se tornado cuidador(a)? 


\section{APÊNDICE 4}

Nota prévia publicada no periódico - Online Brazilian Journal of Nursing - OBJN com o título: qualidade de vida, finitude humana e sobrecarga de cuidadores: um estudo exploratório 

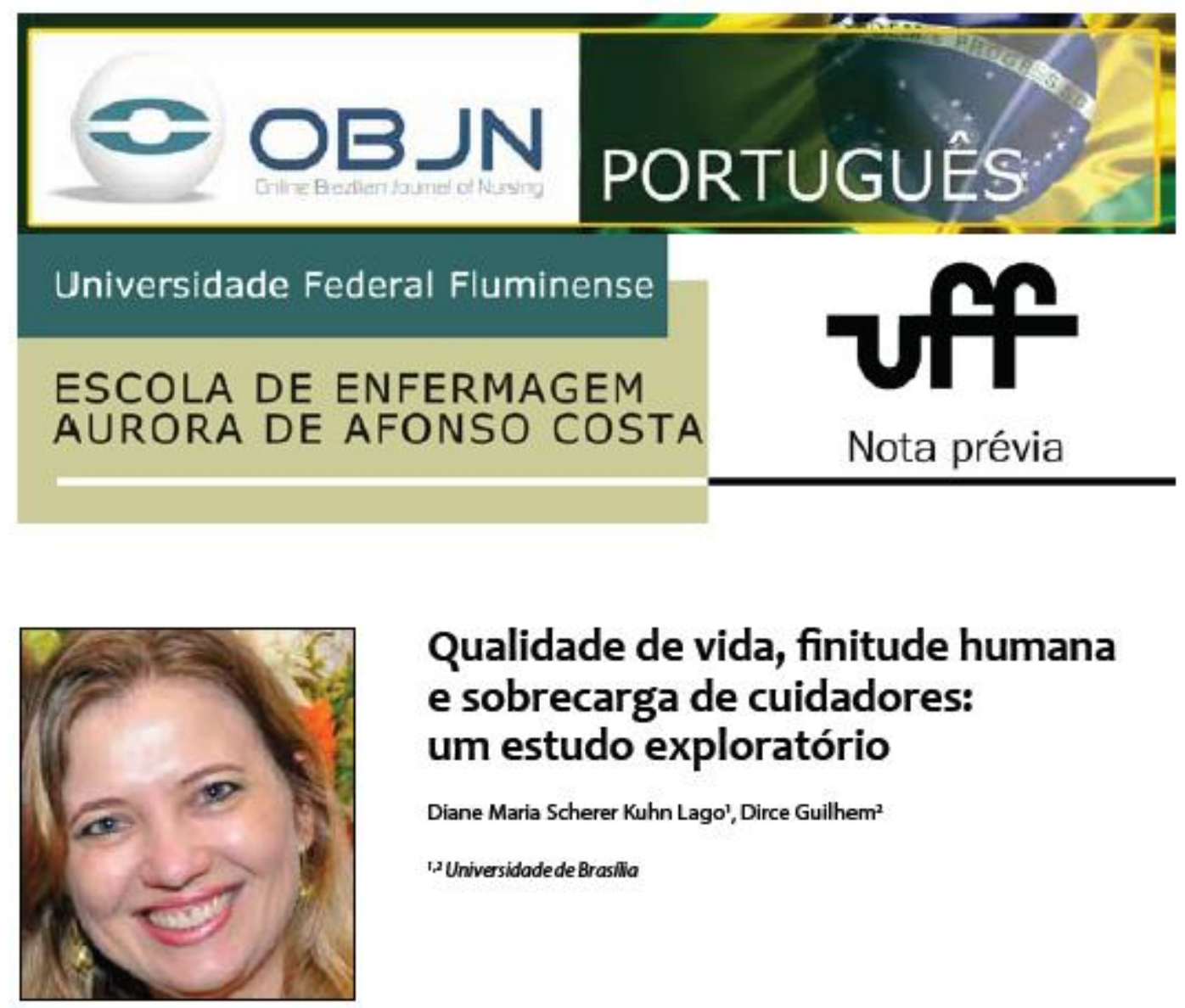

\section{Qualidade de vida, finitude humana e sobrecarga de cuidadores: um estudo exploratório}

Diane Maria Scherer Kuhn Lago', Dirce Guilhem²

1,2 Universidadede Brasilia

\section{RESUMO}

Projeto de tese de doutorado desenvolvido junto ao Programa de Pós-Graduaçăo em Enfermagem da Universidade de Brasilia.

Objetivo: analisar a relaçăo entre percepçăo sobre qualidade de vida e sobrecarga de trabalho e sua relaçăo com a finitude humana e as implicaçóes psicossociais do cuidar de pacientes internados em domicilio. Método: trata-se de estudo descritivo e exploratório, de corte transversal e de cunho qualitativo, utilizandose entrevistas semiestruturadas e instrumentos especficos para a coleta de dados prevista para o período entre os meses de março a setembro de 2013. Os dados seráo analisados utilizando-se o programa estatístico SPSS", versăo 13.0 , além da técnica de análise temática de conteúdo.

Descritores: Qualidade de vida; Cuidadores; Serviços de Assistência Domiciliar.

Lago DMSK, Guilhem D. Quality of life, human finitude and work overload for caregivers: an exploratory study. Online braz j nurs [Internet]. 2013 Oct [cited year mouth day]; 12 Suppl: 761-63. Available from: http://www.objnursing.uff.br/index.php/ nursing/artide/view/4471 


\section{SITUAÇÃO PROBLEMA E SUA SIGNIFICÂNCIA}

A evolução dos tratamentos continuados para diversas doenças crónicas resulta em maior sobrevida de pacientes e traz à tona a preocupaçăo com a qualidade de vida das pessoas e de seus familiares. A internaçäo hospitalar, devido à ausência de resolutividade, passou a ser considerada desnecessária para o tratamento de doenças crónico-degenerativas e, em muitos casos, se mostrou pouco benéfica para o paciente. $A$ internação domiciliar passou a ser considerada uma possibilidade para conciliar o atendimento necessário em saúde com a convivência familiar e da rede social em ambiente saudável e seguro.

Diante de doenças terminais que ameaçam a vida, membros da familia, que possuem vínculo afetivo com o paciente, assumem o papel de cuidador domiciliar. Geralmente, porém, essas pessoas não estäo preparadas para desenvolver esta funçäo, que não obstante a sua complexidade, é agregada às açōes do seu cotidiano $^{(1)}$. Dependendo do tempo destinadoe das funçöes desempenhadas essa pessoa passa a ser o responsável direto ou cuidador principal. Pode, ainda, receber auxilio financeiro para esta atividade, transformando-a em uma atividade formal[(2). A promoçäo integral da saúde e o suporte aos cuidadores familiares representam, portanto, novos desafios para o sistema de saúde brasileiro. O termo'cuidado paliativo', define o fenômeno que envolve equipe multiprofissional e multidimensional com o proposito de atender a pacientes sem possibilidades terapeuticas. Busca promover conforto e bem-estar para o paciente e sua familia, bem como a diminuiçāo dos sintomas negativos, resultando na melhora da sua qualidade de vida e na dignificaçăo do seu processo de morrer ${ }^{(3)}$.

A internação domiciliar prolongada de pacientes em fase terminal traz para ao seio familiar o tema da morte e o coloca como fenómeno do cotidiano. Este tema levanta conflitos individuais e familiares, o que demonstra a importåncia de que seja discutido e (re)elaborado para que haja melhor entendimento sobre a finitude humana.

Na maioria das vezes, o cuidador é um familiar próximo do paciente e presta assistência por tempo indeterminado. Esse envolvimento contínuo provoca sofrimento decorrente do enfrentamento da doença e da proximidade da morte de seu familiar. Dessa forma, surge a necessidade de saber qual a percepçāo sobre a sua própria qualidade de vida, sobrecarga de trabalho e a finitude humana, bem como quais as implicaçōes psicossociais associadas a este papel, fundamental na sociedade atual.

\section{QUESTÅO NORTEADORA}

Quais os fatores que interferem na qualidade de vida e no desgaste físico e emocional do cuidador de paciente internado em domicilio?

\section{OBJETIVOS}

Conhecer a percepçăo de cuidadores domiciliares sobre qualidade de vida e sobrecarga de trabalho e sua relação com a finitude humana e as implicaçōes psicossociais do cuidar de pacientes internados em domicílio.

\section{MÉTODO}

Trata-se de estudo descritivo e exploratorio, de corte transversal e de cunho qualitativo. Participaräo do estudo cuidadores de pacientes internados em domicilio. Foram definidos como critérios de inclusäo: ser cuidador domiciliar principal de paciente do cadastro ativo de um 
Núcleo Regional de Atençäo Domiciliar (NRAD), ter mais de 18 anos de idade, aceitar participar da pesquisa e assinar o Termo de Consentimento Livre e Esclarecido (TCLE); e como critérios de exclusäo: ser cuidador auxiliar e ter menos de 18 anos de idade. Será aplicado o critério de saturação da amostra para delimitaçäo do número de participantes conforme a repetiçāo das informaçōes sem acréscimo de novos elementos para a pesquisa. Para a coleta dos dados, planejada para o período de março e setembro de 2013, seräo utilizados seis instrumentos validados, sendo: 1. Questionário sobre dados sociodemograficos; 2. Word Health Organization Quality of Life Instrument Bref (WHOQOL-bref); 3. Word Health Organization Quality of Life Instrument OId (WHOQOL-old) - para cuidadores com mais de sessenta anos de idade; 4 . Escala de Sobrecarga de Cuidador (ESC); 5. Perfil de Atitudes Perante a Morte; 6. Entrevista semiestruturada com roteiro norteador contendo os seguintes eixos: a. Do diagnóstico inicial até a internaçäo domiciliar; b. O significado da doença; C. O significado da morte; d. Sentimentos frente ao sofrimento; $\mathrm{e}$. Mudanças no cotidiano do cuidador.

Os dados serão analisados utilizando-se o programa Statistical Package for the Social Sciences" (SPSS), versāo 13.0; além da técnica de análise de conteúdo para a entrevista semiestruturada. Seräo construídos diagramas de dispersäo para analisar as correlaçöes entre os resultados dos instrumentos aplicados.

\section{REFERÊNCIAS}

1. Brasil, Ministério da Saúde. Secretaria de Atençăo à Saúde. Departamento de Atençāo Básica. Caderno de atençāo domiciliar. Brasilia, 2012.2v.

2. Born T. Cuidar Melhor e Evitar a Violência - Manual do Cuidador da Pessoa Idosa (org) - Brasilia: Secretaria Especial dos Direitos Humanos - Subsecretaria de Promoçāo e Defesa dos Direitos Humanos, 2008;

3. Sousa A. França J. Nóbrega M. Fernandes M. Costa S. Palliative care: a conceptual analysis Online Braz J Nurs (Online) [internet]. 2010 August 30 [\#\#plugins.citationFormats.vancouver.cited\#\# 2013 Aug 5] 9(2): \#\#plugins.citationFormats.vancouver.availableFrom\#\#:http://www.objnursing. uff.br/index.php/nursing/article/view/2947.doi: http://dx.doi.org/10.5935/1676-4285.20102947

\section{Autores e participação na pesquisa}

Diane Maria Scherer Kuhn Lago - participou na pesquisa, na elaboração, coleta e estruturação da nota prévia.

Dirce Guilhem - participou na orientação e estruturação da nota prévia.

\section{Dados do projeto}

Projeto de tese do Programa de Doutorado em Enfermagem da Universidade de Brasilia. Aprovado pelo Comité de Ettica em Pesquisa da Secretaria de Estado de Saúde do Distrito Federal, sob n CAAE: 08237612.7.0000.5553 e por Banca Examinadora durante o processo de seleção para o Doutorado.

Orientadora: Dirce Guilhem.

Apoio financeiro à pesquisa: Não hả.

Recebido: 06/08/2013

Revisado: $29 / 08 / 2013$

Aprovado: 29/08/2013 
APÊNDICE 5

Artigo publicado na Revista de Enfermagem da Universidade Federal de Pernambuco REUOL 


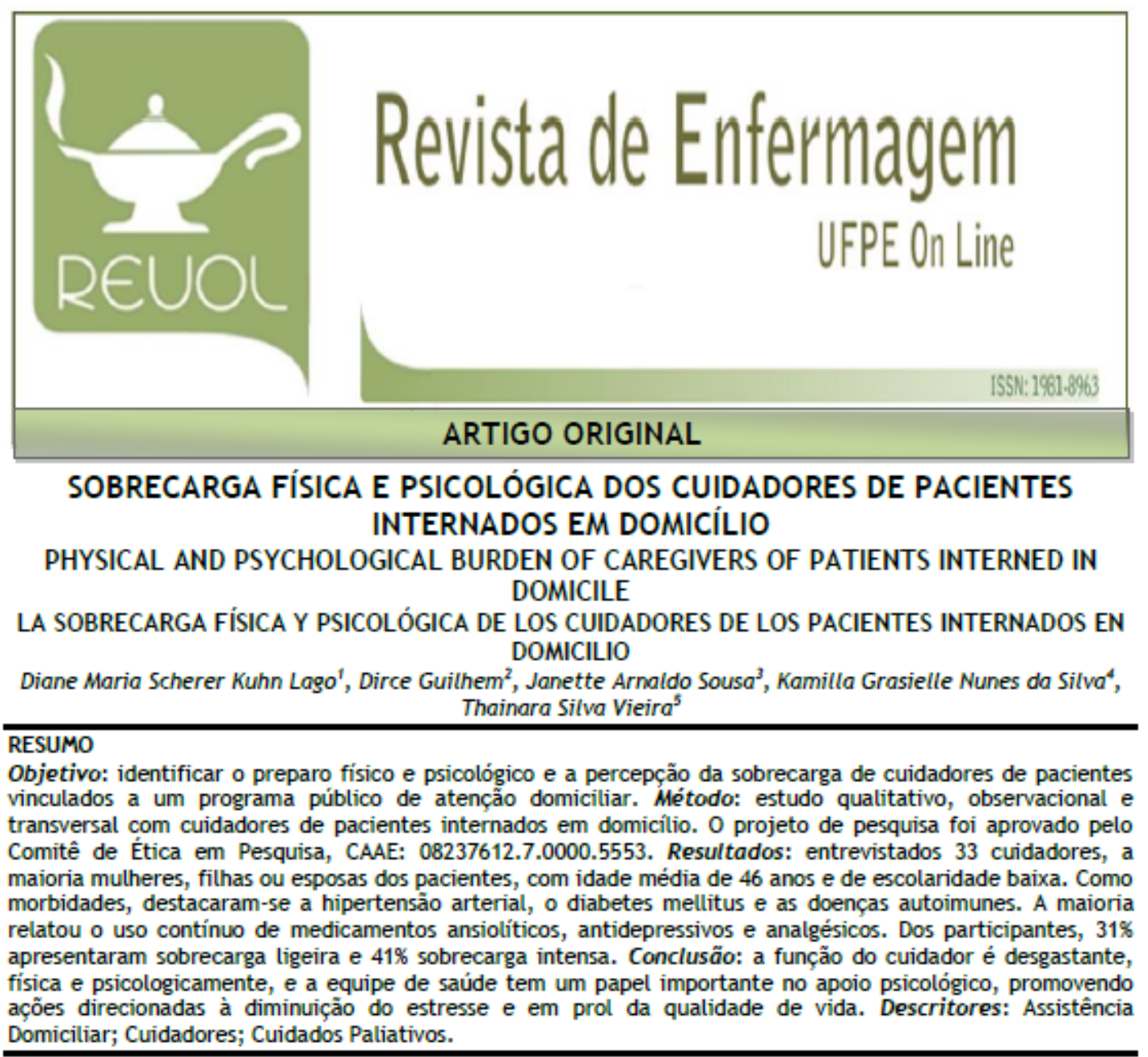
Domiciliar; Cuidadores; Cuidados Paliativos.

\section{ABSTRACT}

Objective: identifying the physical and the psychological fitness and the perception of burden of caregivers of patients linked to a public program of home care. Method: a qualitative, observational and cross-sectional study with caregivers of home inpatients. The research project was approved by the Committee of Ethics in Research, CAAE: 08237612.7.0000.5553. Results: there were interviewed 33 caregivers, mostly women, daughters or wives of patients with an average age of 46 years old, and with low education level. Regarding morbidities, the highlights were hypertension, diabetes mellitus and autoimmune diseases. Most reported continuous use of anxiolytics, antidepressants and painkillers. Of the participants, $31 \%$ had slight and $41 \%$ severe burden. Conclusion: the caregiver's functions are exhausting physically and psychologically and the health team has an important role in psychological support, promoting actions aimed at the reduction of stress and improving quality of life. Descriptors: Home Care; Caregivers; Palliative Care.

\section{RESUMEN}

Objetivo: identificar el estado físico y psicológico y la percepción de la sobrecarga de los cuidadores de pacientes vinculados a un programa público de atención en el hogar. Método: es un estudio cualitativo, observacional y transversal hecho con los cuidadores de los pacientes internos en el hogar. El proyecto de investigación fue aprobado por el Comité de Ética en la Investigación, CAAE: 08237612.7.0000.5553. Resultados: fueron entrevistados 33 cuidadores, la mayoría mujeres, hijas o esposas de los pacientes con una edad media de 46 años, y con bajo nivel de educación. Cómo morbilidades, los aspectos más destacados fueron la hipertensión, la diabetes mellitus y las enfermedades autoinmunes. La mayoría informó el uso continuo de ansiolíticos, antidepresivos y analgésicos. De los participantes, $31 \%$ tenían una ligera sobrecarga y el $41 \%$ sobrecarga severa. Conclusión: el papel del cuidador es agotador física y psicológicamente y el equipo de salud tiene un papel importante en el apoyo psicológico, en la promoción de acciones dirigidas a la reducción del estrés y en la mejora de la calidad de vida. Descriptores: Cuidado del Hogar; Cuidadores; Cuidados Paliativos.

'Enfermeira, Professora Mestre em Gerontologia, Aluna de Doutorado em Enfermagem, Universidade de Brasilia/UnB. Braślia (DF), Brasil. E-mail: diane.lago@gmail.com; 'Enfermeira, Pós-Doutora, Professora Titular, Universidade de Braślia/UnB. Brasilia (DF), Brasil. E-mail: guilhem unb.br: 'AAluna de Graduação em Enfermagem, Universidade de Braślia/UnB, Brasilia (DF), Brasil. E-mail: janette amaldo hhotmail.com; AAluna de Graduação em Enfermagem, Universidade de Braślia/UnB, Brasilia (DF), Brasil. E-mail: janette amaldochotmail.com; 'Aluna de Graduaçào em Enfermagem, Universidade de Brasilia/UnB, Brasilia (DF), Brasil. E-mail: kamilla grasiellechotmail.com; 'Aluna de Graduação em Enfermagem, Universidade de Brasilia/UnB, Brasilia (DF), Brasil. E-mail: tha.svieira@hotmail.com 
ISSN: 1981-8963

Lago DMSK, Guilhem D, Sousa JA et aL.

INTRODUÇAO

O envelhecimento populacional é uma realidade indiscutivel. No Brasil, dados do censo demográfico de 2010 revelam que, em 50 anos, a população brasileira praticamente triplicou, passando de 70 milhões, em 1960, para 190,7 milhões, em 2010. 0 número de idosos cresceu ainda mais, sendo que, em 1960, eles representavam $4,7 \%$ e, em 2010 , chegaram a um patamar de $10,8 \%$. 0 Instituto Brasileiro de Geografia e Estatistica - IBGE traz como estimativa para o ano de 2050, que os idosos representarão $25 \%$ do total da população brasileira. ${ }^{1}$

Para que 0 envelhecimento seja considerado ativo, é fundamental que haja qualidade de vida e a saúde é considerada como fator principal para que este requisito seja alcançado. Estudos relatam que a prevalência de doenças crônico-degenerativas aumenta com a idade. ${ }^{2}$ As doenças crônicodegenerativas e suas consequências podem comprometer a autonomia do idoso, e, desta forma, exigir cuidados permanentes por parte de profissionais de saúde e familiares.

Esta aceleração na transição demográfica associada ao aumento das doenças crônicas degenerativas, implicam no crescimento de custos dos serviços de saúde devido à necessidade de incorporação de tecnologias de alto custo sem, necessariamente, obter, na assistência, os resultados efetivos esperados. ${ }^{3}$

Em geral, as doenças crônico-degenerativas geram a necessidade de internação hospitalar para o tratamento inicial. Após a estabilização do quadro patológico, estas podem ser continuamente tratadas com cuidados especiais oferecidos em ambiente domiciliar. Este tipo de internação traz como vantagem a conciliação do atendimento em saúde necessário e a convivência familiar $e$ de amigos em ambiente saudável e seguro.

A atenção domiciliar (AD) possibilita a redução do período de internação, a agilidade no processo de alta hospitalar e a humanização no atendimento. Nesta modalidade de atenção, os serviços de saúde são oferecidos para o paciente em conjunto com a sua família, realizados na residência resultando em uma maior convivência entre o usuário do serviço de saúde e os profissionais que the atendem. ${ }^{4}$

Desde a criação do Serviço de Assistência Médica Domiciliar e de Urgência - SAMDU pelo Ministério do Trabalho em 1949, o Brasil vem aprimorando este tipo de atendimento $e$ discutindo quem assumiria 0 papel de cuidador do paciente. ${ }^{4}$
DOI: $10.5205 /$ reuol. $5221-43270-1 \cdot$ RV. 0901supl201509

sobrecarga física e psicológica dos cuidadores...

Um dos eixos da $A D$, a desospitalização de pacientes, proporciona atendimento personalizado, vínculo com os profissionais de saúde por meio de assistência integral $e$ humanizada, preservação da autonomia, maior participação da família no tratamento devido à reintegração no ambiente familiar, além de possivel aumento na qualidade de vida. ${ }^{5}$

Para que este atendimento de internação seja feito no domicílio do paciente é importante que haja a figura do cuidador. 0 Ministério da Saúde definiu que o cuidador pode ser uma pessoa da comunidade que foi adquirindo experiência, cuidando de pessoas doentes $\mathrm{e}$ fez desse cuidado uma profissão informal ou ainda algum familiar que se disponha a permanecer um tempo maior na assistência ao paciente. ${ }^{4}$

Em abril de 2002, foi sancionada pelo Presidente da República a Lei n. 10.424 que dispóe sobre as condições para a promoção, proteção e recuperação da saúde, a organização e o funcionamento de serviços correspondentes e dá outras providências, regulamentando a assistência domiciliar no Sistema Único de Saúde (SUS). ${ }^{6}$

Para dar continuidade ao estabelecimento deste atendimento em saúde no Brasil, a Agência Nacional de Vigilância Sanitária (Anvisa) publicou a Resolução de Diretoria Colegiada - RDC n. 11/2006 estabelecendo os requisitos de funcionamento para os Serviços de Atenção Domiciliar públicos e privados em todo o País. As modalidades previstas são de assistência e de internação e são destinadas à pacientes com impossibilidade de locomoção e que necessitam de procedimentos de internação de menor complexidade e que podem ser dispensados em domicílio. ${ }^{7}$

A Secretaria de Estado de Saúde do Distrito Federal criou em seu organograma a Gerência de Atenção Domiciliar, que está vinculada à Diretoria de Atenção Primária em Saúde da Subsecretaria de Atenção à Saúde, e que atende a 10 (dez) Núcleos Regionais de Atenção Domiciliar (NRAD). A estes núcleos cabe a responsabilidade do atendimento a pacientes em modalidades diversas de atenção no domicílio, bem como a orientação aos cuidadores sobre os cuidados dispensados ao paciente e para a manutenção da sua própria saúde.

Por necessidade, muitas vezes, os cuidadores dos pacientes internados em domicílio são pessoas próximas, como familiares, que, por consequência do seu despreparo, apresentam dificuldades em exercer esta função que exige tempo, dedicação e conhecimento. 
ISSN: 1981-8963

Lago DMSK, Guilhem D, Sousa JA et al.

Com base no exposto, torna-se evidente a necessidade de preparo físico e mental dos cuidadores que prestam assistência por tempo indeterminado desenvolvendo esta atividade diária e constante na atenção em saúde domiciliar. Este estudo tem como objetivo:

- Identificar o preparo físico, psicológico e a percepção da sobrecarga de cuidadores de pacientes vinculados a um programa público de atenção domiciliar.

MĖTODO

Estudo qualitativo, observacional e transversal com cuidadores de pacientes internados em domicílio, de ambos os sexos e maiores de idade, vinculados a um Núcleo Regional de Atenção Domiciliar em uma localidade do Distrito Federal.

Foi utilizado o critério de saturação da amostra e realizadas coletas de dados até que as informações coletadas começaram a se repetir. A saturação é alcançada quando as novas informações nos produtos da análise já não produzem modificações nos resultados anteriormente atingidos. ${ }^{8}$

Foram realizadas entrevistas em domicílio com a aplicação de dois instrumentos de pesquisa. Primeiramente, foi utilizado um instrumento específico para conhecer os aspectos sociodemográficos e clínicos dos cuidadores e dos pacientes internados.

Em seguida, foi utilizada a Escala de Sobrecarga de Cuidador (ESC) resumida' para avaliação da sobrecarga dos cuidadores dos pacientes. Esta escala, na versão resumida, é constituída por 22 questões, que incluem aspectos relacionados com a saúde física $e$ psicológica, trabalho, recursos econômicos, relações sociais e a relação com o paciente. Ela se propõe a avaliar a sobrecarga objetiva $e$ subjetiva do cuidador incluindo informações sobre saúde, vida social, vida pessoal, situação financeira, situação emocional e tipo de relacionamento.

Para a análise dos dados, cada item da Escala de Sobrecarga de Cuidador foi pontuado de forma qualitativa e quantitativa da seguinte maneira: nunca (1); quase nunca (2); às vezes (3); muitas vezes (4) e quase sempre (5). Com a aplicação da escala obtémse um score global que varia entre 22 e 110, em que um maior score corresponde a uma
DOI: $10.5205 /$ reuol. $5221-43270-1 \cdot$ RV. 0901 supl201509

sobrecarga fisica e psicológica dos cuidadores...

maior percepção de sobrecarga, de acordo com os seguintes pontos de corte: inferior a 46 - sem sobrecarga; entre 46 a 56 . sobrecarga ligeira e, superior a 56 . sobrecarga intensa. A coleta e a análise dos dados ocorreram de forma concomitante.

Em cumprimento à Resolução n ${ }^{0} 196 / 96$, do Ministério da Saúde, que versa sobre Pesquisa Envolvendo Seres Humanos, este projeto foi submetido ao Comitê de Ética em Pesquisa da Secretaria de Estado de Saúde do Distrito Federal mediante CAAE n. 08237612.7.0000.5553 e aprovado sob o número 187.211. ${ }^{10}$

Para participar da pesquisa, os indivíduos foram orientados quanto aos objetivos, justificativa, metodologia adotada e sobre a segurança quanto ao sigilo, a confiabilidade, a proteção da sua imagem e a não estigmatização, e, de forma livre e orientada optaram pela participação, por meio da assinatura do Termo de Consentimento Livre e Esclarecido.

\section{RESULTADOS}

Participaram desta pesquisa 33 cuidadores de pacientes internados em domicílio, vinculados ao NRAD da Regional de Saúde. Quanto às características sociodemográficas, a amostra foi composta por pessoas com idade média de 46 anos, sendo que $30 \%$ possuíam mais de 60 anos, e, tendo o mais novo dos cuidadores entrevistados, 20 anos e o de maior idade, 73 anos. Predominou o sexo feminino, com 87,6 \% dos participantes, e a baixa escolaridade, sendo que $61 \%$ possuíam entre 3 e 5 anos de estudo formal.

Quanto à religião, houve predominância da católica, além de praticantes de religiões evangélicas de diversas frentes $\mathrm{e}$ ordens. Quanto ao grau de parentesco, a amostra de cuidadores foi composta por filhos(as), esposas, dos pacientes, além de cuidadores não possuíam parentesco direto com o paciente. Apenas dois cuidadores, $\circ$ que representa $6 \%$, não residem na mesma residência que o paciente (Tabela 1). 
ISSN: $1981-8963$

DOI: 10.5205/reuol. $5221-43270-1-$ RV. 0901supl201509

Lago DMSK, Guilhem D, Sousa JA et al.

sobrecarga fisica e psicológica dos cuidadores...

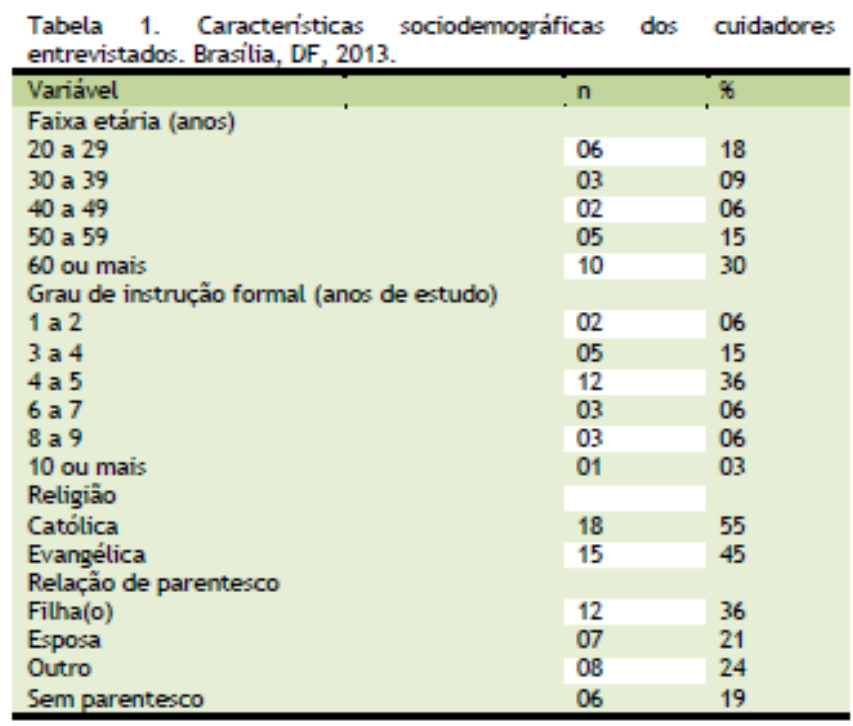

Com relação à sua própria saúde, dor na coluna ou nas costas foi a queixa mais recorrente. Outras queixas que apareceram, com frequência associadas, foram as dores em membros e articulações.

Como morbidade, foi relatada a existência de doenças como Hipertensão Arterial, Diabetes Mellitus e doenças autoimunes como Artrite Reumatóide e Artrose (Tabela 2).

0 uso de medicamentos para aliviar a dor ou para a indução do sono, segundo os próprios entrevistados, é constante, sendo que os ansiolíticos, antidepressivos e analgésicos foram os medicamentos citados como de uso diário e contínuo.

0 sono avaliado em qualidade e quantidade teve resultado ruim, sendo que a maioria dos participantes relatou ter menos de 6 horas de sono diárias (Tabela 2).

Tabela 2. Caracteristicas clínicas de cuidadores entrevistados. Brasilia, DF, 2013.

\begin{tabular}{lll}
\hline Variável & n & \% \\
\hline Relatos de presença de dor & 15 & 45 \\
Dor na coluna/costas & 13 & 39 \\
Membros e articulações & 04 & 12 \\
Outro tipo de dor & 01 & 03 \\
Nấo relatou dor & & \\
Patologias existentes & 10 & 30 \\
Hipertensão Arterial Sistêmica & 05 & 15 \\
Diabetes Mellitus & 06 & 18 \\
Artrite, artrose e outras doenças autoimunes & 06 & 18 \\
Outras doenças & 14 & 42 \\
Sem relato de doenças & & \\
Uso contínuo de medicamentos & 06 & 18 \\
Antidepressivos & 08 & 24 \\
Ansiolíticos & 10 & 30 \\
Analgésicos & & \\
Horas diárias de sono & 20 & 60 \\
Até 6 horas/dia & 10 & 30 \\
Entre 6 e 8 horas/dia & 04 & 12 \\
Mais de 8 horas/dia & & \\
Qualidade do sono & 07 & 21 \\
Bom & 26 & 78 \\
\hline Ruim & & \\
\hline
\end{tabular}

Quanto ao tempo de exercício da função de cuidador, a média foi de 10 anos, sendo que o que exercia por menos tempo, estava apenas há 3 meses na função e o que exercia por mais tempo, segundo seu próprio relato, estava há 40 anos (Tabela 3).

Português/Inglês

Rev enferm UFPE on line., Recife, 9(supl. 1):319-26, jan., 2015
Dos cuidadores entrevistados, $9 \%$ exerceram a função de cuidador na maior parte da vida, seja de criança ou de idosos. Uma cuidadora tinha como profissão anterior a de dona de casa. Os demais tinham diversas funções na área comercial e de autônomo e 
Lago DMSK, Guilhem D, Sousa JA et aL.

tiveram que deixar para se dedicar a cuidar exclusivamente do familiar internado no domicílio. Nenhum dos entrevistados possui formação específica de cuidador e todos exercem a função com o apoio do NRAD, que oferece orientacões específicas relacionadas às dificuldades apresentadas individualmente e em grupo (Tabela 3). sobrecarga fisica e psicológica dos cuidadores...

Com a aplicação da escala para avaliação da sobrecarga dos cuidadores, os resultados apontaram que $28 \%$ dos entrevistados não apresentaram sobrecarga significativa, $31 \%$ apresentaram sobrecarga ligeira e $41 \%$ apresentaram resultados significativos que representam sobrecarga intensa (Tabela 3).

Tabela 3. Tempo de exercício da funçẫo de cuidador, funçâo anteriormente exercida e o resultado da aplicaçấo da Escala de Sobrecarga do Cuidador - ESC. Braślia, DF, 2013.

\begin{tabular}{|c|c|c|c|}
\hline Cuidador & $\begin{array}{l}\text { Tempo que exerce a } \\
\text { funçấo de cuidador deste } \\
\text { paciente }\end{array}$ & $\begin{array}{l}\text { Função anteriormente } \\
\text { exercida }\end{array}$ & $\begin{array}{l}\text { Resultado da Escala de } \\
\text { Sobrecarga do Cuidador }\end{array}$ \\
\hline $\mathrm{C} 1$ & 2 anos & Cuidadora de criança & SI \\
\hline $\mathrm{C}_{2}$ & 4 anos & Comércio - vendas & SI \\
\hline $\mathrm{C} 3$ & 13 anos & Dona de casa & SI \\
\hline $\mathrm{C} 4$ & 6 anos & Recepcionista & SS \\
\hline $\mathrm{C5}$ & 3 anos & $\begin{array}{l}\text { Técnica em } \\
\text { Contabilidade }\end{array}$ & SS \\
\hline C6 & 15 anos & Cobradora de ônibus & SI \\
\hline $\mathrm{C7}$ & 6 anos & Vendedora & SI \\
\hline $\mathrm{CB}$ & 3 meses & Recepcionista & SI \\
\hline C9 & 2 anos & Vendedora & SS \\
\hline $\mathrm{C} 10$ & 2,5 anos & Representante comercial & SS \\
\hline C11 & 11 anos & Cobradora de ônibus & $S L$ \\
\hline $\mathrm{C} 12$ & 1,5 ano & Auxiliar administrativo & $S L$ \\
\hline C13 & 8 anos & Dona de casa & $S L$ \\
\hline $\mathrm{C} 14$ & 5 anos & Costureira & SS \\
\hline $\mathrm{C} 15$ & 5 anos & Vendedora & SI \\
\hline $\mathrm{C} 16$ & 10 anos & Vendedora & SI \\
\hline C17 & 5 anos & Copeira & SS \\
\hline C18 & 3 anos & Recepcionista & SI \\
\hline C19 & 3 anos & Auxiliar de escritório & $S L$ \\
\hline $\mathrm{C}_{20}$ & 40 anos & Comerciante & SS \\
\hline $\mathrm{C}_{21}$ & 3 anos & Serviços Gerais & $S L$ \\
\hline $\mathrm{C} 22$ & 3 anos & Assistente administrativo & $S L$ \\
\hline $\mathrm{C} 23$ & 8 anos & Auxiliar de escritório & SI \\
\hline $\mathrm{C}_{24}$ & 4 anos & Cobradora de ônibus & SS \\
\hline $\mathrm{C} 25$ & 9 anos & Oficina mecânica & SI \\
\hline $\mathrm{C}_{26}$ & 11 meses & Lavoura/agricultora & $S L$ \\
\hline $\mathrm{C} 27$ & 10 anos & Feirante & $S L$ \\
\hline $\mathrm{C} 28$ & 4 anos & Instrutora de autoescola & $S L$ \\
\hline C29 & 10 anos & Cuidadora de criança & $\mathrm{SI}$ \\
\hline $\mathrm{C} 30$ & 16 anos & Serviços gerais & SS \\
\hline $\mathrm{C} 31$ & 10 anos & Vendedora & SI \\
\hline $\mathrm{C} 32$ & 8 anos & Vendedora & $S L$ \\
\hline C 33 & 9 anos & Autônoma & SI \\
\hline
\end{tabular}

SS - Sem sobrecarga / SL - Sobrecarga ligeira / SI - Sobrecarga intensa

DISCUSSAO

Os resultados deste estudo reforçam a questão de que a função do cuidador é exercida, em sua maioria, por mulheres e, que, também como maioria, estas mulheres pertencem à familia próxima da pessoa que recebe os cuidados. 0 papel de cuidador familiar é exercido por mulheres há séculos $\mathrm{e}$ representado socialmente no papel da mãe, dona de casa e cuidadora. Esta função se aproxima da profissão de enfermagem, exercida, em sua maioria, ainda nos dias atuais, por mulheres e que tem como aspecto principal, o papel do cuidado.

Em sua maior parte, o cuidador familiar deste estudo deixou de exercer uma função remunerada no mercado de trabalho, principalmente no comércio. A escolha por qual familiar deixará de trabalhar com emprego formal está relacionada ao rendimento mensal do mesmo. Este processo também pode ser analisado pela falta de opção. Ou seja, não há como escolher não cuidar do familiar adoecido. Geralmente este papel é desempenhado pelas esposas ou filhas mulheres que sofrem esta pressão social para assumir o papel de cuidadora e deixar de exercer a profissão ou a função social até então desempenhada. Esta decisão acarreta desgaste psicológico ${ }^{11}$.

O pouco tempo de estudo formal é considerado um dos fatores favoráveis à tomada de decisão em abandonar o trabalho para cuidar de um familiar. A renda é menor e não possibilita a contratação de cuidadores especializados para esta função. 
Lago DMSK, Guilhem D, Sousa JA et aL.

Estudos indicam que o cuidador participa ativamente do processo de doença, pois acompanha o paciente o tempo todo e está sempre em busca de alternativas e de mais conhecimento para oferecer um cuidado com de melhor qualidade..$^{12 \cdot 3}$

O processo de cuidado a um paciente internado em domicílio tem data de início, mas não de término. 0 início representa um fato subsequente a uma situação específica como recuperação de acidente ou sequela de uma patologia, muitas vezes, degenerativa sofrida pelo paciente. 0 término, quando se trata de sequela de doença degenerativa ocorre apenas no fim da vida. Este fato também representa uma elevação do nivel de estresse, pois a vida do cuidador, muitas vezes se alterou de forma muito significativa $e$ muito rápida.

Cuidar de um paciente com doença avançada, internado no domicílio, é considerado uma carga pesada e pode causar ônus importante ao cuidador e também ao restante da família. Vários estudos mostram que cuidar de alguém de forma ininterrupta representa altos custos no nível psíquico, físico, social e, inclusive, financeiro. Estudos demostraram que há maior risco de infarto agudo do miocárdio e de morte súbita para os cuidadores adultos e idosos. ${ }^{14.5}$ Vários pontos analisados se destacam como precursores às alterações psicossociais do cuidador, como o isolamento social e afetivo, a depressão, o declínio nos relacionamentos, a perda da perspectiva de vida, os distúrbios do sono e o uso constante de psicotrópicos. ${ }^{16}$

Um dos problemas identificados na vida desses cuidadores foi a privação do seu autocuidado, o que interfere diretamente na sua qualidade de vida, causando ainda um desgaste psíquico. Outros estudos realizados também evidenciaram este resultado $\mathrm{e}$ sugeriram a implementação de políticas sociais públicas voltadas ao cuidador..$^{13,17-8}$

Os cuidadores se dedicam em tempo integral ao cuidado, sendo que $94 \%$ deles residem na mesma casa que o paciente, e, portanto, não possuem um horário prédeterminado para exercer a função. Este fato reforça o resultado de sobrecarga intensa, pois se trata de prestação de cuidado intenso e contínuo. Além disso, a questão do adoecimento de algum membro da família próximo, como no caso de filho(a), pai, mãe ou cônjuge acarreta profundas alterações na đinâmica familiar, possibilitando o surgimento de crises e estresse psíquico. ${ }^{13}$

Outro fator importante para análise da sobrecarga do cuidador é sua própria condição de saúde, que, muitas vezes, não é avaliada e Português/Inglês Rev enferm UFPE on line., Recife, 9(supl. 1):319-26, jan., 2015 sobrecarga física e psicológica dos cuidadores...

nem percebida. Neste estudo, o relato da presença de doenças crônicas como Hipertensão Arterial Sistêmica se faz presente em boa parte dos cuidadores. Este resultado era esperado, pois estas doenças crônicodegenerativas estão comumente presentes em pessoas com mais de 60 anos de idade.

Doenças osteoarticulares, que também se mostraram presentes no estudo em proporção importante, representam o desgaste físico que é percebido pelos cuidadores em função da movimentação necessária para o exercício do cuidado em pacientes acamados. Atividade física e exercícios de fortalecimento muscular não são praticados pelos cuidadores regularmente, o que favorece o surgimento de lesões em articulações e dores musculares por esforço. As queixas de dores foram prevalentes e a mais citada foi a dor na coluna ou costas. Resultados semelhantes foram obtidos em outros estudos realizados. 19.20

Em consequência disso, 0 uso de medicamentos para alívio da dor, na maioria das vezes sem prescrição médica e de medicamentos antidepressivos e ansiolíticos prescritos por médicos se tornou frequente, inclusive para induzir o sono, sendo que a dificuldade para dormir também pode ser consequência da dor. A insônia prejudica o raciocínio e a qualidade de vida, levando a um alto nivel de estresse, o que foi evidenciado neste estudo. Entre os cuidadores que atingiram a sobrecarga intensa na avaliação, 95\% relataram ter menos de 6 horas de sono $\mathrm{e}$ que a qualidade do sono era ruim.

\section{CONCLUSÄO}

Exercer a função de cuidador principal de familiar próximo internado no domicílio é tarefa árdua e desgastante, podendo interferir de forma importante na qualidade de vida da familia.

Percebe-se que é necessário acompanhamento próximo do cuidador, por parte da equipe de saúde responsável pelo paciente, na forma de educação permanente e apoio psicológico, promovendo ações direcionadas à diminuição do estresse e em prol da qualidade de vida. A equipe de saúde deve conhecer a sobrecarga dos cuidadores para organizar as ações que se mostrarem pertinentes para cada caso.

0 apoio que o cuidador recebe dos familiares e da equipe de saúde tem aspecto positivo tanto na diminuição do estresse físico, quanto do emocional. É importante também, que ele tenha uma agenda com horários livres para o seu autocuidado e a 
ISSN: $1981-8963$

Lago DMSK, Guilhem D, Sousa JA et aL.

equipe de saúde desempenhe um papel importante nesta orientação.

\section{REFERENCIAS}

1. IBGE - Instituto Brasileiro de Geografia e Estatística. Perfil dos municípios brasileiros [Internet]. 2004 [cited 2014 May 13]. Available from: www.ibge.gov,br.

2. Ballesteros RC, organizador. Gerontologia Social. Madrid; Ediciones Pirâmide; 2011.

3. Mendes EV. O cuidado das condições crônicas na atenção primária à saúde: o imperativo da consolidação da estratégia saúde da família. Organização Pan- Americana da Saúde; 2012.

4. Brasil, Ministério da Saúde. Secretaria de Atenção à Saúde. Departamento de Atenção Básica. Caderno de atenção domiciliar. Brasilia; 2012. 2 v.

5. Brasil, Ministério da Saúde. Secretaria de Atenção à Saúde. Departamento de Atenção Básica. Manual de instrução melhor em casa: a segurança do hospital no conforto do seu lar. Brasilia; 2012, 31p.

6. Brasil, Ministério da Saúde. Lei $\mathrm{n}$. $10424 / G M$ de 2002. Estabelece no âmbito do Sistema Único de Saúde o atendimento e a internação domiciliar, Brasilia; 2002.

7. Brasil, Ministério da Saúde. Agência Nacional de Vigilância Sanitária - ANVISA. RDC n. 11 de 2006. Dispõe sobre o regulamento técnico de funcionamento de serviços que prestam atenção domiciliar. Brasília, 2006.

8. Turato ER. Tratado de Metodologia da Pesquisa Clínico-Qualitativa: construção téorico-epistemológica, discussão comparada e aplicada nas áreas da saúde e humanas. 3rd ed. Petrópolis: Vozes; 2008.

9. Taub A, Andreoli SB, Bertollucci PH. Sobrecarga de cuidador de pacientes com demência: confiabilidade da versão brasileira do inventário de sobrecarga de Zarit. Cad Saúde Pública [Internet]. 2004 [cited 2014 May 13];20(2):372-6. Available from: http://www.scielo.br/scielo.php?pid=S0102$311 \times 2004000200004$ Ascript=sci abstractetting =nt.

10. Brasil, Ministério da Saúde. Conselho Nacional de Saúde. Resolução No 196, de 10 de outubro de 1996: diretrizes e normas reguladoras de pesquisas envolvendo seres humanos. Brasilia; 1996.

11. Floriani CA. Cuidador familiar: sobrecarga e proteção. Rev. Brasileira de Cancerologia [Internet]. 2004 Oct/Dec [cited 2014 May 13];50(4):[about 5 p.]. Available from: http://www.inca.gov.br/rbc/n 50/v04/pdf/s ecao5.pdf
DOI: 10.5205/reuol.5221-43270-1-RV.0901supl201509

sobrecarga fisica e psicológica dos cuidadores...

12. Inocenti A, Rodrigues IG, Miasso Al. Vivências e sentimentos do cuidador familiar do paciente oncológico em cuidados paliativos. Rev. Eletr. Enf [Internet]. 2009 [cited 2014 May 13]; 11(4):858-65. Available from:

http://wmw.fen.ufg.br/revista/v11/n4/v11n4 a11.htm

13. Brito MCC, Oliveira EN, Freitas CASL, Ferreira AGN, Silva $M J$, Nogueira DL.Repercussões na vida do cuidador domiciliar do idoso: estudo de caso. J Nurs UFPE on line [Internet]. 2013 [cited 2014 May 13];7(esp):1030-5. Available from: http://wmw, revista.ufpe.br/revistaenfermage $\mathrm{m} /$ index.php/revista/article/view/3152

14. Lee S, Colditz GA, Berkman L, Kawachi I. Caregiving and the risk of coronary heart disease in U.S. women: a prospective study. Am J Prev Med [Internet]. 2003 [cited 2014 May 13];24(2):113-9. Available from: http://www.ncbi.nlm.nih.gov/pubmed/12568 816

15. Schulz R, Beach SR. Caregiving as a risk factor for mortality: the caregiver health effects study. J Am Med Assoc [Internet]. 1999 [cited 2014 May 13];282(23):2215-9. Available from:

http://www.ncbi.nlm.nih.gov/pubmed/10605 $\underline{972}$

16. Pitceathly $C$, Maguire P. The psychological impact of cancer on patients' partners and other key relatives: a review. Eur J Cancer [Internet]. 2003 [cited 2014 May 13];39:151724. Available from: http: / / europepmc.org/abstract/MED/1285525 7/reload=0;isessionid=KdiGW41X2JCiX6TAUwo $\underline{\mathrm{r} .4}$

17. Beuter M, Rossi JR, Neves ET, Brondani CM. A sobrecarga do familiar no cuidado domiciliar. Rev enferm UFPE on line [Internet]. 2009 July/Sept [cited 2014 May 13];3(2):687-93. Available from: http://wmw,revista.ufpe.br/revistaenfermage $\mathrm{m} /$ index.php/revista/article/view/181/pdf 9 18

18. Cattani RB, Girardon-Perlini NMO. Cuidar de idoso doente no domicílio na voz de cuidadores familiares. Rev Eletrônica de Enfermagem [Internet]. 2004 May-Aug [cited 2014 May 13];6(2):[about 8 p.]. Available from:

http://wmw.fen.ufg.br/revista/revista6 2/pd f/Orig11 idoso.pdf

19. Amendola $F$, Oliveira MAC, Alvarenga MRM. Qualidade de vida dos cuidadores de pacientes dependentes no programa de saúde da família. Texto Contexto Enferm [Internet]. 2008 [cited 2014 May 13]; 17(2):266-72. 
ISSN: $1981-8963$

Lago DMSK, Guilhem D, Sousa JA et al.

Available

http://wuw.scielo.br/pdf/tce/v17n2/07.pdf

20. Souza $C B$, et al. O cuidado domiciliar de idosos com Acidente Vascular Cerebral: cuidadores familiares. Rev Enferm UERJ [Internet]. 2009 Jan-Mar [cited 2014 May 13];17(1):41-5. Available from: http://www.scielo.br/pdf/tce/v17n2/07.pdf
DOI: $10.5205 /$ reuol. $5221-43270-1-$ RV. 0901supl201509

sobrecarga fisica e psicológica dos cuidadores...

Submissão: 14/07/2013

Aceito: 14/12/2014

Publicado: 15/01/2015

\section{Correspondência}

Diane Maria Scherer Kuhn Lago

Universidade de Brasília

Faculdade de Ceilândia

SHIS QI 28, Conjunto 07, Casa 04, Lago Sul

CEP 71670-270 - Brasília (DF), Brasil 
APÊNDICE 6

Artigo submetido à Revista Brasileira de Enfermagem - REBEN

Qualidade de vida de cuidadores domiciliares na oferta de cuidados paliativos 
Scikto

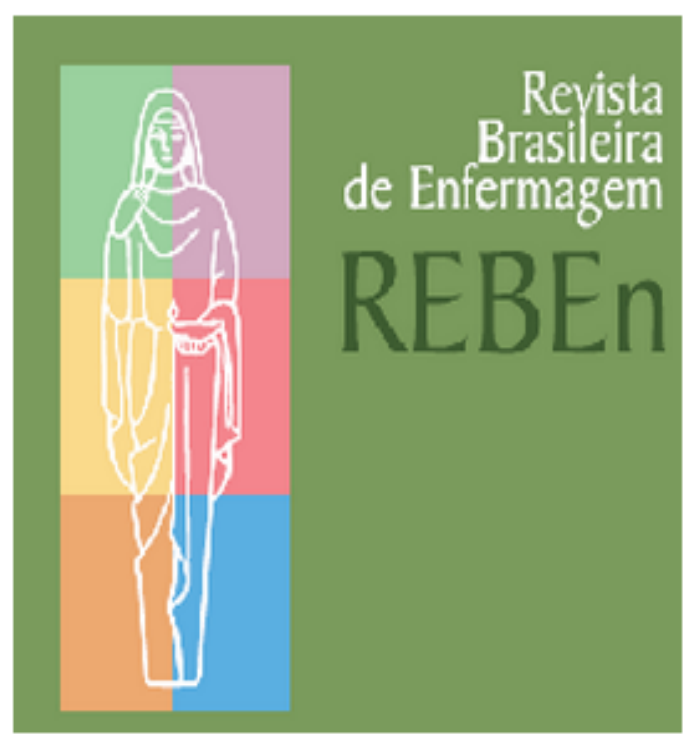

CAPA SOBRE PÁGINA DO USUÁRIO

Capa > Usuário > Autor > Submissões Ativas

\section{Submissões Ativas}

ATIVO ARQUIVO

\begin{tabular}{|c|c|c|c|c|c|}
\hline ID & $\begin{array}{l}\text { MM-DD } \\
\text { ENVIADO }\end{array}$ & SECÃO & AUTORES & Título & SITUACCÃO \\
\hline 149359 & $05-06$ & PES & Lago, Guilhem & $\begin{array}{l}\text { QUALIDADE DE VIDA DE } \\
\text { CUIDADORES } \\
\text { DOMICILIARES NA OFERTA } \\
\text { DE... }\end{array}$ & $\begin{array}{l}\text { Aguardando } \\
\text { designação }\end{array}$ \\
\hline
\end{tabular}

1 a 1 de 1 itens

\section{Iniciar nova submissão}

CLIQUE AQUI para iniciar os cinco passos do processo de submissão.

Revista Brasileira de Enfermagem

SGA Norte Quadra 603 Conj. "B" - Av. L2 Norte 70.830-030 Brasilia, DF, Brasil Tel.: (55 61) 3226-0653 


\title{
Qualidade de vida de cuidadores domiciliares na oferta de cuidados paliativos Quality of life of home caregivers on the delivery of palliative care \\ Calidad de vida de cuidadores domiciliarios en la oferta de cuidados paliativos.
}

Diane Maria Scherer Kuhn Lago

Dirce Guilhem

\begin{abstract}
Resumo
Objetivo: conhecer a percepção sobre qualidade de vida de cuidadores de doentes em cuidados paliativos inseridos em um programa de atenção domiciliar do Distrito Federal. Médodo: estudo descritivo, transversal com abordagem quantitativa. Utilizaram-se três instrumentos: questionário sociodemográfico e clínico, WHOQOL-bref e WHOQOL-old. Foram incluídos 33 cuidadores principais, representando a totalidade dos doentes internados em domicílio. Resultados: grupo composto predominantemente por mulheres $(87,9 \%)$, familiares dos doentes $(82,8 \%)$, média de 46 anos de idade e oferta de cuidados em tempo integral (75,7\%). O IGQV obteve a média de 51,19. Os domínios avaliados com maior e menor escore do WHOQOL-bref foram: relações social e meio ambiente; do WHOQOL-old foram: intimidade e morte e morrer. Conclusão: Conhecimento importante porque contribui para o desenvolvimento de estratégias que priorizem o cuidado humanizado e a qualidade de vida de cuidadores e doentes. Os cuidadores domiciliares proporcionam cuidados contínuos e necessitam atenção especialmente direcionada para suas demandas.
\end{abstract}

Palavras-chave: Qualidade de Vida, Cuidados Paliativos, Assistência Domiciliar.

\begin{abstract}
Objective: to comprehend quality of life's perception from caregivers of sick people in palliative care provided by a domiciliary attention program, Federal District-Brazil. Method: cross-sectional study, with quantitative approach. Data collection used tree instruments: a Sociodemographic and Clinical Questionnaire, WHOQOL-bref and WHOQOL-old. Were included 33 caregivers, representing the totality of in-patients in the domicile. Results: Caregivers were predominantly women $(87,9 \%)$, patients relatives $(82,8 \%)$, medium age of 46 years old, with full time attention $(75,7 \%)$. The QOL average was 51.19. The domains evaluated with higher and lower score of WHOQOL-bref were: social relations and environment; of the WHOQOL-old were intimacy and death and dying. Conclusion: Important knowledge, it can contribute for new strategies' development directed to personalized care and the quality of life of all actors involved in the process of care. The
\end{abstract}


domiciliary caregivers deliver continuum care for sick people and they need special attention to support their own needs.

Keywords: Quality of Life, Caregivers, Palliative Care, Home Nursing.

\section{Resumen}

Objetivo: conocer la percepción sobre calidad de vida de cuidadores de enfermos en cuidados paliativos en un programa de atención domiciliaria del Distrito Federal-Brasil. Método: estudio descriptivo, transversal, con abordaje cuantitativo. La recolección de datos utilizó tres instrumentos: cuestionario sociodemografico y clínico, WHOQOL-bref e WHOQOL-old. Participaram 33 cuidadores principales, la totalidad de enfermos internados en domicilio. Resultados: grupo compuesto por mujeres (87,9\%), familiares de los enfermos $(82,8 \%)$, media de edad 46 años, ofrecían cuidados en tempo integral (75,7\%). El IGCV obtuvo media de 51,19. Los dominios evaluados con mayor y menor escores del WHOQOLbref fueran relaciones sociales y medio ambiente; del WHOQOL-old fueran intimidad y muerte y morir. Conclusión: conocimiento importante, puede embasar nuevas estrategias para promoción del cuidado humanizado y la calidad de vida de los actores involucrados en el proceso de cuidar y ser cuidado. Cuidadores domiciliarios proporcionan cuidados continuos y necesitan atención especialmente direccionada para sus demandas.

Palabras clave: Calidad de Vida, Cuidadores, Cuidados Paliativos, Atención Domiciliaria de Salud.

\section{Introdução}

Estimativa recente do Instituto Brasileiro de Geografia e Estatística (IBGE) prevê que no ano de 2050, 25\% da população brasileira será composta por pessoas idosas. Esse fenômeno da longevidade é explicado principalmente pela diminuição da mortalidade e pela introdução de práticas assistivas que contribuem para a promoção da saúde ${ }^{(1-3)}$. Esse fenômeno colaborou para a existência de transição epidemiológica, considerando-se que o processo do envelhecimento abrange mudanças relacionadas à força física, surgimento de condições crônicas que resultam em perdas funcionais importantes, e diminuição da autonomia por um período de tempo mais prolongado. Nesses casos ocorre a demanda por cuidado permanente ${ }^{(3-5)}$. 
Condições crônicas é o termo utilizado para definir as dimensões do agravo, incluindo-se as alterações causadas na vida do doente, de sua família e na sociedade em geral. Doente é a pessoa que se encontra em estado patológico com diminuição da sua normalidade e vitalidade, estabelecida pela doença ${ }^{(6)}$. Essa situação de saúde exige a adoção de cuidado permanente por períodos de tempo prolongados em função das sequelas e das consequências decorrentes de doenças crônicas não transmissíveis (DCNT) ${ }^{(7-8)}$.

A oferta de cuidado permanente ao portador de DCNT, principalmente para aqueles que se encontram no sistema de cuidados paliativos possui algumas características específicas. Entre elas a busca pela qualidade de vida da pessoa enferma e o convívio com seus familiares e amigos, incluindo-se suporte psicossocial no período de enfrentamento da doença e do luto, quando for necessário. Para se efetivar essa estratégia, a atenção domiciliar passa a ser uma opção de escolha ${ }^{(5,9-11)}$.

Como forma de assistência substitutiva ou complementar àquelas oferecidas em instituições de saúde, a atenção domiciliar vem sendo adotada em vários países do mundo, sendo ofertada no ambiente familiar. Para que se desenvolva com eficiência e qualidade, depende do apoio da família ou de cuidadores contratados para este fim, além da equipe responsável pelo acompanhamento e orientações relacionadas a cuidados específicos que o doente necessita ${ }^{(9-12)}$.

Muitas pessoas assistidas nessa modalidade de atenção se encontram em cuidados paliativos, ou seja, em acompanhamento com o propósito de melhorar sua qualidade de vida e de seus familiares no fim da vida. Isso permite enfrentar problemas associados às doenças por meio da prevenção e do alívio do sofrimento, com a identificação precoce, avaliação correta e tratamento da dor e de outros problemas de ordem física, psicossocial e espiritual ${ }^{(9)}$. O responsável principal pelo acompanhamento, denominado de cuidador, pode sofrer desgaste físico e psicológico ao desenvolver as tarefas do cuidado, principalmente em função da dedicação prolongada e extensiva ${ }^{(10,13)}$.

A qualidade de vida, segundo a Organização Mundial da Saúde (OMS), pode ser entendida como um conceito amplo e complexo que inter-relaciona o ambiente e os aspectos físicos e psicológicos, o nível de independência, as relações sociais e as crenças pessoais. É utilizada de formas distintas e com abordagens diversas envolvendo parâmetros econômicos, sociais e de saúde, que contribuem para a elaboração de diferentes construtos, mas que possuem aspectos em comum, como a multidimensionalidade e a subjetividade em suas dimensões positivas e negativas. Considera-se, em especial, a percepção que a pessoa possui sobre sua saúde e sobre aspectos gerais do contexto da sua vida ${ }^{(11,13)}$. 
A avaliação da qualidade de vida permite conhecer a percepção da pessoa ou do grupo sobre aspectos objetivos e subjetivos, compreendendo o acesso a bens e serviços, ao seu bem-estar e incluindo a presença de sentimentos como angústia, tristeza, prazer e felicidade $^{(14)}$.

O objetivo deste estudo foi o de conhecer o perfil e a percepção sobre qualidade de vida de cuidadores de doentes em cuidados paliativos inseridos em um programa de atenção domiciliar do Distrito Federal.

\section{Método}

Trata-se de estudo observacional, descritivo, de corte transversal com a utilização de metodologia quantitativa com a finalidade de conhecer as características sociodemográficas e clínicas dos cuidadores que aceitaram participar do estudo, bem como sua percepção sobre qualidade de vida e da sobrecarga que a atividade imprime. A pesquisa quantitativa se centra na objetividade recorrendo à linguagem matemática para descrever as causas de um fenômeno e as relações entre variáveis ${ }^{(15-16)}$.

Foram utilizados os seguintes instrumentos de pesquisa: a) um questionário sociodemográfico e clínico criado especificamente para este estudo, contemplando variáveis sociais, demográficas e clínicas, como sexo, idade, grau de instrução, presença de doença e de dor, uso de medicamentos, percepção de apoio, dentre outras, que permitiu conhecer o perfil dos cuidadores entrevistados; b) o WHOQOL-bref (World Health Organization Quality of Life Instrument), instrumento desenvolvido pela OMS para se conhecer a percepção subjetiva sobre qualidade de vida das pessoas. Essa medida possibilita o cálculo de um indicador geral de qualidade de vida e é composto por 26 itens que integram quatro domínios: físico, psicológico, relações sociais e meio ambiente, sendo que cada um destes domínios são compostos por facetas de qualidade de vida ${ }^{(11)}$; c) o WHOQOL-old (World Health Organization Quality of Life Instrument-Older Adults Module), utilizado em complementação, composto por 24 itens atribuídos a 6 domínios: funcionamento dos sentidos, autonomia, morte e morrer, atividades passadas, presentes e futuras, participação social e intimidade e suas respectivas facetas ${ }^{(17)}$. Neste estudo, optou-se por apresentar os dados em uma escala de 0 a 100 por ser mais facilmente interpretada e estar associada a percentuais, sendo que os escores mais altos significam melhor qualidade de vida.

Os dados foram analisados utilizando-se o programa estatístico SPSS 18. Dos valores obtidos para cada uma das facetas que compõem os quatro domínios (físico, psicológico, 
relações sociais e meio ambiente) do instrumento WHOQOL-bref e das facetas que compõem os seis domínios (funcionamento do sensório, autonomia, atividades passadas, presentes e futuras, participação social, morte e morrer e intimidade) do WHOQOL-old, foram obtidas as médias das respostas, o que possibilitou verificar quais facetas foram avaliadas como positivas quais foram avaliadas de forma negativa.

A coleta de dados ocorreu nas residências dos doentes onde foram realizadas entrevistas com os cuidadores durante os meses de fevereiro a junho de 2013, com agendamento prévio. Antes do inicio da coleta foi verificado se a residência possuía um espaço que conferia privacidade ao participante para que as respostas pudessem ser dadas de forma tranquila, respeitando-se todas as paradas necessárias para a realização dos cuidados.

Participaram deste estudo cuidadores principais de todos os doentes vinculados a um Serviço de Atenção Domiciliar no Distrito Federal, totalizando 33 entrevistados. Todos os participantes possuíam mais de 18 anos de idade e concordaram em participar do estudo por meio da assinatura do termo de consentimento livre e esclarecido (TCLE). Para a preservação do anonimato, os entrevistados foram identificados por letra $\mathrm{C}$ de cuidador acompanhada pelo número do entrevistado (C1 a C33).

Em cumprimento à Resolução CNS n. 466/2012, que versa sobre Pesquisa Envolvendo Seres Humanos, este estudo foi aprovado pelo Comitê de Ética da Secretaria de Estado de Saúde do Distrito Federal - CEP/FEPECS/SES/DF, sob o parecer n. 187.211/2013.

\section{Resultados}

Os dados revelaram que houve modificação nos resultados relacionados à auto percepção sobre qualidade de vida entre os cuidadores, que foi influenciada por diversas variáveis como idade, sexo, relação de parentesco com o doente, apoio social recebido, entre outros.

Os participantes possuíam em média, 46 anos de idade com variação entre 20 e 73 anos. A maioria dos entrevistados foi constituída por mulheres $(87,9 \%)$ e familiares $(82,8 \%)$, principalmente filhas ou esposas. Quanto ao grau de instrução, 36,4\% possuíam o ensino fundamental completo e $9,1 \%$ concluíram um curso de graduação. Com relação ao tempo de exercício da função, $31 \%$ dos cuidadores estavam envolvidos no processo entre 5 e 10 anos. 
O cuidado em tempo integral era exercido por $75,7 \%$ dos entrevistados e a percepção sobre o apoio social recebido para o exercício da função de cuidador foi referido por $63,6 \%$ dos entrevistados, sendo que, desses, 54,5\% referiram receber apoio de familiares.

Quanto aos aspectos de saúde dos entrevistados, 57,6\% relataram problemas de saúde, sendo que destes $42,4 \%$ estavam relacionados aos sistemas endócrino e cardiovascular. A presença de dor foi relatada por $75,7 \%$ dos cuidadores e afetava principalmente as costas e os membros superiores. O uso de medicamentos de forma continuada foi referido por $57,6 \%$ dos respondentes, verificando-se que entre eles $42,1 \%$ relataram o uso de ansiolíticos e $31,6 \%$ o uso de antidepressivos. Outro fator relacionado à saúde diz respeito ao sono, sendo que $78 \%$ relataram ter sono ruim, $60 \%$ disseram ter o sono interrompido com menos de 6 horas diárias. O estudo revelou que 41,4\% dos respondentes se consideravam insatisfeitos com relação à própria saúde.

Ao aplicar o WHOQOL-bref foi possível identificar, como descrito na tabela 1 que o Índice Geral de Qualidade de Vida (IGQV) foi de 51,19. O domínio melhor avaliado em relação ao IGQV foi o de relações sociais $(p=0,0289)$ e o de menor avaliação foi o do meio ambiente $(\mathrm{p}=0,0302)$.

Tabela 1 - Média do Índice Geral de Qualidade de Vida e dos domínios do WHOQOL-bref.

\begin{tabular}{lccc}
\multicolumn{1}{c}{ DOMÍNIOS } & MÉDIA (dp) & MIN-MAX & MEDIANA \\
\hline IGQV & $51,19(11,51)$ & $31,74-68,27$ & 50,96 \\
D1 - Físico & $53,79(11,84)$ & $25,00-78,57$ & 53,57 \\
D2 - Psicológico & $52,27(13,46)$ & $29,17-75,00$ & 50,00 \\
D3 - Relações Sociais & $55,30(18,84)$ & $25,00-100,00$ & 50,00 \\
D4 - Meio Ambiente & $46,12(16,67)$ & $15,63-84,38$ & 43,75 \\
& & & \\
\hline
\end{tabular}

Fonte: Cuidadores domiciliares. N (33). Distrito Federal, 2015.

Em cuidadores idosos, com a utilização do WHOQOL-old, os domínios que obtiveram maior significância estatística, quando comparados ao IGQVI foram: Atividades passadas, presentes e futuras $(\mathrm{p}=0,0041)$, Participação social $(\mathrm{p}=0,0131)$ e Autonomia $(\mathrm{p}=0,0474)$. 
Tabela 2 - Média do Índice Geral de Qualidade de Vida dos Idosos e dos domínios do WHOQOL-old.

\begin{tabular}{lccc}
\hline \multicolumn{1}{c}{ DOMÍNIOS } & MÉDIA (DP) & MIN-MAX & MEDIANA \\
\hline Qualidade de Vida do Idoso - IGQVI & $45,52(5,38)$ & $37,50-53,13$ & 44,30 \\
D1/old - Funcionamento do sensório (FS) & $46,88(14,80)$ & $31,25-75,00$ & 37,50 \\
D2/old - Autonomia (AUT) & $45,63(15,04)$ & $31,25-75,00$ & 40,60 \\
D3/old - Atividades passadas, presentes e & $44,38(10,40)$ & $31,25-62,50$ & 43,30 \\
futuras (PPF) & & & \\
D4/old - Participação social (PSO) & $45,63(10,23)$ & $31,25-62,50$ & 43,80 \\
& & & \\
D5/old - Morte e morrer (MEM) & $38,13(12,31)$ & $25,00-62,50$ & 37,50 \\
D6/old - Intimidade (INT) & $52,50(15,37)$ & $37,50-93,75$ & 50,00 \\
& & &
\end{tabular}

Fonte: Cuidadores domiciliares. N (10). Distrito Federal, 2015.

Ao relacionar a média dos escores de qualidade de vida do cuidador e as varáveis sociodemográficas foi possível constatar que o IGQV foi avaliado em 7,17 pontos maior ( $\mathrm{p}=0,0244)$ em cuidadores com mais de 60 anos de idade.

Tabela 3 - Média do IGQV e dos domínios do WHOQOL-bref com relação à idade e existência de parentesco.

\begin{tabular}{lcc}
\hline \multicolumn{1}{c}{ DOMÍNIOS } & \multicolumn{2}{c}{ MÉDIA (dp) } \\
\cline { 2 - 3 } IGQV & \multicolumn{1}{c}{ < de 60 anos } & \multicolumn{2}{c}{ 60 anos ou mais } \\
\cline { 2 - 3 } D1 - Físico & $53,21(11,15)$ & $54,29(12,33)$ \\
D2 - Psicológico & $49,27(11,84)$ & $59,17(12,49)$ \\
D3 - Relações Sociais & $52,90(18,84)$ & $60,83(18,48)$ \\
D4 - Meio Ambiente & $44,03(16,66)$ & $50,94(14,36)$ \\
\end{tabular}

Fonte: Cuidadores domiciliares. N (33). Distrito Federal, 2015. 
Outro dado relevante neste estudo diz respeito à percepção sobre o apoio recebido para o exercício do cuidado, sendo que os cuidadores que disseram receber apoio de amigos ou familiares apresentaram IGQV com 4,29 pontos $(\mathrm{p}=0,0302)$ a mais do que os demais.

\section{Discussão}

A avaliação do IGQV foi maior em cuidadores idosos, o que pode estar relacionado à capacidade de resiliência e de aceitação dos fatos devido maior experiência de vida e, em muitos casos, a uma agenda social diminuída ${ }^{(13,18)}$.

Em concordância com estudos anteriormente realizados houve predomínio de cuidadores familiares, do sexo feminino, representados principalmente por esposas e filhas (18-20). Esse resultado reforça o papel histórico socialmente determinado às mulheres de cuidadoras principais e a responsabilidade de cuidar atribuída ao parente próximo, pertencente ao núcleo familiar. Está culturalmente implícito para sociedade que cabe aos filhos e aos cônjuges cuidar dos adoentados que necessitam de cuidados especiais e contínuos ${ }^{(21-22)}$.

O grau de instrução formal referido pelos entrevistados correspondia à média encontrada em estudos semelhantes ${ }^{(18,22-23)}$. Cabe ressaltar que todas as cuidadoras que relataram ter iniciado ou concluído um curso superior eram filhas dos doentes. O IGQV referido pelos cuidadores com menor grau de instrução foi mais elevado com relação aos demais, o que é apoiado por estudos que apontaram a influência da escolaridade na escolha do cuidador familiar. A inserção no mercado de trabalho formal é mais difícil quanto menor o grau de instrução, o que facilitaria abrir mão de outra função desempenhada até o momento para assumir a função do cuidador ${ }^{(13,24)}$.

A dedicação em tempo integral ao cuidado de outra pessoa expõe o cuidador principal a fatores estressantes como a pressão dos familiares, a imposição da disponibilidade de tempo e, em alguns casos, o desprendimento de força física para realizar a movimentação do doente. Para amenizar essa situação, que pode resultar em adoecimento por desgaste físico e psicológico do cuidador, o apoio social é fundamental ${ }^{(23)}$.

Esse apoio pode ser recebido por meio de momentos de distração, de lazer, ou ainda, da maneira tradicional, com o auxílio nas tarefas diárias ligadas ao cuidado direto dispensado ao doente ou a casa. É importante que o planejamento dos cuidados seja feito em conjunto entre a equipe de saúde, o doente, sua família e o cuidador com o propósito principal de oferecer qualidade de vida, conforto e bem estar biopsicossocial e espiritual ${ }^{(25)}$. Estudos afirmam a existência de correlação entre a percepção positiva da saúde e bem estar e a 
presença de apoio social de pessoas da rede social, inclusive com apresentação de autoestima e autoconfiança adequadas, além de maior capacidade para o enfrentamento das situações adversas ${ }^{(13,23,26)}$.

A presença de doença e de dor influencia diretamente a avaliação do IGQV, pois quanto mais acentuada a dor referida, menor é o escore de qualidade de vida nos domínios físico e psicológico. Estudos indicam que a dedicação do cuidador principal por período prolongado afeta sua vida social diminuindo os momentos de lazer e aumenta a possibilidade de negligência com o autocuidado ${ }^{(20-21)}$. Por outro lado, para que o cuidador possa usufruir dos aspectos positivos relacionados ao ato de cuidar, deve cuidar de si mesmo, tanto no que se refere à esfera física quanto emocional ${ }^{(26)}$.

Já o uso contínuo de medicamentos, principalmente de analgésicos e psicoterápicos apresenta correlação positiva no escore de qualidade de vida. Ou seja, o uso dessas substâncias traz resultado satisfatório para o controle da dor e da ansiedade, levando a melhor percepção da qualidade de vida, principalmente nos domínios físico e psicológico. Resultado contrastante foi encontrado em estudo realizado em 2008 com cuidadores de idosos onde se demonstrou que quanto maior o número de medicamentos utilizados, menor a percepção de qualidade de vida no domínio físico ${ }^{(13)}$.

A quantidade de horas de sono diárias interfere diretamente na avaliação do IGQV, sendo que o sono pode ser definido como um estado neurológico complexo e restaurador, necessário ao funcionamento do organismo ${ }^{(27)}$.

Os escores obtidos com a utilização do WHOQOL-bref indicaram, em conformidade com estudos efetuados anteriormente, que os cuidadores apresentaram avaliação do IGQV em nível mediano, sendo que, em três domínios, um pouco acima de 50 pontos e no domínio meio ambiente a média obtida foi inferior, com 46,12 pontos. Isso indica que questões sociais e de adaptação incidem diretamente a percepção sobre sua qualidade de vida ${ }^{\text {(28-29). }}$.

Entre os cuidadores idosos, utilizando-se instrumento complementar específico para esta categoria, o WHOQOL-old, a avaliação dos domínios ficou abaixo de 50 pontos em cinco dos seis domínios analisados, sendo que apenas o domínio intimidade apresentou escore levemente superior, com 52,50 pontos. Este dado revelou a proximidade do cuidador para com o doente. Quanto ao menor escore obtido, no domínio morte e morrer, cabe ressaltar que a morte representa a finitude humana e desempenha papel marcado pelo desenvolvimento do ciclo vital que na velhice se destaca ${ }^{(28-29)}$. 


\section{Conclusões}

Conhecer a percepção sobre qualidade de vida do cuidador domiciliar principal é importante para a compreensão do desenvolvimento do cuidado integral, que ocorre quando há responsabilidade e envolvimento pessoal por parte do cuidador para com o doente.

Participar diretamente do destino, do sofrimento, do sucesso no presente e no futuro da vida da pessoa cuidada pode causar inquietação, preocupação e angustia afetando diretamente na qualidade de vida do cuidador.

Nesse sentido, é necessário que a equipe de atenção domiciliar acompanhe e ofereça apoio e suporte emocional ao cuidador para o enfrentamento da situação em que se encontra. Deve ser reconhecido como aliado para a expansão do cuidado na residência do doente por parte da equipe de saúde, da família e da sociedade. Apenas dessa forma será possível propor estratégias para o desenvolvimento do cuidado humanizado com a promoção da qualidade de vida dos diferentes atores envolvidos no processo de cuidar e ser cuidado, considerando-se suas demandas específicas.

\section{Referências}

1. IBGE - Instituto Brasileiro de Geografia e Estatística. Perfil dos municípios brasileiros 2013. [citado em 15 de jan. 2015]. Disponível em: http://biblioteca.ibge.gov.br/visualizacao/livros/liv86302.pdf.

2. Kluge F, Zagheni E, Loichinger C, et al. The Advantages of Demographic Change after the Wave: Fewer and Older, but Healthier, Greener, and More Productive? Ed. Jennifer Beam Dowd. PLoS ONE 9.9, 2014 [citado em 05 jun. 2015]. Disponível em: http://journals.plos.org/plosone/article?id=10.1371/journal.pone.0108501

3. Vasconcelos AMN, Gomes MMF. Transição demográfica: a experiência brasileira. Epidemiologia e Serviços de Saúde [online]. 2012 [citado em 31 de mar 2015] 21(4):10 Disponível em: $\quad$ http://scielo.iec.pa.gov.br/scielo.php?pid=S1679$\underline{49742012000400003 \& \text { script}=\text { sci_arttext }}$

4. Mendes EV. O cuidado das condições crônicas na atenção primária a saúde: o imperativo da consolidação da estratégia saúde da família. Organização Panamericana de Saúde, 2012, 512p.

5. Campolina AG, Adami F, Santos JLF, Lebrão ML. A transição de saúde e as mudanças na expectativa de vida saudável da população idosa: possíveis impactos da prevenção de 
doenças crônicas. Cad. Saúde Pública [online], Rio de Janeiro, 29(6):1217-29, 2013 [citado em 31 de mar. 2015]. Disponível em: http://www.scielo.br/scielo.php?script=sci_arttext\&pid=S0102-311X2013000600018

6. Czeresnia D. Canguilhem e o caráter filosófico das ciências da vida. Physis [online]. 2010 [citado em 04 de mai. 2015]. vol.20, n.3, pp. 709-727. ISSN 0103-7331. Disponível em: http://www.scielo.br/pdf/physis/v20n3/v20n3a02.pdf

7. Camarano AA (Organizadora). Cuidados de longa duração para a população idosa: um novo risco social a ser assumido? Rio de Janeiro, Ipea, 2010. 350p.

8. Faria APS, Bellato R. A compreensão do fenômeno condição crônica por diabetes mellitus a partir da experiência de adoecimento. Rev. Eletr. Enf.[online], 2010 [citado em 25 de mar. 2015]; 12(3):520-7. Disponível em: http://www.fen.ufg.br/fen_revista/v12/n3/v12n3a15.htm

9. Academia Nacional de Cuidados Paliativos. Manual de cuidados paliativos. $2^{\mathrm{a}}$ edição. Rio de Janeiro: Diagraphic; 2012 [citado em 31 de mar. 2105]. Disponível em: http://www.paliativo.org.br/biblioteca_resultadobusca.php?sgeral=manual\&button=Busc a

10. Lobo AJS, Santos L, Gomes S. Nível de dependência e qualidade de vida da população idosa. Rev Bras Enferm [online]. 2014 [citado em 05 de jun.2015] nov-dez; 67(6):913-9. Disponível em: $\quad$ http://www.scielo.br/scielo.php?script=sci_arttext\&pid=S0034$\underline{71672014000600913 \& \operatorname{lng}=\mathrm{pt} \& n \mathrm{~nm}=\mathrm{iso} .}$.

11. The WHOQOL Group. The World Health Organization quality of life assessment: position paper from the world health organization. Soc Sci Med. 1995[versão eletrônica]. [citado em 25 de mar.2015]; 41:1403-9. 2. Disponível em: http://www.who.int/mental_health/media/68.pdf

12. Amador DD, Reichert APS, Lima RAG et al. Conceptions of care and feelings of the caregiver of children with cancer. Acta paul. enferm. [online]. 2013 [citado em 05 de jun. 2015], vol.26, n.6, pp. 542-546. ISSN 1982-0194. Disponível em: http://www.scielo.br/pdf/ape/v26n6/en_06.pdf.

13. Amendola F, Oliveira MAC, Alvarenga MRM. Qualidade de vida dos cuidadores de pacientes dependentes no programa de saúde da família. Texto Contexto Enferm. [online], Florianópolis, abr-jun; 2008 [citado em 25 de mar. 2015] 17(2): 266-72. Disponível em: $\quad$ http://www.scielo.br/scielo.php?pid=S0104$\underline{07072008000200007 \& \text { script }=\text { sci_abstract\&tlng }=\text { pt }}$ 
14. Bampi LNS, Baraldi S, Guilhem D, et al. Nurse undergraduate students' perception of quality of life. Rev. Gaúcha Enferm. [online]. 2013 [citado em 05 jun. 2015], vol.34, n.2, pp. 125-132. ISSN 1983-1447. Disponível em: http://www.scielo.br/pdf/rgenf/v34n2/en_v34n2a16.pdf

15. Minayo MCS, Minayo-Goméz C. Difíceis e possíveis relações entre métodos quantitativos e qualitativos nos estudos de problemas de saúde. In: Goldenberg P, Marsiglia RMG, Gomes MHA (Orgs.) [versão eletrônica]. O clássico e o novo: tendências, objetos e abordagens em ciências sociais e saúde. Rio de Janeiro: Fiocruz, 2003 [citado em 25 de mar. 2015] p.117-42. Disponível em: http://books.scielo.org/id/d5t55/09

16. Rausch PK, Vitali MP. Pesquisa Quantitativa e Qualitativa: A integração do conhecimento científico. Sau. \& Transf. Soc.[online], ISSN 2178-7085, Florianópolis, 2013 [citado em 25 de mar. 2015]. v. 4, n. 1, p. 16-18, Disponível em: http://www.redalyc.org/pdf/2653/265325753005.pdf

17. Fleck MP, Chachamovich E, Trentini C. Development and validation of the Portuguese version of the WHOQOL-Old module. Rev Saúde Pública. 2006 [citado em 04 de mai. 2015]; 40(5):785-91. Disponível em: http://www.ufrgs.br/psiquiatria/psiq/WHOQOLOLD\%20Manual\%20POrtugues.pdf

18. Zohar N, Greenberger C, Bachner YG. Profile, burden, and quality of life of Israeli stroke survivor caregivers: a longitudinal study. Journal of Neurosciense Nursing [online], Glenview, 2009 [citado em 25 de mar. 2015]. v. 41, n. 2, p.92-104. Disponível em: http://www.ncbi.nlm.nih.gov/pubmed/19361125

19. Rodriguez PR. El apoyo informal a lãs personas mayores em España y La protección social a La dependência. Del facilismo a lós derechos de ciudadanía. Rev Esp Geriatr Gerontol. [online], 2005 [citado em 25 de mar. 2015]; 40 (supl 3): 5-15. Disponível em: http://www.caritas.es/imagesrepository/CapitulosPublicaciones/525/08\%20EL\%20APOY O\%20INFORMAL\%20COMO\%20DESTINATARIO.pdf

20. Nogueira AS, Souza RAAR, Casarin RG. O estresse nos cuidadores de pacientes em internação domiciliar. Revista Científica da Faculdade de Educação e Meio Ambiente. jul-dez, 2014 [citado em 25 de mar. 2015]. 5(2): 50-64. Disponível em: http://www.faema.edu.br/revistas/index.php/Revista-FAEMA/article/view/239

21. Uesugui HM, Fagundes DS, Pinho DLM. Perfil e grau de dependência de idosos e sobrecarga de seus cuidadores. Acta paul. enferm. [online], São Paulo 2011 [citado em 23 
de mar.2015], 24(5) 685-698. Disponível em: http://www.scielo.br/pdf/ape/v24n5/15v24n5.pdf

22. Anjos KF, Boery RNSO, Pereira R. Quality of life of relative caregivers of elderly dependents at home. Texto contexto - enferm. [online]. 2014 [citado em 05 jun. 2015], vol.23, n.3, pp. 600-608. ISSN 0104-0707. Disponível em: http://www.scielo.br/pdf/tce/v23n3/0104-0707-tce-23-03-00600.pdf

23. Andrade SFO, Melo MO, Rodrigues MJ, et al. Qualidade de Vida e Sobrecarga de Cuidadores de Crianças com Câncer. Psicol. cienc. prof. [online]. 2014 [citado em 05 jun. 2015], vol.34, n.4 pp. 1014-1031. Disponível em: http://www.scielo.br/scielo.php?script=sci_arttext\&pid=S1414$\underline{98932014000401014 \& \operatorname{lng}=\mathrm{pt} \& \mathrm{nrm}=\text { iso }}$

24. Sanches MVP, Nascimento LC, Lima RAG. Crianças e adolescentes com câncer em cuidados paliativos: experiência de familiares. Rev. bras. enferm. [online]. 2014 [citado em 15 de abr. 2015], vol.67, 1, pp. 28-35. ISSN 0034-7167. Disponível em: http://www.scielo.br/pdf/reben/v67n1/0034-7167-reben-67-01-0028.pdf

25. McCoughlan M. A necessidade de cuidados paliativos. In: Pessini L, Bertachini L Humanização e cuidados paliativos. 2. ed. São Paulo: Loyola, 2004. Cap. 11, p. 167-180.

26. Geib LTC, Cataldo Neto A, Wainberg R, Nunes ML. Sono e envelhecimento. Rev Bras Psiquiatr 2003 [impressa]; 25: pp 453-65.

27. Pimenta GMF, Costa MASMC, Gonçalves LHT, Alvarez AM. Profile of the caregiver of dependent elderly family members in a home environment in the city of Porto, Portugal. Rev Esc Enferm USP. [online] Set 2009 [citado em 23 de mar. 2015]; 43(3):606-11. Disponivel em: $\quad$ http://www.scielo.br/scielo.php?script=sci_arttext\&pid=S0080$\underline{62342009000300016}$

28. Gonçalves LHT, Costa MAM, Martins MM, Nassar SM, Zunino R. The family dynamics of elder elderly in the context of Porto, Portugal. Rev Latino-Am Enferm. [online]. MayJun 2011 [citado em 23 de mar. 2015]; 19(3):458-66. Disponível em: http://bases.bireme.br/cgi-

$\underline{\text { bin/wxislind.exe/iah/online/?IsisScript }=i a h / i a h . x i s \& s r c=g o o g l e \& b a s e=L I L A C S \& l a n g=p}$ \&nextAction=lnk\&exprSearch=598611\&indexSearch=ID

29. Silva HS, Gutierrez BAO. Dimensões da qualidade de vida de idosos moradores de rua do município de São Paulo. Saude soc. [online]. 2013 [citado em 05 jun. 2015], vol.22, n.1, pp. 148-159. ISSN 0104-1290. Disponível em: http://www.scielo.br/pdf/sausoc/v22n1/14.pdf 


\section{APÊNDICE 7}

Artigo elaborado para submissão ao periódico Acta Bioethica.

Aspectos bioéticos da relação intrafamiliar no contexto dos cuidados paliativos na atenção domiciliar 


\section{Aspectos bioéticos da relação intrafamiliar no contexto dos cuidados paliativos na atenção domiciliar}

Diane Maria Scherer Kuhn Lago

Dirce Guilhem

Maria da Graça Camargo Neves

\section{Resumo}

O objetivo deste trabalho foi identificar aspectos bioéticos envolvidos no processo de atender continuamente o doente em cuidados paliativos no domicilio. Estudo observacional, descritivo, de corte transversal com utilização de metodologia de abordagem qualitativa. Os dados foram coletados após a aprovação do projeto pelo Comitê de Ética em Pesquisa sob o parecer n. 187.211/2013, por meio de entrevistas realizadas entre os meses de fevereiro e julho de 2013 e incluiu 11 cuidadores familiares principais de doentes atendidos em domicilio. O perfil dos cuidadores revelou que 8 possuem mais de 40 anos de idade e 6 exercem a função há menos de 5 anos. Após a análise dos relatos foram encontradas três categorias temáticas relacionadas aos aspectos bioéticos: autonomia nas escolhas da sua vida; vulnerabilidade ao estresse e sobrecarga e vulnerabilidade a problemas de saúde físicos e psicológicos. Foi possível constatar que a prestação de cuidado informal a familiar doente, associada ao despreparo inicial e a imposição da situação, pode desencadear ansiedade e estresse, acarretando sobrecarga e desestruturação da vida do cuidador. A discussão dos aspectos bioéticos envolvidos nesse processo é essencial para a qualidade da assistência domiciliar e para a qualidade de vida dos cuidadores.

Palavras-chave: Assistência domiciliar, Bioética, Cuidadores familiares, Cuidados paliativos.

\section{Introdução}

Bioética, definida como a ética da vida, é o termo utilizado para a disciplina que promove o exercício da tolerância junto a sociedades plurais (1). Surgiu na década de 1970 como uma proposta inovadora e assumiu propósito de auxiliar na análise das questões éticas relacionadas tanto a problemas morais quanto normativos (2).

Em defesa da melhoria das condições de vida e do estudo sobre a sobrevivência humana, a bioética utiliza bases filosóficas para analisar e discutir questões que envolvam conflitos éticos. O fim da vida humana passa por modificações importantes no tocante ao 
avanço tecnológico decorrente de estudos científicos que resultam em maior longevidade, bem como em maior sobrevida de pessoas enfermas (3-4).

A fase terminal de doença progressiva e incurável tem como uma das características o sofrimento do doente, dos conviventes e de sua rede social. Acompanhar o doente e auxiliá-lo no processo da morte e do morrer é tarefa continua e que tem melhor resultado quando desenvolvida em conjunto pela família, cuidador e serviço de saúde (4-5).

O acompanhamento dispensado ao doente, ou seja, a pessoa que desenvolve um estado patológico, estabelecido pela doença que se caracteriza pela diminuição da sua vitalidade é definido como cuidados paliativos e adota como princípios, dentre outros, o alívio da dor e de outros sintomas; a preservação da dignidade e da privacidade; o oferecimento/recebimento do suporte emocional e espiritual; a possibilidade de ter tempo para dizer adeus e partir quando for o momento e, ainda, controlar quem participará desse momento (5-8).

Respeito à pessoa em todos os momentos da sua vida representa uma das principais prerrogativas da bioética, sendo que os princípios dos cuidados paliativos contribuem para que o respeito no fim da vida seja amplamente valorizado (8-10).

A morte é considerada um tabu em muitas sociedades. $\mathrm{O}$ medo de sua proximidade divide espaço com a negação e são sentimentos vivenciados pela família e pelo doente. Muitas vezes, essas emoções são experimentadas também pelos profissionais de saúde que nem sempre estão preparados para oferecer apoio nesse processo. O preparo deve ser contínuo e extensivo envolvendo questões espirituais e humanitárias (8,11-12).

A vulnerabilidade intrínseca do ser humano se torna mais evidente no fim da vida, bem como em momentos de exposição a problemas de saúde. Socialmente, a vulnerabilidade pode ser considerada dinâmica por compreender eventos que causem danos advindos das relações sociais, culturais, políticas e econômicas. A capacidade de reação e de ajuste ao perigo é entendida como vulnerabilidade, sendo que qualquer alteração pode aumentá-la ou diminuí-la (13-14).

Os doentes em cuidados paliativos costumam apresentar maior vulnerabilidade, principalmente no tocante ao processo de tomada de decisão sobre o tratamento e os cuidados dispensados. Nesse mesmo sentido, os cuidadores familiares enfrentam esta situação de fragilidade, pois a comunicação eficiente e adequada, fator essencial para o retorno do equilíbrio pessoal e familiar e minimização da condição pode estar comprometida nesta fase $(15-16)$.

Após exposição do contexto em que se insere o estudo, definimos como objetivo apresentar os aspectos bioéticos envolvidos no processo do cuidar de doente com a oferta de 
cuidados paliativos em domicilio. Este artigo foi extraído de um estudo mais amplo que teve a finalidade de analisar os aspectos bioéticos do cuidar e da relação entre a percepção sobre qualidade de vida e sobrecarga de trabalho de cuidadores domiciliares.

\section{Metodologia}

Trata-se de estudo observacional, descritivo, de corte transversal com a utilização de metodologia com abordagem qualitativa. A abordagem qualitativa permite conhecer a historia de cuidado envolvendo os sentimentos e as vivências individuais dos cuidadores com a valorização das angústias e ansiedades. Busca compreender e interpretar sentidos e significações que uma pessoa dá aos fenômenos em foco, via observação ampla e entrevistas em profundidade (17).

Para a realização deste estudo foram entrevistados cuidadores principais de 11 doentes em cuidados paliativos vinculados a um Serviço de Atenção Domiciliar no Distrito Federal. Todos são familiares dos doentes, maiores de 18 anos de idade e que concordaram em participar da pesquisa por meio da assinatura do termo de consentimento livre e esclarecido (TCLE). Para a preservação do anonimato, os entrevistados foram identificados por letra $\mathrm{C}$ de cuidador seguido por números $(\mathrm{C} 1 \mathrm{a} \mathrm{C} 11)$.

Com o objetivo de conhecer o perfil dos cuidadores foi aplicado um questionário contendo dados sociodemográficos. Em seguida, com o propósito de identificar os aspectos bioéticos que envolviam os sentimentos vivenciados e as mudanças sociais decorrentes da função do cuidar, foram realizadas entrevistas com os cuidadores nas residências dos doentes, entre os meses de fevereiro e julho de 2013, com agendamento prévio.

Para a avaliação dos resultados, foi utilizado o método de análise de conteúdo proposto por Bardin (18). O processo analítico é composto por um conjunto de técnicas de análise das comunicações visando obter, por procedimentos sistemáticos e objetivos de descrição do conteúdo das mensagens, indicadores que permitam a inferência de conhecimentos relativos às condições de produção destas mensagens.

Em cumprimento a Resolução CNS n. 466/12, que versa sobre Pesquisa Envolvendo Seres Humanos, este estudo foi aprovado pelo Comitê de Ética da Secretaria de Estado de Saúde do Distrito Federal - CEP/FEPECS/SES/DF, sob o parecer n. 187.211/2013.

\section{Resultados}


Com relação ao perfil dos cuidadores participantes do estudo, cabe ressaltar que todos são familiares dos doentes internados em domicilio e respondem por maior parte dos cuidados prestados ao mesmo. A tabela 1 apresenta as principais características demográficas e clínicas dos mesmos.

Tabela 1- Características sociodemográficas e clínicas dos cuidadores familiares principais de doentes cuidados em domicilio.

\begin{tabular}{ll}
\hline \multicolumn{1}{c}{ CARACTERÍSTICAS SOCIODEMOGRÁFICAS } & (N= 11) \\
\hline Sexo & 02 \\
Masculino & 09 \\
Feminino & \\
Grupo etário & 03 \\
18 a 39 anos & 06 \\
40 a 59 anos & 02 \\
60 anos ou mais & \\
Grau de parentesco & 04 \\
Filha (o) & 01 \\
Mãe & 05 \\
Esposa (o) & 01 \\
Outro & \\
Apresenta doença & 08 \\
Sim & 03 \\
Não & 03 \\
Apresenta dor & 03 \\
Sim & 03 \\
Não & \\
\hline Total & 03 \\
\hline & \\
\hline
\end{tabular}

Os participantes eram predominantemente do sexo feminino, 8 possuíam idade superior a 40 anos, 6 relataram estar em união estável e 5 possuíam estudo até o Ensino Fundamental 1 Completo - EF1C o que representa menos de 5 anos de estudo formal. Quanto ao tempo como cuidador principal, 6 estavam há menos de 5 anos na função. O apoio social para o desenvolvimento dos cuidados foi percebido por 4 dos 11 cuidadores entrevistados. 
Com relação aos dados relacionados à saúde dos cuidadores, 8 relataram possuir alguma doença em tratamento continuo, sendo que 6 desses agravos estavam relacionadas aos sistema cardiovascular e endócrino, com predominância da hipertensão arterial sistêmica - HAS e diabetes mellitus - DM. Entre os participantes, 5 relataram mais de uma patologia em tratamento. Quanto à intensidade da dor, 7 relataram sentir dor moderada ou intensa. Associado a este dado, a qualidade do sono foi definida como ruim por 6 cuidadores devido à sua interrupção, e por oito pela quantidade inferior a 6 horas por noite,

Com base nos relatos dos cuidadores sobre o processo do cuidar e sua função como cuidador, emergiram das verbalizações três categorias temáticas nas quais os aspectos bioéticos puderam ser claramente definidos: a. Autonomia nas escolhas da sua vida; $b$. Vulnerabilidade ao estresse e sobrecarga e c. Vulnerabilidade a problemas de saúde físicos e psicológicos. Alguns fragmentos das falas foram incluídos na apresentação e análise dos resultados como forma de exemplificar e proporcionar melhor entendimento sobre as situações vivenciadas.

a. Autonomia nas escolhas da sua vida: Esta categoria inclui aspectos relacionados a controle do tempo, incerteza em relação ao futuro, solidão e perda das amizades.

Transformar-se em cuidador principal envolve questões de ordem pessoal, social e psicológica. O fato de ter de assumir a função sem preparo prévio e, muitas vezes sem esperar, influencia diretamente na autonomia de suas vidas.

O relato a seguir evidencia este aspecto relacionado ao controle do tempo: "Tenho 30 anos e a minha vida tá parada... minha vida é tão programada que eu tenho que pensar antes de sair... Parei de estudar, de trabalhar... acho que até parei de viver... namorar... quando?(C5)” Da mesma forma, a incerteza com relação ao futuro é descrita no relato: “Eu abri mão da faculdade, né? Eu me privei de muita coisa para cuidar do meu filho. Só eu cuido dele, não tem outra pessoa.(C2)”’.

A solidão é vivenciada pelos cuidadores devido ao tempo de dedicação ao doente dentro de casa, muitas vezes, sozinho. Alguns doentes não se comunicam mais verbalmente ou apresentam problemas de ordem neurológica quando a comunicação é perturbada. O relato de uma cuidadora deixa claro esta incerteza quanto ao apoio social e às amizades: "Muitas vezes me pego pensando... Quem é meu amigo? Ainda tenho amigos? Parece que a vida dá um nó. (C3)"

Outro relato importante apresenta a empatia e alteridade dos cuidadores para com o seu familiar adoentado: “Às vezes eu penso: Como será que seria se fosse eu no lugar 
dele?(C8)" E essa empatia pode trazer uma sobrecarga evidenciada pela cobrança interna do seu desempenho na função, como descrito no relato: "Será que eu estou cuidando bem dele? Será que ele tem tudo o que merece?(C7)’. A cobrança é acentuada quando associada ao reconhecimento do seu trabalho pelos demais familiares, como evidenciado pelo depoimento de uma cuidadora que é esposa do doente: "Eu faço tudo pra ele ter uma vida melhor. Só que os outros (familiares) ainda acham que é pouco. Reclamam, falam que ele tá magro, que parece que não tá bem... O que querem que eu faça? Ele tá doente, não tá bem mesmo. Isso cansa mais do que cuidar dele, sabia?(C11)”,

b. Vulnerabilidade ao estresse e sobrecarga: Estão incluídos nesta categoria aspectos relacionados a convivência com o sofrimento do outro, relacionamento com o doente e sobrecarga devido a função desempenhada.

A convivência com o sofrimento alheio de outra pessoa, principalmente quando esta é próxima sentimentalmente, pode resultar em sobrecarga, sendo, em muitas vezes, necessário disfarçar os próprios sentimentos para preservar o outro. $\mathrm{O}$ cuidado pode resultar em pressão e estresse e, consequentemente em uma sobrecarga física e emocional do cuidador.

Um cuidador descreveu a angústia sentida ao perceber o sofrimento da doente: "Tudo passa, mas isso parece que não tem fim. Ela geme quando a gente pega nela. Quando vai dar banho, ela chora... Às vezes eu penso: pra que dar banho? ... cansa demais e dói na gente ver ela chorar...?(C2)” Da mesma forma, outra cuidadora relatou sofrer ao cuidar da mãe devido a dor percebida ao realizar os cuidados de higiene: “...ultimamente para mim está sendo um sofrimento terrivel (...) cada vez que eu vou trocar ela (mãe), ela começa a gemer. é sofrimento para ela e para mim também. Pra mim mais ainda, entendeu?(C6)”

c.Vulnerabilidade a problemas de saúde físicos e psicológicos: Nesta categoria estão inclusos aspectos relacionados às questões físicas e psicológicas associadas à dedicação ao cuidado.

O trabalho contínuo, sem intervalos de descanso regulares, carregar o paciente para a cadeira de rodas ou para mudar de decúbito no leito são situações que causam dores e lesões, podendo acarretar em desgaste físico:

O cansaço físico por parte do cuidador é descrito nos relatos a seguir: "Ele (pai) é pesado e a gente precisa mudar de lado toda hora pra não dar ferida. Muitas vezes eu fazia sozinha... Agora não consigo fazer mais. Machuquei as costas. (C3)” Esta situação pode se agravar quando o cuidador deixa de cuidar de si próprio para se dedicar exclusivamente ao 
outro, como neste depoimento: "A gente fica tão cansada que até esquece se já comeu. Que hora foi a última vez que comeu... (C9)"

A aceitação por parte do doente com relação a sua condição de saúde interfere, principalmente no desgaste emocional do cuidador como descrito no relato: "Ele (pai) é muito teimoso mesmo... Toda hora ele arranca o curativo, a gente coloca e ele tira. É difícil...(C7)". Outra situação desgastante diz respeito ao relacionamento conjugal entre doente e cuidador, quando esse entende que é obrigado a cuidar do doente por ser seu marido ou sua esposa: "Ninguém mais quer cuidar dele. Então só tem eu, ele é meu marido e eu tenho que aceitar...(C4)"ou ainda quando o doente culpa o cuidador cônjuge sobre a sua situação, muitas vezes, relacionado à demência sofrida: "Ele me xinga toda hora. Fala pra eu sair, fazer festa. Que era tudo o que eu queria, que ele ficasse numa cama pra eu poder ficar solteira novamente.(C10)"

\section{Discussão}

Oferecer cuidado contínuo a outra pessoa, principalmente quando esta faz parte do seu círculo familiar é tarefa complexa, pois envolve dedicação e conhecimento. Em muitos casos, a escolha para o desenvolvimento do cuidado não é voluntária, o que pode acarretar em desgaste físico e emocional por parte do cuidador principal (19-21).

O preparo do cuidador escolhido para assumir a função tem que ser abrangente e deve envolver conhecimento sobre técnicas e procedimentos necessários para a realização do cuidado, que deverá ser dispensado de forma humanizada, com o propósito de amenizar o sofrimento e as dificuldades encontradas pelos atores envolvidos no processo (22).

O cuidado desenvolvido em casa é complexo, possui características específicas e entrelaça a família, o cuidador, o doente e a equipe de profissionais de saúde. A família assume a responsabilidade de cuidar e necessita receber atenção para manter o equilíbrio frente ao estresse vivenciado. A família é importante em todas as fases da vida humana, mas tem destaque especial no inicio e no fim da vida, pois nesses dois estágios, a fragilidade e a vulnerabilidade são intensificadas (22-23).

Diversos sentimentos vivenciados pelos cuidadores familiares principais foram percebidos neste estudo. Estão presentes em todas as etapas do cuidado. No inicio do processo, os cuidadores relataram estresse relacionado à necessidade de adaptação do ambiente e da vida pessoal. Nesse momento, várias emoções estão presentes, como medo e 
incerteza sobre o futuro. Esses sentimentos inquietantes podem ser comparados à sensação de perigo iminente (24-26).

Foi identificada nas verbalizações, a alteridade, vista como uma relação entre pessoas que se voltam um para o outro representando disponibilidade, respeito, entrega e aceitação (27).

Após alguns anos de acompanhamento, o cansaço e o desânimo se acentuam e surge o sentimento de abandono e de solidão expresso em vários relatos, além da sobrecarga evidenciada pela culpa e pela obrigação em atender aos anseios do doente a da família. Essa pretensão evidencia a cobrança interna e externa com relação ao cuidado e a dedicação contínua ao doente influencia na liberdade de escolha e na autonomia do cuidador (24-26).

A sensação de estagnação da própria vida é evidenciada, principalmente em cuidadores mais jovens e com maior escolaridade, pois são os que mais abrem mão de oportunidades sociais e de trabalho. O temor de não ser compreendido pelo doente, pelo restante da família e até mesmo pela sociedade torna impeditivo para muitos cuidadores a exposição desses sentimentos ambíguos de forma clara (25).

A vulnerabilidade do cuidador frente ao processo contínuo do cuidar fica demonstrada pelo desgaste físico e emocional. É fundamental que o cuidador esteja ciente da sua própria fragilidade e precariedade como ser humano, além de entender que o outro também é vulnerável, pois só dessa forma se tornará possível cultivar forças para ajudar a si próprio e para cuidar do outro $(22,28)$.

\section{Conclusão}

Considerando-se os aspectos aqui elencados é possível constatar que a vivência e o acompanhamento contínuos, com a oferta de cuidados paliativos a um familiar, associados aos sentimentos de impotência, ansiedade e despreparo, além da percepção sobre a terminalidade da vida resulta em desgaste físico e emocional podendo acarretar sobrecarga para o cuidador ocasionando a desestruturação de sua vida pessoal.

Conclui-se, portanto, que a discussão acerca dos aspectos bioéticos presentes na atenção domiciliar, principalmente no tocante ao cuidador, é essencial para a qualidade da assistência nesta área e para a qualidade de vida do cuidador.

\section{Referências}


1. Diniz D, Guilhem D. O que é Bioética? Coleção Primeiros Passos, 315. Ed. Brasiliense, São Paulo, 2002. 69p.

2. Andrade CG de, Costa SFG da, Vasconcelos MF, Zaccara AAL, Duarte MCS, Evangelista CB. Bioética, cuidados paliativos e terminalidade: revisão integrativa da literatura. Rev enferm UFPE on line, Recife, 7(esp):888-97, 2013 Mar [citado em 25 de Setembro de 2013]. Disponível em: http://www.revista.ufpe.br/revistaenfermagem/index.php/revista/article/view/3775/pdf_2 240.

3. Nunes L. Ética em cuidados paliativos: limites ao investimento curativo. Revista Bioética 200816 (1): 41 - 50. [citado em 25 de Setembro de 2013]. Disponível em: http://revistabioetica.cfm.org.br/index.php/revista_bioetica/article/view/54/57

4. Vilaça CM, Barreiros DS, Galli FA, Borçari IT, Andrade LF, Goulart MA, et. al. O autocuidado de cuidadores informais em domicílio. Percepção de acadêmicos de enfermagem. Rev Elet de Enfermagem, [online] v.7, n.2, p. 221-226, 2005. [citado em 25 de Setembro de 2013]. Disponível em: http://www.fen.ufg.br/revista/revista7_2/relato_02.htm

5. Rego S, Palácios M. A finitude humana e a saúde pública; Cad. Saúde Pública, Rio de Janeiro, 22(8):1755-1760, 2006 Ago [citado em 25 de Julho de 2013]. Disponível em: http://www.scielo.br/scielo.php?script=sci_arttext\&pid=S0102-311X2006000800025

6. Czeresnia D. Canguilhem e o caráter filosófico das ciências da vida. Physis [online]. 2010 [Acesso em 04 de maio de 2015]. vol.20, n.3, pp. 709-727. ISSN 0103-7331. Disponível em: http://www.scielo.br/pdf/physis/v20n3/v20n3a02.pdf

7. Academia Nacional de Cuidados Paliativos (ANCP). Manual de cuidados paliativos. Rio de Janeiro: Diagraphic, 2009 [citado em 13 de Nov de 2014]. Disponível em: http://www.paliativo.org.br/biblioteca_resultadobusca.php?spublicacao=Livros

8. O'Neill B, Fallon M. ABC of palliative care: principles of palliative care and pain control. Br Med J.1997;315:801-4 [citado em 25 de Janeiro de 2013]. Disponível em: http://www.tandfonline.com/doi/abs/10.1300/J457v01n01_06\#.VRCr8PnF_n0

9. Alencar SCS, Lacerda MR, Centa ML. Finitude humana e enfermagem: reflexões sobre o (des)cuidado integral e humanizado ao paciente e seus familiares durante o processo de morrer. Fam Saúde Desenv Curitiba, v.7, n.2, p.171-180, maio/ago. 2005. [citado em 13 de Outubro de 2013]. Disponível em: http://ojs.c3sl.ufpr.br/ojs2/index.php/refased/article/view/8045/5668 
10. Wittmann-Vieira R, Goldim JR. Bioética e Processo de Enfermagem. In Almeida MA, et al. Processo de enfermagem na prática clínica: estudos clínicos realizados no Hospital de Clínicas de Porto Alegre. Porto Alegre: Artmed; 2011. p. 67-75.

11. Cassorla RMS. Negação e outras defesas frente à morte. In: Santos FS, organizador. Cuidados paliativos: discutindo a vida, a morte e o morrer. São Paulo (SP): Atheneu; 2009. p.59-76.

12. Negreiros TCGM. Espiritualidade: desejo de eternidade ou sinal de maturidade? Revista Mal estar e Subjetividade. v. 3, n. 2, p. 275-91, 2003. [citado em 13 de Novembro de 2013] Disponível em: http://pepsic.bvsalud.org/pdf/malestar/v3n2/03.pdf

13. Junges JR. Vulnerabilidade e saúde: limites e potencialidades das políticas públicas. In: Brachifontaine CP, Zoboli ELCP (org.). Bioética, vulnerabilidade e saúde. São Paulo: Centro Universitário São Camilo; 2007. p. 110-138.

14. Marandola Junior E, Hogan DJ. As dimensões da vulnerabilidade. São Paulo Perspect. 2006; [citado em 25 de Janeiro de 2015]. 20(1): 33-43. http://produtos.seade.gov.br/produtos/spp/v20n01/v20n01_03.pdf

15. Bushatsky M, Sarinho ESC, Lima LS, Faria JH, Baibich-Faria T. Cuidados Paliativos em pacientes fora de possibilidade terapêutica. Revista - Centro Universitário São Camilo 2012; [citado em 25 de Janeiro de 2015]. 6(4):399-408. Disponível em: http://www.saocamilo-sp.br/pdf/bioethikos/87/A6.pdf

16. Fornells HA. Cuidados paliativos en el domicilio. Acta Bioethica 2000 [citado em 25 de Janeiro de 2015]. Año VI, $\mathrm{n}^{\circ}$ 1. Disponível em: http://www.scielo.cl/scielo.php?script=sci_arttext\&pid=S1726-569X2000000100005

17. Minayo MC. O desafio do conhecimento: pesquisa qualitativa em saúde. 12 edição. Rio de Janeiro: Hucitec, 2010, 408p.

18. Bardin, L. Análise de Conteúdo. Lisboa: Edições 70, 2014. Reimp. 288p.

19. Inocenti A, Rodrigues IG, Miasso AI. Vivências e sentimentos do cuidador familiar do paciente oncológico em cuidados paliativos. Rev. Eletr. Enf. 2009 [citado em 25 de Janeiro de 2015]. Disponível em: https://www.fen.ufg.br/fen_revista/v11/n4/pdf/v11n4a11.pdf

20. Silva CAM, Acker JIBV. O cuidado paliativo domiciliar sob a ótica de familiares responsáveis pela pessoa portadora de neoplasia. Rev Bras Enferm. 2007 [citado em 25 de Janeiro de 2015]. Disponível em: http://www.scielo.br/pdf/reben/v60n2/a04v60n2.pdf

21. Proot IM, Abu-Saad HH, Crebolder HFJM, Goldsteen M, Luker KA, Widdershoven GAM. Vulnerability of family caregivers in terminal palliative care at home; balancing 
between burden and capacity. Scand. J. Caring Sci. 2003. [citado em 15 de Setembro de 2013]. Disponível em: http://www.ncbi.nlm.nih.gov/pubmed/12753511

22. Santos DMA, Lattaro RCC, Almeida DA. Cuidados paliativos de enfermagem ao paciente oncológico terminal: revisão da literatura. Rev Ini Cient Lib. V.1, n.1, 2011. [citado em 15 de Setembro de 2013]. Disponível em: http://www.libertas.edu.br/revistalibertas/revistalibertas1/artigo05.pdf

23. Yamada KN, Dellaroza SMG, Siqueira JE. Aspectos éticos envolvidos na assistência a idosos dependentes e seus cuidadores. O Mundo da Saúde. São Paulo: 2006. [citado em 15 de Setembro de 2013] out/dez 30 (4): 667-672. Disponível em: http://www.saocamilosp.br/pdf/mundo_saude/41/19_aspectos_eticos.pdf

24. Todd K, Roberts S., Black C. The Living with Cancer Education Programme. II. Evaluation of an Australian education and support programme for cancer patients and their family and friends. Euro Journ Cancer Care, 11(4):280-9, 2002. [citado em 2015 Jan]. Disponível em: http://www.ncbi.nlm.nih.gov/pubmed/12492465

25. Floriani CA, Cuidador familiar: sobrecarga e proteção. Rev Bra Can 50(4): 341-345, 2004. [Citado em 23 de Agosto de 2012]. Disponível em: http://www.inca.gov.br/rbc/n_50/v04/pdf/seca05.pdf

26. O'Connel B, Baker L. Managing as carers of stroke survivors: strategies from the field. International Journal of Nursing Practice, 2006, [Citado em 23 de Agosto de 2012].10, 121-126. Disponível em http://www.ncbi.nlm.nih.gov/pubmed/15149459

27. Buber M. Do Diálogo e do Dialógico. Trad. de Marta Ekstein de Souza Queiroz e Regina Weinberg. São Paulo: Perspectiva, 2007, 176p.

28. Waldow VR; Borges RF. The Caregiving Process In Vulnerability Perspetive. Rev. Latino-Am. Enfermagem. 2008 Jul-Ago; [Citado em 25 de Janeiro de 2015]; 16(4):76571. Disponível em: http://www.scielo.br/scielo.php?script=sci_arttext\&pid=S0104$\underline{11692008000400018 \& \operatorname{lng}=\text { en } \& n r m=i s o \& \operatorname{lng}=p t}$ 
ANEXO 1 


\section{Escala de Sobrecarga do Cuidador}

\section{(Zarit \& Zarit, 1987; tradução para o português: Márcia Scazufca)}

\section{Instruções:}

A seguir encontra-se uma lista de afirmativas que reflete como as pessoas algumas vezes sentem-se quando cuidam de outra pessoa.

Depois de cada afirmativa, indique com que frequência o(a) $\mathrm{Sr} / \mathrm{Sra}$ se sente daquela maneira. Não existem respostas certas ou erradas.

\section{Nunca $=1$ Quase nunca $=2 \quad$ Às vezes $=3 \quad$ Muitas vezes $=4 \quad$ Quase sempre $=5$}

1. $\mathrm{O}(\mathrm{a}) \mathrm{Sr} / \mathrm{Sra}$ sente que o $\mathrm{S}^{*}$ pede mais ajuda do que ele necessita?

2. O(a) $\mathrm{Sr} / \mathrm{Sra}$ sente que por causa do tempo que o(a) $\mathrm{Sr} / \mathrm{Sra}$ gasta com o(a) $\mathrm{S}^{*}$, o(a) (a) $\mathrm{Sr} / \mathrm{Sra}$ não tem tempo suficiente para si mesmo?

3. O(a) Sr/Sra se sente estressado entre cuidar do(a) $\mathrm{S}^{*}$ e suas outras responsabilidades com a família e o trabalho?

4. O(a) Sr/Sra se sente envergonhado com o comportamento do(a) $\mathrm{S}^{*}$ ?

5. O(a) Sr/Sra se sente irritado quando o(a) S* está por perto?

6. $\mathrm{O}$ (a) $\mathrm{Sr} / \mathrm{Sra}$ sente que o(a) $\mathrm{S}^{*}$ afeta negativamente seus relacionamentos com outros membros da família ou amigos?

7. O(a) Sr/Sra sente receio pelo futuro de S* está?

8. O(a) Sr/Sra sente que $\mathrm{S}^{*}$ depende do $\mathrm{Sr} / \mathrm{Sra?}$

9. O(a) Sr/Sra se sente tenso quando S* está por perto?

10. O(a) Sr/Sra sente que a sua saúde foi afetada por causa do seu envolvimento com $\mathrm{S}^{*}$ ?

11. O(a) $\mathrm{Sr} / \mathrm{Sra}$ sente o o(a) $\mathrm{Sr} / \mathrm{Sra}$ não tem tanta privacidade como gostaria, por causa de $\mathrm{S}^{*}$ ?

12. O(a) $\mathrm{Sr} / \mathrm{Sra}$ sente que a sua vida social tem sido prejudicada porque o(a) $\mathrm{Sr} / \mathrm{Sra}$ está cuidando de $\mathrm{S}^{*}$ ?

13. $\mathrm{O}(\mathrm{a}) \mathrm{Sr} / \mathrm{Sra}$ se sente à vontade de ter visita em casa, por causa de $\mathrm{S}^{*}$ ?

14. O(a) $\mathrm{Sr} / \mathrm{Sra}$ sente que $\mathrm{S}^{*}$ espera que o(a) $\mathrm{Sr} / \mathrm{Sra}$ cuide dele/dela como se o(a) $\mathrm{Sr} / \mathrm{Sra}$ fosse a única pessoa de quem ele/ela pode depender?

15. $\mathrm{O}$ (a) $\mathrm{Sr} / \mathrm{Sra}$ sente que não tem dinheiro suficiente para cuidar de $\mathrm{S}^{*}$, somando-se as suas outras despesas?

16. O(a) Sr/Sra sente que será incapaz de cuidar de $S^{*}$ por muito mais tempo? 
17. O(a) Sr/Sra sente que perdeu o controle da sua vida desde a doença de $\mathrm{S}^{*}$ ?

18. O(a) Sr/Sra gostaria de simplesmente deixar que outra pessoa cuidasse de $\mathrm{S}^{*}$ ?

19. O(a) Sr/Sra se sente em dúvida sobre o que fazer por S*?

20. $\mathrm{O}(\mathrm{a}) \mathrm{Sr} / \mathrm{Sra}$ sente que deveria estar fazendo mais por $\mathrm{S}^{*}$ ?

21. O(a) Sr/Sra sente que poderia cuidar melhor de $S^{*}$ ?

22. O(a) Sr/Sra sente que poderia cuidar melhor de $S^{*}$ ?

23. De uma maneira geral, quando o(a) $\mathrm{Sr} / \mathrm{Sra}$ se sente sobrecarregado(a) por cuidar de $\mathrm{S}^{*}$ ? 


$$
-
$$




\section{Instrumento de avaliação da qualidade de vida abreviado - WHOQOL-bref}

\section{Instruções}

Este questionário é sobre como você se sente a respeito de sua qualidade de vida, saúde e outras áreas de sua vida. Por favor, responda a todas as questões. Se você não tem certeza sobre que resposta dar em uma questão, por favor, escolha entre as alternativas a que lhe parece mais apropriada.

Esta, muitas vezes, poderá ser sua primeira escolha. Por favor, tenha em mente seus valores, aspirações, prazeres e preocupações. Nós estamos perguntando o que você acha de sua vida, tomando como referência as duas últimas semanas. Por exemplo, pensando nas últimas duas semanas, uma questão poderia ser:

\begin{tabular}{|l|c|c|c|c|c|}
\hline & Nada & $\begin{array}{c}\text { muito } \\
\text { pouco }\end{array}$ & médio & muito & completamente \\
\hline $\begin{array}{l}\text { Você recebe dos outros o apoio de que } \\
\text { necessita? }\end{array}$ & 1 & 2 & 3 & 4 & 5 \\
\hline
\end{tabular}

Você deve circular o número que melhor corresponde ao quanto você recebe dos outros o apoio de que necessita nestas últimas duas semanas. Portanto, você deve circular o número 4 se você recebeu "muito" apoio como abaixo.

\begin{tabular}{|l|c|c|c|c|c|}
\hline & Nada & $\begin{array}{c}\text { muito } \\
\text { pouco }\end{array}$ & médio & muito & completamente \\
\hline $\begin{array}{l}\text { Você recebe dos outros o apoio de que } \\
\text { necessita? }\end{array}$ & 1 & 2 & 3 & 4 & 5 \\
\hline
\end{tabular}

Você deve circular o número 1 se você não recebeu "nada" de apoio.

Versão em Português. Coordenação do GRUPO WHOQOL no Brasil - Dr. Marcelo Pio de Almeida Fleck- Professor Adjunto -Departamento de Psiquiatria e Medicina Legal - Universidade Federal do Rio Grande do Sul - Porto Alegre - RS - Brasil

Por favor, leia cada questão, veja o que você acha e circule no número e lhe parece a melhor resposta. 


\begin{tabular}{|c|l|c|c|c|c|c|}
\hline & & $\begin{array}{c}\text { muito } \\
\text { ruim }\end{array}$ & ruim & $\begin{array}{c}\text { nem ruim } \\
\text { nem boa }\end{array}$ & $\begin{array}{c}\text { boa } \\
\text { boa }\end{array}$ \\
\hline 1 & Como você avaliaria sua qualidade de vida? & 1 & 2 & 3 & 4 & 5 \\
\hline
\end{tabular}

\begin{tabular}{|l|l|c|c|c|c|c|}
\hline & & $\begin{array}{c}\text { muito } \\
\text { insatisfeito }\end{array}$ & insatisfeito & $\begin{array}{c}\text { nem satisfeito } \\
\text { nem } \\
\text { insatisfeito }\end{array}$ & $\begin{array}{c}\text { Muisfeito } \\
\text { satisfeit } \\
\text { o }\end{array}$ \\
\hline 2 & $\begin{array}{l}\text { Quão satisfeito(a) você está com a } \\
\text { sua saúde? }\end{array}$ & 1 & 2 & 3 & 4 & 5 \\
\hline
\end{tabular}

As questões seguintes são sobre o quanto você tem sentido algumas coisas nas últimas duas semanas.

\begin{tabular}{|l|l|c|c|c|c|c|}
\hline & & nada & $\begin{array}{c}\text { muito } \\
\text { pouco }\end{array}$ & médio & $\begin{array}{c}\text { muito } \\
\text { mente }\end{array}$ & completa \\
\hline 3 & $\begin{array}{l}\text { Em que medida você acha que sua dor } \\
\text { (física) impede você de fazer o que você } \\
\text { precisa? }\end{array}$ & 1 & 2 & 3 & 4 \\
\hline 4 & $\begin{array}{l}\text { O quanto você precisa de algum tratamento } \\
\text { médico para levar sua vida diária? }\end{array}$ & & & & & \\
\hline 5 & O quanto você aproveita a vida? & & & & & \\
\hline 6 & $\begin{array}{l}\text { Em que medida você acha que a sua vida } \\
\text { tem sentido? }\end{array}$ & & & & & \\
\hline 7 & O quanto você consegue se concentrar? & & & & & \\
\hline 8 & Quão seguro(a) você se sente em sua vida & & & & & \\
\hline 9 & Quária? & & & & & \\
\hline
\end{tabular}

As questões seguintes perguntam sobre quão completamente você tem sentido ou é capaz de fazer certas coisas nestas últimas duas semanas.

\begin{tabular}{|c|l|c|c|c|c|c|}
\hline & & nada & $\begin{array}{c}\text { muito } \\
\text { pouco }\end{array}$ & médio & $\begin{array}{c}\text { muito } \\
\text { mente }\end{array}$ \\
\hline 10 & $\begin{array}{l}\text { Você tem energia suficiente para seu dia-a- } \\
\text { dia? }\end{array}$ & 1 & 2 & 3 & 4 & 5 \\
\hline 11 & Você é capaz de aceitar sua aparência física? & & & & & \\
\hline 12 & $\begin{array}{l}\text { Você tem dinheiro suficiente para satisfazer } \\
\text { suas necessidades? }\end{array}$ & & & & & \\
\hline
\end{tabular}




\begin{tabular}{|c|l|l|l|l|l|l|}
\hline 13 & $\begin{array}{l}\text { Quão disponíveis para você estão as } \\
\text { informações que precisa no seu dia-a-dia? }\end{array}$ & & & & & \\
\hline 14 & $\begin{array}{l}\text { Em que medida você tem oportunidades de } \\
\text { atividade de lazer? }\end{array}$ & & & & & \\
\hline
\end{tabular}

As questões seguintes perguntam sobre quão bem ou satisfeito você se sentiu a respeito de vários aspectos de sua vida nas últimas duas semanas

\begin{tabular}{|l|l|c|c|c|c|c|}
\hline & & $\begin{array}{c}\text { muito } \\
\text { ruim }\end{array}$ & ruim & $\begin{array}{c}\text { nem ruim } \\
\text { nem boa }\end{array}$ & $\begin{array}{c}\text { boa } \\
\text { boa }\end{array}$ \\
\hline 15 & Quão bem você é capaz de se locomover? & 1 & 2 & 3 & 4 & 5 \\
\hline
\end{tabular}

\begin{tabular}{|c|c|c|c|c|c|c|}
\hline & & $\begin{array}{c}\text { muito } \\
\text { insatisfeito }\end{array}$ & $\begin{array}{l}\text { insatisfei } \\
\text { to }\end{array}$ & $\begin{array}{c}\text { nem } \\
\text { satisfeito } \\
\text { nem } \\
\text { insatisfeito }\end{array}$ & satisfeito & $\begin{array}{c}\text { Muito } \\
\text { satisfeito }\end{array}$ \\
\hline 16 & $\begin{array}{l}\text { Quão satisfeito(a) você está com o seu } \\
\text { sono? }\end{array}$ & 1 & 2 & 3 & 4 & 5 \\
\hline 17 & $\begin{array}{l}\text { Quão satisfeito(a) você está com sua } \\
\text { capacidade de desempenhar as } \\
\text { atividades do seu dia-a-dia? }\end{array}$ & & & & & \\
\hline 18 & $\begin{array}{l}\text { Quão satisfeito(a) você está com sua } \\
\text { capacidade para o trabalho? }\end{array}$ & & & & & \\
\hline 19 & $\begin{array}{l}\text { Quão satisfeito(a) você está consigo } \\
\text { mesmo? }\end{array}$ & & & & & \\
\hline 20 & $\begin{array}{l}\text { Quão satisfeito(a) você está com suas } \\
\text { relações pessoais (amigos, parentes, } \\
\text { conhecidos, colegas)? }\end{array}$ & & & & & \\
\hline 21 & $\begin{array}{l}\text { Quão satisfeito(a) você está com sua } \\
\text { vida sexual? }\end{array}$ & & & & & \\
\hline 22 & $\begin{array}{l}\text { Quão satisfeito(a) você está com o } \\
\text { apoio que você recebe de seus amigos? }\end{array}$ & & & & & \\
\hline 23 & $\begin{array}{l}\text { Quão satisfeito(a) você está com as } \\
\text { condições do local onde mora? }\end{array}$ & & & & & \\
\hline 24 & $\begin{array}{l}\text { Quão satisfeito(a) você está com o seu } \\
\text { acesso aos serviços de saúde? }\end{array}$ & & & & & \\
\hline 25 & $\begin{array}{l}\text { Quão satisfeito(a) você está com o seu } \\
\text { meio de transporte? }\end{array}$ & & & & & \\
\hline
\end{tabular}


As questões seguintes referem-se a com que frequência você sentiu ou experimentou certas coisas nas últimas duas semanas.

\begin{tabular}{|l|l|c|c|c|c|c|}
\hline & nada & $\begin{array}{c}\text { Algumas } \\
\text { vezes }\end{array}$ & $\begin{array}{c}\text { frequen } \\
\text { temente }\end{array}$ & $\begin{array}{c}\text { Muito } \\
\text { frequente } \\
\text { mente }\end{array}$ & sempre \\
\hline 26 & $\begin{array}{l}\text { Com que frequência você tem sentimentos } \\
\text { negativos tais como mau humor, desespero, } \\
\text { ansiedade, depressão? }\end{array}$ & 1 & 2 & 3 & 4 & 5 \\
\hline
\end{tabular}

Alguém lhe ajudou a preencher este questionário?

Quanto tempo você levou para preencher este questionário?.

Você tem algum comentário sobre o questionário?

OBRIGADO PELA SUA COLABORAÇÃO 
ANEXO 3

Instrumento de avaliação da qualidade de vida em idosos - WHOQOL-old 


\section{Instrumento de avaliação da qualidade de vida em idosos - WHOQOL-old}

\section{Instruções:}

ESTE INSTRUMENTO NAO DEVE SER APLICADO INDIVIDUALMENTE, MAS SIM EM CONJUNTO COM O INSTRUMENTO WHOQOL-BREF.

Este questionário pergunta a respeito dos seus pensamentos, sentimentos e sobre certos aspectos de sua qualidade de vida, e aborda questões que podem ser importantes para você como membro mais velho da sociedade.

Por favor, responda todas as perguntas. Se você não está seguro a respeito de que resposta dar a uma pergunta, por favor, escolha a que lhe parece mais apropriada. Esta pode ser muitas vezes a sua primeira resposta.

Por favor, tenha em mente os seus valores, esperanças, prazeres e preocupações. Pedimos que pense na sua vida nas duas últimas semanas.

Por exemplo, pensando nas duas últimas semanas, uma pergunta poderia ser:

O quanto você se preocupa com o que o futuro poderá trazer?

\begin{tabular}{l|l|l|l|l|} 
Nada & \multicolumn{2}{|c|}{ Muito pouco } & Mais ou menos & Bastante \\
1 & 2 & 3 & 4 & 5
\end{tabular}

Você deve circular o número que melhor reflete o quanto você se preocupou com o seu futuro durante as duas últimas semanas. Então você circularia o número 4 se você se preocupou com o futuro "Bastante", ou circularia o número 1 se não tivesse se preocupado "Nada" com o futuro. Por favor, leia cada questão, pense no que sente e circule o número na escala que seja a melhor resposta para você para cada questão.

Muito obrigado(a) pela sua colaboração!

As seguintes questões perguntam sobre o quanto você tem tido certos sentimentos nas últimas duas semanas. 
old_01 Até que ponto as perdas nos seus sentidos (por exemplo, audição, visão, paladar, olfato, tato), afetam a sua vida diária?

\begin{tabular}{l|l|l|l|l|} 
Nada & \multicolumn{1}{|r|}{ Muito pouco } & Mais ou menos & Bastante & \multicolumn{2}{|r}{ Extremamente } \\
1 & 2 & 3 & 4 & 5
\end{tabular}

old_02 Até que ponto a perda de, por exemplo, audição, visão, paladar, olfato, tato, afeta a sua capacidade de participar em atividades?

\begin{tabular}{|c|c|c|c|c|}
\hline Nada & Muito pouco & Mais ou menos & Bastante & Extremamente \\
\hline & 2 & 3 & 4 & 5 \\
\hline
\end{tabular}

old_03 Quanta liberdade você tem de tomar as suas próprias decisões?

\begin{tabular}{l|l|l|l|l|l|} 
Nada & \multicolumn{1}{|r|}{ Muito pouco } & Mais ou menos & Bastante & Extremamente \\
1 & 2 & 3 & 4 & 5
\end{tabular}

old_04 Até que ponto você sente que controla o seu futuro?

\begin{tabular}{l|l|l|l|l|l|} 
Nada & \multicolumn{1}{|r|}{ Muito pouco } & Mais ou menos & Bastante & & Extremamente \\
1 & 2 & 3 & 4 & 5
\end{tabular}

old_05 O quanto você sente que as pessoas ao seu redor respeitam a sua liberdade?

Nada

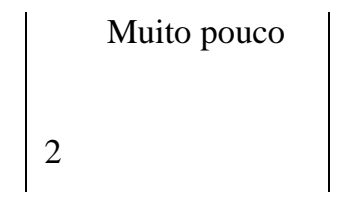

\begin{tabular}{|l|l} 
Mais ou menos & Bastante \\
3 &
\end{tabular}

Extremamente

old_06 Quão preocupado você está com a maneira pela qual irá morrer?

\begin{tabular}{l|l|l|l|l|l|} 
Nada & \multicolumn{1}{|r|}{ Muito pouco } & Mais ou menos & Bastante & & Extremamente \\
1 & 2 & 3 & & 5
\end{tabular}

old_07 O quanto você tem medo de não poder controlar a sua morte?

\begin{tabular}{|c|c|c|c|c|}
\hline Nada & Muito pouco & Mais ou menos & Bastante & Extremamente \\
\hline 1 & 2 & 3 & 4 & 5 \\
\hline
\end{tabular}


old_08 O quanto você tem medo de morrer?

\begin{tabular}{|c|c|c|c|c|}
\hline Nada & Muito pouco & Mais ou menos & Bastante & Extremamente \\
\hline 1 & 2 & 3 & 4 & 5 \\
\hline
\end{tabular}

old_09 O quanto você teme sofrer dor antes de morrer?

\begin{tabular}{l|l|l|l|l|} 
Nada & \multicolumn{1}{|r|}{ Muito pouco } & Mais ou menos & Bastante & Extremamente \\
1 & 2 & 3 & 4 & 5
\end{tabular}

As seguintes questões perguntam sobre quão completamente você fez ou se sentiu apto a fazer algumas coisas nas duas últimas semanas.

old_10 Até que ponto o funcionamento dos seus sentidos (por exemplo, audição, visão, paladar, olfato, tato) afeta a sua capacidade de interagir com outras pessoas?

\begin{tabular}{l|l|l|l|l|} 
Nada & \multicolumn{1}{|r|}{ Muito pouco } & \multicolumn{1}{|c|}{ Médio } & Muito & \\
1 & 2 & 3 & 4 & 5
\end{tabular}

old_11 Até que ponto você consegue fazer as coisas que gostaria de fazer?

\begin{tabular}{l|l|l|l|l|l|} 
Nada & \multicolumn{1}{|r|}{ Muito pouco } & \multicolumn{2}{|c|}{ Médio } & Muito & \\
1 & 2 & 3 & & 4 & 5
\end{tabular}

old_12 Até que ponto você está satisfeito com as suas oportunidades para continuar alcançando outras realizações na sua vida?

\begin{tabular}{|c|c|c|c|c|}
\hline Nada & Muito pouco & Médio & Muito & Completamente \\
\hline 1 & 2 & 3 & 4 & 5 \\
\hline
\end{tabular}

old_13 O quanto você sente que recebeu o reconhecimento que merece na sua vida?

\begin{tabular}{|c|c|c|c|c|}
\hline Nada & Muito pouco & Médio & Muito & Completamente \\
\hline 1 & 2 & 3 & 4 & 5 \\
\hline
\end{tabular}


old_14 Até que ponto você sente que tem o suficiente para fazer em cada dia?

\begin{tabular}{|c|c|c|c|c|}
\hline Nada & Muito pouco & Médio & Muito & Completamente \\
\hline 1 & 2 & 3 & 4 & 5 \\
\hline
\end{tabular}

As seguintes questões pedem a você que diga o quanto você se sentiu satisfeito, feliz ou bem sobre vários aspectos de sua vida nas duas últimas semanas.

old_15 Quão satisfeito você está com aquilo que alcançou na sua vida?

\begin{tabular}{l|l|l|l|l|} 
Muito insatisfeito & \multicolumn{1}{|c|}{ Insatisfeito } & $\begin{array}{c}\text { Nem satisfeito nem } \\
\text { insatisfeito }\end{array}$ & Satisfeito & Muito satisfeito \\
1 & 2 & 3 & 4 & 5
\end{tabular}

old_16 Quão satisfeito você está com a maneira com a qual você usa o seu tempo?

\begin{tabular}{l|l|l|l|l|} 
Muito insatisfeito & \multicolumn{1}{|c|}{ Insatisfeito } & $\begin{array}{c}\text { Nem satisfeito nem } \\
\text { insatisfeito }\end{array}$ & Satisfeito & Muito satisfeito \\
1 & 2 & 3 & 4 & 5
\end{tabular}

old_17 Quão satisfeito você está com o seu nível de atividade?

\begin{tabular}{l|l|l|l|l|} 
Muito insatisfeito & \multicolumn{1}{|c|}{ Insatisfeito } & $\begin{array}{c}\text { Nem satisfeito nem } \\
\text { insatisfeito }\end{array}$ & Satisfeito & Muito satisfeito \\
1 & 2 & 3 & 4 & 5
\end{tabular}

old_18 Quão satisfeito você está com as oportunidades que você tem para participar de atividades da comunidade?

\begin{tabular}{|c|c|c|c|c|}
\hline Muito insatisfeito & Insatisfeito & Nem satisfeito nem & Satisfeito & Muito satisfeito \\
\hline 1 & 2 & 3 & 4 & 5 \\
\hline
\end{tabular}

old_19 Quão feliz você está com as coisas que você pode esperar daqui para frente?

\begin{tabular}{l|l|l|l|l|} 
Muito insatisfeito & \multicolumn{1}{|c|}{ Insatisfeito } & $\begin{array}{c}\text { Nem satisfeito nem } \\
\text { insatisfeito }\end{array}$ & Satisfeito & Muito satisfeito \\
1 & 2 & 3 & 4 & 5
\end{tabular}


old_20 Como você avaliaria o funcionamento dos seus sentidos (por exemplo, audição, visão, paladar, olfato, tato)?

\begin{tabular}{l|l|l|l|l|} 
Muito insatisfeito & \multicolumn{1}{|c|}{ Insatisfeito } & $\begin{array}{c}\text { Nem satisfeito nem } \\
\text { insatisfeito }\end{array}$ & Satisfeito & Muito satisfeito \\
1 & 2 & 3 & 4 & 5
\end{tabular}

As seguintes questões se referem a qualquer relacionamento íntimo que você possa ter. Por favor, considere estas questões em relação a um companheiro ou uma pessoa próxima com a qual você pode compartilhar (dividir) sua intimidade mais do que com qualquer outra pessoa em sua vida.

old_21 Até que ponto você tem um sentimento de companheirismo em sua vida?

\begin{tabular}{l|l|l|l|l|} 
Nada & Muito pouco & \multicolumn{2}{|r|}{ Médio } & Muito \\
1 & 2 & 3 & 4 & 5
\end{tabular}

old_22 Até que ponto você sente amor em sua vida?

\begin{tabular}{l|l|l|l|l|} 
Nada & \multicolumn{1}{|r|}{ Muito pouco } & \multicolumn{1}{|c|}{ Médio } & Muito & Completamente \\
1 & 2 & 3 & 4 & 5
\end{tabular}

old_23 Até que ponto você tem oportunidades para amar?

\begin{tabular}{l|l|l|l|l|l|} 
Nada & Muito pouco & \multicolumn{1}{|r|}{ Médio } & Muito & \\
1 & 2 & 3 & 4 & 5
\end{tabular}

old_24 Até que ponto você tem oportunidades para ser amado?

\begin{tabular}{|c|c|c|c|c|}
\hline Nada & Muito pouco & Médio & Muito & Completamente \\
\hline 1 & 2 & 3 & 4 & 5 \\
\hline
\end{tabular}

VOCÊ TEM ALGUM COMENTÁRIO SOBRE O QUESTIONÁRIO?

OBRIGADO(A) PELA SUA COLABORAÇÃO! 
ANEXO 4

Parecer consubstanciado do CEP 


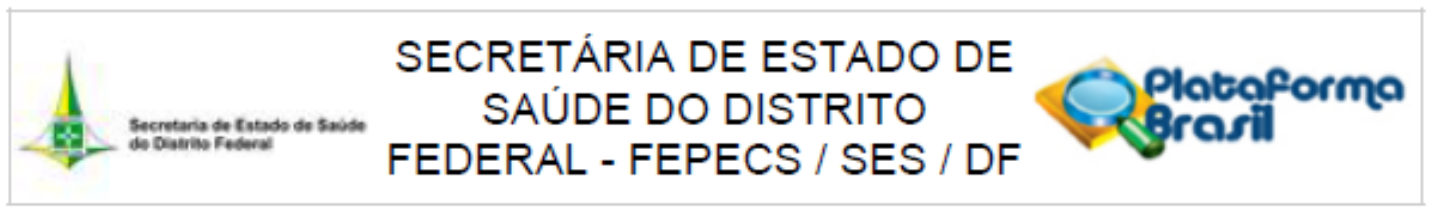

\section{PARECER CONSUBSTANCIADO DO CEP}

\section{DADOS DO PROJETO DE PESQUISA}

Título da Pesquisa: PERCEPÇÃO DA QUALIDADE DE VIDA DE CUIDADORES DE PACIENTES EM UM PROGRAMA DE ATENCÃO DOMICILIAR:

UMA RELAÇÃ̃O ENTRE QUALIDADE DE VIDA, FINITUDE HUMANA E SOBRECARGA DO CUIDADOR

Pesquisador: DIANE MARIA SCHERER KUHN LAGO

Área Temática:

Versão: 3

CAAE: 08237612.7 .0000 .5553

Instituição Proponente:Secretaria de Saúde do Distrito federal - Regional de Saúde de Ceilândia

\section{DADOS DO PARECER}

Número do Parecer: 187.211

Data da Relatoria: 21/01/2013

\section{Apresentação do Projeto:}

A evolução dos tratamentos continuados resultando em maior sobrevida destes pacientes, trouxe à tona a preocupação com a qualidade destete mpo de vida. A internação domiciliar passou a ser considerada como uma solução encontrada para conciliar atendimento em saúde necessário e convivência familiar e de amigos em ambiente saudável e seguro para o tratamento destes pacientes. Na maior parte dos casos, o cuidador é um familiar próximo do paciente que também sofre com a doença e com a proximidade da morte de seu familiar. Este estudo qualitativo objetiva analisar a relação entre a percepção da qualidade de vida e da sobrecarga de trabalho dos cuidadores com a percepção da finitude humana e as implicações psicossociais do cuidar de pacientes internados em domicílio. Utilizará, para tanto cinco instrumentos de pesquisa que terão seus resultados analisados conjuntamente. Será realizado com cuidadores vinculados ao Núcleo Regional de Atenção Domiciliar de Ceilândia/DF

\section{Objetivo da Pesquisa:}

Objetivo geral

Analisar a relação entre a percepção da qualidade de vida e da sobrecarga de trabalho com a percepção da finitude humana e as implicações psicossociais do cuidar de pacientes internados em domicílio

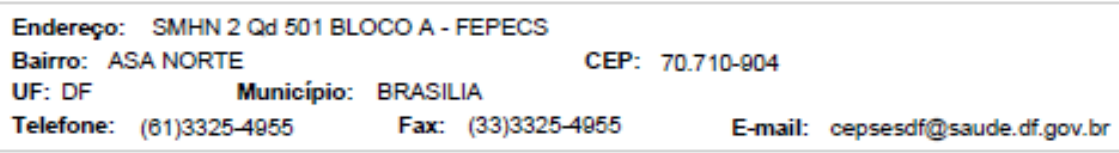




SECRETÁRIA DE ESTADO DE
SAÚDE DO DISTRITO
FEDERAL - FEPECS / SES / DF

Objetivos específicos:

1. Identificar a percepção sobre a qualidade de vida dos cuidadores domiciliares;

2. Identificar a percepção sobre a sobrecarga de trabalho dos cuidadores domiciliares;

3. Identificar o significado da morte para o cuidador de paciente internado em domicílio;

4. Identificar os sentimentos vivenciados pelo cuidador no ato de cuidar;

5. Investigar as mudanças sociais decorrentes do cuidar de um paciente internado em domicílio

Avaliação dos Riscos e Benefícios:

Os objetivos do estudo estão claramente definidos Os sujeitos foram adequadamente identificados. A beneficência para os sujeitos está clara Os possiveis benefícios apresentam-se com maior magnitude em relação aos riscos aos sujeitos da pesquisa. Os antecedentes científicos que justificam a pesquisa foram apresentados.

Visando a redução dos riscos psicológicos os sujeitos participarão de grupos de discussão com equipe psicossocial quinzenalmente, nas dependências do NRAD, e terão atendimento individualizado com profissional psicólogo sempre que necessário em até seis meses após sua participação conforme declaração do profisional.

Comentários e Considerações sobre a Pesquisa:

Trata-se de pesquisa descritiva que avaliará cuidadores de pacientes acompanhados pelo Núcleo Regional de Atenção domiciliar do Hospital Regional de Ceilândia. Serão realizadas entrevistas, conforme roteiro estruturado apresentado e aplicado quatro questionários (Questionário de dados sociodemográficos, Word Health Organization Quality of Life Instrument Bref Word Health Organization Quality of Life Instrument Old,Escala de Sobrecarga de Cuidador ESC e Instrumento Perfil de Atitudes Perante a Morte). As entrevistas serão gravadas.

Os dados serão analisados de forma qualitativa por meio de avaliação dos resultados dos instrumentos utilizados e por meio de cruzamento de resultados para análise da relação dos mesmos entre si.

Período da Pesquisa: De setembro de 2012 a dezembro de 2013, sendo a coleta de dados no período de janeiro a março de 2013.0 pesquisador declara que os dados serão coletados após aprovação pelo CEP. Amostra: 30 sujeitos

Critérios de inclusão e exclusão: Descritos

Considerações sobre os Termos de apresentação obrigatória:

Folha de rosto: Apresentada. Assinada pelo Diretor de Atenção à Saúde de Ceilândia.

Termo de Concordância: Apresentado assinado pelo responsável pela chefe do NRAD Ceilândia.

Currículum Vitae do(s) pesquisador(es): Apresentado.

Cronograma da Pesquisa: Apresentado.

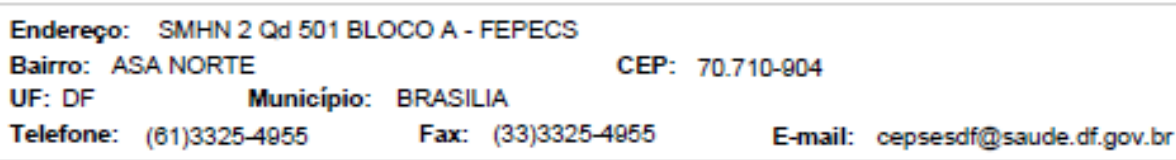




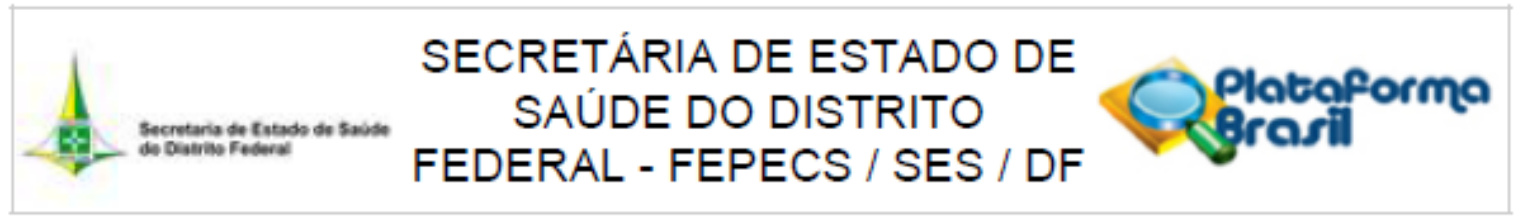

Planilha de orçamento: Apresentada. Informa que a pesquisa será realizada com recursos prórios da pesquisadora.

Recomendações:

O pesquisador assume o compromisso de garantir o sigilo que assegure o anonimato e a privacidade dos sujeitos da pesquisa e a confidencialidade dos dados coletados. Os dados obtidos na pesquisa deverão ser utilizados exclusivamente para a finalidade prevista no seu protocolo, que só poderá iniciar após aprovação pelo CEP/FEPECS.

O pesquisador deverá encaminhar relatório final ao término da pesquisa

Conclusões ou Pendências e Lista de Inadequações:

Projeto aprovado.

Situação do Parecer:

Aprovado

Necessita Apreciação da CONEP:

Não

Considerações Finais a critério do CEP:

BRASILIA, 21 de Janeiro de 2013

Assinador por:

Maria Rita Carvalho Garbi Novaes

(Coordenador)

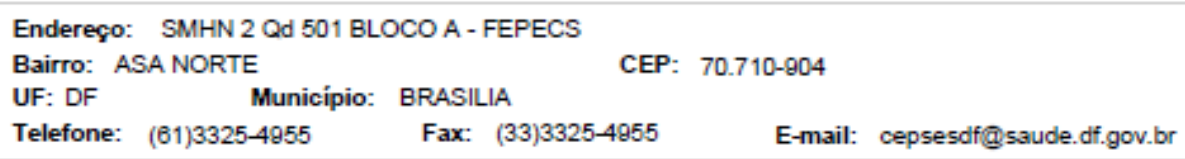

